\title{
Determinants of ecstasy use and harm reduction strategies: Informing evidence-based intervention development
}

Citation for published version (APA):

Peters, G. J. (2008). Determinants of ecstasy use and harm reduction strategies: Informing evidencebased intervention development. [Doctoral Thesis, Maastricht University]. Maastricht University. https://doi.org/10.26481/dis.20081219gp

Document status and date:

Published: 01/01/2008

DOI:

10.26481/dis.20081219gp

Document Version:

Publisher's PDF, also known as Version of record

Please check the document version of this publication:

- A submitted manuscript is the version of the article upon submission and before peer-review. There can be important differences between the submitted version and the official published version of record.

People interested in the research are advised to contact the author for the final version of the publication, or visit the DOI to the publisher's website.

- The final author version and the galley proof are versions of the publication after peer review.

- The final published version features the final layout of the paper including the volume, issue and page numbers.

Link to publication

\footnotetext{
General rights rights.

- You may freely distribute the URL identifying the publication in the public portal. please follow below link for the End User Agreement:

www.umlib.nl/taverne-license

Take down policy

If you believe that this document breaches copyright please contact us at:

repository@maastrichtuniversity.nl

providing details and we will investigate your claim.
}

Copyright and moral rights for the publications made accessible in the public portal are retained by the authors and/or other copyright owners and it is a condition of accessing publications that users recognise and abide by the legal requirements associated with these

- Users may download and print one copy of any publication from the public portal for the purpose of private study or research.

- You may not further distribute the material or use it for any profit-making activity or commercial gain

If the publication is distributed under the terms of Article 25fa of the Dutch Copyright Act, indicated by the "Taverne" license above, 


\section{Determinants of ecstasy use and harm reduction strategies}

Informing evidence-based intervention development 


\section{(C) 2008, Gjalt-Jorn Peters}

Cover design and layout: Gjalt-Jorn Peters (using Inkscape, GIMP \& Microsoft Word). ISBN: 978-1-4092-4071-6

This Ph. D. thesis is available at http://phdthesis.nl.

This work is licensed under the Creative Commons Attribution-Non-Commercial-Share Alike License. To view a copy of this licence, visit http://creativecommons.org/licenses/by-nc-sa/2.0/ or send a letter to Creative Commons, 171 Second Street, Suite 300, San Francisco, California 94105, USA. 


\section{Determinants of ecstasy use and harm reduction strategies Informing evidence-based intervention development}

Proefschrift ter verkrijging van de graad van doctor aan de Universiteit Maastricht, op gezag van de Rector Magnificus, Prof. Mr. G. P. M. F. Mols, volgens het besluit van het College van Decanen, in het openbaar te verdedigen op vrijdag 19 december 2008 om 14:00 uur

door

$$
\text { Gjalt-Jorn Peters }
$$

geboren op 26 oktober 1981

te Sneek 
Promotores:

Prof. Dr. Gerjo Kok

Prof. Dr. Herman P. Schaalma

Beoordelingscommissie:

Prof. Dr. Harm Hospers (voorzitter)

Prof. Dr. Kay Bartholomew (University of Texas, Houston \& UM)

Prof. Dr. Tom Ter Bogt (Universiteit Utrecht)

Dr. Pepijn van Empelen (Erasmus Universiteit)

Prof. Dr. Nanne De Vries

De studies in dit proefschrift zijn financieel ondersteund door het ministerie van Volksgezondheid, Welzijn en Sport. 


\section{Table of contents}

$\begin{array}{lll}\text { Chapter } 1 & \text { Introduction } & 7\end{array}$

Chapter 2 Social cognitive determinants of ecstasy use to target in evidence- 21 based interventions: a meta-analytic review

Chapter 3 A structured review of reasons for ecstasy use and related 35 behaviours: pointers for future research

Chapter 4 Careers in ecstasy use: do ecstasy users cease of their own accord? Implications for intervention development

Chapter 5 Social cognitive determinants of ecstasy use: does studying mixed samples of non-users and users leads to over-estimation of association strengths?

Chapter 6 Social cognitive determinants of trying out ecstasy: why interventions based on research into using ecstasy may have a hard time preventing ecstasy use

Chapter 7 Social cognitive determinants of ceasing ecstasy use: ceasing is not the opposite of using

Chapter 8 Behavioural specificity in ecstasy use research: why we should not examine the determinants of using ecstasy

Chapter 9 Determinants of ecstasy testing: informing evidence-based intervention development

Chapter 10 Discussion

Numbered reference list

Alphabetic reference list

English summary

Nederlandse samenvatting

Curriculum Vitae

Acknowledgements 



\section{Chapter 1 Introduction}

In May 2001, the Dutch government published a note outlining its intention to intensify efforts to decrease ecstasy-related harm [1]. Although this intention was primarily based on the observation that large quantities of ecstasy were produced in and exported from the Netherlands, and accordingly most proposed intensifications regarded law enforcement, a need for development of health promotion interventions targeting ecstasy use was also asserted. A health promotion intervention is any non-juridical incarnation of a deliberate effort to change people's behaviour to improve their health and/or quality of life.

Because behaviour is the outcome of a person's reactions and thoughts in a particular situation, behaviour can be influenced by changing the situation and/or the relevant thoughts. An effective health promotion intervention targets the aspects of a situation and/or thoughts that actually determine the behaviour that is intervened upon [2]. Knowing which variables determine behaviour is therefore prerequisite to developing an effective intervention. The current thesis comprises eight chapters reporting the results of studies conducted to synthesise and extend the knowledge about the determinants of ecstasy use and related behaviours. Before outlining these chapters, the context of this thesis will be described. First, the relevance of intervening on ecstasy use is explained; then, the theoretical background of the research to enable such interventions is explained.

\section{Ecstasy}

In 1912, a German pharmaceutical company called Merck wished to evade a competitors patent on a blood clotting agent called Hydrastinin [3]. It succeeded, and on the $24^{\text {th }}$ of December 1912, Merck patented a number of chemical reactions, mentioning a chemical called Methylsafrylamin as an 
intermediate step to ultimately synthesise Methylhydrastinin, Mercks newly developed blood clotting agent. This chemical received only cursory attention until the United States army sponsored a secret animal study at the University of Michigan in 1953 and 1954, where the toxicity and behavioural effects of Methylsafrylamin and seven other drugs were compared [4], and Merck resynthesised it in 1959 because of an interest in the production of stimulants. Although no records could be found, it is likely that the effects on humans were studied during this period, and that this somehow inspired non-scientific interest. Eleven years later, tablets were seized in Chicago that contained this same chemical, now referred to as 3,4-melthyldioximethamphetamine (MDMA). In 1978, a chemist called Alexander Shulgin and his co-workers synthesised and used MDMA, and their reports of its effects further popularised the drug. In 1984, MDMA's street name 'ecstasy' was coined in California, and shortly thereafter, most countries started banning ecstasy [3]. The basis for banning ecstasy appeared to be that it was a drug, used by drug users who also use other illegal drugs. There was no evidence supporting any of the three criteria for banning a drug (illegal use, similarity to other illegal drugs, and potential for addiction or harmful effects) [5].

The potential positive effects of ecstasy are euphoria, increased energy, tenderness/closeness, feeling peaceful/calm, increased sensual awareness, and changes in visual perception [6]. Ecstasy also has negative effects, but these are less frequent and less intense than the positive effects [6]. Potential negative effects are teeth grinding, thirst, muscle tightness, accelerated heartbeat, nausea and/or vomiting, body temperature changes, fatigue or mental fatigue, headache, dizziness, nervousness, depression, fear and/or paranoia, and confused thought. Other potential effects are sweating, numbness/tingling, sleeplessness, and decreased appetite. In their own words, users describe ecstasy's effects as "ecstasy makes everything seem like it's perfect", "you love everyone and everything", "music feels better", "you can say what is on your mind without worrying what others will think", and you feel more connected to others and able to emotionally bond [7]. This experience has been described as "the peak of human experience" [8]. Because ecstasy's effects of inducing tenderness, closeness, peace and calm are quite unique, and indeed, its human psychopharmacology is dissimilar to that of most other known drugs, it has been argued that ecstasy should be pharmacologically categorised as an 'entactogen' (roughly meaning 'touching within'), a previously nonexistent category [9]. 
Ecstasy use has always been linked strongly to a relatively young musical genre that also greatly gained in popularity during the eighties. In the Netherlands this genre is currently known as 'dance'. Dance was born out of disco and the electronic music of Kraftwerk in the early eighties in Chicago ('house'), Detroit ('techno') and New York ('garage') [10]. Now, in 2008, this musical genre is the centre of a 'dance scene' that encompasses huge dance events with ten-thousands of visitors, clubs playing dance, organisations, DJ's, dance music producers, and of course visitors. In the Netherlands, this dance scene is estimated to encompass over 11000 jobs, organising over 30 dance events, catering to over 700000 adolescents and young adults and generating over $€ 500000000$ a year [11]. It is not known to what degree dance and ecstasy contributed to each others popularity, but it is clear that the dance scene has two characteristics which are exceptionally compatible with ecstasy's effects. First, especially during the eighties and early nineties, those popularising dance generally propagated the ideals of peace, love, unity and respect. These ideals reflect the experience induced by ecstasy's entactogenic effects. Second, a distinguishing characteristic of dance is a strong focus on rhythm, enabling the mixing of different 'dance tracks' into one continuous set. Dancing is usually not done in pairs as was customary until dance evolved, but in a way that can be interpreted as either individually or collectively, and often for hours on end. The energising effects of ecstasy enable dancers to do this.

Regardless of any cause-consequence relationship between ecstasy's effects and the way the dance scene evolved, currently, ecstasy is linked strongly to the dance scene. In the Netherlands in 2005, $4.3 \%$ of all men and women between 15 and 64 had ever used ecstasy, 1.2\% had used the past year, and $0.4 \%$ had used the past month [12]. In 2001 and 2002, at four Dutch dance events, on average $76 \%$ of the visitors had ever used ecstasy, and $45.6 \%$ had used ecstasy at the party [13]. In other countries, similarly high percentages are found. For example, in New York, 45.2\% of club and lounge visitors had ever used ecstasy [14]. The millions of people taking ecstasy every weekend would not be a cause for concern if ecstasy use would be harmless. However, ecstasy is potentially damaging to health.

The potential neurotoxic effects of ecstasy are controversial. This controversy is related to the exceptional difficulty of studying potential harmful effects of ecstasy. The expected neurotoxicity renders it ethically unfeasible to administer ecstasy to a random sample of participants in varying dosages. Those using ecstasy of their own accord are often poly-substance users, making 
it very hard to distinguish the effects of ecstasy of the effects of the other substances. Finally, if differences are found between non-users and ecstasy users, there is no way to know whether these differences will have been caused by ecstasy, whether these differences have caused the ecstasy use, or whether another variable is responsible for both the differences and the ecstasy use. Further, in 2002, Science published a paper demonstrating severe MDMA neurotoxicity in primates [15]. This paper received a lot of media attention and had a great influence on the public opinion regarding ecstasy. However, in 2003, the paper was retracted, because it turned out that the primates had accidently received methamphetamine instead of MDMA [16]. This increased the controversy further.

A number of recent reviews and meta-analyses have summarized the growing body of research, finding ecstasy use associated to poorer neurocognitive functioning in a number of domains [17-21], although the methodological issues remain [22], and it is not yet clear to which degree neurological effects of ecstasy are reversible. However, a recent large-scale Dutch study, the Netherlands XTC Toxicology (NeXT) study, has been initiated that addresses many methodological problems [23]. The first results imply that other drugs such as amphetamine may have played a role in prior studies reporting negative health effects of ecstasy [24], and that a small dose of ecstasy may be harmless [25]. In time, this study and studies with similar designs may be able to answer the question of ecstasy's neurotoxicity. Regardless of neurotoxicity, many users report negative effects that they attribute to their ecstasy use, such as decreased concentration, depression, insomnia and fatigue [26]. Thus, in all, although the current evidence is largely circumstantial, it seems wise to consider ecstasy as potentially damaging.

Ecstasy's prevalence and potential harmfulness justify the regulation of ecstasy use to minimize the damage ecstasy causes. There are basically two ways to influence any given behaviour: by force or by inducing volition (or by a combination of these two). In modern society, if a government wants to influence behaviour by force, it can do so mainly through legislation, and the Dutch Government has utilised this tool by outlawing ecstasy use. However, the high prevalence of ecstasy use evidences the inefficacy of this approach. This inefficacy does not seem specific to ecstasy: the Netherlands chose to adopt a less prohibitionist policy concerning cannabis, which is legally available in the Netherlands; yet, life-time and current use figures for, for example, the strictly prohibitionist United States, are significantly and substantially higher [e.g. see 
27]. Thus, legislation seems insufficient to regulate drug use, and this leaves the possibility of influencing drug use by inducing volition. Such a non-juridical incarnation of a deliberate effort to change people's behaviour to improve their health and/or quality of life is a health promotion intervention based on voluntary behaviour change and/or environmental changes that facilitate the health promoting behaviour.

\section{Intervention Mapping}

Bartholomew, Parcel, Kok and Gottlieb [2] have developed a protocol that can guide development of such health promotion interventions, appropriately called Intervention Mapping. The research described in this thesis is based on a project proposal that the Dutch government subsidised to enable intervention development regarding ecstasy use, and this research proposal follows the Intervention Mapping protocol. Intervention Mapping encompasses six steps: needs assessment, matrices, theory-based methods and practical strategies, program development, adoption and implementation plan, and evaluation plan. Although this orderly presentation in steps suggests consecutiveness, these steps have an iterative nature. A very brief description of these steps will be provided here.

The needs assessment, step 1, comprises mapping what the problem is exactly, which behaviours and environmental factors cause this problem, among whom, and in what context. During this step one also aims to gain an understanding of the community in which the intervention is to be implemented. In step 2, the specific sub-behaviours constituting the targeted behaviours or performance objectives are established and crossed with personal and external determinants in matrices, resulting in a list of change objectives: concrete objectives for the intervention. In step 3, theory-based methods are matched to the relevant change objectives. Being theory-based, these methods have a generic character, and they can often be translated into practice in several ways. Matching the selected theory-based method to a practical strategy allows adequate translation to the context at hand in a way that enables coherent integration of all selected methods in a program. In step 4, program development, the strategies specified at step 3 are integrated into one program that carefully considers the intended participants and context. In this step, the program producers (e.g. web designers and graphic artists) are informed of their tasks, and the program is pretested and piloted. 
Although step 5 and step 6 are finalised in the last stages of intervention development, they are actually initialised simultaneously with step 1 . In step 5 , adoption and implementation, potential users of the program and those who need to take decisions to ensure successful implementation are identified. Then, interventions are developed to ensure that these users and decision-makers implement the intervention successfully: performance objectives underlying their desired behaviour are hypothesised; these are crossed with hypothesised determinants in matrices similar to those from step 2; the thus generated change objectives are matched to methods and strategies; and an integrative program is developed. In the final step, step 6, the evaluation plan in completed. This plan allows evaluation of whether the decisions, made at each step of the intervention mapping process, were correct. This can then inform future intervention development, regardless of whether the intervention is successful.

Intervention Mapping guides the string of decisions that accompanies the development of a theory and evidence-based intervention. Being theory and evidence-based, these decisions should be made on the basis of adequate information. Intervention Mapping proposes to gather this information through the so-called core processes of using evidence, theory, and new research. New research is used to answer questions left unanswered by the available evidence and theory when a decision needs to be made. Of course, the more research and interventions have been published in any given area, the more questions will have been answered, and the less new research is necessary to develop an intervention for any given behaviour, target population, and context, that fall within that area. Likewise, when research, theory development, and published interventions are scarce within an area, Intervention Mapping requires a lot of new research to provide the information that the necessary decisions need to be based on.

The current thesis was initially intended to describe a complete Intervention Mapping project from start to end, with each chapter corresponding to one or several Intervention Mapping steps. However, as the initial literature studies were completed, it became clear that regarding ecstasy use, research and theory development are scarce. It followed that, in order to be able to develop a theory and evidence-based intervention addressing ecstasy use, a lot of new research was required, to the extent that the research required to enable progression to steps 3 and further was so substantial that this thesis focuses exclusively on reporting the results of this research. Thus, the studies 
reported here have all been conducted to allow generation of the matrices required in step 2 of the Intervention Mapping protocol.

\section{Step 1: Needs assessment}

The needs assessment (step 1) was conducted to assess what needs to be done to minimise the damage that ecstasy causes. Because ecstasy cannot do damage if it is not used, starting and stopping ecstasy use are both behaviours that are potential intervention targets for an intervention aiming to minimize harm. However, these behaviours are not the only potential intervention targets. If ecstasy is used, the amount of potential damage is related to the way in which it is used. Application of so-called harm reduction strategies (HRSs) can minimize the damage that ecstasy causes. The needs assessment concentrated on identification of these HRSs. This was done through the available literature and through consultation of the linkage group. This linkage group was a group of experts on ecstasy use patterns and implementers of the prospective intervention that was consulted at various stages of the project (see

\section{Table 1.1: Behaviours resulting from the needs assessment}

\begin{tabular}{|c|c|}
\hline Activity or harm reduction strategy & Associated behaviour \\
\hline \multicolumn{2}{|l|}{ Regarding the use itself } \\
\hline Starting ecstasy use & Trying out ecstasy \\
\hline Ceasing ecstasy use & Ceasing ecstasy use \\
\hline Moderating frequency of use & $\begin{array}{l}\text { Not using more than once every four to } \\
\text { six weeks }\end{array}$ \\
\hline Moderating intensity of use & $\begin{array}{l}\text { Not using more than } 1.5 \mathrm{mg} \text { MDMA per } \\
1 \mathrm{~kg} \text { body weight }\end{array}$ \\
\hline \multicolumn{2}{|l|}{ Before any instance of use } \\
\hline Ascertaining pill contents & Bringing pill to a testing facility \\
\hline Sleeping sufficiently & $\begin{array}{l}\text { Sleeping at least } 8 \text { hours in the three } \\
\text { nights before use }\end{array}$ \\
\hline Ensuring sufficient hydration of body before use & $\begin{array}{l}\text { Drinking } 2 \text { litres of water on each of the } \\
\text { three days before use, and compensating } \\
\text { for consumption alcohol or caffeine }\end{array}$ \\
\hline \multicolumn{2}{|l|}{ During any instance of use } \\
\hline Preventing dehydration and hyponatraemia & Drinking half a litre of water hourly \\
\hline Regulating body temperature & $\begin{array}{l}\text { Chilling out for at least twenty minutes } \\
\text { every two hours }\end{array}$ \\
\hline \multirow[t]{4}{*}{ Not combining with other drugs } & Not combining with alcohol \\
\hline & Not combining with cocaine \\
\hline & Not combining with speed \\
\hline & Not combining with GHB \\
\hline
\end{tabular}


Appendix 1.i). It was found that no studies have addressed the effects of HRSs in a controlled environment. However, there is a small body of qualitative literature [28] where ecstasy users report the HRSs they apply. In addition, evidence concerning these strategies has been generated through visits to firstaid posts at dance events and in hospitals. The linkage group provided insight in this data. The resulting list of harm reduction strategies will be briefly reported here.

The most well-known HRS is preventing dehydration during use. Users usually put this into practice by drinking water during use, and closely related to that is another well-known HRS: preventing an imbalance in the proportion of water and natrium in the blood resulting from excessive water intake called hyponatraemia. Another HRS is regulating one's body temperature. It has been shown that body temperature is positively associated to damage [29]. These HRSs can all be applied during use. There are also HRSs applicable before use and after use. Before use, the exact pill contents can be determined. This allows a user to regulate the dosage and to avoid ingesting other drugs. In addition, before use, users can minimize the risk of acute damage by sleeping sufficiently, eating properly, and ensuring that the body is properly hydrated. Moderating frequency and intensity of ecstasy use can also minimize ecstasyrelated harm. Finally, combining with other drugs can substantially increase acute risks.

Harm reduction strategies such as 'preventing dehydration' express conceptual goals rather than actual behaviours that can be targeted by an intervention. Often, such a goal can be achieved through several behaviours, but for the current purposes, one behaviour is selected for each HRS, except combining with other drugs, where the four most prevalent party drugs in the Netherlands were selected. The harm reduction strategies and the corresponding behaviours that resulted from the needs assessment are listed in Table 1.1. These behaviours are potential intervention targets. To determine which of these behaviours are the most adequate intervention targets, information is required as to what causes each behaviour.

\section{Step 2: Determinants}

Any behaviour is the outcome of a person's thoughts in a particular situation. If the thoughts and situational elements that determine whether a behaviour will be conducted are known, attempts can be made to influence these. The 
particular thoughts that lead to a certain behaviour are the consequence of a number of psychological variables. Those psychological variables that determine a particular behaviour are called personal determinants. Similarly, those situational elements that determine a particular behaviour are called external or environmental determinants. An intervention can address one or both types of determinants. To study the relevance of external determinants, ideally one would compare a situation where they are present with a situation where they are absent. However, such experimentation was not feasible regarding ecstasy use (e.g. testing ecstasy at parties is not legal; the resources to provide free water lacked, etc). Therefore, the current project concentrated on identifying personal determinants of behaviour, and this are the findings that will be reported in the following chapters (though perceived effects of the environment are included in certain personal measures like subjective norm and perceived control, as will become clear below). Therefore, to illustrate this concept of personal determinants, a theory on social-cognitive determinants of behaviour that has successfully been applied to several health behaviours will be described: the Theory of Planned Behaviour, based on Ajzen and Fishbein's Theory of Reasoned Action [30-33].

The Theory of Planned Behaviour (TPB) postulates intention as main proximal determinant of behaviour. Thus, according to the TPB, whether a person performs a particular behaviour in any given situation is largely determined by that persons intention to perform that behaviour in that situation. Measuring intention is quite straightforward. An example is the question "Do you intend to try out ecstasy at a dance event in the next three months?", with answer options from "absolutely not" to "absolutely". This specification of context ("at a dance event in the next three months") is important because, for example, attitude regarding ecstasy use at a dance event may be different from attitude regarding ecstasy use at the birthday party of one's mother. Intention itself has three determinants.

The first is attitude. A person's attitude expresses the likelihood and desirability of all potential consequences of that behaviour. The combination of likelihood and desirability of each specific consequence is called an attitudinal belief. Attitude can be measured in two ways. First, all attitudinal beliefs can be measured and aggregated, for example: "trying out ecstasy will make me more sociable" with answer options from "very unlikely" to "very likely", combined with another question "For me, being more sociable is ..." with answer options from "very undesirable" to "very desirable". Alternatively, attitude can be 
measured directly. This method traditionally uses so-called 'semantic differentials', for example: "I think trying out ecstasy is ..." with answer options from "unwise" to "wise" or from "unpleasant" to "pleasant".

The second determinant of intention is subjective norm. Subjective norm expresses the perceived approval of disapproval of a person's social referents (referred to as normative beliefs), weighed with a person's motivation to comply with the relevant social referent. Subjective norm can also be measured in two ways. First, the normative beliefs relating to all social referents can be measured, for example: "regarding me trying out ecstasy at a dance event in three months, my best friend ..." with answer options from "strongly disapproves" to "strongly approves", including an "I don't know" option (which will be referred to as the nescience option). This is multiplicatively combined with "regarding trying out ecstasy, for me, the opinion of my best friend is ..." with answer options from "very unimportant" to "very important". Alternatively, subjective norm can be assessed directly with the question "regarding me trying out ecstasy at a dance event in three months, people who are important to me ..." with answer options "strongly disapprove" to "strongly approve", again including a nescience option. Although the nescience option is recoded to signify absence of normative influence, the proportion of nescient participants can be useful information when developing an intervention.

The third determinant of intention is perceived behavioural control (PBC). PBC expresses the degree of control one perceives to have over performing a given behaviour in a variety of situations. The degree of control one perceives to have over performing that behaviour in one specific situation is called a control belief. PBC differs from the other two determinants of intention, because perceived control is a function of perceived barriers or facilitators and perceived skills, which are usually functions of actual barriers or facilitators and skills. For example, perceived control over drinking sufficient water at an event where no water can be obtained will be low, given the fact that the behaviour is practically impossible. Regardless of one's intention, the behaviour would not be conducted. Accordingly, of the three determinants of intention, PBC is the only one that is also a direct determinant of behaviour. PBC can be measured for example by "for me, getting my ecstasy tested before using it in the next three months would be ..." with answer options from "very difficult" to "very easy" (because this measurement, and PBC itself, are very similar to 
self-efficacy [30], a variable postulated in Bandura's Social Cognitive Theory [34], the words are often used interchangeably).

Thus, by measuring intention, attitude, subjective norm, and perceived behavioural control, a behaviour's determinant configuration, the relative relevance of each determinant, can be established. For example, if many participants indicate unawareness (nescience) regarding their friends' approval or disapproval of them trying out ecstasy, while most people disapprove of their friends trying out ecstasy, an intervention could aim to encourage discussion of the topic. On the other hand, this seems a less prudent aim if few participants indicate nescience, and most participants' friends appear to approve of them trying out ecstasy.

Over the years, a number of additions to the TPB have been suggested, such as the descriptive norm, a variable expressing the perception of the behaviour of social referents (as opposed to their approval or disapproval). These will be explained where they are relevant. Likewise, although the TPB is but one of many theories and models developed to aid explanation of human behaviour (another is, for example, Bandura's Social Cognitive Theory [34], which was mentioned above), not all these theories and models can be explained here. Nonetheless, this example can hopefully also facilitate understanding of these other theories by conveying the implicit logic that most theories share. Finally, it is important to note that the Theory of Planned Behaviour addresses the explanation of behaviour, not how to change any of the postulated variables. Thus, the TPB (and many other theories that can aid in explaining behaviour) can help mapping a behaviour's determinant configuration; but once the determinant configuration has been identified, other theories and models have to be invoked to decide how the most relevant determinants can be changed. However, as this thesis reports studies that deal with identification of determinant configurations, theories and models of change will not be considered presently (but see chapter 7 of Bartholomew et al. [2]).

\section{Structure of the thesis}

In Intervention Mapping, the answer to any question is first sought in the existing literature, and subsequently, on the basis of the found information, the need for new data is assessed and addressed. And indeed, when aiming to develop an intervention that targets the behaviours listed in Table 1.1, it makes 
sense to first assess whether determinant configurations for these behaviours are already available in the literature. Chapter 2 describes a meta-analysis that does exactly this, by synthesising quantitatively all studies into the determinants of ecstasy use and related behaviours [35]. Ideally, had sufficient research been conducted, this meta-analysis would have resulted in a list of determinant configurations that could then have served as input for steps 2 and further of Intervention Mapping. However, this was not the case. Because metaanalyses' quantitative nature necessitates very severe inclusion criteria, it was plausible that studies that contain valuable non-quantitative information about potential determinants of a behaviour were excluded from this meta-analysis. To address this possibility, a qualitative review into the reasons of ecstasy use and related behaviours was conducted, the results of which are reported in chapter 3. Thus, together, these two studies provided a complete overview of the literature regarding determinants or reasons for ecstasy use and related behaviours.

However, none of the quantitative studies synthesised in chapter 2 addressed any of the behaviours from Table 1.1. Although a number of the qualitative studies synthesised in chapter $3 \mathrm{did}$, none of these qualitative studies had been conducted in the Netherlands. Additional research was required. First, to assess whether Dutch ecstasy users had similar reasons as their American, English and Australian counterparts, an interview study was conducted among non-users, users, and ex-users of ecstasy recruited at Dutch dance parties. The results are reported in chapter 4 . Then, a largely quantitative online survey was conducted among Dutch dance scene members, which allowed identification of the determinant structure of each of the behaviours inTable 1.1. Of this survey, the results pertaining to using ecstasy are reported in chapter 5, the results pertaining to trying out ecstasy are reported in chapter 6 , and the results pertaining to ceasing ecstasy use are reported in chapter 7 , after which the comparison of these results is reported in chapter 8. Results pertaining to the behaviour of getting one's ecstasy tested are reported in chapter 9 , and the results of the studies reported in chapters 2 to 9 will be synthesised in chapter 10 . 
Appendix 1.i: The members of the linkage group: experts regarding ecstasy use patterns and implementers of the intervention that were consulted during various stages of the project.

\begin{tabular}{ll}
\hline Name & Organisation \\
\hline Floor van Bakkum & Unity, JellinekMentrum Preventie \\
Linda Bolier & Uitgaan en drugs, Trimbos Instituut \\
Lonneke van Deursen & Unity, JellinekMentrum Preventie \\
Ninette van Hasselt & Uitgaan en drugs, Trimbos Instituut \\
Jaap Jamin & Unity, JellinekMentrum Preventie \\
Roel Kerssemakers & Unity, JellinekMentrum Preventie \\
Jan Krul & EducareGroningen \\
\hline
\end{tabular}





\section{Chapter 2 Social cognitive determinants of ecstasy use to target in evidence-based interventions: a meta-analytic review}

(This chapter is co-authored by Gerjo Kok and Charles Abraham, and is published in Addiction, volume 103, pages 109-118, under the same title)

Ecstasy use is potentially damaging to health $[20 ; 36 ; 37]$ yet prevalent $[38 ; 39]$. Legislative changes have not been effective in discouraging ecstasy use, and the development of theory-based behavioural interventions is warranted because these have been successful in generating behaviour change in other areas [40; 41].

Behaviour change interventions are more likely to be effective if they target modifiable antecedents of the target behaviour. For example, if expected positive outcomes of a target behaviour differentiate between those who do and do not engage in that behaviour, it is prudent to target outcome expectancies in behaviour change interventions [2]. Which potentially modifiable cognitive antecedents of ecstasy use should interventions target? Unfortunately, although ecstasy was synthesized in 1912 [3], and ecstasy use has been studied for 20 years (e.g. [42; 43]), there is no systematic review of this research identifying potentially modifiable cognitive antecedents of use. We aimed to summarize research to date, synthesizing quantitatively all published, quantitative studies of psychological determinants of ecstasy use among young persons living in Western society.

\section{Method}

The search strategy comprised three iterative steps. First, the databases PsycINFO, MedLine and ERIC (Education Resources Information Center) were searched using several combinations of keywords (see Appendix 2.i). The results of the final query were then scanned manually for relevant entries by examining the paper titles and abstracts (see Appendix 2.ii). Four inclusion criteria were used. Firstly, a study should investigate the target population of 
young recreative ecstasy users in western society, as factors influencing behaviour can be population-specific [32;44;45]. Secondly, a study should measure one or more potentially modifiable determinants of ecstasy use-related behaviour; that is, an antecedent that could be influenced potentially by health promotional interventions (excluding for example demographics, personality, etc.); for a list, see chapter 7 of Bartholomew et al. [2]. Thirdly, the study should measure either actual behaviour or intention. Finally, it should assess quantitatively the relationship between determinants and behaviour or intention. Publications selected by this process were examined in detail. Second, reference lists of these papers were scanned for relevant publications (the ancestry approach). Third, texts citing the relevant papers were located using the Web of Science database (the descendancy approach).

Potentially modifiable determinants were extracted from the studies using a recommended published list [2], on the basis of which two authors selected determinants from each paper and perfect agreement was observed. Associations between determinants and behaviour or intention across studies were integrated by converting all statistics to the correlation coefficient $r$. These coefficients were then transformed to Fisher's $Z$ and weighed by sample size -3 (cf. [46]). The mean Fisher's $Z$ was then transformed back to the correlation coefficient $r+$. When a study tested a variable several times (e.g. frequency of use and intensity of use), the resulting effect sizes were averaged before being included in the calculations.

\section{Results}

The search yielded 367 hits, from which 15 publications were included (see Appendix 2.ii). Many excluded studies had a biological focus (e.g. [37]), examined determinants not feasibly changed by health promoting interventions (e.g. [47]), or used qualitative methods (e.g. [28]). All included publications studied the behaviour 'using ecstasy' (or the intention to use); none examined determinants of trying out ecstasy, ceasing use, changing use patterns or applying harm reduction practices. Of these 15 publications, six were discarded after thorough examination, as they were then discovered to yield no quantitative information on the relevance of potentially modifiable determinants of behaviour in the target population ([48-53]; see also Appendix 2.ii). Application of the ancestry approach yielded no additional publications (365 citations scanned), but the descendancy approach yielded one additional 
Table 2.1: Quantitative studies into the determinants of using ecstasy and measures used.

\begin{tabular}{|c|c|c|c|c|c|c|c|}
\hline No. & Sample details & $\mathbf{n}$ & Age & $\%$ & Relevant variables & I & $\mathbf{R}$ \\
\hline \multirow[t]{7}{*}{ [54] } & UK & 364 & 19 & $44 \%$ & Negative mood function scale & 3 & 5 \\
\hline & Before July 2002 & & & & Social function scale & 5 & 5 \\
\hline & Poly-drug users & & & & Negative effects & 4 & 5 \\
\hline & & & & & Other functions (9 functions) & 1 & 5 \\
\hline & & & & & Extent of peer use & 1 & 4 \\
\hline & & & & & Partner/best friend use & 1 & 2 \\
\hline & & & & & Intensity of use & 1 & - \\
\hline \multirow[t]{7}{*}{ [55] } & UK & 100 & 19 & $45 \%$ & Mood function scale & 3 & 5 \\
\hline & Before March 1998 & & & & Social/contextual function scale & 5 & 5 \\
\hline & Alcohol and drug & & & & Negative effects/events scale & 3 & 5 \\
\hline & users & & & & Extent of peer use & 1 & 5 \\
\hline & & & & & Intention & 1 & 7 \\
\hline & & & & & Intensity of use & 1 & - \\
\hline & & & & & Frequency of use & 1 & - \\
\hline \multirow[t]{7}{*}{ [56a] } & UK & 186 & $19-25$ & $58 \%$ & Attitudes & 6 & 7 \\
\hline & March 1992 & & & & Subjective norms & 1 & 7 \\
\hline & Students & & & & Perceived behavioural control & 6 & 7 \\
\hline & & & & & Behavioural beliefs (17) & 2 & 19 \\
\hline & & & & & Normative beliefs (5) & 2 & 19 \\
\hline & & & & & Control beliefs (8) & 2 & 19 \\
\hline & & & & & Intention to use ecstasy & 4 & 7 \\
\hline \multirow[t]{8}{*}[56b]{$^{1}$} & UK & $\mathrm{t}_{1}: 203$ & 23 & $41 \%$ & Attitudes & 8 & 7 \\
\hline & Mid-1996 & $\mathrm{t}_{2}: 123$ & & & Normative influences & 13 & 7 \\
\hline & Club members & & & & Perceived behavioural control & 1 & 7 \\
\hline & & & & & Self-efficacy & 1 & 7 \\
\hline & & & & & Behavioural beliefs & 13 & 7 \\
\hline & & & & & Control beliefs & 6 & 7 \\
\hline & & & & & Intention & 3 & 7 \\
\hline & & & & & Behaviour (longitudinal) & 4 & - \\
\hline \multirow[t]{8}{*}{ [57] } & Netherlands & 844 & 22 & $33 \%$ & Negative outcome expectancies & 11 & 2 \\
\hline & 2000, 2001 & & & & Enhancement outcome expectancies & 3 & 2 \\
\hline & Party attendants & & & & Euphoria outcome expectancies & 4 & 2 \\
\hline & & & & & Sex outcome expectancies & 4 & 2 \\
\hline & & & & & Dancing outcome expectancies & 3 & 2 \\
\hline & & & & & Insight outcome expectancies & 4 & 2 \\
\hline & & & & & $\begin{array}{l}\text { Communication outcome } \\
\text { expectancies }\end{array}$ & 4 & 2 \\
\hline & & & & & Whether ecstasy was currently used & 1 & 2 \\
\hline \multirow[t]{7}{*}[58]{$^{*}$} & UK & $\mathrm{t}_{1}: 461$ & $19-22$ & $55 \%$ & Attitude & 2 & 7 \\
\hline & $\mathrm{t}_{1}$ : October & $t_{2}: 136$ & $19-22$ & $65 \%$ & Injunctive Norms & 6 & 7 \\
\hline & 1994-1995 & & & & Perceived Behavioural Control & 8 & 7 \\
\hline & $\mathrm{t}_{2}$ : May & & & & Descriptive Norms & 2 & 6 \\
\hline & 1995-1996 & & & & Moral Norm & 1 & 7 \\
\hline & Students & & & & Intention & 1 & 8 \\
\hline & & & & & Behaviour (longitudinal) & 1 & 8 \\
\hline
\end{tabular}




\begin{tabular}{|c|c|c|c|c|c|c|c|}
\hline \multirow[t]{4}{*}{ [59] } & UK & 657 & 19 & $55 \%$ & Frequency of past use & 1 & 7 \\
\hline & Before 2003 & & & & Intentions to use & 1 & 9 \\
\hline & College students & & & & Normative influence (friends' use) & 1 & 6 \\
\hline & & & & & Beliefs about ecstasy use (7 beliefs) & 1 & 5 \\
\hline \multirow[t]{8}{*}[60]{$^{*}$} & UK & $\mathrm{t}_{1}: 84$ & 20 & $74 \%$ & Attitude & 10 & 8 \\
\hline & & $\mathrm{t}_{2}: 32$ & & & Subjective norm & 2 & 8 \\
\hline & & & & & $\begin{array}{l}\text { Perceived behavioural control over } \\
\text { obtaining ecstasy }\end{array}$ & 3 & 8 \\
\hline & & & & & $\begin{array}{l}\text { Perceived behavioural control over } \\
\text { taking ecstasy }\end{array}$ & 4 & 8 \\
\hline & & & & & Intention & 5 & 8 \\
\hline & & & & & Habit & 2 & 8 \\
\hline & & & & & Specific attitudinal beliefs (13 beliefs) & 1 & 5 \\
\hline & & & & & Behaviour (longitudinal) & 1 & 2 \\
\hline \multirow[t]{11}{*}{ [13] } & The Netherlands, & 490 & 22 & $34 \%$ & Energy motives & 4 & 5 \\
\hline & 2001-2002 & & & & Euphoria motives & 3 & 5 \\
\hline & & & & & Self-insight motives & 2 & 5 \\
\hline & & & & & Sociability/flirtatiousness motives & 8 & 5 \\
\hline & & & & & Sexiness motives & 4 & 5 \\
\hline & & & & & Coping motives & 3 & 5 \\
\hline & & & & & Conformism motives & 4 & 5 \\
\hline & & & & & Perceived positive effects & 24 & 2 \\
\hline & & & & & Perceived negative effects & 11 & 2 \\
\hline & & & & & Perceived friends' use & 1 & 5 \\
\hline & & & & & Frequency of ecstasy use & 1 & 5 \\
\hline \multirow[t]{7}{*}{ [61] } & UK & 200 & 21 & $66 \%$ & Attitude & 5 & $?$ \\
\hline & & & & & Subjective norm & 5 & 5 \\
\hline & & & & & $\begin{array}{l}\text { Perceived behavioural control over } \\
\text { obtaining ecstasy }\end{array}$ & 3 & 7 \\
\hline & & & & & Perceived behavioural control over & & \\
\hline & & & & & taking ecstasy & 11 & ? \\
\hline & & & & & Intention & 6 & 7 \\
\hline & & & & & Habit & 2 & 7 \\
\hline \multirow[t]{10}{*}{ [62] } & USA & 70 & 20 & $47 \%$ & Risk associated with using ecstasy & 1 & 4 \\
\hline & Club rave attendees & & & & once or twice & & \\
\hline & & & & & $\begin{array}{l}\text { Risk associated with using ecstasy } \\
\text { regularly }\end{array}$ & 1 & 4 \\
\hline & & & & & Harmful short-term physical effects & 1 & 4 \\
\hline & & & & & Harmful long-term physical effects & 1 & 4 \\
\hline & & & & & $\begin{array}{l}\text { Harmful short-term psychological } \\
\text { effects }\end{array}$ & 1 & 4 \\
\hline & & & & & $\begin{array}{l}\text { Harmful long-term psychological } \\
\text { effects }\end{array}$ & 1 & 4 \\
\hline & & & & & Positive physical effects & 1 & 4 \\
\hline & & & & & Positive psychological effects & 1 & 4 \\
\hline & & & & & Ecstasy use within the past 12 months & 1 & 2 \\
\hline
\end{tabular}

No. = number in reference list, $\mathrm{I}=$ number of items used to measure variable, $\mathrm{R}=$ number of scale points on response scale of each item. ${ }^{*}$ Longitudinal design. 
publication [out of 85 unique citing publications; 54]. Of the final set of ten publications [13; 54-62], one publication described two studies [56; 56a and 56b refer to studies 1 and 2, respectively]. Table 2.1 describes the 11 included studies, listing the sample details, the extracted potentially modifiable antecedents and how they were measured in the original studies.

All 11 studies can be viewed as tests of two theoretical frameworks which are applied frequently in drug use research [63]. Six studies [56a, 56b; 58-61] tested the theory of planned behaviour (TPB; [30]). The TPB proposes that the most proximal cognitive determinant of behaviour is intention which, in turn, is predicted by attitude (i.e. evaluation of likely consequences of that behaviour), subjective norm (i.e. perception of others' approval of the behaviour) and perceived behavioural control (PBC, i.e. perception of control based on perception of skills and external obstacles/facilitators). Each of these constructs is based on underlying beliefs. Several extensions of the TPB have been proposed [64]; for example, personal norm (personal moral evaluation of the behaviour), descriptive norm (perception of others' performance of the behaviour [65]), habit [66] and anticipated regret (the regret one experiences when prospectively imagining having - or not having-performed a behaviour $[67 ; 68])$.

Five studies $[13 ; 54 ; 55 ; 57 ; 62]$ tested expectancy models (e.g. [69]), which propose that behaviour is determined by expectations people have of the behaviours' consequences. Two studies [54; 55] assessed how often participants used ecstasy for particular reasons (e.g. 'in the past year, how often have you used ecstasy to help you to let go of inhibitions?'), implying germane expectations (such as 'taking ecstasy helps me let go of inhibitions'). Three studies $[13 ;$ 57; 62] used more traditional measures (e.g. 'I have experienced/would expect that ecstasy makes it easier to communicate'). Note that these expectations are viewed as underlying beliefs in the TPB, particularly in relation to the structure of attitudes [30; 32].

In both the TPB and outcome expectancy models, higher-level constructs, such as attitudes, are based on lower-level beliefs. Most studies tested models involving this hierarchical cognitive structure. For the purposes of this review, higher-level constructs are referred to as 'compound constructs' and lowerorder cognitions as 'expectancies' (e.g. beliefs about probable consequences of ecstasy use). Details of the particular theoretical models explored in the original studies are not provided here. 
Only bivariate analyses were synthesized because multivariate analyses were incommensurable over studies as they tested different models. [In order to resolve this by conducting uniform regression analyses, all authors were asked to provide matrices of covariance. However, due to lost data sets, missing data and nonresponse, not enough data could be retrieved to render this feasible. The authors are grateful to M. Conner and T. ter Bogt, who did supply additional data.] It is worth noting none the less that in the two TPB-based studies in which ecstasy use was regressed onto compound constructs, the average (weighed) $R^{2}$ was 0.51 [56b; 58], and in the five TPB-based studies in which intention to use was regressed onto compound constructs the average $R^{2}$ was 0.67 [56a, 56b; 58; 60; 61]. The average $R^{2}$ for the three expectancy studies in which ecstasy use was regressed onto expectancies was 0.35 [13;54; 57], and in the expectancy study where intention to use was regressed onto expectancies was 0.64 [55]. In three prospective studies ecstasy use was found to be related strongly to prior intention to use with an average (weighed) $r$ of 0.71 [56b; 58; $60]$.

Table 2.2 shows the strength of association between predictor variables and measures of ecstasy use and intention to use. The strongest predictor of intention and use was the TPB-specified attitude measure. Attitudes are thought to be based on more specific expectancies [30;32] and these are shown separately in Table 2.2, grouped into 'positive' and 'negative' expectancies. In addition to these perceived advantages and disadvantages of ecstasy use, normative measures have been used, especially subjective and descriptive norms, as well as perceived behavioural control over ecstasy use. Variables proposed as extensions to the TPB have been categorized as 'miscellaneous'. Table 2.2 is based on the Pearson correlations reported in five studies $[54 ; 55 ; 58$; $60 ; 61]$ and correlation matrices received from the authors of two publications $[13 ; 56]$. One study [57] reported $t$-values, which were converted into effect size correlations using $r=\sqrt{ }\left[t^{2} /\left(t^{2}+d f\right)\right]$. The results from two studies [59; 62] could not be converted and will be provided later. Only associations found in at least two samples, of magnitudes corresponding to a medium (Cohen's $d=.5$ [70], $r=$ $.24)$ or large effect size $(d=.8$ and $r=.37)$, are considered.

All significant associations were in the expected direction and some large effect sizes were observed, suggesting that both the theory of planned behaviour and the expectancy approach can help to explain ecstasy use and intentions to use. In the TPB studies, intention and behaviour are associated most strongly with TPB's attitude, with a large effect size $(r+=0.53$ with 
Table 2.2: Effect sizes of predictors of ecstasy use and intention to use.

\begin{tabular}{|c|c|c|c|c|c|c|c|}
\hline \multirow[b]{2}{*}{ Variable type } & \multirow[b]{2}{*}{ Compound or expectancy } & \multicolumn{3}{|c|}{$\begin{array}{l}\text { Association with } \\
\text { behaviour }\end{array}$} & \multicolumn{3}{|c|}{$\begin{array}{l}\text { Association with } \\
\text { intention }\end{array}$} \\
\hline & & $k$ & $r+$ & & $k$ & $r+$ & \\
\hline Attitude & Attitude $[\mathrm{C}]$ & 5 & .53 & (L) & 5 & .63 & (L) \\
\hline Positive & Social function $[\mathrm{C}]$ & 4 & .09 & & 2 & .30 & (M) \\
\hline \multirow[t]{14}{*}{ Expectancies } & Produces a positive mood state & 3 & 12 & (S) & 2 & .28 & (M) \\
\hline & Mood function $[\mathrm{C}]$ & 4 & .20 & $(\mathrm{~S})$ & 1 & .41 & (L) \\
\hline & Helps lose weight & 2 & .09 & & 1 & .08 & \\
\hline & Enhances sex & 3 & .11 & (S) & & & \\
\hline & Helps stay awake & 3 & .08 & & & & \\
\hline & Helps keep fit & 1 & .14 & (S) & 1 & .22 & (S) \\
\hline & Enhances insight/openness & 2 & .18 & (S) & & & \\
\hline & Helps to relax/helps coping & 2 & .08 & & & & \\
\hline & Produces excitement & & & & 1 & .31 & (M) \\
\hline & Produces intoxication & 1 & .19 & (S) & & & \\
\hline & Eases after-effects & 1 & .15 & (S) & & & \\
\hline & Improves other drugs' effects & 1 & .11 & (S) & & & \\
\hline & Is conforming to peers & 1 & .05 & & & & \\
\hline & Helps work & 1 & .05 & & & & \\
\hline \multirow{13}{*}{$\begin{array}{l}\text { Negative } \\
\quad \text { Expectancies }\end{array}$} & Short term negative effects $[\mathrm{C}]$ & 4 & .47 & (L) & & & \\
\hline & Produces mood swings & 1 & -.34 & (M) & 2 & -.31 & (M) \\
\hline & Leads on to more frequent use & 1 & -.30 & (M) & 2 & -.39 & (L) \\
\hline & Produces mental side-effects & 1 & -.24 & (M) & 2 & -.40 & (L) \\
\hline & Leads on to 'worse' drugs & 1 & -.23 & (S) & 2 & -.31 & (M) \\
\hline & Produces physical side-effects & 1 & -.18 & (S) & 2 & -.39 & (L) \\
\hline & Makes one unhealthy & 1 & -.18 & (S) & 2 & -.30 & (M) \\
\hline & Produces depression & 1 & -.18 & (S) & 2 & -.28 & (M) \\
\hline & Produces lethargy & 1 & -.05 & & 2 & -.20 & (S) \\
\hline & Produces addiction & 1 & -.32 & (M) & 1 & -.12 & (S) \\
\hline & Leads to death & 1 & -.30 & (M) & 1 & -.32 & (M) \\
\hline & Produces paranoia & 1 & -.27 & (M) & 1 & -.26 & (M) \\
\hline & Makes one feel run down & 1 & -.17 & (S) & 1 & -.25 & (M) \\
\hline \multirow{6}{*}{$\begin{array}{l}\text { Subjective } \\
\text { injunctive } \\
\text { normative }\end{array}$} & Subjective norms (approval) [C] & 5 & .39 & (L) & 5 & .52 & (L) \\
\hline & Best friends' approval & 1 & .36 & (M) & 1 & .25 & (M) \\
\hline & Partners approval & 1 & .15 & (S) & 1 & .30 & (M) \\
\hline & Parents' approval & 1 & .10 & (S) & 1 & .01 & \\
\hline & Health experts' approval & 1 & .09 & & 1 & .00 & \\
\hline & Other ecstasy users' approval & 1 & .07 & & 1 & .08 & \\
\hline \multirow{4}{*}{$\begin{array}{l}\text { Subjective } \\
\text { descriptive } \\
\text { normative }\end{array}$} & Subjective norms (descriptive) [C] & 1 & .52 & $(\mathrm{~L})$ & 1 & .63 & $(\mathrm{~L})$ \\
\hline & Perceived peer use & 2 & .39 & (L) & 1 & .43 & (L) \\
\hline & Perceived use in close relatives & 2 & .21 & (S) & & & \\
\hline & Perceived best friend/partner use & 1 & .37 & (L) & & & \\
\hline \multirow{6}{*}{$\begin{array}{l}\text { Perceived } \\
\text { behavioural } \\
\text { control }\end{array}$} & $\mathrm{PBC}[\mathrm{C}]$ & 3 & .33 & (M) & 3 & .52 & $(\mathrm{~L})$ \\
\hline & PBC (over obtaining ecstasy) & 2 & .20 & (M) & 2 & .25 & (M) \\
\hline & PBC (over taking ecstasy) & 2 & .01 & & 2 & -.03 & \\
\hline & Being with friends who use & 1 & .45 & (L) & 2 & .62 & (L) \\
\hline & Going out dancing & 1 & .41 & (L) & 2 & .67 & (L) \\
\hline & Being offered ecstasy & 1 & .40 & (L) & 2 & .59 & (L) \\
\hline
\end{tabular}




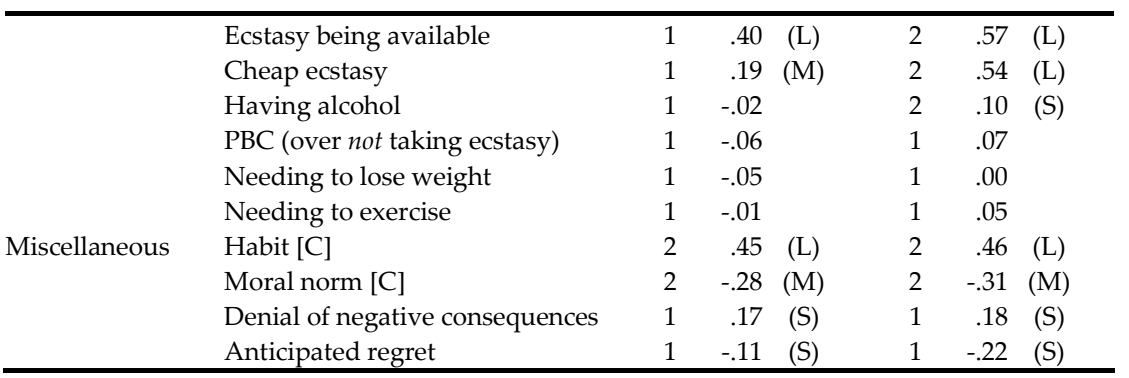

$[\mathrm{C}]=$ compound construct, $k=$ no. of samples, $r+=$ weighted average correlation, $(\mathrm{S})=$ small, $(\mathrm{M})=$ medium, $(\mathrm{L})=$ large effect size magnitude according to Cohen [70]. PBC: perceived behavioural control.

behaviour, $r+=0.63$ with intention). Specifically, this compound construct appears to be associated mainly with positive outcomes regarding mood control and social facilitation, and negative expectations regarding short term negative effects, escalating use and physical and mental side effects.

Normative influences are also important covariates of use and intention to use with stronger associations observed for descriptive $(r+=0.52$ with behaviour, $r+$ $=0.63$ with intention) than injunctive norms ( $r+=0.39$ with behaviour, $r+=0.52$ with intention). The strongest effects sizes for expectancies underpinning these compound constructs were observed for perceived ecstasy use by peers and approval of use by one's best friend and partner. The results also indicate that whether parents, health experts, and 'other ecstasy users' approve is inconsequential.

Perceived behavioural control was related to use with a medium (near large) effect size $(r+=0.33)$ and also strongly related to intention $(r+=0.52)$. Underlying beliefs showed a medium effect regarding control over obtaining ecstasy and large effects of control in relation to being with friends who use, going out dancing, being offered ecstasy and ecstasy being available. Two proposed extensions to TPB appear relevant: habit, with a large effect size $(r+=$ 0.45 with behaviour, $r+=0.46$ with intention), and moral norm, with a medium effect size ( $r+=-0.28$ with behaviour, $r+=-0.31$ with intention).

Two studies reported results using statistics that could not be transformed to an effect size measure. One study [59] conducted a polynomial logistic regression predicting user group (six levels: rejecters, at risk non-users, exusers, and light, moderate and heavy users; for details, see [59]), testing whether a number of variables contributed significantly to model fit when predicting user group. Another study [62] conducted $t$-tests on beliefs (also 
Table 2.3: Significant and non-significant predictors of user group (user group had 6 levels in study [59] and 2 levels in study [62]).

\begin{tabular}{lllll}
\hline Variable & Study & Significance Association & Effect size \\
\hline Perceived use by friends & {$[59]$} & $<.001$ & Positive & $\mathrm{M}$ \\
Anticipated regret ('use would induce guilt') & {$[59]$} & $<.001$ & Negative & $\mathrm{M}$ \\
Is hard to resist & {$[59]$} & $<.001$ & Positive & $\mathrm{M}$ \\
Moral norm ('ecstasy use is immoral') & {$[59]$} & $<.05$ & Negative & $\mathrm{S}$ \\
Perceived availability of ecstasy & {$[59]$} & $<.05$ & Positive & $\mathrm{S}$ \\
Is bad for one's physical health & {$[59]$} & None & - & - \\
Is bad for one's mental health & {$[59]$} & None & - & - \\
Subjective norm (approval) & {$[59]$} & None & - & - \\
Harmful long-term physical effects & {$[62]$} & $<.01$ & Negative & $\mathrm{M}$ \\
Risk associated with using regularly & {$[62]$} & $<.01$ & Negative & $\mathrm{M}$ \\
Risk association with using once or twice & {$[62]$} & $<.05$ & Negative & $\mathrm{M}$ \\
Harmful long-term psychological effects & {$[62]$} & $<.05$ & Negative & $\mathrm{M}$ \\
Harmful short-term physical effects & {$[62]$} & None & - & - \\
Harmful short-term psychological effects & {$[62]$} & None & - & - \\
Positive physical effects & {$[62]$} & None & - & - \\
Positive psychological effects & {$[62]$} & None & - & - \\
\hline
\end{tabular}

$\mathrm{S}=$ small, $\mathrm{M}=$ medium effect size magnitude according to Cohen [70].

predicting user group, with two levels: non-user and user), but did not report $t$ values, exact $p$-values, or variance information. The variables tested in these studies are shown in Table 2.3. Effect sizes were estimated (conservatively) on the basis of sample size and significance.

These additional results confirm the relevance of descriptive norm, negative expectancies (particularly long-term effects), and perceived control, and add anticipated regret, with at least a medium effect size, to the list.

\section{Discussion}

Synthesis of the included studies shows the main predictors of intention to use and actual ecstasy use to be attitude (specifically positive outcomes regarding mood control and social facilitation, and negative outcomes regarding escalating use and physical and mental side effects); subjective and descriptive norms regarding one's friends, partner and peers; perceived control regarding obtaining ecstasy and control in relation to being with friends who use, going out dancing, being offered ecstasy and ecstasy being available; and habit, moral norm, and anticipated regret. In addition to lending support to both the TPB and expectancy models, these findings show that some expectancies underlying attitude are irrelevant (e.g. ecstasy enhances sex), as are norms relating to some 
social referents (e.g. parents), and perceived control regarding some ecstasyrelated behaviours (e.g. taking ecstasy).

As it is now clear which determinants best predict intention to use and ecstasy use according to the research so far, these determinants seem advisable intervention targets. However, not all determinants are equally easy to modify. As attitude encompasses several specific expectancies, it may be easier to target these more concrete expectancies than the abstract attitude construct. Also, not all expectancies are influenced equally easily. Because most users have experienced positive mood shifts, it may be difficult to develop persuasive messages that undermine this expectancy among users [6]. Negative variables are also associated strongly, and changed more easily. However, simply presenting information about negative outcomes ('fear appeals') has been shown not to work, or even work inversely, unless a number of critical conditions are met, such as efficacy enhancement (see [40; 71]; also see [72]). Similarly, it may be difficult to change a subjective norm if it reflects reality. As ecstasy use is social [73] and most users take ecstasy at a dance event [8] where ecstasy use is high (in the Netherlands, about two-thirds of the visitors use ecstasy; [74]), it might be hard to reduce descriptive norms, especially if participants' friends use ecstasy. Similarly, it may be challenging to establish a disapproving norm (see [75]).

Similarly, it may be difficult to reduce perceived control over obtaining ecstasy among users, as they likely have repeatedly performed this behaviour successfully. However, the large effects of specific control beliefs suggest that users who wish to stop may well be aided by adopting a stimulus control strategy avoiding the social contexts of use. In addition, enhancing refusal skills would influence perceived behavioural control, while also diminishing the effect of undesirable subjective norms (by decreasing users' motivation to comply, see [30]). Thus, among those with intentions not to use, refusal skills training and stimulus control are recommended [76]. Finally, habit and moral norm are useful predictors but may be difficult to change ([2], but also see [77]). Although anticipated regret has a smaller association with use and intention to use it can be changed more easily (e.g. [67]). A list of methods and strategies to change these determinants, and the theoretical parameters prerequisite to success, is provided in chapter 7 of Bartholomew et al. [2].

This review is limited mainly by the fact that only bivariate associations could be synthesized and by two consequences of the paucity of research into ecstasy use thus far. First, the small number of studies into determinants of 
ecstasy use limit the robustness of the current findings. Second, many theories and models have not yet been studied and are therefore not included in this review. Only social cognitive theories have been tested; no studies have investigated, for example, the predictive value of implicit cognitions. However, recent research implies that implicit processes may be changeable [78]. Moreover, within social cognitive research, recently developed constructs such as consideration of future consequences [79] have not been applied to ecstasy use, but may aid in intervention development.

Regarding the theories that have been studied, in order to gain a more comprehensive understanding of motives for ecstasy use future research should combine the two theoretical perspectives studied thus far, so that relative overlap can be determined. It would be interesting to see whether, and to what degree, particular expectancies account for the predictive utility of the TPB attitude measures. Also, the list of expectancies that has been studied so far may omit a number of consequences (such as 'suicide Tuesday', a term for a period following use when low serotonin levels can induce depressive feelings).

Another important gap in the literature concerns behaviours other than 'using ecstasy'. Not only can the determinants of trying out ecstasy, starting use, ceasing use and maintaining cessation differ from the determinants of using ecstasy [32], little is known about the determinants of harm reduction practices, such as getting ones ecstasy tested by a test service, ensuring sufficient hydration and maintaining a low body temperature (although studies such as [80] are a step in the right direction). Intervening to promote these behaviours could prove to be more beneficial to the health of party visitors, given the difficulty of intervening on most variables determining ecstasy use.

In conclusion, this review suggests that there is sufficient evidence to guide intervention development so that evidence-based practice is established. These interventions could then be evaluated to test the utility of particular theoretical frameworks. The priorities for interventions should be negative expectancies, perceived behavioural control and anticipated regret. Tailored interventions can offer refusal skills training and strategies to avoid risky situations to participants not intending to use ecstasy. 
Appendix 2.i: Search terms used in PsycINFO (equivalent terms used in corresponding fields in MedLine and ERIC) [query in words, as corresponding to 'concepts' column, in brackets].

\begin{tabular}{|c|c|c|c|}
\hline No. & Concept & Operationalization & Fields \\
\hline 1 & Language & (English) or (Dutch) & Language \\
\hline 2 & $\begin{array}{l}\text { Publication } \\
\text { type }\end{array}$ & $\left(\right.$ journal $\left.^{*}\right)$ or (peer-reviewed-journal) & $\begin{array}{l}\text { Publication } \\
\text { type }\end{array}$ \\
\hline 3 & $\begin{array}{l}\text { Publication } \\
\text { date }\end{array}$ & $>1980$ & $\begin{array}{l}\text { Publication } \\
\text { year }\end{array}$ \\
\hline 4 & Ecstasy & $\begin{array}{l}\text { (clubdrug*) or (club near drug*) or (dance near drug*) or } \\
\text { (dancedrug*) or (party near drug*) or (partydrug*) or (xtc) or } \\
\text { (MDMA) or (methylenedioxymethamphetamine) or ('3,4- } \\
\text { methylenedioxymethamphetamine') or (ecstasy) }\end{array}$ & $\begin{array}{l}\text { Title, abstract, } \\
\text { keywords }\end{array}$ \\
\hline 5 & Theoretical & $\begin{array}{l}\left(\text { theor }^{*}\right) \text { or }\left(\text { attitud }^{*}\right) \text { or }(\text { motivat } \\
\left(\text { norm }^{*}\right) \text { or }(\text { perceived near control) or }(\mathrm{pbc}) \text { or }(" \text { social } \\
\text { cognitive") or (self adj efficacy) or (stages near change) or } \\
\text { (perceived adj (harm or risk or functions)) or (functional) or } \\
\text { (outcome adj (expectancies or expectations)) or (sct) or (tpb) } \\
\left.\text { or (patter*) or (psychosoc }{ }^{*}\right) \text { or (health adj belief adj model) or } \\
(\mathrm{hbm})\end{array}$ & $\begin{array}{l}\text { Title, abstract, } \\
\text { keywords }\end{array}$ \\
\hline
\end{tabular}

6 Determinants (determin $\left.{ }^{*}\right)$ or $\left(\right.$ facto $\left.^{*}\right)$ or $\left(\right.$ variabl $\left.^{*}\right)$ or (parameter $\left.{ }^{*}\right)$ or $\quad$ Title, abstract, $\left(\right.$ reason $\left.^{*}\right)$ or $\left(\right.$ caus $\left.^{*}\right)$ or $\left(\right.$ motiv $\left.^{*}\right)$ or $\left(\right.$ incentive $\left.^{*}\right)$ or $\left(\right.$ correlat $\left.^{*}\right)$ or keywords (antecedent $\left.{ }^{*}\right)$ or $\left(\right.$ character $\left.^{*}\right)$

7 Initiation $\left(\operatorname{start}^{*}\right)$ or $\left(\right.$ commenc $\left.^{*}\right)$ or $\left(\right.$ originat $\left.^{*}\right)$ or (onset) or (initiat $\left.{ }^{*}\right)$ or Title, abstract, (instigat $^{*}$ ) or ((use) not (user)) or (using) or (usage) or keywords (establish*)

8 Maintenance (maint $\left.{ }^{*}\right)$ or $\left({\text { sustain*) or }\left(\text { continu }^{*}\right) \text { or }\left(\text { uphold }^{*}\right) \text { or (persist }}^{*}\right)$ Title, abstract, or (further*) or (prolong*) keywords

9 Cessation $\left(\right.$ end $\left.^{*}\right)$ or $\left(\right.$ stop $\left.^{*}\right)$ or $\left(\right.$ discontinu $\left.^{*}\right)$ or $\left(\right.$ terminat $\left.{ }^{*}\right)$ or $\left(\right.$ ceas $\left.^{*}\right)$ or Title, abstract, $\left(\right.$ cessat $\left.^{*}\right)$ or $\left(\right.$ abstain $\left.^{*}\right)$ or $\left(\right.$ abstin $\left.^{*}\right)$ or $\left(\right.$ quit $\left.^{*}\right)$ or $\left(\right.$ remiss $\left.^{*}\right)$ or $\quad$ keywords $\left(\right.$ resolut $\left.^{*}\right)$ or $\left(\right.$ recover $\left.^{*}\right)$

10 Harm (harm or risk or damage or casualt*) and (reduc* or manag* Title, abstract, reduction or limit* or minimi*) keywords

11 Excluded ((treatment not ("not in treatment" or "non-treatment" or "non Anywhere treatment" or "no treatment")) or rat or rats or mouse or mice or animal or monkey* or pigeon* or spectro* or cardio* or seroton* $^{*}$ or dopamin* or neurotransm* or receptor* or psychiatr* or psychopath* or cell* or diagnos*)

12 Inclusion \#1 and \#2 and \#3 (Language and Publication Type and Publication Date)

13 Behaviour \#7 or \#8 or \#9 or \#10 (Initiation or Maintenance or Cessation orHarm reduction)

14 Empirical $^{*}$ \#6 near \#13 (Determinants and Behaviour)

15 Final query* \#12 and \#4 near (\#5 or \#14) not \#11 (Inclusion and Ecstasy and (Theoretical or Empirical) not Excluded)

* When executed, the query consisted of one command; therefore the use of the 'near'operator was valid here. 
Appendix 2.ii: Search procedure, number of resulting hits, and results of each step.

\begin{tabular}{|c|c|c|}
\hline Step & Activity & $\begin{array}{l}\text { Number of } \\
\text { resulting } \\
\text { publications }\end{array}$ \\
\hline 1 & $\begin{array}{l}\text { Input of query at August 20 th } 2007 \text { in PsycINFO (162), MedLine (194) \& } \\
\text { ERIC (11) }\end{array}$ & 367 \\
\hline 2 & Removal of duplicate records (83) & 284 \\
\hline 3 & $\begin{array}{l}\text { Removal of records about publications that (entries were removed in this } \\
\text { order): }\end{array}$ & \\
\hline 3.1 & studied biological variables (e.g. sequelae of ecstasy use; 75) & 209 \\
\hline 3.2 & $\begin{array}{l}\text { did not study ecstasy use or a related behaviour (such as trying out ecstasy, } \\
\text { ceasing use, changing use patterns, or applying harm reduction practices; }\end{array}$ & \\
\hline & 32) & 177 \\
\hline 3.3 & $\begin{array}{l}\text { studied variables that cannot be changed using a health promotion } \\
\text { intervention (e.g. sex, ethnicity or religion; 68) }\end{array}$ & 109 \\
\hline 3.4 & $\begin{array}{l}\text { studied ecstasy use as an independent variable in a multivariate or } \\
\text { longitudinal analysis (22) }\end{array}$ & 87 \\
\hline 3.5 & did not employ quantitative methods (e.g. qualitative studies; 30) & 57 \\
\hline 3.6 & did not study behaviour or cognitions (25) & 32 \\
\hline 3.7 & $\begin{array}{l}\text { studied a 'non-normal' subpopulation or gathering data from samples } \\
\text { inseparably encompassing these subpopulations (e.g. dependent } \\
\text { participants, patients or delinquents)*, studying generic drug categories } \\
\text { (e.g. "hard drugs"')**, or not explicitly stating which drugs were studied } \\
\text { (14) }\end{array}$ & 18 \\
\hline 3.8 & were not published in a peer-reviewed journal (3) & 15 \\
\hline
\end{tabular}

* inclusion of these subpopulations would restrict generalization of the results to the target population of the current study (i.e. the average adolescent; see [32; 81]),

** this demand of drug specificity is necessary because previous research has shown that beliefs about drugs can vary between different drugs [82], rendering aggregation questionable. 



\title{
Chapter 3 A structured review of reasons for ecstasy use and related behaviours: pointers for future research
}

\author{
(This chapter is co-authored by Gerjo Kok, and has been \\ submitted for publication under the same title)
}

Ecstasy use is potentially damaging to health [20; 21] yet prevalent [38; 39]. Theory-based behavioural interventions have successfully generated behaviour change in other areas [40;41], and may likewise have beneficial effects when applied to ecstasy use. However, development of an effective intervention requires knowledge about which modifiable determinants need to be targeted [2]. A recent meta-analysis of quantitative studies on ecstasy use and related behaviours, which aimed to provide this knowledge, concluded that much research is still necessary [35]. Specifically, of all behaviours relevant to ecstasy use (e.g. trying out ecstasy, applying harm reduction strategies, ceasing ecstasy use) only the broad behavioural category of 'using ecstasy' had been addressed by the included studies. Because meta-analyses aim to integrate quantitatively the literature, they generally exclude studies that do not report certain statistics. For example, the meta-analysis about ecstasy use included only studies that "assess quantitatively the relationship between determinants and behaviour or intention" [35]. These restrictive inclusion criteria led to the exclusion of all qualitative and exploratory studies into the reasons for ecstasy use, while paradoxically, it is exactly this exploratory methodology that renders these studies particularly valuable in setting the research agenda. The current review sets out to inform future research into ecstasy use and related behaviours by summarising this qualitative and exploratory literature that has not yet been summarized.

Although the aforementioned meta-analysis did result in a list of determinants that seem relevant for ecstasy use (i.e. attitude, subjective norm, perceived behavioural control, moral norm, anticipated regret and habit), consideration of the most salient underlying beliefs indicated that some of these determinants of ecstasy use may prove exceptionally hard to modify [35]. For 
example, although non-users had a lower descriptive norm than users (i.e. nonusers perceived there to be less ecstasy use at dance events), this difference appeared to reflect an under-estimation of actual ecstasy use prevalence on the part of non-users. This means that an intervention aiming to decrease descriptive norms would have to present incorrect information about the prevalence of ecstasy. The difficulties of intervening on the reported determinants seem to be underlined by a recent evaluation of an intervention among ecstasy users, where the authors concluded that a brief motivational intervention was no more efficient than the information-only control condition [though use decreased in both conditions, which most control participants attributed to the self-assessment at baseline; 83]. In addition, none of the reviewed studies specifically addressed the initiation or cessation of ecstasy use or the application of harm reduction strategies. All studies addressed the broad behavioural category of 'using ecstasy' [e.g. by comparing users with nonusers, or examining the intention to 'use ecstasy'; 35], which may be problematic because determinants of related but different behaviours such as these are assumed to differ [2;84]. Finally, it seemed that the summarized research had not addressed a number of potentially relevant determinants [35].

Thus, so far, only one of several relevant behaviours has been studied; the identified determinants appear hard to modify; and relevant determinants may have been omitted. To investigate whether studies into other ecstasy use-related behaviours or addressing other determinants do exist, but were excluded by the rigid exclusion criteria of the meta-analysis drawing these conclusions, the current paper reviews all qualitative studies and studies that did not report an association with intention or behaviour, but did report reasons for performing (or not performing) an ecstasy use-related behaviour (e.g. trying out ecstasy, ceasing ecstasy use, getting ecstasy tested, or drinking water during use). This overview can then serve as a starting point for the required quantitative research into ecstasy use, eventually enabling development of effective evidence-based interventions.

\section{Methods}

Relevant literature was identified through the databases PsycINFO and MedLine. These were accessed through the Ovid SilverPlatter WebSpirs interface (version 5.12). At the $21^{\text {tu }}$ of August 2008, the query 
“((ecstasy or MDMA or xtc or methyldioxymethamphetamine or "party drug" or "party drugs" or "club drug" or "club drugs" or "dance drug" or "dance drugs") in TI,AB) and (LA=english)"

was entered and yielded 4574 hits (12 32 from PsycINFO and 2021 from MedLine). The phrase "not (mouse or mice or rat or rats)" was added, which eliminated 1321 hits. The remaining 3253 entries were downloaded and imported into a reference management program [85], which automatically identified and deleted 741 duplicates (defined as entries with the same title and year of publication). The titles and abstracts of the 2512 remaining records were manually inspected for relevance, and all publications reporting reasons for an ecstasy use-related behaviour were acquired. The acquired publications were examined in more detail, and if upon closer inspection a paper turned out to not report any reasons for ecstasy use or a related behaviour, it was excluded accordingly.

Most excluded records described biological studies, followed by a large number of publications describing prevalence of drug use, sometimes combined with demographical variables. A number of studies also investigated consequences, perceived effects, or risks of ecstasy use. Unless these were mentioned as reasons for ecstasy use or related behaviours (e.g., cessation), there is no reason to assume that they influence behaviour (e.g., experiencing anxiety need not influence ecstasy use, as suggested by the fact that that effect is reported by current users of ecstasy [6]; likewise, abstainers can hold similar expectancies as users without commencing use [86]). Specifically, when consequences of ecstasy use (effects, risks or otherwise) were neither reported in response to a question about reasons nor considered as reasons by the author of the original paper, they were not considered as reasons in the current paper either. Also, studies not reporting original empirical data were excluded (e.g., discussions or reviews). Finally, potential population-specificity of factors influencing behaviour [32;44;45] prompted exclusion of studies that did not investigate the target population (i.e. young recreative ecstasy users in western society).

\section{Results}

\section{Included studies}

Details of the included 22 publications [82; 87-107] are provided in Table 3.1. The included studies examined several behaviours, and given the qualitative 


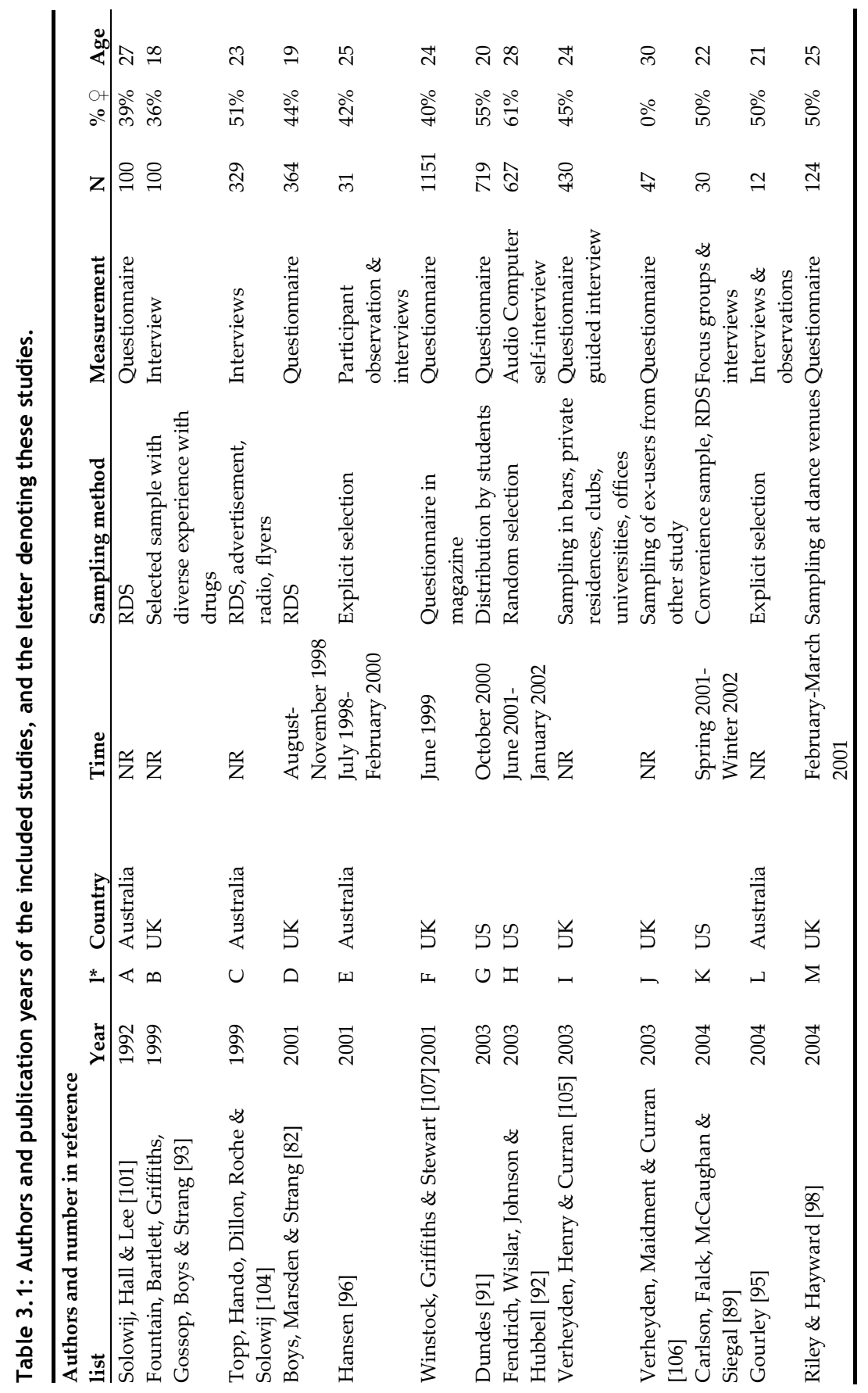




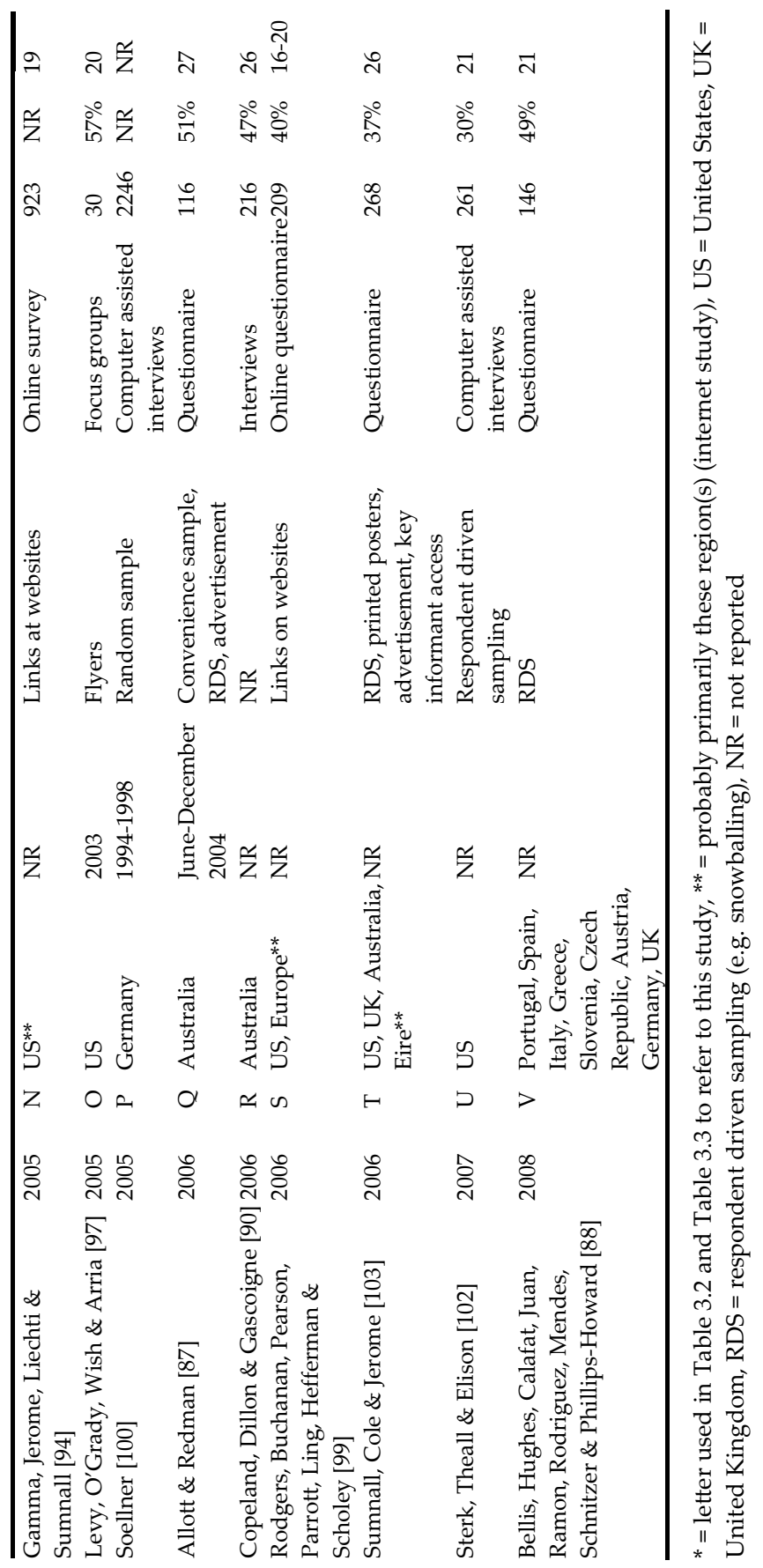


nature of these data, this renders presentation of all results challenging. In 2006, Baylen and Rosenberg [6] reported a review with a goal similar to the current goal, and with resulting data that were structured similarly. As the way in which they report their results seems very useful for the current purposes, this approach will roughly be followed. Two groups of behaviours share a number of reasons, and the results pertaining to these groups of behaviours are therefore presented in the same table. One table contains "use behaviours": behaviours leading to consumption of more ecstasy (starting use, "using ecstasy" in general, using more ecstasy, and not ceasing ecstasy use, see Table 3.2). The other table contains "non-use behaviours": behaviours leading to consumption of less ecstasy (not starting use, using less ecstasy, or ceasing use, see Table 3.3). In addition to these seven behaviours, a number of studies addressed reasons for combining ecstasy with other drugs and applying harm reduction strategies $[87 ; 90 ; 96 ; 97 ; 101 ; 102 ; 107]$. Because of the multitude of different behaviours, these reasons will not be tabulated but rather discussed in the text. The authors have clustered the reasons in Tables 2 and 3 to the best of their abilities, but exclusively to ease presentation and discussion, as the qualitative nature of this review prohibits integration of the results. The original descriptions for each reason are listed in the first column of every table, and the original (unclustered) lists of reasons are also available [108].

\section{Use behaviours}

A number of patterns emerge when all studies are combined (see Table 3.2). First, like quantitative studies, most qualitative studies focussed on the behaviour 'using ecstasy'. However, there is still a lot of data on other behaviours, such as starting to use ecstasy, using more ecstasy, and not ceasing ecstasy use. Reasons to start using ecstasy seem to fall into the following categories: availability, curiosity, to be on the same level as friends, ease of use, to enhance mood, to get intoxicated, because positive effects outweigh negative effects, for recreation, and as self-medication. In addition, whether potential users feel safe about the ecstasy contents and the setting seems to play a role (but only for a minority of potential users). Most data on reasons for trying out ecstasy come from interview studies and do not provide an indication as to how relevant each reason is.

Regarding using ecstasy, such indications are more widely available, which allows tentative ordering of the reason categories by relevance. The following categories contain at least one reason that was endorsed by more than half of the participants (very relevant reasons): to be on the same level as 


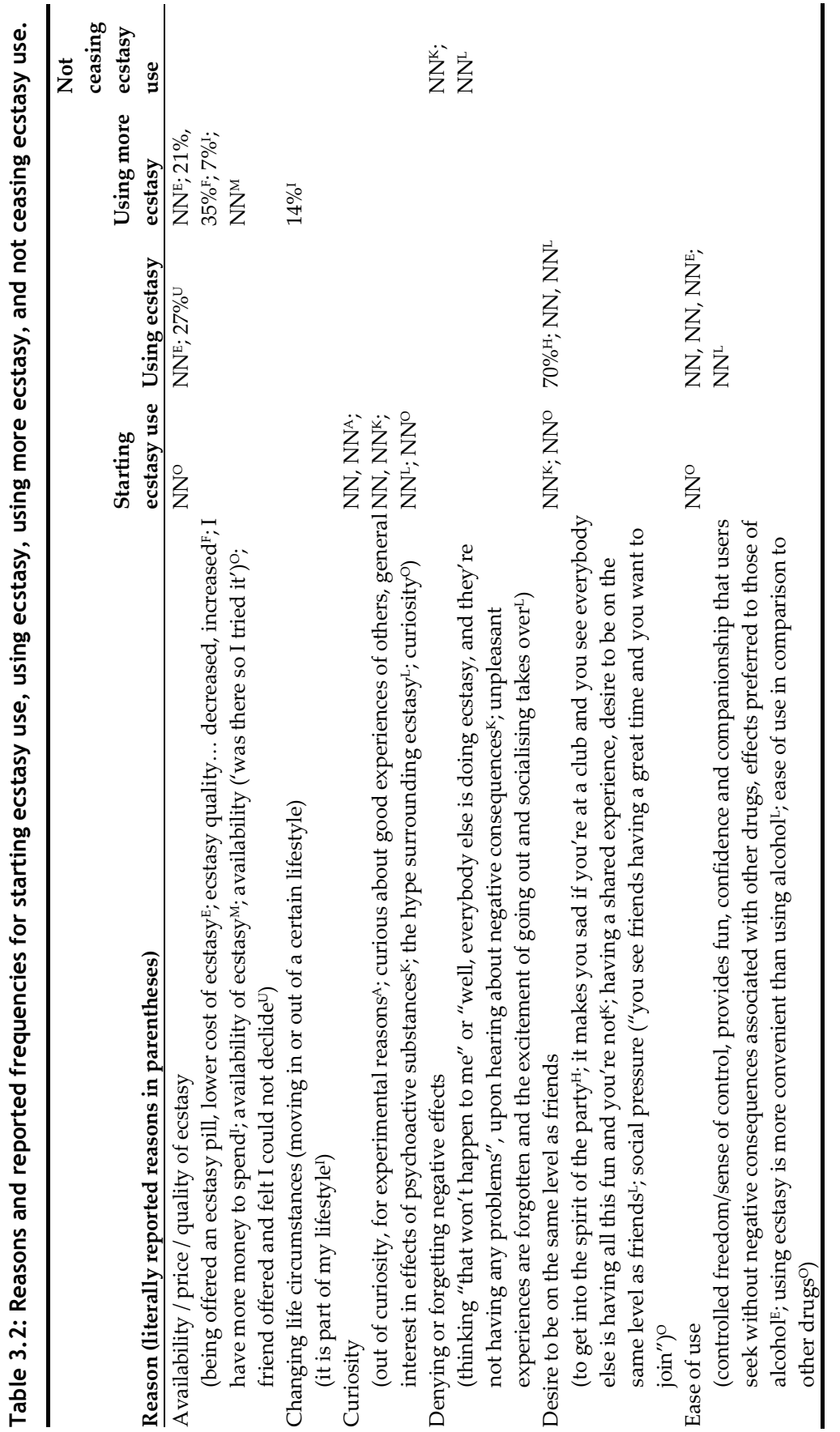




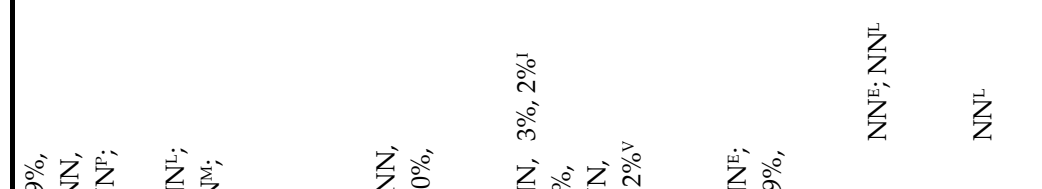

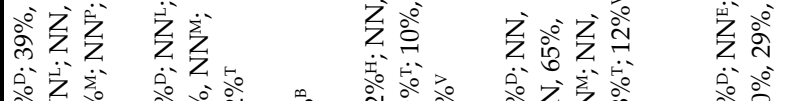

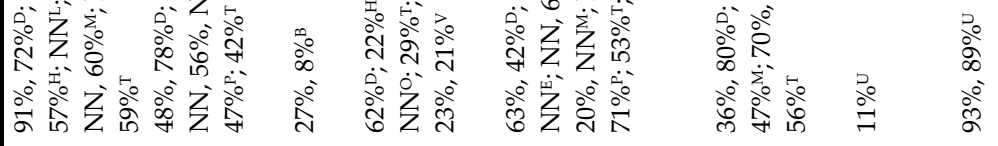

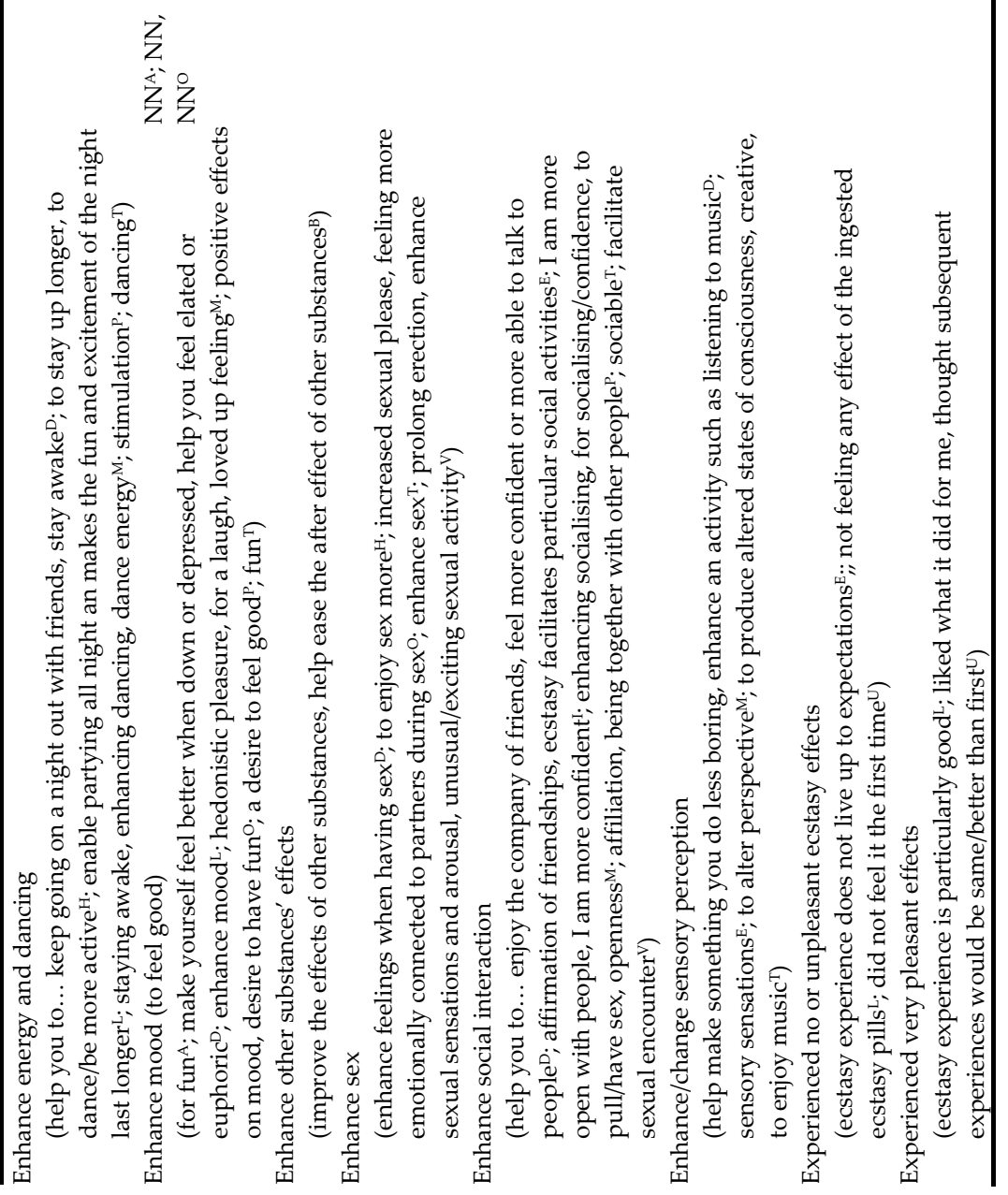




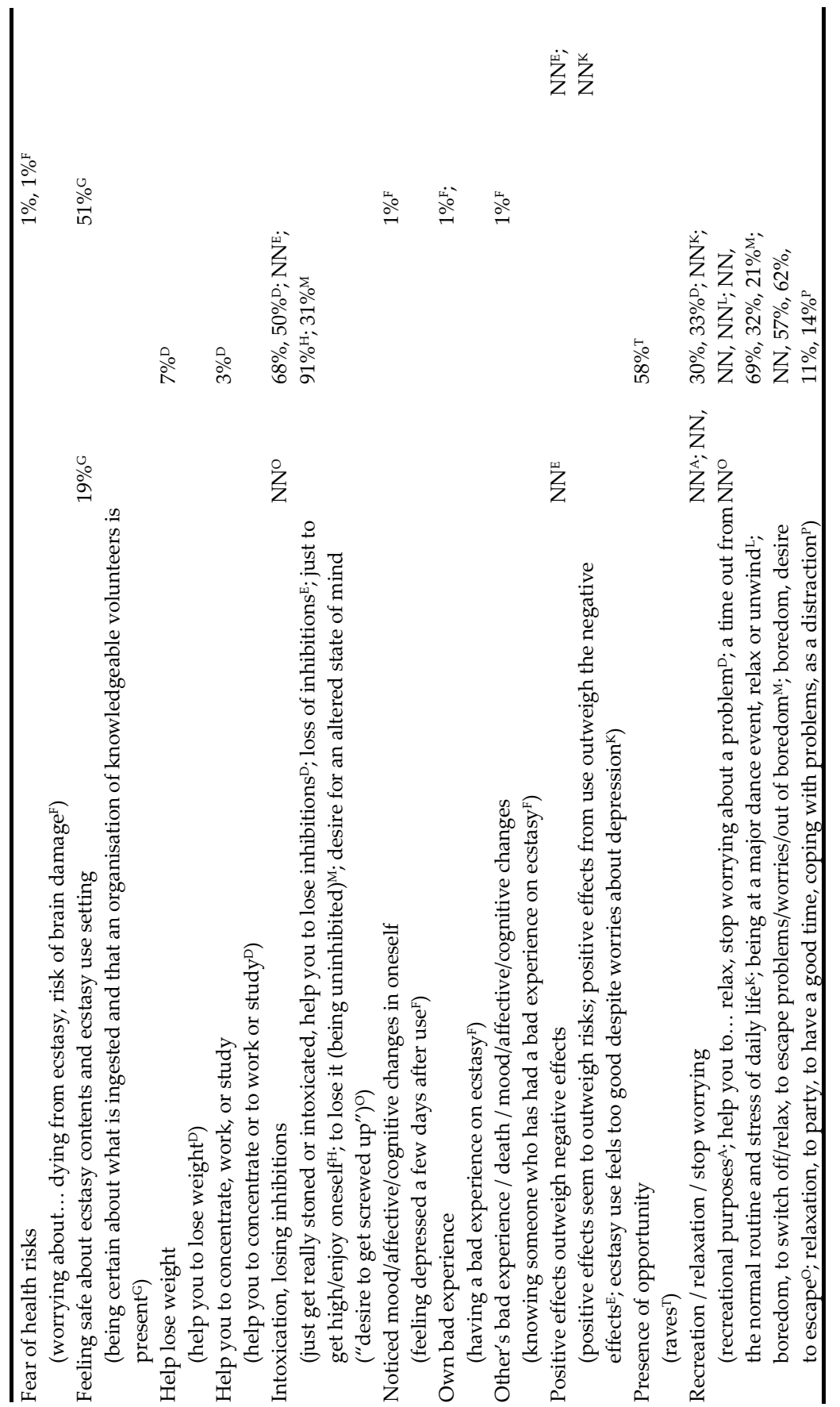




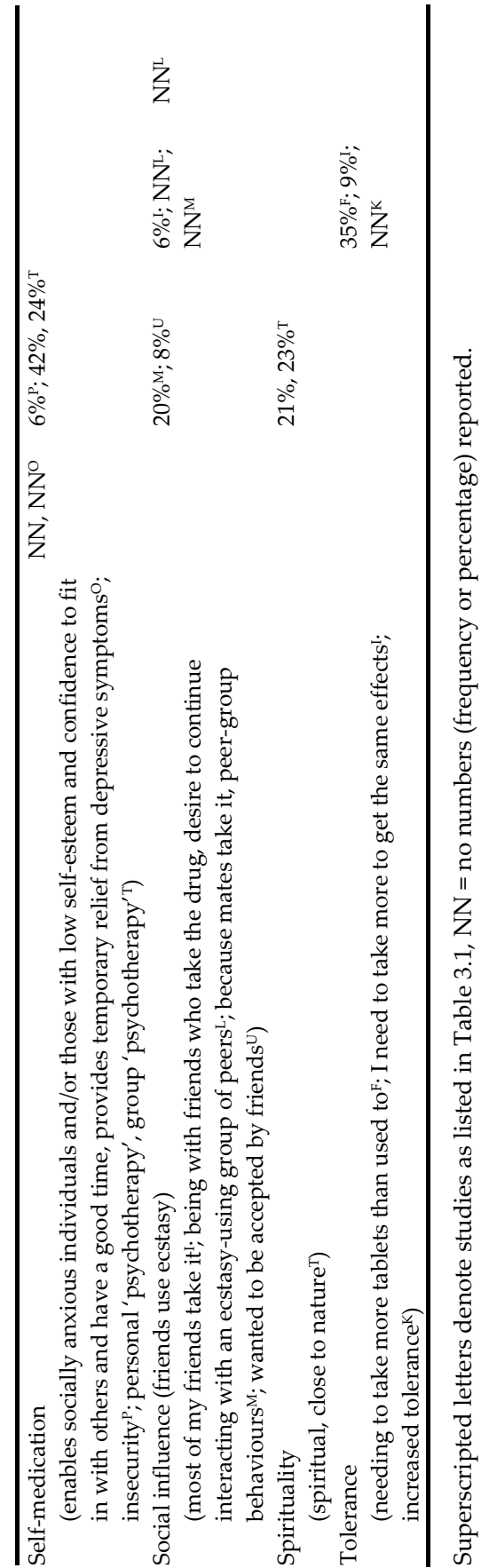


friends, to enhance energy and dancing, to enhance mood, to enhance sex, to enhance social interaction, to enhance sensory perception, because pleasant effects were experienced, to get intoxicated, because of an opportunity, and recreation. The following categories were reported by less than half, but more than one in ten participants (moderately relevant reasons): availability, enhance other substances' effects, because no effects were experienced, self-medication, social influence, and spirituality. Two categories were reported by less than one in ten participants (irrelevant reasons): to help lose weight and to help concentrate. No information was available as to the relevance of the category ease of use.

For using more ecstasy (encompassing both increasing frequency and increasing dosage), only one reason was very relevant: feeling safe about ecstasy contents and setting. Moderately relevant reasons were availability, changing life circumstances, and tolerance, and social influence and to enhance social interaction were irrelevant reasons. Fear of health risks, noticing mood/affective/cognitive changes in oneself, and one's own or another's bad experience were each reported as reasons for using more ecstasy by $1 \%$ of the participants of study $\mathrm{F}$, which can reasonably be assumed to reflect measurement errors. There was no information about the relevance of ease of use and not experiencing the expected effects.

For not ceasing ecstasy use, like for trying out ecstasy, no information was available to estimate the relevance of each reason. The reported reasons fell in the following categories: because positive effects outweigh negative effects, because negative effects are denied or forgotten, or because of social influence.

When this information is combined for all use behaviours, it becomes clear that although some reason categories are equally relevant for all behaviours, there are also differences. Understandably, curiosity only seems relevant for starting ecstasy use; denial of negative effects only seems relevant for not ceasing use; and tolerance is only relevant for using more ecstasy. However, other differences are less intuitive. For example, social influence, and ecstasy's ability to provide energy and enhance social interaction and sensory perception do not seem to play a big role in starting to use ecstasy.

\section{Non-use behaviours}

When looking at behaviours that health promoters would generally construe as the desirable behaviours, it is clear that most research focussed on using less ecstasy and ceasing ecstasy use (see Table 3.3). Regarding the less studied behaviour "not starting ecstasy use", no study reported a reason that was 


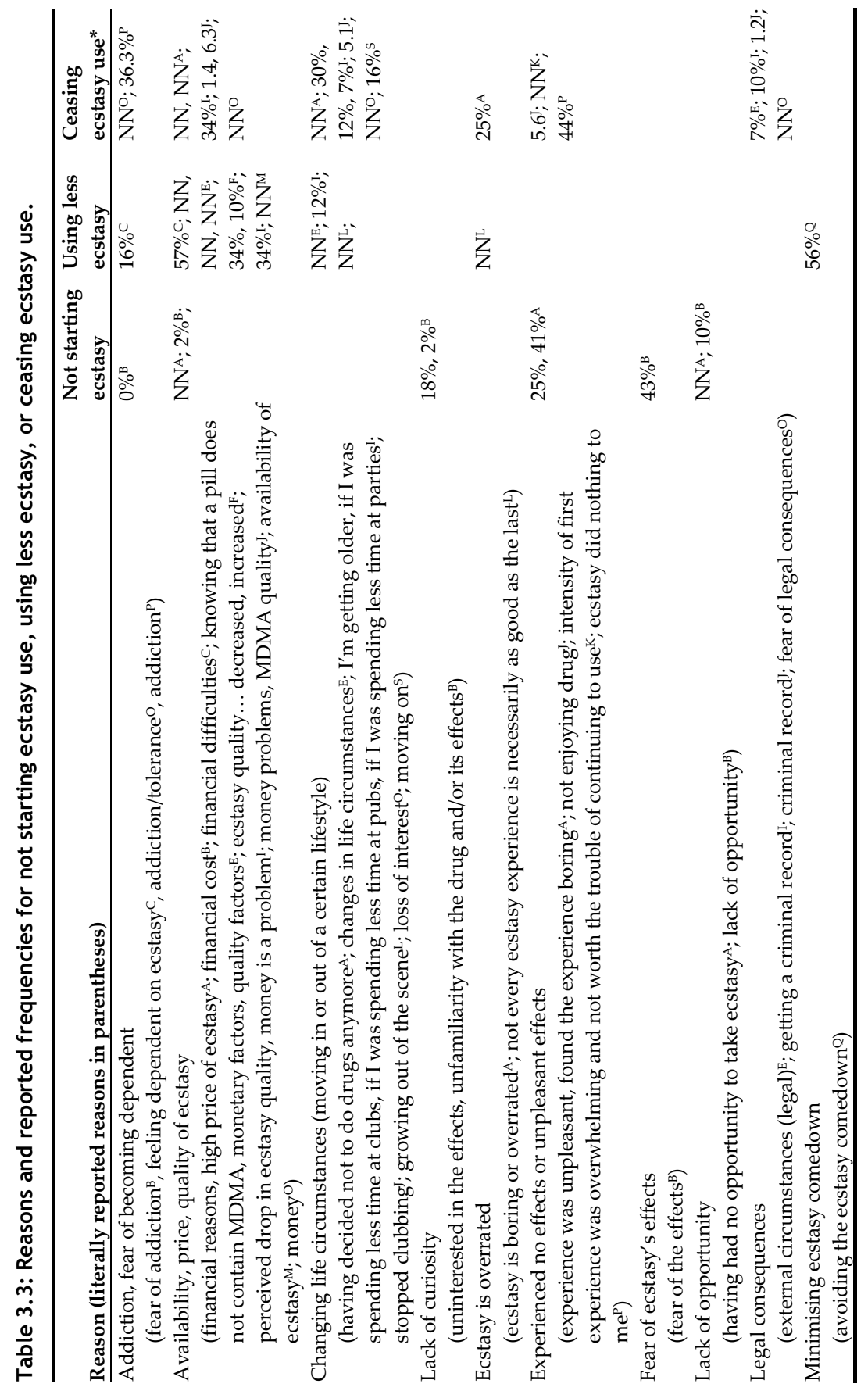




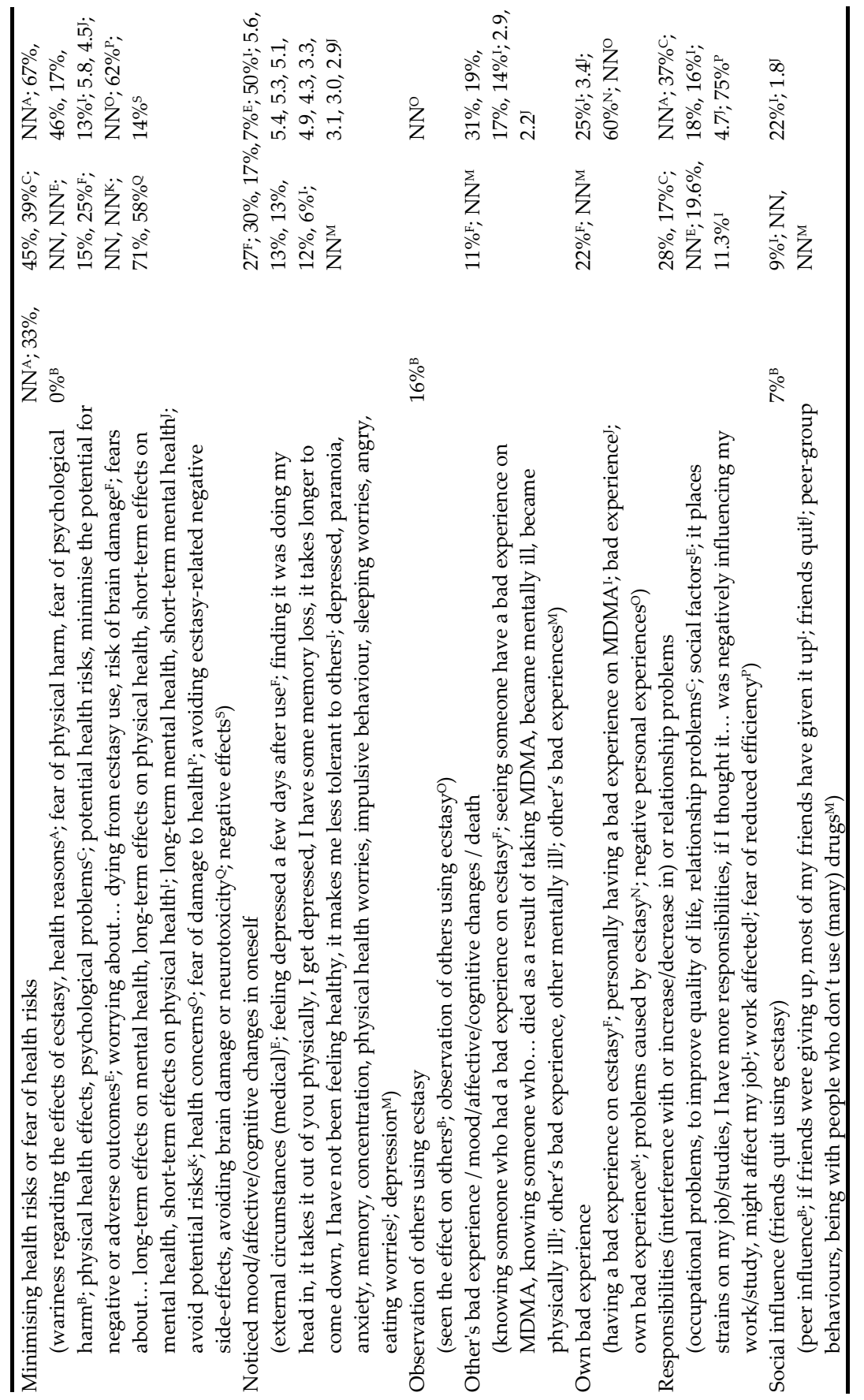




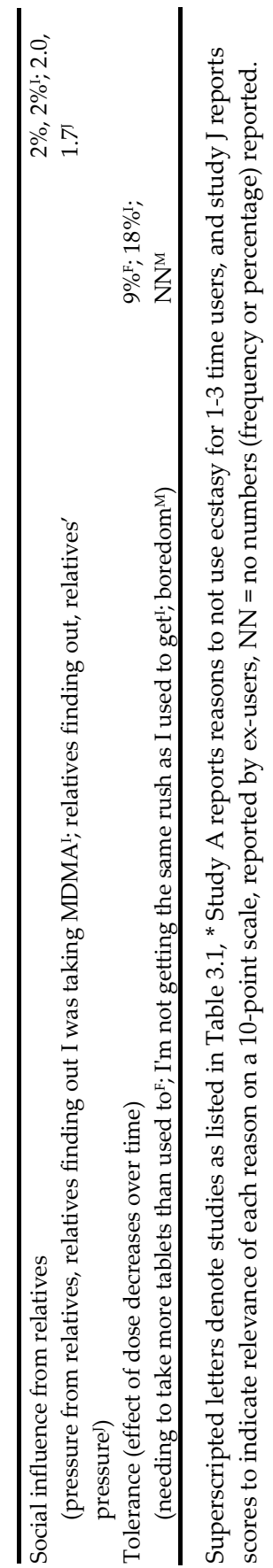


endorsed by more than half of the participants, indicating substantial variation in people's reasons to refrain from starting ecstasy use. The most relevant reasons fell in the following categories: lack of curiosity, experience was unpleasant or absent, fear of ecstasy's effects, lack of opportunity, fear of health risks, and observation of others using ecstasy. Fear of addiction, availability, and social influence seemed to be less relevant.

Regarding using less ecstasy, availability, minimising ecstasy comedown (the unpleasant period following ecstasy intoxication) and minimising health risks seemed to be the most relevant reason categories. Less relevant were the fear of addiction, changing life circumstances, having a bad experience on ecstasy, noticing mood/affective/cognitive changes in oneself, one's own or another's bad experience, responsibilities, and tolerance. Social influence again seemed the least relevant, and no relevance information was provided for the reason that ecstasy is overrated.

For ceasing ecstasy use, four relevant categories emerged: personally having a bad experience, fearing or minimising health risks, noticing mood/affective/cognitive changes in oneself, and responsibilities. Less relevant categories were fear of addiction, availability, changes in life circumstances, judgement that ecstasy is overrated, not experiencing desirable effects of ecstasy (any more), legal consequences, another person's bad experience, and social influence. Social influence from relatives was irrelevant, and it could not be estimated how relevant the observation of others using ecstasy was.

Although the reasons for using less ecstasy and ceasing ecstasy use were quite similar, different reasons were reported for not starting ecstasy. For example, the cost of ecstasy does not deter potential users, but it does cause users to use less or even cease use, whereas other people's bad experiences can be a reason to use less ecstasy or cease altogether, but has never been reported as a deterrent by non-users. Fearing or minimising health risks was reported for all three behaviours, although markedly less frequently as a deterrent to not start using ecstasy. When comparing these reasons with the 'use behaviours', it became clear that there was very little overlap. It seems that people have different reasons for starting ecstasy use and for not starting ecstasy use, and yet different reasons for using less ecstasy and for ceasing ecstasy use, and yet again for using ecstasy.

\section{Combining drugs and applying harm reduction strategies}

Five studies reported reasons to combine ecstasy with other drugs, and all reasons fell in one of two categories: to enhance the ecstasy experience, or to 
minimize the comedown. To enhance the ecstasy experience, ecstasy was combined with ADHD medication, amphetamine, benzodiazepines, ketamine, LSD, marijuana, and Viagra (studies A, E, O and R). To minimize the comedown, ecstasy was combined with alcohol, antihistamine, benzodiazepines, cocaine, heroin, ketamine, marijuana, oxycodone-containing analgesics, rohypnol and valium (studies A, E, F, O and R). Interestingly, studies also reported that people refrained from combining with other drugs to maximize the ecstasy experience (studies $\mathrm{A}$ and $\mathrm{K}$ ). Other reasons to refrain from combining were to minimize health risks (studies $\mathrm{E}$ and $\mathrm{K}$ ) and after having heard about people dying from ecstasy use (study K). To minimize health risks, participants also pre- or postloaded with vitamins, 5-HTP, or SSRI's (studies $\mathrm{O}, \mathrm{Q}$ and R). Preloading was also reported to enhance the ecstasy experience (study R), and postloading to minimize the comedown (studies $\mathrm{Q}$ and $\mathrm{R}$ ), and one study reported that participants drunk water during use to minimize the comedown (study Q).

Most other harm reduction strategies were applied too minimize the potential for negative or adverse outcomes or health risks, namely drinking water and chilling out during ecstasy use (both from study Q; chilling out means taking breaks from dancing), purchasing fewer ecstasy pills per occasion and limiting one's supply, only using when in a positive mood and with friends, and the more altruistic behaviours of guiding initiates and monitoring others (all from study E). Then, a number of behaviours served to deal with the uncertain contents of ecstasy pills: using only after someone else had tried the ecstasy (study E), obtaining pills from a reliable source (studies $\mathrm{K}$ and $\mathrm{O}$ ), and purchasing pills in bulk (study E). However, one study also reported that participants could avoid getting their ecstasy tested because they considered the uncertainty (as to the pill contents) 'part of the process' (study E). Finally, one study reported a user who liked to drive under the influence of ecstasy because he enjoyed the experience (study E).

\section{Discussion}

The papers included in this review contain valuable information. Compared to the synthesis of quantitative literature [35], the studies included here have indeed addressed more behaviours and more potential determinants. Though a minority of reasons reported here has already been quantitatively studied, those quantitative studies have only examined their relevance for the behaviour 
'using ecstasy', and the results show that reasons for different behaviours (e.g. 'using ecstasy' and starting or ceasing ecstasy use) differ. This means that an intervention targeting the important determinants for 'using ecstasy' may be unable to effectively influence other behaviours (such as starting or ceasing ecstasy use). This also means that development of evidence-based interventions addressing these other behaviours first requires studies that map the determinant configurations for those specific behaviours.

Unfortunately, this review cannot inform intervention development, because this review only provides an overview of how frequently a reason was reported, and comparison of the frequency with which reasons were reported with the effect sizes found in the meta-analysis for the behaviour 'using ecstasy' showed that frequently reported reasons can correspond to beliefs that were not associated to frequency of use (i.e. beliefs held equally strongly by users and abstainers or by heavy users and light users). For example, using to 'enhance energy and dancing' was mentioned as reason for ecstasy use by between $39 \%$ and $91 \%$, yet the belief that ecstasy helps to stay awake was associated to ecstasy use with a trivial effect size in the meta-analysis ([35]; i.e. Cohen's $d<.2$ [109]). A second limitation of this review is the fact that with one exception all included studies have been performed in the US, the UK and Australia. It remains to be seen whether these conclusions apply to other countries such as the Netherlands. Third, following from the qualitative methodology, no conclusions can be drawn except that reasons for related but different behaviours differ; nothing can be said about the degree to which they differ. This conclusion does, however, imply that determinant configurations (i.e. relative relevance of each of the determinants of a behaviour) of related but different behaviours differ as well.

Thus, there is a need to find out whether and to what degree determinant configurations for ecstasy use-related behaviours differ, ideally by comparing one or more behaviours (e.g. trying out ecstasy, using ecstasy and ceasing use) in one study. If these determinant structures do indeed differ, interventions should target different determinants depending on the specific behaviour that is targeted. In addition, future studies should measure the beliefs underlying the reasons for each behaviour. For trying out ecstasy, reasons related to availability, curiosity, desire to be on the same level as friends, ease of use, enhancing mood, feeling safe about ecstasy contents and ecstasy use setting, intoxication, positive effects outweighing negative effects, recreation, and selfmedication should be measured. For using ecstasy, reasons relating to 
availability, desire to be on the same level as friends, ease of use, enhancing energy and dancing, mood, other substances' effects, sex, social interaction, and sensory perception, experiencing no or very pleasant effects, losing weight and helping to concentrate, intoxication, the presence of an opportunity, recreation, self-medication, social influence and spirituality should be measured. For using ecstasy more often, reasons relating to availability, changing life circumstances, enhancing social interaction, experiencing no or very pleasant effects, feeling safe about ecstasy contents and ecstasy use setting, social influence, and tolerance should e measured. For not ceasing ecstasy use, reasons relating to the denial of negative effects, positive effects outweighing negative effects, and social influence should be measured.

For not starting to use ecstasy, reasons relating to fear of addiction, availability, lack of curiosity, experiencing no positive effects, fear of ecstasy's effects, lack of opportunity, fear of health risks, observation of others using ecstasy, and social influence should be measured. For using less ecstasy, reasons relating to fear of addition, availability, changing life circumstances, ecstasy being considered overrated, minimising the ecstasy comedown, minimising or fearing health risks, noticing changes in oneself, one's own or others' bad experience, responsibilities, social influence, and tolerance should be measured. For ceasing ecstasy use, reasons relating to addiction, availability, changing life circumstances, ecstasy being considered overrated, experiencing no or unpleasant effects, legal consequences, minimising or fearing health risks, noticing changes in oneself, observing others using ecstasy, one's own or others' bad experience, responsibilities, social influence from friends and relatives, and tolerance should be measured.

Just after the current review was completed, two new manuscripts were published that also addressed reasons to refrain from trying out ecstasy [110; 111]. Vervaeke, Benschop and Korf conducted a factor analysis and found support for three factors: fear of the effects, rationality, and lack of opportunity [110]. Rosenberg, Baylen, Murray, Phillips, Tisak, Versland and Pristas used a different method and distinguished eight factors: harm to thinking, school, work, or athletic performance; ecstasy use is contrary to values/self-image; fear of failing a drug-test; fear of effects on body; difficulty with acquiring ecstasy; fear of dangerous outcomes; no enjoyment expected from ecstasy; and fear of loss of control. Most reasons underlying these factors reflect reasons from the earlier studies that were included in this review, but additional reasons to start ecstasy use are also reported: uncertainty about pill contents, medical reasons, 
no access to ecstasy, already using another substance, and not using on principle [in 110], and against religion, fear of damage to reputation, want to be a role model, don't know where to get it, fear of losing control [in 111]. Especially interesting are the different factor structures revealed by these two studies. This can be attributed to their different methodologies of constructing the factors, or to the different locales (Dutch versus American).

\section{Conclusions}

The results of this review provide a clear agenda for the research needed to develop evidence-based interventions addressing ecstasy use. Worth noting in this respect is that many studies reported overlapping reasons, both within and between studies. For example, it is unclear whether and if so, to what degree, the reasons "help enjoy the company of friends", "enhance socialising", and "being together with other people" reflect similar determinants. Ideally, a number of largely orthogonal beliefs can be identified [by studies such as 110 ; and 111], the relevance of each of which can then be established for each behaviour. As multiple theoretical frameworks seem to apply to ecstasy use [35], it seems advisable for future studies to include variables specified by different theories so that it can be determined whether and how the relevant beliefs underlie these variables.

Finally, the combination of this study and the meta-analysis [35] has important implications. First, by virtue of their strict quantitative approach, meta-analyses provide only a very narrow view into the literature, excluding many studies that may provide valuable pointers for future research. By considering these excluded studies, qualitative reviews remain very valuable tools in synthesising the state of the literature. Second, conclusions from such qualitative reviews need to be quantitatively verified. As was also the case in the current review, results from qualitative research may not be corroborated by quantitative data. Thus, a balanced synthesis of the state of the art requires both meta-analytical and qualitative reviews. 



\title{
Chapter 4 Careers in ecstasy use: do ecstasy users cease of their own accord? Implications for intervention development
}

\author{
(This chapter is co-authored by Gerjo Kok and Herman Schaalma, \\ and is in press at BMC Public Health under the same title)
}

Ecstasy (MDMA, 3, 4-methylenodioxymethamphetamine) use is potentially damaging to one's health $[17 ; 20 ; 21]$. A number of recent reviews and metaanalyses have summarized the growing body of research, finding ecstasy use to be associated to poorer neurocognitive functioning in a number of domains [1721]. In addition, many users report negative effects that they attribute to their ecstasy use, such as decreased concentration, depression, insomnia and fatigue [26]. Nonetheless, ecstasy use remains prevalent. In the Dutch general population in 2005, 4.3\% of all men and women between 15 and 64 had ever used ecstasy, $1.2 \%$ had used the past year, and $0.4 \%$ had used the past month [12]. Although these prevalence rates are lower than those of cannabis $(22.6 \%$ lifetime, $5.4 \%$ last-year, and 3.3\% past-month use), of dance event visitors, around two-thirds use ecstasy [74; 112], whereas less than half use cannabis [112]. With over $13 \%$ of the $15-35$ year-olds in the Netherlands visiting at least one dance event each year [11], this high prevalence in the dance scene is worrying.

Although it is generally acknowledged that prevention activities are needed to reduce the detrimental health effects of ecstasy use, to date there is a lack of formative research that would enable the theory- and evidence-based development of such interventions [35; 113]. Recent research syntheses of ecstasy use correlates suggest that ecstasy cessation may be rather difficult to accomplish, since many ecstasy users may cease their use because of external events, such as a change in life circumstances (e.g. new job, relationship) or interference of use with 'normal life' [35; 114]. This might imply that a harm reduction approach could be more effective in promoting the health of ecstasy users than interventions promoting ecstasy cessation. This suggestion is further 
supported by the lack of effects of attempts to promote ecstasy use abstinence [83].

A recent meta-analysis [35] of the determinants of ecstasy use and related behaviour concluded that as yet, there has been no quantitative research into the determinants of ceasing ecstasy use, and that the determinants of using ecstasy do not seem to lend themselves well for health promotion interventions (quantitative research was defined as research analysing the significance and strength of associations between determinants and intention or behaviour). A subsequent qualitative review [114] showed that people's reasons to cease ecstasy use have been studied qualitatively (e.g. in studies using interviews or univariate analyses), and these reasons differ from reasons to use or to initiate use. An important reason to cease use was a change in life circumstances. Four of the ten studies reporting on reasons for cessation were conducted in Australia [95; 115-117], two in the United States [7; 48], one in the United Kingdom [118], one in Germany [100], and two using the internet, with respondents from multiple countries [99; 119].

In Australia, the topic was touched upon in four qualitative studies. The first study was conducted by Solowij et al. [117], who reported the following reasons why one-to-three time users had not used again: it did not live up to their expectations, wariness regarding the effects, financial reasons, or having found the experience boring or unpleasant. Topp et al. [116] found that reasons for wanting to reduce use were financial difficulties, physical health effects, psychological problems, occupational problems, to improve their quality of life, relationship problems, and feeling dependent on ecstasy. Gourley [95] found that "interviewees attributed their declining use to the fact that they were going to raves and other social events less often and were therefore growing out of the ecstasy scene" (p. 62). Hansen et al. [115], stated that "significant changes in user patterns were generally linked to a change in life circumstances" (p. 190).

In the United States (US), Carlson et al. [48] reported a qualitative study and specifically detailed three cases. In one case, an interviewee had tried ecstasy twice: the first time, she found the experience unpleasant; the second time, she experienced nothing. Then, after college, she got a job and planned to get married, and commented, "Since I've been out of college, I've lost touch with it". Levy et al. [7] reported a variation of motivational factors related to quitting ecstasy use: negative personal experiences while using ecstasy, health concerns, addiction/tolerance, money, loss of interest, negative observations of others using ecstasy, and fear of legal consequences. 
In Germany, Soellner [100] asked for motives to cease use, and found that $75 \%$ endorsed "fear of reduced efficiency", $62 \%$ endorsed "fear of damage to health", and 37\% endorsed "addiction". Another 44\% stated that they stopped using without special reasons. However, Soellner indicated that it remains unknown whether the reported fears were related to health promotion efforts or to one's own experience.

In the United Kingdom (UK), Verheyden et al. [118] asked ex-users to rate the importance of a list of possible reasons for cessation. The most highly rated reason was "MDMA quality" (6.3), followed by "long-term mental health" (5.8), "not enjoying drug" and "depressed" (both 5.6), "paranoia" (5.4), "anxiety" (5.3), "memory" and "stopped clubbing" (5.1).

Gamma et al. [119] asked respondents in a web-survey whether they would cease ecstasy use if it caused problems, and found that although $30 \%$ would definitely cease and $30 \%$ would maybe cease, $16 \%$ were not sure, $18 \%$ would perhaps continue, and $7 \%$ would definitely continue. This illustrates that even when users experience problems themselves, this does not guarantee cessation. Rodgers et al. [99] reported that the most frequently reported reason to cease ecstasy use was "moving on" (16\%), followed by "negative effects" $(14 \%)$.

None of these studies has taken place in the Netherlands, and it is questionable whether their results are valid for the Dutch situation. Because of the relatively liberal drug policy in the Netherlands, drug use patterns may differ from those in other countries, particularly regarding the application of drug use harm reduction strategies [120-123]. In addition, different dance drugs are used in the Netherlands than in other countries [124]. For example, methamphetamine use is prevalent in Australia [125] and the US [126], but virtually nonexistent in the Netherlands [127; 128]. LSD use shows a similar but less pronounced pattern $[38 ; 112]$. As recreational drugs have been shown to be each others substitutes [129], these differences may affect ecstasy use patterns. To date, there is hardly any qualitative information available about Dutch ecstasy users, with only one study reporting Dutch data. Although these results do point in the direction of automatic cessation of ecstasy use, they are based on an unpublished source [8].

In order to explore ecstasy use patterns in the Netherlands, and in particular, ecstasy cessation, we conducted a qualitative study among Dutch dance scene members. Ecstasy users, as well as non-users and ex-users, were recruited in order to enable balanced data collection regarding the three periods 
that seem to comprise an ecstasy use career: initiation, regular use and cessation. Although snow-balling techniques are frequently used in illicit drug research and there is some evidence that snow-balling [130] and respondentdriven sampling [131] may provide representative samples, we decided to recruit participants at dance events to ascertain recruitment of regular dance event visitors and to be able to control the inclusion of non-users, users and exusers. In addition to ecstasy use careers, we addressed harm reduction strategies employed by ecstasy users. The current paper provides a summary of the results of these interviews.

\section{Methods}

In April and May 2004, we recruited 160 participants among visitors of three dance events in the Netherlands. Visitors were approached in the chill out areas and asked whether they would be willing to participate in a qualitative study on ecstasy use in exchange for monetary compensation. Visitors who agreed to participate were asked to fill out a small form where they provided contact information and information on their use of ecstasy, speed, cocaine, GHB, ketamine, ephedra and poppers. Specifically, they indicated whether they used each drug and if so, how frequently. If they did not use a drug, they indicated whether they had used the drug in the past but no longer used it now (ex-use) or whether they had never used the drug (non-use).

Afterwards, the 160 potential participants were called randomly. Although a minority of phone numbers turned out to be invalid, the majority of the potential participants that were invited agreed to participate in the study. Therefore, it was not necessary to contact all potential participants. The most common reason to refuse participation was inconvenience of the interview locations and times. Of the 32 participants that were recruited, 24 participants filled five focus groups, and 8 people were invited for individual interviews. Two non-using participants scheduled for individual interviews turned up together, and the interviewer interviewed them simultaneously. The other individual interviews were conducted with a non-user, three users and two exusers. Of the five focus groups, one consisted of a non-user, two users, and an ex-user; one of a non-user, three users, and an ex-user; two of three users and two ex-users; and one of two users and three ex-users. The choice to combine focus groups and individual interviews was based on the lack of evidence as to how the interview method would affect the discussions about ecstasy use in 
this population. Combining both methods allowed provisional exploration of potential differences between the two methods.

Because both urban and rural participants were recruited, the focus group discussions (FGDs) and interviews were conducted at three locations throughout the Netherlands. Two trained interviewers conducted the sessions, using both a detailed interview/FGD scheme and a shorter topic list. These documents determined in which order the topics would be discussed, starting with neutral issues like music, going out and use of alcohol, tobacco and cannabis. Subsequently, ecstasy use was discussed, particularly the initiation of use, fluctuations in use, applying harm reduction practices, and cessation. The topics covered in the interviews partly depended on whether the interviewee was a non-user, a user or an ex-user, or, in the case of FGDs, on the group composition. Permission to perform this investigation was granted by the Ethical Committee Psychology of Maastricht University (the ECP).

The FGDs and interviews were transcribed and imported into QSR NVivo1.3 [132]. This allowed for coding of fragments using a flexible set of categories. Although these categories were initially based on concepts from the Theory of Planned Behaviour [30], a theory that has been found useful in explaining ecstasy use [56; 60], it turned out that categories were so quickly adjusted and refined as the coding process progressed, that these initial categories hardly guided the coding process. The relevant and recurring categories that emerged will guide the description of the results. When applicable, results will be illustrated with a quote from the participants, translated from Dutch.

\section{Results}

Participants' average age was 21 years, with 38\% being female, 22\% identifying as religious, and $47 \%$ living in an urban area (defined as a municipality with over 100.000 inhabitants). Of the 32 participants, 5 had self-identified as nonusers on the recruitment form, 16 as users, and 11 as ex-users. During the interviews, however, it became clear that not all self-identified ex-users had decided to never use ecstasy again. In fact, most 'ex-users' did not define ex-use as a decision to 'never use ecstasy again', but rather as the circumstance that they did not plan to use ecstasy in the foreseeable future. Few 'ex-users' decidedly ruled out any future use. Most ecstasy users used ecstasy once a month or less, and quite a few only used a few times a year. The only variable 
that seemed to be associated with user type was age, with non-users having a mean age of 18, while the mean age of both other groups was $22(t=3.00, p<$ .01 ). The individual interviews lasted on average 45 minutes, whereas the FGDs lasted on average two hours.

Two differences between individual interviews and FGDs were observed. First, participants of FGDs seemed to speak less freely than those interviewed individually; for example, non-users interviewed individually seemed more negative about drug use than those in focus groups. Second, compared to those interviewed individually, users in FGDs seemed to be more concerned about appearing in control of their drug use. However, these differences may have been a consequence of the heterogeneity of the FGDs (combining non-users, users and ex-users); more homogenous groups may not have exhibited these patterns.

Regarding 'regular ecstasy use', the ecstasy use-related behaviour that has been studied most thoroughly, no reasons were reported that have not yet been summarized in an earlier meta-analysis [35] and qualitative review [114]. Basically, ecstasy using participants confirmed the observation that people use ecstasy because it enhances the perceived experience of a dance party. Specifically, participants indicated that ecstasy provided euphoria, energy and connectedness with peers, decreased social inhibitions, and 'levelled' individuals with ecstasy-using friends. Participants revealed a strong norm against using ecstasy to cope with problems: several users indicated that people should only use ecstasy when feeling good. We will not elaborate on these and alike reasons for ecstasy use, in order to allow for a more in-depth consideration of career transitions (i.e. from non-use to use and from use to exuse) and application of harm reduction practices.

\section{Not starting to use ecstasy}

Non-using participants indicated five major reasons for refraining from ecstasy. First, they indicated fear for the direct and acute effects of ecstasy. Second, they reported the negative health effects as a barrier. Third, some participants indicated fear of addiction. Reported reasons for this fear included observing ecstasy-using friends who no longer visited parties without using ecstasy, perceiving oneself as particularly sensitive to addiction, and having a conviction that all drugs were destructive and addictive. The fourth reason to abstain from trying out ecstasy was related to such a conviction: for a number of non-users, their refraining from ecstasy did not seem to be the result of consideration of the consequences of ecstasy use, but rather of adherence to 
what seemed like a strict moral principle. The fifth reason was simply the belief that one did not need ecstasy to enjoy oneself, or more specifically, to 'act crazily', referring to ecstasy's disinhibiting effects. Non-users further revealed that they did not perceive any social pressure to engage in ecstasy use; most of them indicated that they had non-using friends. Moreover, they did not regard ecstasy use to be highly prevalent at dance parties.

\section{Initiation of ecstasy use}

The interviews clearly identified curiosity about the effects as the main reason to start ecstasy use, often initiated by interaction with ecstasy-using friends. Interestingly, many users indicated that among users it is generally 'not done' to encourage non-using friends to try out ecstasy. Yet, at the same time, users seemed to exhibit an enthusiasm about the drugs' effects that, through peer modelling, seemed to have quite encouraged non-using friends. Although they were curious, most users indicated that they were also quite nervous about negative effects when they tried out ecstasy. One user explained how he wanted to try out ecstasy, but in the end, was too afraid of its effects (a second attempt did succeed):

"I have all my friends in that scene, so it happens automatically. The first time I had ... I was going to do it, then I said: 'No, let's not after all', because I was afraid, for the effects and for a ... Well, the second time I did do it, and, well, it was not disappointing, let's put it like that."

(21-year-old male ecstasy user, focus group discussion)

Another user indicated that she waited until she had a relationship with someone who she trusted sufficiently. It appeared that once non-users had become curious about ecstasy, they waited for or actively created the right circumstances for them to try it out. However, even then, most users still exhibited ambivalence in that they remained wary about potential negative effects (mainly unexpected acute effects):

"Yes, look, you know that it's bad for you, period! Smoking is bad, alcohol is bad, drugs are bad. Ehm, and everybody who uses drugs knows that, everybody is always a bit afraid, like, 'what I'm doing now, it's not completely ok', but it feels so good, so, and I live only once."

(25-year-old male ecstasy user, focus group discussion) 


\section{During use: harm reduction strategies}

Throughout their use, the large majority of ecstasy users remained quite aware of the health risks of ecstasy use, and most indicated that they applied a variety of harm reduction strategies. All users clearly seemed to be aware of the need to hydrate during use, and most indicated that they did so. Some participants, however, mentioned that they disliked drinking large amounts of water when they were high, and some others reported that they just tended to forget. A few users had the impression that alcoholic beverages and energy-drinks could also hydrate (whereas these actually dehydrate). Although most users indicated that they were aware of the need to eat during use, many revealed that they disliked eating while high, as ecstasy use causes a very dry mouth. Some users mentioned that they ate the fruit sold at dance events. To compensate for the low intake of food during ecstasy use, most users indicated that they tried to eat properly before use. However, it was generally believed that failure to do so would not have serious negative consequences. Accordingly, in situations of unplanned ecstasy use, many seemed quite willing to forego their intention to eat properly in advance. Moreover, a minority of users revealed that they took ecstasy on an empty stomach to increase its effects. Another harm reduction strategy that was generally acknowledged, was visiting the chill out with sufficient frequency to prevent a high body temperature. However, only a few users seemed to consider this important, and although most indicated that they visited the chill out occasionally, these visits did not seem guided by harm reduction motives.

All in all, our interviews suggest that most ecstasy users attempt to practice harm reduction strategies consistently, but that many were quite willing to let short-term pleasure prevail. Perhaps because of an awareness of their unreliable application of harm reduction strategies, many users claimed to consume healthy nutrients after use, such as nuts, milk and fruit, and in some cases vitamins. These nutrients were perceived as replenishing the body after drug use, and several users showed some lay conceptions of the serotonin depletion due to ecstasy use. Our interviews further revealed that many users tried to get enough sleep, both before and after use, in order to balance the health effects of ecstasy. Both the intake of specific nutrients and the assurance of enough sleep seemed expressions of a belief that ecstasy use damages one's body, and that rest and replenishment is needed to counterbalance the harmful effects of drug use. 
Another important harm reduction strategy is verifying the pill contents, since the dose of MDMA (ecstasy's active component) varies greatly, and pills sold as 'ecstasy' may contain different substances [133]. Yet, pill testing did not seem to be a very popular harm reduction strategy. A few users indicated that they had used testing kits and some others mentioned that they had checked the internet for pill details (e.g., pillreports.com). However, the only reliable method to determine pill content is to have a pill tested in a laboratory. A Dutch government-funded organisation, the Trimbos Institute, organises over twenty pill testing facilities all-over the Netherlands. These are free or very cheap to use and anonymous. However, users indicates less use of these facilities than of testing kits and the internet. Major reasons for the unpopularity of pill testing were a trust in drug dealers or friends who provided ecstasy, as well as the perceived hassle to reach testing facilities.

Finally, many users indicated that they moderated their ecstasy use. Most users moderated the intensity of their use by planning how many pills they would like to take, and taking only that amount to parties. However, this strategy also seemed to be inspired by the possibility of being caught at the drug checks at dance events. Another frequently mentioned way to moderate the intensity of use was to start with a whole pill, but only take 'booster doses' of half a pill. Likewise, many users indicated that they moderated the frequency of their ecstasy use, and that they limited use to less than once a month or once every six weeks -one of the harm reduction guidelines promoted by health educators in The Netherlands. Most users had moderated their frequency of use from the start, but a minority reported that they had gone through a period of very frequent use, where their lives had revolved around dance events, before eventually diminishing their use.

\section{Ceasing ecstasy use}

The ex-users that were interviewed reported three main reasons to cease ecstasy use: responsibilities, loss of interest, and experiencing acute serious effects. The most frequently reported reason to cease use was changing responsibilities. Exusers indicated that they had reduced their drug use when they noticed that their use interfered with their job or study. Additionally, changing jobs, entering a relationship, or having children were mentioned as reasons to cease use. Interestingly, the interviews with users suggested that they anticipate ceasing ecstasy use, and many referred to their current use as a 'phase' in their lives: 
"Look, in this phase of my life I'm just at school, I study, in this phase I don't see myself stopping [with use] ... After that there's a new phase ... And see, whether that's the reason ... Or, or ... Wife, children, job, I don't know ... That depends, but ... I think that in any case, I will have stopped before I get to $30 \ldots$ That is kind of like a deadline...

(22-year-old male ecstasy user, focus group discussion)

Specifically, the age of thirty was repeatedly mentioned as some kind of 'hard deadline' for ceasing ecstasy use and visiting dance events. However, the fact that the ex-users in our study had been recruited at dance parties indicates that at least some ex-users continue visiting dance events even after having ceased ecstasy use.

The second reason to cease ecstasy use that was frequently mentioned was loss of interest. Ex-users indicated that they had reached a point where 'they had seen it all', implying that the novelty of ecstasy use and dance events fades, perhaps in interaction with the introduction of new responsibilities. Third, a few ex-users indicated that they had reconsidered their ecstasy use because of experiences with acute and severe negative effects, such as being hospitalised themselves or having experienced a hospitalised friend.

Our interviews further suggested that ceasing ecstasy use was not perceived as a difficult thing to do. Most users indicated that they were rather confident regarding their ability to cease their drug use. Some ex-users reported that once they had decided to cease, this had indeed had been easy. Some others, however, reported that cessation was hampered by their desire to be 'on the same level' as their ecstasy using friends:

“No, I don't see that [stop using while friends keep on using] happening ... I have considered that numerous times. [...] At some point you're just standing there, and you're completely sober, and you think like: 'ok, that guy is completely off it,' and then you don't really enjoy it any more, then you might as well go home."

(22-year-old male ecstasy user, individual interview)

Also, dance events were generally experienced as more pleasant when ecstasy was used, and accordingly, some users reported that ceasing drug use would probably go together with ceasing to attend dance events. 


\section{Not ceasing ecstasy use}

The most worrying aspect of ecstasy use, potential long-term health damage, was not reported as a major reason for cessation. Although the interviews indicated that users were quite aware of the long-term health risks of ecstasy use, almost none of the users seemed to be worried about the long-term effects of their drug use. This lack of worry about long-term effects seemed to be related to the control users perceive to have over acute negative health effects, and the fact that almost nobody had experienced acute negative effects of their drug use -possibly due to the harm reduction strategies that were frequently employed- let alone long-term negative effects. Moreover, those who mentioned that they had experienced mild acute negative effects (e.g. a bad trip) tended to attribute such incidents to accidental factors like a bad pill. Participants who had experienced severe health problems among acquaintances or their friends, tended to attribute the problems to ignorance and misuse of ecstasy:

\footnotetext{
"What if a good friend of yours would end up in a hospital?" "Then, eh, then I would first just ask how much he used. Because it's like this: for example, if I think he used too much, then it's just his own fault."

(21-year old male ecstasy user, focus group discussion)
}

\section{Discussion}

First of all, our study suggests that ecstasy use among young people in the Netherlands has a strong social character. Many of the drug-using young people that we have interviewed, revealed that they had started using ecstasy because of curiosity and because they felt tempted by, and attracted to, the positive effects ecstasy seemed to have on their friends during dance events. They wanted to be part of the thrill their friends seemed to experience through ecstasy use; they wanted to be on the same level. And once they had experienced the thrill, it became common practice to continue ecstasy use while visiting dance events with friends. Generally, this meant using a few times a year, and rarely more frequently than once a month. For dance party visitors who refrained from ecstasy, the thrill of ecstasy use seemed not to outweigh their fear for negative health effects of ecstasy. Moreover, non-users indicated that they did not need ecstasy to "freak out" at dance events. And, perhaps most importantly, they seemed to visit dance events with friends who also do not use ecstasy. 
A second major result of our study is that ecstasy users seem to be well aware of the health consequences of ecstasy use, and of the harm reduction strategies they can employ to reduce or balance these consequences. Moreover, our study indicates that, although many users mentioned inconsequent and inferior harm reduction strategies, almost none of them had ever experienced acute health problems due to ecstasy use.

A third important outcome of our study is that ceasing ecstasy use seems to be something that 'just happens' due to circumstances, for instance because visiting dance events on ecstasy does no longer fit with other obligations, such as a job or study, or with changing social relationships. As such, ecstasy cessation hardly ever seems to be the result of a careful consideration of pros and cons, nor do negative health experiences seem to play a substantial role.

A fourth result of our study is that ecstasy users generally do not expect cessation to be hard, which is in line with the experiences of those who had actually ceased use. The only factor that seemed to hamper cessation to some extent seems the desire to continue visiting dance events with ecstasy-using friends.

These findings substantiate those reported by Ter Bogt et al. [8]: most ecstasy users seem to cease use of their own accord, either because it starts to interfere with their 'normal life', or because they lose interest. The findings also seem consistent with the results from other countries (i.e. Australia, the US, the UK and Germany), although a number of reasons have not been reported by the Dutch sample. Financial reasons, relationship or social problems, feeling dependent, and fear of legal consequences were not reported by the Dutch sample. The omission of financial reasons is likely a consequence of the low prices of ecstasy in the Netherlands, with pills being as cheap as 1 or 2 euro when bought in bulk [128]. Fear of legal consequences likely did not play a role because of the aforementioned liberal drug policy in the Netherlands (although this reason is not very prevalent in other countries, either). Finally, the low frequencies of ecstasy use may have prevented social and relationship problems, as well as feelings of dependence, from manifesting themselves. Paradoxically, these low frequencies of use may be an indirect consequence of the liberal drug policy as well [120-123]. This policy allowed harm reduction initiatives to flourish, and many users seemed to limit their use frequency conform the guidelines provided by Dutch harm reduction initiatives (e.g., Unity, a peer education project, and "uitgaan en drugs", an initiative from the Trimbos Institute). 
These findings also corroborate earlier findings that ecstasy users' perceptions of ecstasy's risks approximate "its scientifically recognized risk relative to other drugs" [119, p. 190], and that while acute negative effects may impact drug use, this should not be expected of the possibility of long-term neuro-toxic damage [119]. Non-users are aware of ecstasy's dangers, and it seems that among those that start using, this awareness does not disappear. This suggests that health educators have been successful in their endeavours to convey the health risks of ecstasy use, but that this information neither deters curious non-users, nor causes cessation in users.

The factors that do cause cessation, interference with 'real life' and loss of interest, seem hard to influence through health promotion interventions. What does this mean for future health promotion programs targeting ecstasy use? The link between ecstasy use and dance events suggests that banning dance parties might be an effective strategy to reduce ecstasy use. However, as the dance scene became popular through illegally organised dance events, this does not seem a viable solution. At illegal events, organised harm reduction initiatives would be precluded. Furthermore, ecstasy use may also shift to another context. In all, banning dance events would seem a harmful course of action. Second, increasing fear of ecstasy's health effects might help to discourage ecstasy use, but most users' estimates of ecstasy's dangers actually reflect the scientifically recognized risk. In addition, people have generally not experienced any risks themselves. Presenting risk information that is not supported by the scientific literature likely discredits the messenger. Moreover, fear-based information has been shown to be an ineffective intervention strategy [134].

Third, regarding ecstasy use prevention, intervening on non-users' fear of addiction may be successful. It may be possible to use the phenomenon that for ecstasy users, ceasing ecstasy use seems linked to ceasing attendance of dance events. This form of dependence may well be an undesirable outcome for nonusers who consider trying ecstasy out, since in all likelihood, they will not want to find themselves in the situation where they have to give up attending dance events if they want to stop using ecstasy. This new argument to abstain may take away some of the casualness seemingly associated with trying ecstasy out. This argument can be combined with non-users' belief that they do not need ecstasy to have a good time, by informing potential users that trying out ecstasy might make them need the drug in order to have a good time. 
The two other reasons to not start using ecstasy do not appear feasible intervention targets. First, because no publication has reported on the successful creation of negative moral norms regarding a target behaviour, there is no known method to establish a moral objection to (hard)drug use. Second, the fact that the main reason to initiate ecstasy use is curiosity, implies that nonusers' trigger to start using ecstasy is unlikely to be a change in their belief that they do not 'need' the disinhibiting effects of ecstasy.

Because most users seem to cease regardless of health promotion efforts, health educators may be able to achieve more health benefits by promoting harm reduction strategies (HRSs). Although many users already attempt to apply these, not all users manage to correctly and consistently do so. In addition, many users are willing to neglect application when this interferes with their goals of having a good time [consistent with the hedonistic nature of the dance scene; 8]. In fact, some users knowingly neglect certain HRSs, such as eating properly beforehand, to maximise drug effects. This has also been found for chilling out $[29 ; 135 ; 136]$. Thus, successful health promotion about HRSs has clear health potential. However, a problem for health promotion about harm reduction is a lack of evidence on which to base guidelines. Although there are a number of studies into which harm reduction strategies users employ [e.g. 80; 137], there are no studies documenting the effects of these practices. Until this becomes clear, training users' skills to implement intentions to apply HRSs may be beneficial. In addition, the implementation of harm reduction strategies may be enabled or enhanced by improved party conditions, for example by providing on site testing facilities, food that is edible with a dry mouth, free water distribution, organised chilling breaks, and prompts to drink, eat, and chill out.

The current study is limited in several ways. First, the study has a crosssectional design. It would be interesting to see which patterns emerge when a group of participants is followed over time. The Dutch NeXT study provides a good example of a design that would allow this [138; 139]. Also, Von Sydow et al. [140] have conducted a quantitative longitudinal study, and although they found that indeed, over time, many users automatically ceased or reduced their use, they did not examine reasons or determinants of these transitions. The second limitation is typical of qualitative research, which relies strongly on participants' self-reported reasons and self-reported causal links between reasons and behaviour. Although this qualitative methodology is particularly suitable for exploratory research, the downside is that quantitative verification 
of the results is required, the latter methodology being less dependent upon participants' introspective skills and allows statistical inference and thereby generalisation. A third limitation is that, although the employment of both FGD's and individual interviews provided preliminary indications as to differences in the way participants discussed their (non-)drug use, this issue has not been explored more thoroughly. It would be interesting to explore this topic in more depth.

Regardless of these limitations, this study contributes to growing evidence that health communication about the negative effects of ecstasy use may not be able to generate behaviour change [141]. Because of this, and the high probability that ecstasy users cease their use regardless of the efforts of health promoters, it seems wise for health promoters to focus on harm reduction.

\section{Conclusions}

The most important reasons to start using were curiosity about and desire for ecstasy's effects and a desire to be on the same level as friends. Those who refrained from using indicated that they did not need ecstasy to "flip out" at parties, and that for them, the fear of ecstasy's direct effects and negative health effects outweighed the thrill, and perhaps more importantly, that they generally visited dance events with friends who do not use ecstasy. Most users did not used frequently, and although all users applied harm reduction strategies, these were often inferior and applied inconsistently. Ecstasy use cessation seemed prompted by changing life circumstances (job/study responsibilities, relationships, losing interest in dance scene), rather by consideration of pros and cons of use, and accordingly, potential health effects do not seem to play a substantial role. Most users do not expect cessation to be hard, and most exusers agree. The only apparent complication emerged for users who, while trying to cease, continued to visit dance events with ecstasy using friends. Furthermore, there is evidence that health educators have successfully conveyed ecstasy's health risks, as most users' risk perception seems to approximate ecstasy's scientifically recognized risk.

Differences with other countries in the saliency of reasons to cease seem may be explained by the Netherlands' liberal drug policy, which allowed harm reduction initiatives to flourish: many users seem to limit their use frequency according to the guidelines provided by Dutch harm reduction initiatives Unity and Uitgaan \& Drugs, and these low use frequencies may have prevented the 
social, relationship, health, and dependence problems, that were cited by users in other countries, from manifesting. Ecstasy prevention interventions may focus on the fact that once somebody tries out ecstasy, chances are that they will use at most or all dance parties they attend, thus developing some form of dependence. This may take away some of the casualness associated with trying out ecstasy. In general, however, it seems that harm reduction interventions have the greatest potential for achieving health benefits. Improving party conditions, for example by providing free water and organising breaks to chill out, may prove very beneficial. Finally, there is an urgent need for more research into the effectiveness of the different harm reduction strategies. 


\section{Chapter 5 Social cognitive determinants of ecstasy use: does studying mixed samples of non- users and users leads to over-estimation of association strengths?}

Ecstasy use is potentially damaging to health [17; 20; 21] yet prevalent [74; 112], and although accordingly, a need for intervention development has been asserted, it has also been observed that evidence to base these interventions on is scarce [35]. If evidence-based interventions are to be developed, more research into the determinants of ecstasy use is necessary. In the Netherlands, in particular, only two quantitative studies have addressed determinants of ecstasy use, and both explored the applicability of the outcome expectancy approach to studying drug use [13; 86]. This approach assumes that behaviour is a function of people's expectations about outcomes of that behaviour (e.g. the expectation that using ecstasy produces a positive mood state). Although these studies yielded interesting results, they did not provide any information as to the relevance of other determinants that have been found predictive of ecstasy use in other countries, particularly the United Kingdom [56; 58-61]. This is especially problematic because the expectancies that were most strongly associated to intention to use ecstasy reflect actual effects of ecstasy, rendering them inadequate as intervention targets [35]. Intervention developers in the Netherlands therefore remain largely without evidence to inform intervention development. The current study aims to provide this evidence.

Although there have been studies into the role of other determinants in other countries, these results may not generalise to the Netherlands. Because of the relatively liberal drug policy in the Netherlands, drug use patterns may differ from those in other countries [120-123]. In addition, different dance drugs are used in the Netherlands than in other countries [124]. For example, methamphetamine use is prevalent in Australia [125] and the US [126], but 
virtually nonexistent in the Netherlands [127; 128]. LSD use shows a similar but less pronounced pattern $[38 ; 112]$. As recreational drugs have been shown to be each others substitutes [129], these differences may affect ecstasy use patterns. Thus, before being able to base interventions on these determinants, their role in ecstasy use in the Netherlands needs to be addressed.

These other determinants were mainly drawn from the Theory of Planned Behaviour [TPB; 30]. The TPB postulates intentions as most proximal social cognitive determinant of behaviour, in turn predicted by attitude (i.e. evaluation of the likelihood and desirability of that behaviour's consequences), subjective norm (i.e. perception of others' approval of the behaviour) and perceived behavioural control [PBC, i.e. perception of control based on perception of skills and external obstacles/facilitators; very similar to self efficacy; 30]. In addition to these traditional TPB determinants, four additional determinants have been found predictive of ecstasy use [35]: subjective descriptive norm [an extension of the traditional subjective normative construct that assesses the perceived behaviour of social referents; 142], anticipated regret [or affect; the amount of negative emotions one experiences when prospectively imagining not having performed the target behaviour; 143; 144], moral norm [ones personal norm regarding performing a behaviour; 58; 145], and habit.

Studies into ecstasy use have generally employed either a TPB approach [e.g. 56; 58; 59-61] or an outcome expectancy approach [based on Social Cognitive Theory, 34; e.g. 54; 55], but no study as yet has combined these approaches. Although each approach does have merit in itself [35], these singleapproach studies preclude conclusions about the degree of overlap of the two approaches. In general, the TPB considers outcome expectancies to be lowerlevel determinants that underlie its attitude construct [146], but it remains unclear whether this relationship holds for ecstasy use (i.e. whether outcome expectancies underlie attitude regarding ecstasy use). To address this issue, the current study included a number of outcome expectancies so that their association with TPB's attitude may be assessed. These expectancies were drawn from the two previous Dutch studies [13; 86], with two additions based on a Dutch qualitative study [147].

One last limitation of research that mapped the determinants configurations of ecstasy use so far, was that these analyses mostly computed bivariate and multivariate association strength measures for the combined sample of non-users and users $[13 ; 56 ; 58 ; 60 ; 61]$. Although some studies have compared the two groups [59; 86], variables distinguishing between non-users 
and users need not predict intention to use in either of the two groups. Indeed, a recent qualitative review suggested that reasons for trying out ecstasy among non-users are different from reasons for using ecstasy among ecstasy users [114]. If this is the case, the determinant configuration (the relative relevance of each determinant) arrived at when analysing these combined samples may not be representative for either of the two subsamples of non-users and users. Boys and colleagues $[55 ; 148]$ did analyse determinant configurations within two samples of users, but they did not measure any TPB determinants.

In sum, the current study was designed to address a number of lacunae in ecstasy use research. First, the determinant configuration of using ecstasy will be mapped both for the combined sample and the separate samples of nonusers and users. Second, the overlap of the TPB and the outcome expectancy approach will be addressed. Third, the relative relevance of the traditional TPB determinants and three of the four additional TPB determinants that were found predictive of ecstasy use will be determined (habit was not included, as using ecstasy cannot sensibly be operationalised for non-users of ecstasy). Fourth, this study will allow comparison of these determinant configurations between the Netherlands and other countries.

\section{Methods}

\section{Procedure}

An online questionnaire study was conducted as the internet has been argued to be a suitable medium for studying hidden populations such as non-misusing illicit drug users [149]. Participants were recruited by links at several dancerelated Dutch websites (most participants came from the online community at http://partyflock.nl). The questionnaire was administered by a self-chosen virtual interviewer in a Flash interface [150; also see 151]. To activate the proper context for respondents, the interview took place to the background of several party pictures while dance music was playing. Server-side parsing of the content (using PHP and MySQL; see [152]) enabled tailoring of the questionnaire to the respondent (i.e. presentation of every item depended upon previous answers).

This possibility to tailor the questionnaire enabled data collection for several behaviours simultaneously, but only results pertaining to using ecstasy will be reported here, and therefore only methodological details relevant to these results. At the first measurement ( $\left.t_{1}\right)$, demographics, drug use, party 
behaviour, ecstasy expectations, and behavioural intentions were measured for all participants, after which a subset of participants answered questions about the determinants of using ecstasy (the other participants answered questions about the determinants of other behaviours). After three months, participants could access the follow-up measurement ( $\left.\mathrm{t}_{2}\right)$, where their ecstasy use behaviour in the past three months, and their intention to use or try out ecstasy in the next three months, were measured. Five months later ( $t_{3}$; logistical problems delayed this follow-up two months), behaviour was measured again. Participants were attended to the follow-ups by e-mail, and six weekly reminders were sent out. Permission to perform this investigation was granted by the Ethical Committee Psychology of Maastricht University (the ECP).

\section{Measurements}

At $\mathrm{t}_{1}$, demographic variables (gender, age and education level), drug use ('which of these substances do you occasionally use at parties?') and party behaviour were measured with one item each, as well as a number of consistently reported ecstasy expectations (the leading statement "if I take ecstasy, I . . ." for users, or "if I would take ecstasy I would ..." for non-users, was followed by "feel very good", "feel more connected to other people", "make contact easier", "understand myself better", "have better sex", "get a lot of energy", "live my life more intensely", "have a better life than without ecstasy", "damage my health", "feel bad the next couple of days", "feel nauseous", and "get stiff jaws"). These expectation measures were not aggregated because factor analyses revealed different factor structures for users and non-users. Behavioural intention was measured with two items (i.e. 'do you intend to [use/try out] ecstasy in the next three months?' and 'do you think that you will indeed do that?', both absolutely not-absolutely; range 1-5; $\alpha=.92$ for using and .93 for trying out).

Attitude was measured with five semantic differentials (i.e. 'I think that using ecstasy is/would make me ...', unpleasant-pleasant, bad-good, unwisewise, not nice-nice, unhappy-happy; range $1-5 ; \alpha=.92$ ). Subjective norm was measured by multiplying an item tapping injunctive subjective norm (e.g., 'how would your parents feel if you were to use ecstasy?', disapproving-approving; range -2-2, also including an option 'I don't know' with the same value as the middle option 'neutral', i.e. 0) with an item tapping motivation to comply (e.g. 'how important do you find your parents' opinion about whether you use ecstasy?', very unimportant-very important; range 1-5) for best friend, other friends, and parents, and dividing the product by 5 to get a range of $-2-2(\alpha=$ 
.78). Perceived behavioural control was measured with two items (i.e. 'imagine that you would want to use ecstasy', followed by 'does it seem easy to you to use ecstasy?', 'do you think you would manage to use ecstasy?', absolutely notabsolutely; range $1-5 ; \alpha=.86$ ). Descriptive norm was measured by three items (measuring whether ones best friend, friends with whom one attends parties, and other friends use ecstasy, absolutely not-absolutely, range 1-5, $\alpha=.65$ ). Moral norm was measured by two reverse items (i.e. 'using ecstasy contrasts my principles', 'I would feel troubled if I were to use ecstasy' absolutely notabsolutely; range $1-5 ; \alpha=.91)$. Anticipated regret was measured by three items (i.e. 'imagine that in a few weeks at a party you use ecstasy. Imagine how you would feel the next day. Would you [regret it/worry/feel guilty]?', not at allvery much; range $1-5 ; \alpha=.94)$.

At $t_{2}$, intention was measured with the first of the two intention items used at $t_{1}$. Behaviour at $t_{2}$ and $t_{3}$ was measured by asking whether since the last questionnaire, participants had taken ecstasy, and if so, how often (to which participants typed in a number). In addition, the number of parties participants had attended in the past three months was measured.

\section{Analyses}

As Cohen argued, "the primary product of a research inquiry is one or more measures of effect size" [153, p. 1310]. Especially with large samples, trivial associations can become significant. Therefore, rather than their significance, associations' meaningfulness will guide the discussion of the results. Associations are considered meaningful when they are non-trivial. We distinguish five levels of association strength (effect size): trivial, weak (Cohen's $\mathrm{d}>$.2; Pearson's $\mathrm{r}>$.1; Cramer's V > .1; odds ratio > 1.5), moderate (Cohen's d > .5; Pearson's r > .3; Cramer's V > .3; odds ratio > 2.5), strong (Cohen's d > .8; Pearson's $\mathrm{r}>$.5; Cramer's V > .5; odds ratio $>4$ ), and very strong (Cohen's d > 1.3; Pearson's r > .7; Cramer's V > .7; odds ratio > 10) [70; 109; see also 154; 155].

For the significance tests of bivariate associations between one dichotomous and one continuous variable, the t-test for unequal variances will be used (in recognition of the issues pointed out by Ruxton [156]). In addition to bivariate analyses, we will conduct a number of multivariate analyses to enable exploration of associations between variables while artificially keeping other variables constant. In particular, we used linear and logistic regression. In these analyses, Cook's distances were examined (but always remained low), and cases with absolute studentised residuals $>3$ were considered outliers and discarded from the analyses (at most, this lead to the removal of 6 cases). 


\section{Results}

At the first measurement ( $\left.\mathrm{t}_{1}\right), 5525$ non-users and users participated (ex-users are not currently considered). At the second measurement ( $\left.\mathrm{t}_{2}\right), 2644$ participants were retained (48\%), and at the third measurement ( $\left.\mathrm{t}_{3}\right), 1607$ participants (61\%). At $t_{1}, 260$ users and 234 non-users participated in the section where the determinants of using ecstasy were measured. Of these, 91 non-users and 138 users were retained at $\mathrm{t}_{2}$, and 58 non-users and 80 users at $\mathrm{t}_{3}$. Drop-out analyses for demographic variables, used drugs, party behaviour, intention, and expectancies showed that none of these variables was significantly and meaningfully associated to whether participants did not drop out, dropped out at $\mathrm{t}_{2}$, or dropped out at $\mathrm{t}_{3}$ (highest Cohen's $\mathrm{d}=.17$ for age). The characteristics of participating ecstasy users and non-users, as well as labeled association strength measures for the difference between non-users and users and significance tests are shown in Table 5.1. Compared to non-users, ecstasy users were more likely to be male, use other drugs (except alcohol), visit big parties (but not small parties) more often, be older, score higher on all positive expectations and lower on all negative expectations (except the expectation to get stiff jaws), and score much higher on all TPB determinants.

In bivariate analyses, participants' intention at $t_{1}$ very strongly predicted whether they would indeed have used ecstasy at $t_{2}$ (2.2 vs. 4.1, Cohen's $d=1.80$, $\mathrm{t}[2642]=46.0, \mathrm{p}<.001)$, and intention at $\mathrm{t}_{2}$ very strongly predicted use at $\mathrm{t}_{3}(1.9$ vs. 3.9, Cohen's $d=1.9, \mathrm{t}[1605]=38.8, \mathrm{p}<.001)$. In a multivariate analysis where ecstasy use at $\mathrm{t}_{2}$ was logistically regressed on intention and perceived behavioural control $(\mathrm{PBC})$ at $\mathrm{t}$, the resulting model $\left(\mathrm{N}=229, \chi^{2}[2]=146.2, \mathrm{p}<\right.$ .001 ) correctly predicts ecstasy use at $t_{2}$ for $84.7 \%$ of the cases (Nagelkerke $R^{2}=$ .64 ; corrected $\mathrm{OR}=4.4, \mathrm{p}<.001$ for intention and corrected $\mathrm{OR}=2.3, \mathrm{p}<.05$ for $\mathrm{PBC}$ ). When the analysis was repeated for each user-group separately (nonusers and users), PBC did not reach significance. Thus, although intention was highly predictive of later ecstasy use in all analyses, PBC did not contribute to this prediction when non-users and users were examined separately. This crucial role for intention warrants closer examination of its determinants.

The correlations between all determinants, in the combined sample of non-users and users for whom all determinants were measured, are shown in Table 5.2. The correlations between the TPB determinants and intention, both for the combined sample of non-users and users and for the two user-groups separately, and the regression weights in regression analyses of intention on the traditional (step 1) and additional (step 2) TPB determinants, are shown in 
Table 5.1: Participant characteristics (for means, standard deviations are provided in parentheses) and differences between non-users and ecstasy users.

\begin{tabular}{|c|c|c|c|c|c|c|}
\hline \multirow[b]{2}{*}{ Variable name or categories } & \multirow[b]{2}{*}{ Range } & \multicolumn{2}{|c|}{$\%$ or mean $(\mathrm{sd})$} & \multicolumn{3}{|c|}{ Difference $^{1}$} \\
\hline & & $\begin{array}{l}\text { Non-users } \\
(\mathrm{n}=1772)\end{array}$ & $\begin{array}{c}\text { Ecstasy users } \\
\quad(\mathrm{n}=3753)\end{array}$ & $\mathbf{L b l}^{2}$ & Unit & Value \\
\hline Gender (being female) & & $56 \%$ & $41 \%$ & + & OR & .55 \\
\hline Higher educated & & $41 \%$ & $45 \%$ & - & OR & $1.19^{*}$ \\
\hline Alcohol use & & $83 \%$ & $84 \%$ & - & OR & $1.10^{\text {ns }}$ \\
\hline Tobacco use & & $40 \%$ & $60 \%$ & + & OR & 2.29 \\
\hline Cannabis use & & $21 \%$ & $51 \%$ & ++ & OR & 3.94 \\
\hline Speed use & & $2 \%$ & $38 \%$ & +++ & OR & 29.97 \\
\hline Cocaine use & & $2 \%$ & $38 \%$ & +++ & OR & 37.57 \\
\hline GHB use & & $.3 \%$ & $16 \%$ & +++ & OR & 56.57 \\
\hline Poppers use & & $.7 \%$ & $7.4 \%$ & +++ & OR & 10.78 \\
\hline Nitruous oxide use & & $1.7 \%$ & $7.0 \%$ & +++ & OR & 4.20 \\
\hline Psylocybin use & & $.8 \%$ & $3.9 \%$ & +++ & OR & 5.08 \\
\hline Ketamine use & & $.2 \%$ & $5.1 \%$ & +++ & OR & 30.40 \\
\hline LSD use & & $.2 \%$ & $1.7 \%$ & +++ & OR & 10.39 \\
\hline Visits a big party twice a year or less & & $35 \%$ & $13 \%$ & + & $\mathrm{V}$ & .28 \\
\hline - every two to six months & & $53 \%$ & $60 \%$ & & & \\
\hline - every month or more & & $12 \%$ & $27 \%$ & & & \\
\hline Visits a club/small party bimonthly & & $23 \%$ & $23 \%$ & - & $\mathrm{V}$ & $.05^{*}$ \\
\hline - every two to four weeks & & $52 \%$ & $56 \%$ & & & \\
\hline - every week or more & & $25 \%$ & $21 \%$ & & & \\
\hline Age in years & $11-53$ & $20.27(4.53)$ & $23.64(6.06)$ & ++ & $\mathrm{d}$ & .60 \\
\hline Expectation to feel very good & $1-5$ & $2.56(1.37)$ & $4.40 \quad(.76)$ & +++ & $\mathrm{d}$ & 1.84 \\
\hline Expectation to feel more connected & $1-5$ & $2.55(1.39)$ & $4.20 \quad(.92)$ & +++ & $\mathrm{d}$ & 1.51 \\
\hline Expectation to make contact easy & $1-5$ & $2.76(1.43)$ & $4.06(1.05)$ & +++ & $\mathrm{d}$ & 1.09 \\
\hline Expectation to understand self better & $1-5$ & $1.76(1.03)$ & $2.67(1.17)$ & +++ & $\mathrm{d}$ & .81 \\
\hline Expectation to have better sex & $1-5$ & $2.35(1.27)$ & $3.20(1.25)$ & ++ & $\mathrm{d}$ & .68 \\
\hline Expectation to get a lot of energy & $1-5$ & $3.63(1.34)$ & $4.18 \quad(.93)$ & ++ & $\mathrm{d}$ & .51 \\
\hline Expectation to live a more intense life & $1-5$ & $1.88(1.10)$ & $2.83(1.29)$ & ++ & $\mathrm{d}$ & .78 \\
\hline Expectation to have a better life & $1-5$ & $1.65(1.17)$ & $2.49(1.32)$ & ++ & $\mathrm{d}$ & .65 \\
\hline Expectation to damage health & $1-5$ & $4.31(1.10)$ & $4.06(1.02)$ & + & $\mathrm{d}$ & -.24 \\
\hline Expectation to feel bad for a few days & $1-5$ & $4.11(1.11)$ & $3.53(1.25)$ & + & $\mathrm{d}$ & -.48 \\
\hline Expectation to feel nauseous & $1-5$ & $3.33(1.23)$ & $1.93(1.12)$ & + & $\mathrm{d}$ & -.22 \\
\hline Expectation to get stiff jaws & $1-5$ & $3.52(1.23)$ & $3.55(1.23)$ & - & $\mathrm{d}$ & $.03^{\text {ns }}$ \\
\hline Intention & $1-5$ & $1.55(.89)^{3}$ & $3.92(1.00)^{3}$ & ++++ & $\mathrm{d}$ & 2.50 \\
\hline Attitude & $1-5$ & $2.19(.97)^{3}$ & $3.79(.52)^{3}$ & +++ & $\mathrm{d}$ & 2.09 \\
\hline Subjective norm & $-2-2$ & $-.87(.64)^{3}$ & $-.03(.45)^{3}$ & ++++ & $\mathrm{d}$ & 1.58 \\
\hline Perceived behavioural control & $1-5$ & $3.34(1.33)^{3}$ & $4.72(.51)^{3}$ & ++++ & $\mathrm{d}$ & 1.39 \\
\hline Descriptive norm & $1-5$ & $2.32(1.07)^{3}$ & $3.79(.79)^{3}$ & ++++ & $\mathrm{d}$ & 1.58 \\
\hline Moral norm & $1-5$ & $2.27(1.33)^{3}$ & $4.41(.86)^{3}$ & ++++ & $\mathrm{d}$ & 1.93 \\
\hline Anticipated regret & $1-5$ & $3.17(1.39)^{3}$ & $1.46(.74)^{3}$ & +++ & $\mathrm{d}$ & -1.56 \\
\hline
\end{tabular}

${ }^{1}$ All differences are significant at an alpha of .001 , unless specified otherwise, ${ }^{*} \mathrm{p}<.005$, ns Not significant ( $\mathrm{p}>$.05), ${ }^{2}$ Association strength labels: - trivial, + weak, ++ moderate, +++ strong, ++++ very strong ${ }^{3}$ For the TPB determinants, the sample size is 234 for non-users and 260 for ecstasy users. 


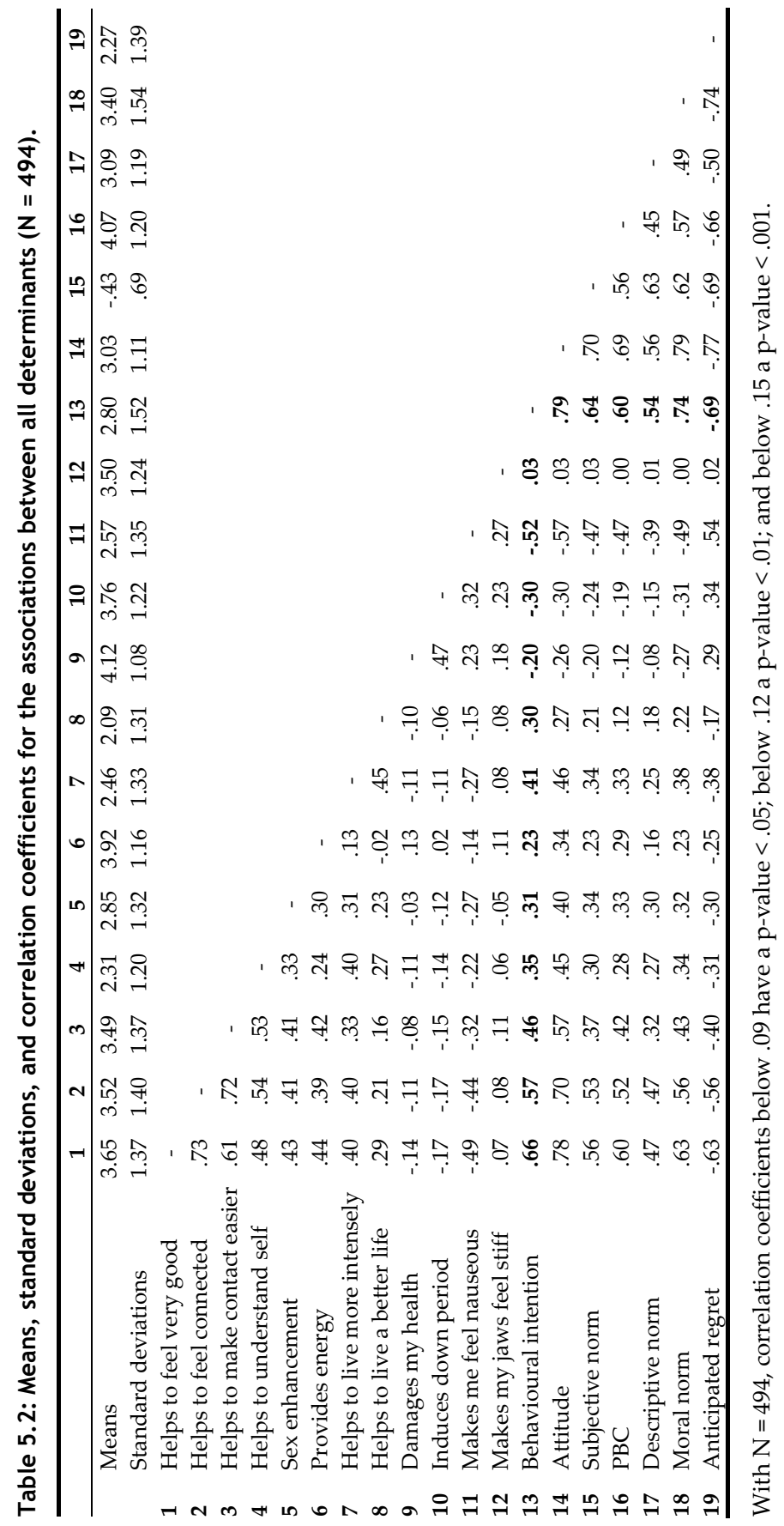


Table 5.3: Correlation coefficients and regression analyses to predict intention from traditional (step 1) and additional (step 2) TPB determinants.

\begin{tabular}{|c|c|c|c|c|c|c|c|c|c|}
\hline \multirow[b]{3}{*}{$\overline{\text { Attitude }}$} & \multicolumn{3}{|c|}{$\begin{array}{l}\text { Non-users and users } \\
(\mathrm{N}=491)\end{array}$} & \multicolumn{3}{|c|}{$\begin{array}{l}\text { Non-users } \\
(N=231)\end{array}$} & \multicolumn{3}{|c|}{$\begin{array}{c}\text { Users } \\
(N=257)\end{array}$} \\
\hline & $\mathbf{r}$ & $\beta$ step 1 & $\beta$ step 2 & $\mathbf{r}$ & $\beta$ step 1 & $\beta$ step 2 & $\mathbf{r}$ & $\beta$ step 1 & $\beta$ step 2 \\
\hline & $.80^{* * * *}$ & $.64^{* * *}$ & $.43^{* * * *}$ & $.67^{* * * *}$ & $.61^{* * *}$ & $.47^{* * *}$ & $.44^{* * *}$ & $.38^{* * *}$ & $.29^{* * *}$ \\
\hline Subjective norm & $.55^{* * * *}$ & $.16^{* * *}$ & .07 & $.45^{* * *}$ & $.14^{*}$ & .07 & $.21^{* * *}$ & .05 & .02 \\
\hline PBC & $.61^{* * *}$ & .07 & .05 & $.37^{* * *}$ & .01 & -.01 & $.27^{* * *}$ & .11 & .08 \\
\hline Descriptive norm & $.55^{* * *}$ & & $.10^{* *}$ & $.26^{* * *}$ & & .05 & .01 & & -.03 \\
\hline Moral norm & $.75^{* * *}$ & & $.25^{* * *}$ & $.53^{* * *}$ & & .12 & $.36^{* * *}$ & & $.17^{*}$ \\
\hline Anticipated regret & $-.70^{* * *}$ & & -.05 & $-.58^{* * *}$ & & -.13 & $-.30^{* * *}$ & & -.11 \\
\hline $\mathrm{R}^{2}$ & & .66 & .70 & & .48 & .51 & & .20 & .24 \\
\hline $\mathrm{R}^{2}$ change & & .66 & .04 & & .48 & .03 & & .20 & .04 \\
\hline $\mathrm{F}$ of $\mathrm{R}^{2}$ change & & $320.47^{* * *}$ & $18.16^{* * *}$ & & $70.11^{* * *}$ & $3.67^{*}$ & & $21.63^{* * *}$ & $4.44^{* *}$ \\
\hline DfF (change) & & 3 & 3 & & 3 & 3 & & 3 & 3 \\
\hline DfF (error) & & 487 & 484 & & 227 & 224 & & 253 & 250 \\
\hline
\end{tabular}

${ }^{*} \mathrm{p}<.05,{ }^{* *} \mathrm{p}<.01,{ }^{* * *}, \mathrm{p}<.001$.

Table 5.3. In the first step of the regression analyses, in the combined sample, all three traditional TPB determinants achieve significance, whereas in both separate samples, only attitude achieves significance. In the second step, the significant determinants in the combined analysis are attitude, descriptive norm, and moral norm. Among the non-users, only attitude remains as significant determinant, and among users, only attitude and anticipated regret. In the combined analysis, the final model explains $70 \%$ of the variation in intention; among non-users, $51 \%$; and among users, only $24 \%$ (parsimonious models containing only the significant determinants explain $69 \%, 47 \%$, and $22 \%$, respectively).

To assess the degree of overlap between the expectation approach and the TPB approach, we conducted two analyses. First, to establish the degree to which the expectations explain variation in TPB's attitude, attitude was regressed upon the expectations. The results are shown in Table 5.4. For the combined sample, the expectations together explain most variation in TPB's attitude measure $(78 \%)$, but the proportion of explained variation is lower for non-users (62\%) and lower again for ecstasy users (40\%). The bivariate correlations show the same pattern: whereas for the combined sample, there are two very strong associations, three strong associations, and five moderate associations, for non-users, there are three strong associations and five moderate associations, and for users, there is only one strong association and no moderate associations. Thus, it seems that attitude consists of different 
expectations for non-users and users, and that most relevant expectations for users have not been measured.

Second, we examined whether these expectations have additional predictive value over the TPB. We did this by saving, for every participant, their predicted intention to use ecstasy as predicted by the parsimonious models described above. The difference between each participants' measured intention and their predicted intention (the residual) represents the part of intention that cannot be explained by the TPB determinants. We then regressed this residual upon the expectations. This shows what percentage of intention, of the part that cannot be explained by the TPB determinants, can be explained by the expectations, providing a measure of their additional value. The advantage of this approach compared to conducting a hierarchical regression analysis is that in this way, only the variation in intention that is not already accounted for by the TPB determinants is considered, whereas in a hierarchical regression

Table 5.4: Correlation coefficients for association between ecstasy expectations and attitude, regression analyses where attitude was predicted from the ecstasy expectations, and regression analyses where the residuals were predicted from the ecstasy expectations (these residuals are the differences between measured intention and intention predicted by a parsimonious model consisting of the significant predictors in step 2 in Table 5.3.

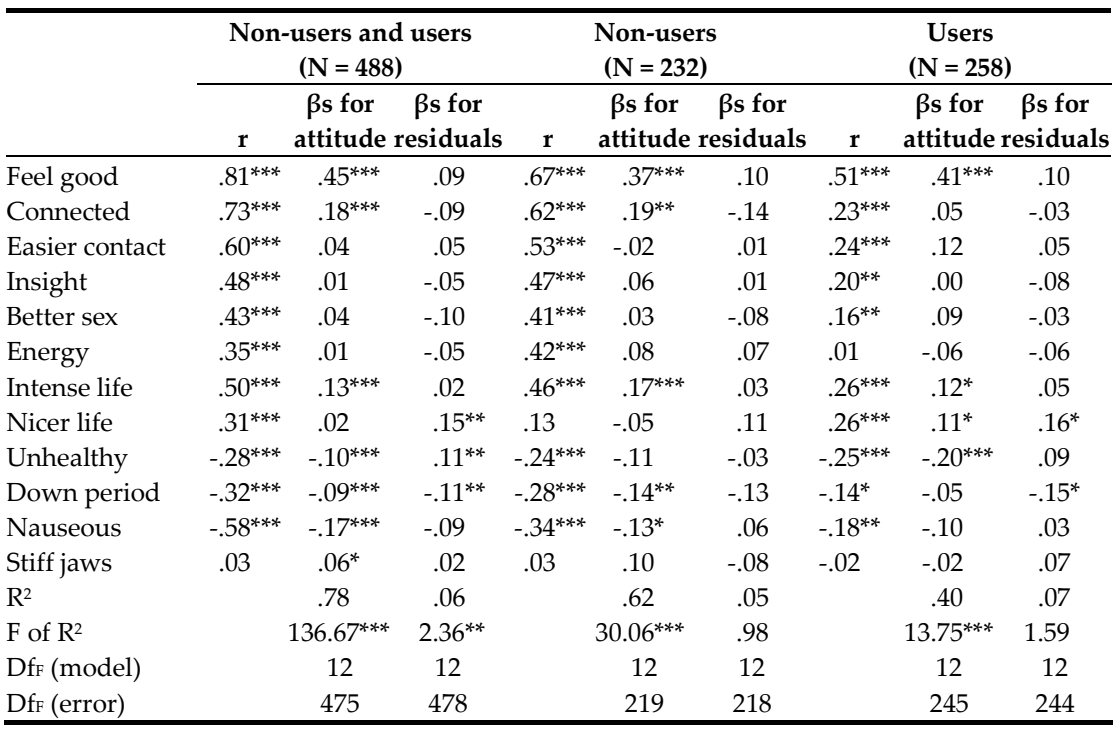

${ }^{*} \mathrm{p}<.05,{ }^{* *} \mathrm{p}<.01,{ }^{* * *} \mathrm{p}<.001$. 
analysis, it is possible that expectations' regression coefficients achieve significance by explaining variation that was previously explained by for example attitude. The results are shown in Table 5.4: in the combined sample, the expectations explain $6 \%$ of the unexplained part of intention; among nonusers, $5 \%$; and among users, $7 \%$. For the combined sample, $30 \%$ of intention is unexplained; for non-users, $52 \%$; and for users, $76 \%$. Thus, of the total intention measure, the expectations explain an additional 1.5\% in the combined sample; $2.6 \%$ among non-users; and 5.3\% among users. However, the model only achieves significance in the combined sample, where the expectations that using ecstasy makes one lead a nicer life, that it is unhealthy, and that it makes one feel down for a few days after use achieve significance, explain variation in intention that was not explained by TPB's direct attitude measure.

\section{Discussion}

Participants' intention was highly predictive of subsequent ecstasy use, rendering it expedient to map the determinant configuration underlying this intention. When looking at differences in determinant scores between non-users and users, all TPB determinants and most ecstasy expectations were very strongly associated to user-group. Although this may be taken to indicate that all these determinants are viable intervention targets, closer inspections reveal different results. When mapping these determinants' associations to intention to use ecstasy, among the combined sample of both non-users and ecstasy users, indeed all TPB determinants were strongly or very strongly associated to intention. However, among non-users, only attitude, moral norm and anticipated regret were strongly associated, subjective norm and perceived behavioural control (PBC) were moderately associated, and descriptive norm was only weakly associated. Among ecstasy users, attitude, moral norm, and anticipated regret were moderately associated, subjective norm and PBC were weakly associated, and descriptive norm not at all. When investigating the multivariate associations, similar patterns emerge, with considerable less predictive power among non-users and users than in the combined sample, and with different predictors in the three analyses (in the combined sample, attitude, descriptive norm and moral norm; among non-users, only attitude; and among users, attitude and moral norm).

Regarding the ecstasy expectations, similar patterns were observed. In bivariate analyses, most expectations had moderate to strong associations with 
TPB's attitude in the combined sample, but these associations were weaker among the non-users, and weaker again among the ecstasy users. This was also reflected in the variation in attitude these expectations explained together in multivariate analyses. Three final regression analyses showed that the expectations could offer only very limited additional predictive power over the TPB, and accordingly, the model was only significant in the combined sample.

The current study suffers three limitations. First, the behavioural measure relies on self-reports. Even though these have been shown to be reliable [112; 157], of course, it would have been desirable to eliminate all possibility of measurement error. Second, clearly, a number of relevant beliefs and determinants have not been measured. This is partly because results from a recent qualitative review [114] were not yet available. Third, the intention to use ecstasy was only measured for ecstasy users; for non-users, the intention to try out ecstasy was measured. Although it is unlikely that this inconsistency cased the differential results, future research should eliminate this inconsistency to rule our this explanation. Finally, the current sample was recruited purely by letting participants voluntarily participate. It cannot be excluded that certain groups of participants, for example non-users that are strongly inclined to remain non-users and have no interest in ecstasy at all, have not participated.

Despite these limitations, this study provides answers to all questions it set out to answer. First, it seems that indeed, determinants that distinguish between non-users and users are not necessarily the determinants predicting intention to use within either group. Similarly, not all determinants are equally strongly associated to intention to use among non-users and users (e.g. some determinants are strongly associated to intention among non-users, but only weakly among user). Second, the current data support the theoretical assumption that TPB's attitude encompasses the expectations from Social Cognitive Theory. Of course, this does not mean that these expectations need not be measured any more: on the contrary, it is these specific cognitive measures that can guide intervention development. However, future research should combine them with other TPB determinants. Third, although TPB determinants, both traditional and additional, have predictive value, only attitude and moral norm consistently retain predictive value in multivariate analyses. However, since interventions can generally not be certain to influence particular determinants, intervention targets should be based on bivariate analyses, rather than the conditional multivariate analyses. These bivariate analyses show attitude, moral norm and anticipated regret to be the strongest 
predictors of intention among non-users, and, to a lesser degree, among users, followed by subjective norm and PBC. Fourth, these results are indeed in line with prior research. Bivariate associations between TPB determinants and intention were a bit higher than in the meta-analysis [35] in the combined sample, a bit lower among non-users, and lower again among users, reflecting the fact that most TPB studies so far studies combined samples. When comparing multivariate outcomes, the nonsignificance of $\mathrm{PBC}^{\prime} \mathrm{s}$ beta does not seem in line with the results from most studies [56; 58; 60], but in another recent TPB study [61], PBC also fails to achieve significance multivariately. This could be explained if ecstasy has become easier to obtain, but such a conclusion would definitely require more research.

In conclusion, a number of lessons for future research emerge. First, usergroups should not be aggregated. Studies should examine either non-users or ecstasy users, or both, but not by combining the samples. Second, studies should measure both specific expectancies and the TPB determinants. The TPB approach can provide information as to the relative importance of the determinants, whereas the underlying expectations can provide interventions with specific targets if attitude proves sufficiently relevant. Third, more research is necessary to map the determinants of using ecstasy both among non-users and among ecstasy users. Although the proportion of explained variation is satisfactory when examining the combined sample $\left(\mathrm{R}^{2}=.70\right.$; TPB reviews found mean $\mathrm{R}^{2} \mathrm{~s}$ of .39 [46] and .41 [33]), we understand the separate samples less well. It may be possible that indeed, it is necessary to not only be sufficiently specific about the population, but also about the behaviour of interest [114]: perhaps we should examine the determinants of 'trying out ecstasy' and of 'ceasing ecstasy use', rather than of the more generic 'using ecstasy'. 



\section{Chapter 6 Social cognitive determinants of trying out ecstasy: why interventions based on research into using ecstasy may have a hard time preventing ecstasy use}

Ecstasy use is potentially damaging to health [17; 20; 21] yet prevalent [74; 112], and although accordingly, a need for intervention development has been asserted, it has also been observed that evidence to base these interventions on is scarce [35]. If evidence-based interventions are to be developed, more research into the determinants of ecstasy use is necessary. In particular, all quantitative research into ecstasy use has examined determinants of the behaviour 'using ecstasy' [35], whereas recent qualitative evidence suggests that reasons, and therefore possibly determinants, of related but distinct behaviours such as 'trying out ecstasy' and 'ceasing ecstasy use' may be different [114]. To address this issue, the current paper reports a study that examines the determinants of trying out ecstasy.

Interventions promoting abstinence from ecstasy use can do so either by targeting non-users and preventing them from trying out ecstasy, or by targeting users and causing them to cease using ecstasy. Thus, the behaviours of interest for such interventions are trying out ecstasy and ceasing ecstasy use, not using ecstasy. This discrepancy may prove problematic because the theories that guided these studies (i.e. Ajzen's Theory of Planned Behaviour [TPB; 30; e.g. 56; 58-61] and the expectation part of the outcome expectancy constructs from Bandura's Social Cognitive Theory [13; SCT; 34; e.g. 54; 55; 57]) both emphasised the relevance of sufficiently specific measures [30; 34]. For example, in exercise research, evidence has been found that suggests that similar but related behaviours can have different determinant configurations (e.g. a social cognitive determinant that significantly contributes to predicting one behaviour need not contribute to the prediction of related behaviours; [84]). Although in ecstasy use, such studies are lacking, a qualitative review did find different 
reasons for trying out ecstasy, using ecstasy, and ceasing ecstasy use [114]. If these concerns prove grounded, then that means that there is no research available to inform interventions aimed at preventing ecstasy use or promoting cessation.

The determinants that will be measured are drawn from the Theory of Planned Behaviour [TPB; 30], which has been shown applicable to ecstasy use $[56 ; 58 ; 60 ; 61]$ and as such provides a good starting point. The TPB postulates intentions as most proximal social cognitive determinant of behaviour, in turn predicted by attitude (i.e. evaluation of the likelihood and desirability of that behaviour's consequences), subjective norm (i.e. perception of others' approval of the behaviour) and perceived behavioural control [PBC, i.e. perception of control based on perception of skills and external obstacles/facilitators; very similar to self efficacy; 30]. In addition to these traditional TPB determinants, four additional determinants have been found predictive of ecstasy use [35]: subjective descriptive norm [an extension of the traditional subjective normative construct that assesses the perceived behaviour of social referents; 142], anticipated regret [or affect; the amount of negative emotions one experiences when prospectively imagining not having performed the target behaviour; 143; 144], moral norm [ones personal norm regarding performing a behaviour; 58; 145], and habit. Of these, however, habit will not be included, as trying out ecstasy cannot sensibly be habitual. The outcome expectancy approach [based on Social Cognitive Theory, 34] has also proved informative in explaining ecstasy use $[13 ; 54 ; 55 ; 86]$, and it has been suggested that these two approaches be combined in future research [35]. Therefore, in the current study, a number of expectancies specified in previous Dutch studies [13; 86] were also measured, along with two additions that were based on a Dutch qualitative study [147].

In sum, the current study was designed to address a number of lacunae in ecstasy use research. First, the determinant configuration of trying out ecstasy will be mapped, allowing comparison to the determinant configuration of using ecstasy [see 35]. Second, the overlap of the TPB and the outcome expectancy approach will be addressed. Third, the relative relevance of the traditional TPB determinants and three of the four additional TPB determinants that were found predictive of ecstasy use will be determined. 


\section{Methods}

\section{Procedure}

An online questionnaire study was conducted as the internet has been argued to be a suitable medium for studying hidden populations such as non-misusing illicit drug users [149]. Participants were recruited by links at several dancerelated Dutch websites (most participants came from the online community at http://partyflock.nl). The questionnaire was administered by a self-chosen virtual interviewer in a Flash interface [150; also see 151]. To activate the proper context for respondents, the interview took place to the background of several party pictures while dance music was playing. Server-side parsing of the content (using PHP and MySQL; see [152]) enabled tailoring of the questionnaire to the respondent (i.e. presentation of every item depended upon previous answers).

This possibility to tailor the questionnaire enabled data collection for several behaviours simultaneously, but only results pertaining to trying out ecstasy will be reported here, and therefore only methodological details relevant to these results. At the first measurement $\left(t_{1}\right)$, demographics, drug use, party behaviour, ecstasy expectations, and behavioural intentions were measured for all participants, after which a subset of participants answered questions about the determinants of trying out ecstasy (the other participants answered questions about the determinants of other behaviours). After three months, participants could access the follow-up measurement ( $\left.t_{2}\right)$, where their ecstasy use behaviour in the past three months, and their intention try out ecstasy in the next three months, were measured. Five months later $\left(t_{3} ;\right.$ logistical problems delayed this follow-up two months), behaviour was measured again. Participants were attended to the follow-ups by e-mail, and six weekly reminders were sent out. Permission to perform this investigation was granted by the Ethical Committee Psychology of Maastricht University (the ECP).

\section{Measurements}

At $\mathrm{t}_{1}$, demographic variables (gender, age and education level), drug use ('which of these substances do you occasionally use at parties?') and party behaviour were measured with one item each, as well as a number of consistently reported ecstasy expectations (the leading statement "if I would take ecstasy I would ..." was followed by "feel very good", "feel more connected to other people", "make contact easier", "understand myself better", "have better sex", "get a lot of energy", "live my life more intensely", "have a better life than without 
ecstasy", "damage my health", "feel bad the next couple of days", "feel nauseous", and "get stiff jaws"). Behavioural intention to try out ecstasy was measured with two items (i.e. 'do you intend to try out ecstasy in the next three months?' and 'do you think that you will indeed do that?', both absolutely notabsolutely; range $1-5 ; \alpha=.94$ ).

Attitude was measured with five semantic differentials (i.e. 'I think that trying out ecstasy is/would make me ...', unpleasant-pleasant, bad-good, unwise-wise, not nice-nice, unhappy-happy; range $1-5 ; \alpha=.90)$. Subjective norm was measured by multiplying an item tapping injunctive subjective norm (e.g., 'how would your parents feel if you were to use ecstasy?', disapprovingapproving; range -2-2, also including an option 'I don't know' with the same value as the middle option 'neutral', i.e. 0) with an item tapping motivation to comply (e.g. 'how important do you find your parents' opinion about whether you use ecstasy?', very unimportant-very important; range 1-5) for best friend, other friends, and parents, and dividing the product by 5 to get a range of $-2-2$ $(\alpha=.72)$. Perceived behavioural control was measured with two items (i.e. 'imagine that you would want to try out ecstasy', followed by 'does it seem easy to you to try out ecstasy?', 'do you think you would manage to try out ecstasy?', absolutely not-absolutely; range 1-5; $\alpha=.72$ ).

Descriptive norm was measured by a single item ('did your best friend try ecstasy, and what does he/she think about it?' with as answer options 'no, and he/she does not want to' (coded 1), 'yes, but he/she no longer uses' and 'yes, and I don't know whether he/she still uses' (both coded 2), 'no, and I don't know whether he/she wants to' (3), 'yes, and he/she still uses' (4), and finally 'no, but he/she does want to' (5). Moral norm was measured by two reverse items (i.e. 'trying out ecstasy contrasts my principles', 'I would feel troubled if I were to try out ecstasy' absolutely not-absolutely; range $1-5 ; \alpha=.87$ ).

Anticipated regret was measured by three items (i.e. 'imagine that in a few weeks at a party you try out ecstasy. Imagine how you would feel the next day. Would you [regret it/worry/feel guilty]?', not at all-very much; range 1-5; $\alpha=.90$ ).

At $t_{2}$, intention was measured with the first of the two intention items used at $\mathrm{t}_{1}$. Behaviour at $\mathrm{t}_{2}$ and $\mathrm{t}_{3}$ was measured by asking whether since the last questionnaire, participants had taken ecstasy, and if so, how often (to which participants typed in a number). In addition, the number of parties participants had attended in the past three months was measured. 


\section{Analyses}

As Cohen argued, "the primary product of a research inquiry is one or more measures of effect size" [153, p. 1310]. Especially with large samples, trivial associations can become significant. Therefore, rather than their significance, associations' meaningfulness will guide the discussion of the results. Associations are considered meaningful when they are non-trivial. We distinguish five levels of association strength (effect size): trivial, weak (Cohen's $\mathrm{d}>.2$; Pearson's $\mathrm{r}>.1$; Cramer's V > .1; odds ratio > 1.5), moderate (Cohen's d > .5; Pearson's r > .3; Cramer's V > .3; odds ratio > 2.5), strong (Cohen's d > .8; Pearson's $\mathrm{r}>$.5; Cramer's V > .5; odds ratio $>4$ ), and very strong (Cohen's d > 1.3; Pearson's r > .7; Cramer's V > .7; odds ratio > 10) [70; 109; see also 154; 155].

For the significance tests of bivariate associations between one dichotomous and one continuous variable, the t-test for unequal variances will be used (in recognition of the issues pointed out by Ruxton [156]). In addition to bivariate analyses, we will conduct a number of multivariate analyses to enable exploration of associations between variables while artificially keeping other variables constant. In particular, we used linear and logistic regression. In these analyses, Cook's distances were examined (but always remained low), and cases with absolute studentised residuals $>3$ were considered outliers and discarded from the analyses (two cases).

\section{Results}

At the first measurement ( $\left.\mathrm{t}_{1}\right), 1,772$ non-users participated. At the second measurement ( $\left.\mathrm{t}_{2}\right), 803$ of these were retained $(45 \%)$, and at the third measurement ( $\left.\mathrm{t}_{3}\right), 479$ participants $(60 \%)$. At $\mathrm{t}_{1}, 443$ non-users participated in the TPB determinant subsample (where the determinants of trying out ecstasy were measured). Of these, 221 were retained at $\mathrm{t}_{2}$, and 121 at $\mathrm{t}_{3}$. Drop-out analyses for demographic variables, used drugs, party behaviour, intention and expectancies showed that only one variable was significantly and meaningfully associated to whether participants dropped out at $\mathrm{t}_{2}$ : sex just achieved a small odds ratio $\left(\mathrm{OR}=1.5, \chi^{2}[1]=17.99, \mathrm{p}<.001\right)$. Drop-out at $\mathrm{t}_{3}$ was only significantly and meaningfully predicted by the expectation that using ecstasy lead to a stiff jaw (Cohen's $d=.20, t[674.09]=-2.76, p<.01)$. The characteristics of the participants are shown in Table 6.1, separate for non-intenders (those participants that indicated to be certain of their intention to not use ecstasy, intention $=1$ ) and intenders (with a higher intention). Compared to non- 
Table 6.1: Participant characteristics (for means, standard deviations are provided in parentheses) and differences between non-intenders and intenders.

\begin{tabular}{|c|c|c|c|c|c|c|}
\hline \multirow[b]{2}{*}{ Variable name or categories } & \multirow[b]{2}{*}{ Range } & \multicolumn{2}{|c|}{$\%$ or mean $(\mathrm{sd})$} & \multicolumn{3}{|c|}{ Difference $^{1}$} \\
\hline & & $\begin{array}{c}\text { Non-intenders } \\
\quad(n=1198)\end{array}$ & $\begin{array}{c}\text { Intenders } \\
(n=574)\end{array}$ & $\mathrm{Lbl}^{2}$ & Unit & t Value \\
\hline Gender (being female) & & $57 \%$ & $55 \%$ & - & OR & $.95^{\mathrm{ns}}$ \\
\hline Higher educated & & $38 \%$ & $48 \%$ & - & OR & 1.48 \\
\hline Alcohol use & & $80 \%$ & $88 \%$ & + & OR & 1.86 \\
\hline Tobacco use & & $36 \%$ & $47 \%$ & + & OR & 1.58 \\
\hline Cannabis use & & $13 \%$ & $39 \%$ & +++ & OR & 4.41 \\
\hline Speed use & & $.3 \%$ & $5.4 \%$ & ++++ & OR & 17.04 \\
\hline Cocaine use & & $.7 \%$ & $3.5 \%$ & +++ & OR & 5.37 \\
\hline GHB use & & $.3 \%$ & $.5 \%$ & + & OR & $2.09^{\text {ns3 }}$ \\
\hline Poppers use & & $.2 \%$ & $1.9 \%$ & ++++ & OR & $11.68^{4}$ \\
\hline Nitruous oxide use & & $1.4 \%$ & $2.4 \%$ & + & OR & $1.74^{\mathrm{ns}}$ \\
\hline Psylocybin use & & $.5 \%$ & $1.4 \%$ & ++ & OR & $2.81^{* 3}$ \\
\hline Ketamine use & & $.1 \%$ & $.3 \%$ & +++ & OR & $4.19^{\text {ns3 }}$ \\
\hline LSD use & & $0 \%$ & $.5 \%$ & - & OR & $1.01^{* 3}$ \\
\hline Visits a big party twice a year or less & & $35 \%$ & $35 \%$ & - & $\mathrm{V}$ & $.02^{\mathrm{ns}}$ \\
\hline - every two to six months & & $53 \%$ & $52 \%$ & & & $.03^{\mathrm{ns}}$ \\
\hline - every month or more & & $12 \%$ & $13 \%$ & & & $-.12^{*}$ \\
\hline Visits a club/small party bimonthly & & $23 \%$ & $21 \%$ & - & $\mathrm{V}$ & .92 \\
\hline - every two to four weeks & & $51 \%$ & $54 \%$ & & & .77 \\
\hline - every week or more & & $26 \%$ & $25 \%$ & & & .65 \\
\hline Age in years & $11-51$ & $20.45(4.28)$ & $19.89(4.99)$ & - & d & .65 \\
\hline Expectation to feel very good & $1-5$ & $2.19(1.31)$ & $3.35(1.14)$ & +++ & $\mathrm{d}$ & .60 \\
\hline Expectation to feel more connected & $1-5$ & $2.22(1.34)$ & $3.23(1.24)$ & +++ & $\mathrm{d}$ & .65 \\
\hline Expectation to make contact easy & $1-5$ & $2.48(1.42)$ & $3.37(1.24)$ & ++ & $\mathrm{d}$ & .65 \\
\hline Expectation to understand self better & $1-5$ & $1.56(.93)$ & $2.19(1.09)$ & ++ & $\mathrm{d}$ & .37 \\
\hline Expectation to have better sex & $1-5$ & $2.11(1.22)$ & $2.85(1.23)$ & ++ & $\mathrm{d}$ & -.44 \\
\hline Expectation to get a lot of energy & $1-5$ & $3.36(1.41)$ & $4.19 \quad(.95)$ & ++ & $\mathrm{d}$ & -.39 \\
\hline Expectation to live a more intense life & $1-5$ & $1.65(1.01)$ & $2.34(1.14)$ & ++ & $\mathrm{d}$ & -.45 \\
\hline Expectation to have a better life & $1-5$ & $1.52(1.16)$ & $1.94(1.16)$ & + & $\mathrm{d}$ & $.03^{\mathrm{ns}}$ \\
\hline Expectation to damage health & $1-5$ & $4.46(1.08)$ & $3.99(1.08)$ & + & $\mathrm{d}$ & 2.45 \\
\hline Expectation to feel bad for a few days & $1-5$ & $4.24(1.10)$ & $3.82(1.08)$ & + & $\mathrm{d}$ & 1.83 \\
\hline Expectation to feel nauseous & $1-5$ & $3.51(1.27)$ & $2.97(1.03)$ & + & $\mathrm{d}$ & .64 \\
\hline Expectation to get stiff jaws & $1-5$ & $3.51(1.30)$ & $3.55(1.07)$ & - & $\mathrm{d}$ & $.24^{* *}$ \\
\hline Intention & $1-5$ & $1.00(.00)^{4}$ & $2.58(1.01)^{4}$ & ++++ & $\mathrm{d}$ & .62 \\
\hline Attitude & $1-5$ & $1.85(.80)^{4}$ & $3.26(.74)^{4}$ & ++++ & $\mathrm{d}$ & 1.40 \\
\hline Subjective norm & $-2-2$ & $-.73(.71)^{4}$ & $-.30(.58)^{4}$ & ++ & $\mathrm{d}$ & -1.07 \\
\hline Perceived behavioural control & $1-5$ & $4.06(.96)^{4}$ & $4.28(.78)^{4}$ & + & $\mathrm{d}$ & $.95^{\mathrm{ns}}$ \\
\hline Descriptive norm & $1-5$ & $1.93(1.19)^{4}$ & $2.74(1.45)^{4}$ & ++ & d & 1.48 \\
\hline Moral norm & $1-5$ & $1.84(1.05)^{4}$ & $3.42(1.23)^{4}$ & ++++ & $\mathrm{d}$ & 1.86 \\
\hline Anticipated regret & $1-5$ & $3.49(1.27)^{4}$ & $2.18(1.16)^{4}$ & +++ & $\mathrm{d}$ & 1.58 \\
\hline
\end{tabular}

${ }^{1}$ For all differences, $\mathrm{p}<.001$, unless specified otherwise, ${ }^{2}$ Association strength labels:

- trivial, + weak, ++ moderate, +++ strong, ++++ very strong, ${ }^{3}$ For these variables, the chisquare statistic is not reliable (one cell had predicted count $<5$, ${ }^{*} \mathrm{p}<.05$, ${ }^{* *} \mathrm{p}<.01$, ns Not significant ( $\mathrm{p}>.05),{ }^{4}$ For these, $\mathrm{n}=260$ for non-intenders and 183 for intenders. 


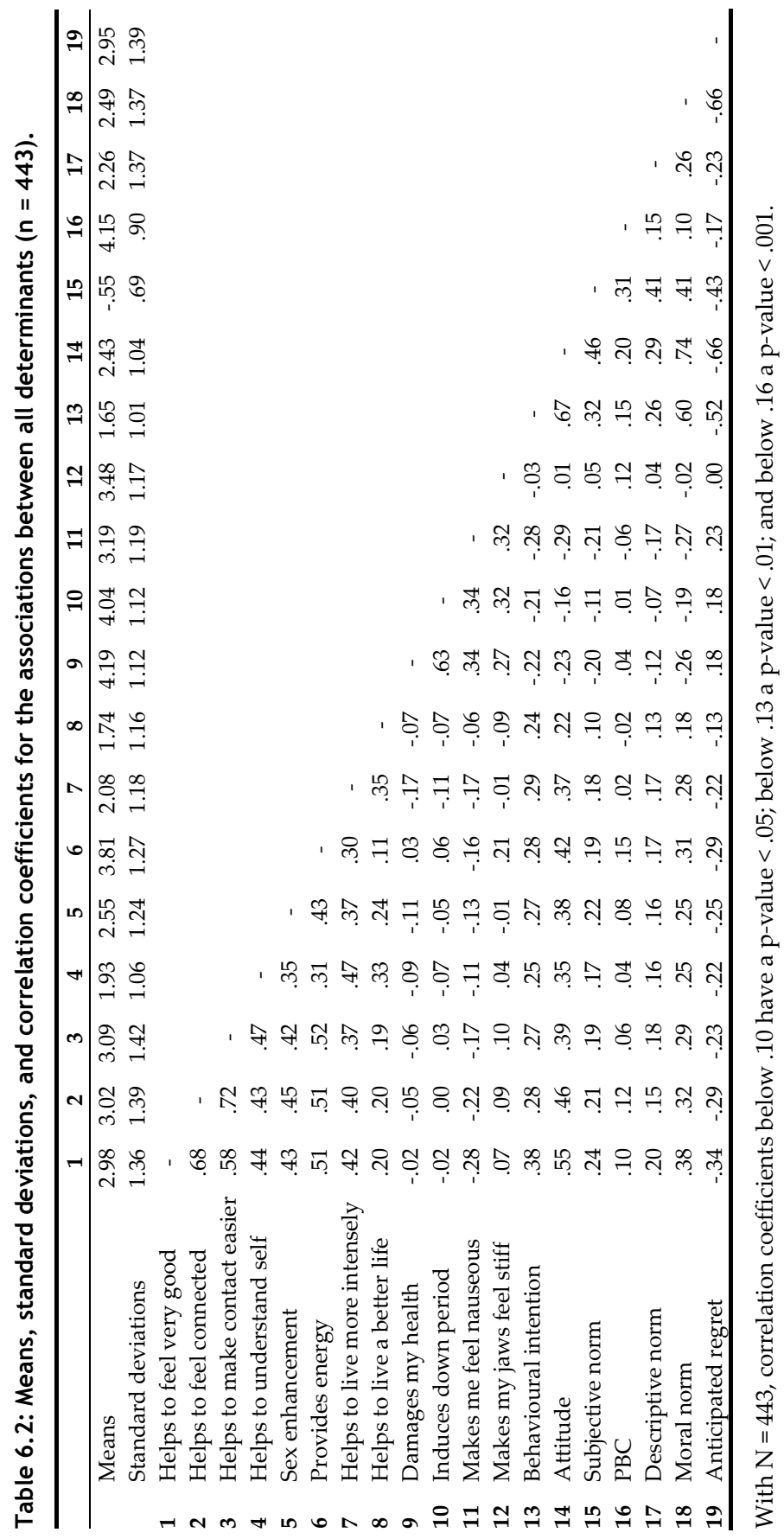


Table 6.3: Regression analyses to predict intention from traditional (step 1) and additional (step 2) TPB determinants $(\mathrm{N}=438)$.

\begin{tabular}{lcc}
\hline & $\beta$ step 1 & $\beta$ step 2 \\
\hline Attitude & $.69^{* * * *}$ & $.48^{* * * *}$ \\
Subjective norm & -.02 & -.09 \\
Perceived behavioural control & .00 & .01 \\
Descriptive norm & & $.08^{*}$ \\
Moral norm & & $.21^{* * *}$ \\
Anticipated regret & & -.08 \\
$\mathrm{R}^{2}$ & .45 & .49 \\
$\mathrm{R}^{2}$ change & .45 & .04 \\
F of R $\mathrm{R}^{2}$ change & $120.16^{* * *}$ & $9.54^{* * * *}$ \\
DfF (change) & 3 & 3 \\
DfF (error) & 434 & 431 \\
\hline
\end{tabular}

${ }^{*} \mathrm{p}<.05,{ }^{* *} \mathrm{p}<.01,{ }^{* * *} \mathrm{p}<.001$.

intenders, intenders were more likely to be higher educated, use alcohol, tobacco, cannabis, speed and cocaine, have higher positive expectations and lower negative expectations (except for the expectation to get stiff jaws when using ecstasy) and score higher on all TPB determinants.

In bivariate analyses, participants' intention at $\mathrm{t}_{1}$ very strongly predicted whether they would indeed have tried out ecstasy at $t_{2}$ (1.44 vs. 2.87 , Cohen's $d$ $=1.79, \mathrm{t}[801]=-6.21, \mathrm{p}<.001)$, and intention at $\mathrm{t}_{2}$ very strongly predicted use at $\mathrm{t}_{3}(1.29$ vs. 2.53 , Cohen's $d=1.97, \mathrm{t}[446]=-4.76, \mathrm{p}<.001)$. When using the dichotomised intention measure to compare non-intender to intenders, similar strong associations were found, with intenders at $t_{1}$ being over seven times more likely to have tried out ecstasy at $\mathrm{t}_{2}\left(\mathrm{OR}=7.25, \chi^{2}[1]=28.23, \mathrm{p}<.001\right)$, and intenders at $t_{2}$ being over eleven times more likely to have tried out ecstasy at $t_{3}$ $\left(\mathrm{OR}=11.81, \chi^{2}[1]=27.28, \mathrm{p}<.001\right.$; however, the $\chi^{2}$ is not reliable as one cell had an expected count $<5$ ). Of the 221 participants in the TPB determinants subsample that were retained at $\mathrm{t}_{2}$, only 14 had tried out ecstasy. Therefore, it was not possible to conduct a multivariate analysis to assess the associations of intention and perceived behavioural control (PBC) simultaneously.

Nonetheless, it is clear that intention to try out ecstasy is a very strong predictor of subsequent ecstasy use. This crucial role for intention warrants closer examination of its determinants.

The correlations between all determinants are shown in Table 6.2. Regression weights in regression analyses of intention on the traditional (step 1) and additional (step 2) TPB determinants are shown in Table 6.3. In the first step of the regression analyses, only attitude achieves significance, and the 
model explains $45 \%$ of the variation in intention. In the second step, in addition to attitude, descriptive norm and moral norm achieve significance, explaining $49 \%$ of the variation in intention (a parsimonious model with only these three predictors explains $48 \%$ of the variation in intention).

To assess the degree of overlap between the expectation approach and the TPB approach, we conducted two analyses. First, to establish the degree to which the expectations explain variation in TPB's attitude, attitude was regressed upon the expectations. The results are shown in Table 6.4. The expectations together explain $46 \%$ of the variation in TPB's attitude measure. The significantly contributing expectations are the expectation that ecstasy helps to feel very good, that it enhances sex, provides energy, and that it damages ones health and causes nausea. Second, we examined whether these expectations have additional predictive value over the TPB. We did this by saving, for every participant, their predicted intention to use ecstasy as predicted by the parsimonious model described above. The difference between each participants' measured intention and their predicted intention (the residual) represents the part of intention that cannot be explained by the TPB

Table 6.4: Regression analyses where attitude was predicted from the ecstasy expectations, and regression analyses where the residuals were predicted from the ecstasy expectations (these residuals are the differences between measured intention and intention predicted by a parsimonious model consisting of the significant predictors in step 2 in Table 6.3).

\begin{tabular}{lcc}
\hline & $\beta$ s for attitude $(\mathbf{N}=440)$ & $\beta$ s for residuals $(\mathbf{N}=\mathbf{4 3 8})$ \\
\hline Help to feel very good & $.34^{*}$ & .06 \\
Helps feeling more connected & .06 & $-.18^{*}$ \\
Helps to make contact easier & -.03 & .09 \\
Helps to understand myself better & .05 & -.06 \\
Sex enhancement & $.09^{*}$ & -.01 \\
Provides energy & $.16^{*}$ & .00 \\
Helps to live life more intensely & .06 & .03 \\
Helps to live a better life & .06 & .09 \\
Damages my health & $-.19^{*}$ & .01 \\
Makes me feel bad for days after use & -.05 & -.10 \\
Makes me feel nauseous & $-.08^{*}$ & -.06 \\
Makes my jaws feel stiff & .03 & .01 \\
R & .46 & .04 \\
F of R & $30.18^{* * *}$ & 1.32 \\
DfF (model) & 12 & 12 \\
DfF (error) & 427 & 425 \\
\hline
\end{tabular}

${ }^{*} \mathrm{p}<.05,{ }^{* *} \mathrm{p}<.01,{ }^{* * *} \mathrm{p}<.001$. 
determinants. We then regressed this residual upon the expectations. This shows what percentage of intention, of the part that cannot be explained by the TPB determinants, can be explained by the expectations, providing a measure of their additional value. The advantage of this approach compared to conducting a hierarchical regression analysis is that in this way, only the variation in intention that is not already accounted for by the TPB determinants is considered, whereas in a hierarchical regression analysis, it is possible that expectations' regression coefficients achieve significance by explaining variation that was previously explained by for example attitude. As can be seen in Table 6.4, the model fails to achieve significance, explaining only $4 \%$ of the unexplained part of intention. Because $51 \%$ of the intention to try out ecstasy remains unexplained, this means that the expectations together explain an addition $2 \%$ of intention.

\section{Discussion}

Non-users' intention to try out ecstasy was highly predictive of subsequent ecstasy use, rendering it expedient to map the determinant configuration underlying this intention. Bivariate analyses showed strong associations between determinants and intention. Specifically, when examining correlation coefficients, the determinants that were most strongly associated to intention to try out ecstasy were attitude, moral norm and anticipated regret (all with strong associations), followed by subjective norm and the expectation that ecstasy helps to feel very good (both moderately associated). When comparing nonintenders with intenders, attitude and moral norm had very large associations, and anticipated regret and the expectations to feel very good and to feel more connected when using ecstasy had strong associations, and subjective norm and many other expectations had moderate associations. However, when analysing these associations multivariately, these determinants turned out to explain mostly the same variation in intention. When only looking at the traditional TPB determinants, only attitude achieved significance, explaining $45 \%$ of intention, and when adding the additional TPB determinants to the model, descriptive norm and moral norm also achieved significance, together explaining $49 \%$ of the variation in intention. Subsequent analyses showed that the expectations explained $46 \%$ of TPB's attitude, but that together, they could not explain variation in intention that was not already explained by the TPB. 
The current study suffers three limitations. First, the behavioural measure relies on self-reports. Even though these have been shown to be reliable [112; 157], of course, it would have been desirable to eliminate all possibility of measurement error. Second, no belief-based measures were used. Although earlier studies have found direct measures to yield no different results from belief-based measures [58], it would have been interesting to see whether these results would replicate. Third, a number of relevant beliefs and determinants have not been measured. This is partly because results from a recent qualitative review [114] were not yet available. Future research should include more beliefs drawn from qualitative research so as to gain a better understanding of nonusers' intention to try out ecstasy. Fourth, the current sample was recruited purely by letting participants voluntarily participate. It cannot be excluded that certain groups of participants, for example non-users that are strongly inclined to remain non-users and have no interest in ecstasy at all, have not participated. The NeXT study [see for example 110] is an excellent example of a study utilising a design that does not suffer such flaws.

Despite these limitations, this study does provide interesting results. First, this is the first study to address the behaviour trying out ecstasy. And perhaps related to this, it became clear that less than half of potential future users' intention to try out ecstasy is understood. Although this is promising for the first study examining this behaviour (reviews found mean $R^{2} s$ of .39 [46] and .41 [33]) it is also clear that interventions aiming to prevent ecstasy use have an urgent need for more research to inform them. As long as it is not clear which determinants are relevant and which beliefs underlie these determinants, developing evidence-based interventions remains problematic. Second, the current data do support the theoretical assumption that TPB's attitude encompasses the expectations from Social Cognitive Theory. These results also make clear that for trying out ecstasy, this attitude measure encompasses many expectations that are as yet unknown, as less than half of the variation in attitude is understood. Since it is these specific cognitive measures that can guide intervention development, it seems advisable to direct research attention to mapping these expectations. Such studies should, however, combine these measurements with other TPB determinants, so that it may become clear whether indeed all expectations underlie attitude.

And finally, when comparing the associations between determinants and the intention to try out ecstasy to the associations found in a meta-analysis of the determinants of using ecstasy [35], it seems that indeed the determinant 
configuration of trying out ecstasy differs from that of using ecstasy. Attitude is strongly associated to intention both for using and for trying out, but subjective norm, descriptive norm and PBC are strongly associated to intention to use, whereas subjective norm and descriptive norm are moderately associated to intention to try out, and PBC only weakly. Moral norm, on the other hand, is only moderately associated to intention to use ecstasy, but strongly associated to intention to try out ecstasy, and anticipated regret is only weakly associated to intention to use, but strongly to intention to try out. Because the results from the meta-analysis represent an amalgamation of results from studies that use different measurement methods for the TPB determinants in different populations, and the current study used slightly different measurements again, it cannot be excluded that these measurement differences caused the different association strengths until a study compares samples where the same measurement was used. However, as these apparent differences are in line with the qualitative evidence [114; 147], and are predicted by the TPB [the condition of compatibility; see 30], it seems reasonable to assume that they do reflect real differences. Thus, whereas the strongest predictors of intention to use ecstasy are attitude, subjective norm, descriptive norm, and perceived behavioural control, the strongest predictors of intention to try out ecstasy are attitude, moral norm, and anticipated regret. This means that interventions aiming to prevent ecstasy use would do well to target these determinants, rather than subjective norms, descriptive norms or PBC. 


\section{Chapter 7 Social cognitive determinants of ceasing ecstasy use: ceasing is not the opposite of using}

Ecstasy use is potentially damaging to health [17; 20; 21] yet prevalent [74; 112], and although accordingly, a need for intervention development has been asserted, it has also been observed that evidence to base these interventions on is scarce [35]. If evidence-based interventions are to be developed, more research into the determinants of ecstasy use is necessary. In particular, all quantitative research into ecstasy use has examined determinants of the behaviour 'using ecstasy [35], whereas recent qualitative evidence suggests that reasons, and therefore possibly determinants, of related but distinct behaviours such as 'trying out ecstasy' and 'ceasing ecstasy use' may be different. To address this issue, the current paper reports a study that examines the determinants of ceasing ecstasy use.

Interventions promoting abstinence from ecstasy use can do so either by targeting non-users and preventing them from trying out ecstasy, or by targeting users and causing them to cease using ecstasy. Thus, the behaviours of interest for such interventions are trying out ecstasy and ceasing ecstasy use, not using ecstasy. This discrepancy may prove problematic because the theories that guided these studies (i.e. Ajzen's Theory of Planned Behaviour [TPB; 30; e.g. 56; 58-61] and the expectation part of the outcome expectancy constructs from Bandura's Social Cognitive Theory [13; SCT; 34; e.g. 54; 55; 57]) both emphasised the relevance of sufficiently specific measures [30; 34]. For example, in exercise research, evidence has been found that suggests that similar but related behaviours can have different determinant configurations (e.g. a social cognitive determinant that significantly contributes to predicting one behaviour need not contribute to the prediction of related behaviours; [84]). Although in ecstasy use, such studies are lacking, a qualitative review did find different reasons for trying out ecstasy, using ecstasy, and ceasing ecstasy use [114]. If 
these concerns prove grounded, then that means that there is no research available to inform interventions aimed at preventing ecstasy use or promoting cessation.

The determinants that will be measured are drawn from the Theory of Planned Behaviour [TPB; 30], which has been shown applicable to ecstasy use $[56 ; 58 ; 60 ; 61]$ and as such provides a good starting point. The TPB postulates intentions as most proximal social cognitive determinant of behaviour, in turn predicted by attitude (i.e. evaluation of the likelihood and desirability of that behaviour's consequences), subjective norm (i.e. perception of others' approval of the behaviour) and perceived behavioural control [PBC, i.e. perception of control based on perception of skills and external obstacles/facilitators; very similar to self efficacy; 30]. In addition to these traditional TPB determinants, four additional determinants have been found predictive of ecstasy use [35]: subjective descriptive norm [an extension of the traditional subjective normative construct that assesses the perceived behaviour of social referents; 142], anticipated regret [or affect; the amount of negative emotions one experiences when prospectively imagining not having performed the target behaviour; 143; 144], moral norm [ones personal norm regarding performing a behaviour; 58; 145], and habit. Of these, however, habit will not be included, as cease ecstasy use cannot sensibly be habitual. The outcome expectancy approach [based on Social Cognitive Theory, 34] has also proved informative in explaining ecstasy use $[13 ; 54 ; 55 ; 86]$, and it has been suggested that these two approaches be combined in future research [35]. Therefore, in the current study, a number of expectancies specified in previous Dutch studies [13; 86] were also measured, along with two additions that were based on a Dutch qualitative study [147].

In sum, the current study was designed to address a number of lacunae in ecstasy use research. First, the determinant configuration of cease ecstasy use will be mapped, allowing comparison to the determinant configuration of using ecstasy [see 35]. Second, the overlap of the TPB and the outcome expectancy approach will be addressed. Third, the relative relevance of the traditional TPB determinants and three of the four additional TPB determinants that were found predictive of ecstasy use will be determined. 


\section{Methods}

\section{Procedure}

An online questionnaire study was conducted as the internet has been argued to be a suitable medium for studying hidden populations such as non-misusing illicit drug users [149]. Participants were recruited by links at several dancerelated Dutch websites (most participants came from the online community at http://partyflock.nl). The questionnaire was administered by a self-chosen virtual interviewer in a Flash interface [150; also see 151]. To activate the proper context for respondents, the interview took place to the background of several party pictures while dance music was playing. Server-side parsing of the content (using PHP and MySQL; see [152]) enabled tailoring of the questionnaire to the respondent (i.e. presentation of every item depended upon previous answers).

This possibility to tailor the questionnaire enabled data collection for several behaviours simultaneously, but only results pertaining to ceasing ecstasy use will be reported here, and therefore only methodological details relevant to these results. At the first measurement ( $\left.\mathrm{t}_{1}\right)$, demographics, drug use, party behaviour, ecstasy expectations, and behavioural intentions to use ecstasy were measured for all participants, after which a subsample of participants answered questions about the intention to cease ecstasy use and the underlying determinants (the other participants answered questions about the determinants of other behaviours). After three months, participants could access the follow-up measurement ( $\left.\mathrm{t}_{2}\right)$, where their ecstasy use behaviour in the past three months was measured, after which a different subsample of participants answered the same questions about the intention to cease ecstasy use and the underlying determinants. In this way, two independent samples were recruited. Five months later ( $t_{3}$; logistical problems delayed this follow-up two months), again participants' ecstasy use behaviour was measured. Participants were attended to these follow-ups by e-mail, and six weekly reminders were sent out. Permission to perform this investigation was granted by the Ethical Committee Psychology of Maastricht University (the ECP).

\section{Measurements}

At $\mathrm{t}_{1}$, demographic variables (gender, age and education level), drug use ('which of these substances do you occasionally use at parties?') and party behaviour were measured with one item each, as well as a number of consistently reported ecstasy expectations (the leading statement "if I would take ecstasy I would ..." 
was followed by "feel very good", "feel more connected to other people", "make contact easier", "understand myself better", "have better sex", "get a lot of energy", "live my life more intensely", "have a better life than without ecstasy", "damage my health", "feel bad the next couple of days", "feel nauseous", and "get stiff jaws"). Behavioural intention to use ecstasy was measured with two items at $\mathrm{t}_{1}$ (i.e. 'do you intend to use ecstasy in the next three months?' and 'do you think that you will indeed do that?', both absolutely not-absolutely; range $1-5 ; \alpha=.92$ ), but at $\mathrm{t}_{2}$ and $\mathrm{t}_{3}$, only the first of these two items was used.

In the subsamples at $\mathrm{t}_{1}$ and $\mathrm{t}_{2}$, behavioural intention to cease ecstasy use was measured with the same two items used for using ecstasy at $t_{1}$ (i.e. 'do you intend to cease ecstasy use in the next three months?', $\alpha=.87$ at $\mathrm{t}_{1}$ and .84 at $\mathrm{t}_{2}$ ). Attitude was measured with five semantic differentials (i.e. 'I think that ceasing ecstasy use is/would make me ...', unpleasant-pleasant, bad-good, unwise-wise, not nice-nice, unhappy-happy; range $1-5 ; \alpha=.73$ at $\mathrm{t}_{1}$ and .75 at $\mathrm{t}_{2}$ ). Subjective norm was measured by multiplying an item tapping injunctive subjective norm (e.g., 'how would your parents feel if you were to cease using ecstasy?', disapproving-approving; range -2-2, also including an option 'I don't know' with the same value as the middle option 'neutral', i.e. 0) with an item tapping motivation to comply (e.g. 'how important do you find your parents' opinion about whether you cease using ecstasy?', very unimportant-very important; range 1-5) for best friend, other friends, and parents, and dividing the product by 5 to get a range of $-2-2\left(\alpha=.52\right.$ at $\mathrm{t}_{1}$ and .75 at $\left.\mathrm{t}_{2}\right)$. Perceived behavioural control was measured with two items (i.e. 'imagine that you would want to cease ecstasy use', followed by 'does it seem easy to you to cease ecstasy use?', 'do you think you would manage to cease using ecstasy?', absolutely notabsolutely; range $1-5 ; \alpha=.78$ at both $\mathrm{t}_{1}$ and $\mathrm{t}_{2}$ ).

Two descriptive norm measures were employed. The first measured whether ones best friend had ceased ecstasy use recently (i.e. 'did your best friend cease using ecstasy in the past year?', with answer options 'no, and he/she did not try either' (coded 1), 'no, but he/she doesn't use anyway' (2), 'no, but he/she did try' (3), and 'yes' (4)), and the second measured how many other friends has ceased ecstasy use recently (i.e. 'how many of your other friends have ceased using ecstasy in the past year?', with answer options 'none' (coded 1), 'some' (2), 'about half' (3), 'many' (4), 'most' (5), and 'most did not use ecstasy in the first place' (also coded 3)). Because of these incomparable scales, these two items were not aggregated. Moral norm was measured by two reverse 
items (i.e. 'cease ecstasy use contrasts my principles', 'I would feel troubled if I were to cease using ecstasy' absolutely not-absolutely; range $1-5 ; \alpha=.83$ at t 1 and .79 at $\mathrm{t}_{2}$ ). Anticipated regret was measured by three items (i.e. 'imagine that you would want to cease using ecstasy, but that at a party, you end up taking ecstasy anyway. Imagine how you would feel the next day. Would you [regret it/worry/feel guilty]?', not at all-very much; range $1-5 ; \alpha=.87$ at both $\mathrm{t}_{1}$ and $\mathrm{t}_{2}$ ).

At $t_{2}$ at $t_{3}$, party attendance was measured by asking participants how many parties they had attended. If participants had not attended any parties, they could indicate one or more of seven reasons, one of which was 'because I want to cease ecstasy use and I enjoy parties less when I don't use ecstasy' (other reasons included 'there were no nice parties' and 'I was saving for a different party'). If they had attended one or more parties, ecstasy use in the past three months was measured, and if they had not used, they could indicate one or more of nine reasons, one of which was 'I want to cease ecstasy use' (other reasons included 'I failed to obtain ecstasy' and 'I had to drive back'). Thus, two dichotomous behavioural measures were available: whether participants had used ecstasy between two measurements or not (ecstasy use); and whether participants had indicated that they had not used because they wanted to cease ecstasy use (ecstasy cessation). At $t_{3}$, we measured reasons to cease use: those participants who had visited one or more parties, had not used ecstasy, and indicated that they wanted to cease, were asked why they wanted to cease. They could choose one or more of 12 reasons and were offered the possibility of entering a different reason as well.

\section{Analyses}

As Cohen argued, "the primary product of a research inquiry is one or more measures of effect size" [153, p. 1310]. Especially with large samples, trivial associations can become significant. Therefore, rather than their significance, associations' meaningfulness will guide the discussion of the results. Associations are considered meaningful when they are non-trivial. We distinguish five levels of association strength (effect size): trivial, weak (Cohen's $\mathrm{d}>$.2; Pearson's $\mathrm{r}>.1$; Cramer's V > .1; odds ratio > 1.5), moderate (Cohen's d > .5; Pearson's $r>$.3; Cramer's V > .3; odds ratio > 2.5), strong (Cohen's d > .8; Pearson's r > .5; Cramer's V > .5; odds ratio > 4), and very strong (Cohen's d > 1.3; Pearson's r > .7; Cramer's V > .7; odds ratio > 10) [70; 109; see also 154; 155]. For the significance tests of bivariate associations between one dichotomous and one continuous variable, the t-test for unequal variances will be used (in 
recognition of the issues pointed out by Ruxton [156]). Differences between correlations were tested by converting the correlations to Fisher's $\mathrm{Z}$ using:

$$
Z_{\text {Fisher }}=\frac{1}{2} \log _{e} \frac{1+r}{1-r}
$$

Then, the effect size $\mathrm{q}$ for the difference between two correlations was calculated using [70]:

$$
q=Z_{\text {Fisher }_{1}}-Z_{\text {Fisher }_{2}}
$$

Finally, a $\mathrm{p}$ value for this difference was attained by calculating the surface of the standard normal function for:

$$
Z_{\text {Fisher }_{\text {Difference }}}=\frac{q}{\sqrt{\frac{1}{N_{1}-3}+\frac{1}{N_{2}-3}}}
$$

The difference between two correlations is considered small when $\mathrm{q}>=.1$; medium when $\mathrm{q}>=.3$; and large when $\mathrm{q}>=.5$ [70]. In addition to bivariate analyses, we will conduct a number of multivariate analyses to enable exploration of associations between variables while artificially keeping other variables constant. In particular, we used linear and logistic regression. In these analyses, Cook's distances were examined (but always remained low), and cases with absolute studentised residuals $>3$ were considered outliers and discarded from the analyses (one case was discarded).

\section{Results}

At the first measurement ( $\left.\mathrm{t}_{1}\right), 3754$ ecstasy users participated. At the second measurement ( $\left.\mathrm{t}_{2}\right), 1807$ of these were retained (48\%), and at the third measurement ( $\left.t_{3}\right), 1105$ participants (61\%). At $t_{1}, 276$ users participated in the TPB determinant subsample (where the determinants of ceasing ecstasy use were measured), of whom 168 were retained at $\mathrm{t}_{2}(61 \%)$, and 95 at $\mathrm{t}_{3}(57 \%)$. At $\mathrm{t}_{2}$, 301 users participated in the TPB determinants subsample, of whom 165 were retained at $\mathrm{t}_{3}(55 \%)$. Figure 7.1 illustrates these samples sizes at the three measurement moments and user group transitions.

Drop-out analyses for demographic variables, used drugs, party behaviour and expectancies showed that no variables were significantly and 


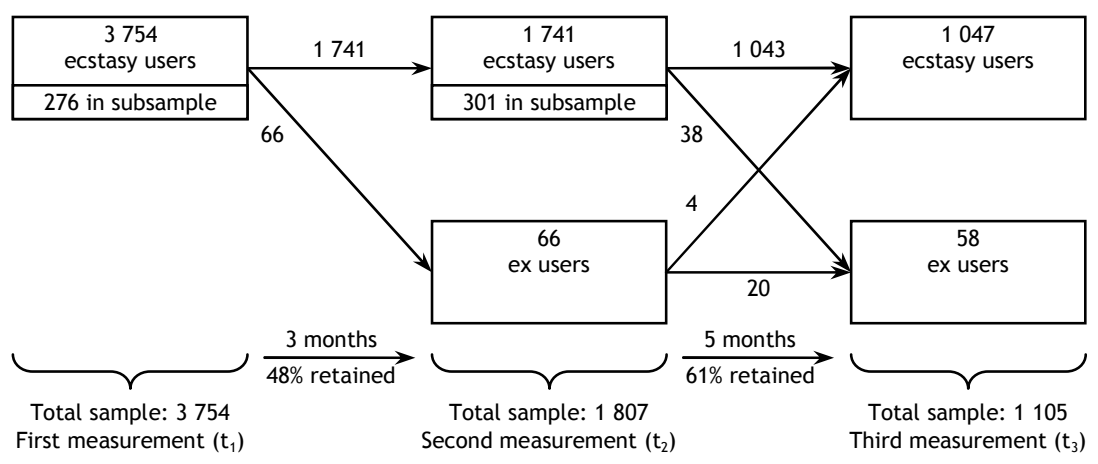

Figure 7.1: Sample sizes and characteristics.

meaningfully associated to whether participants dropped out. However, when looking at the TPB determinants, intention to cease is weakly associated to dropout at $\mathrm{t}_{2}$ (within the $\mathrm{t}_{1}$ subsample: 2.17 vs. 1.93 , Cohen's $\mathrm{d}=-0.28, \mathrm{t}[274]=$ $2.18, \mathrm{p}<.05$ ) and $\mathrm{t}_{3}$ (within the $\mathrm{t}_{2}$ subsample: 2.44 vs. 2.12 , Cohen's $\mathrm{d}=-0.34$, $\mathrm{t}[299]=2.96, \mathrm{p}<.01)$, and anticipated regret is weakly associated to dropout at $\mathrm{t}_{2}$ (within the $\mathrm{t}_{1}$ subsample: 2.19 vs. 2.48 , Cohen's $\mathrm{d}=0.26, \mathrm{t}[274]=-2.10, \mathrm{p}<.05$ ). These lower intentions imply that the users that were retained at $t_{2}$ may be, on average, more persistent users than those comprising the sample at $t$. If this is the case, the second subsample may not be a random sample of users.

Indeed, differences between the subsamples are apparent in Table 7.1, which shows the characteristics of the participants in, and comparisons between, the two subsamples. Use of cannabis and GHB differ slightly, but more importantly and interestingly, intention is higher, not lower, in the $t_{2}$ sample, as are attitude and subjective norm. (perceived behavioural control (PBC) and anticipated regret have trivial effect sizes). Although the effect sizes are only small, they indicate the $t_{2}$ subsample may indeed not be a random sample (despite the similarities in demography). In any case, the $t_{2}$ subsample is not a more persistent subsample: if anything, it seems more eager to cease using. This difference between the samples will be addressed where appropriate, and possible explanations and implications will be more fully considered in the discussion.

In bivariate analyses, participants' intention at $t_{1}$ very strongly predicted whether they would indeed have ceased ecstasy use at t2 (1.90 vs. 2.90, Cohen's $\mathrm{d}=1.41, \mathrm{t}[166]=-3.11, \mathrm{p}<.01)$, and intention at $\mathrm{t}_{2}$ very strongly predicted cessation at $\mathrm{t}_{3}(2.06$ vs. 3.13 , Cohen's $\mathrm{d}=1.17, \mathrm{t}[163]=-3.23, \mathrm{p}<.01)$. However, 
Table 7.1: Participant characteristics (for means, standard deviations are provided in parentheses) for the subsamples at $t_{1}$ and $t_{2}$, and effects sizes and significances for the difference between these two subsamples.

\begin{tabular}{|c|c|c|c|c|c|}
\hline \multirow[b]{2}{*}{ Variable name or categories } & \multirow[b]{2}{*}{ Range } & \multicolumn{2}{|c|}{$\%$ or mean $(\mathrm{sd})$} & \multicolumn{2}{|c|}{ Difference } \\
\hline & & $\begin{array}{l}\text { Subsample at } t_{1} \\
(n=276)\end{array}$ & $\begin{array}{c}\text { Subsample at } t_{2} \\
(n=301)\end{array}$ & Unit & Value \\
\hline Gender (being female) & & $42 \%$ & $45 \%$ & OR & 1.14 \\
\hline Higher educated & & $50 \%$ & $42 \%$ & OR & .73 \\
\hline Alcohol use & & $84 \%$ & $84 \%$ & OR & 1.00 \\
\hline Tobacco use & & $59 \%$ & $63 \%$ & OR & 1.15 \\
\hline Cannabis use & & $54 \%$ & $44 \%$ & OR & $.67^{*}$ \\
\hline Speed use & & $36 \%$ & $40 \%$ & OR & 1.17 \\
\hline Cocaine use & & $36 \%$ & $41 \%$ & OR & 1.24 \\
\hline GHB use & & $24 \%$ & $14 \%$ & OR & $.54^{* *}$ \\
\hline Poppers use & & $7 \%$ & $8 \%$ & OR & 1.16 \\
\hline Nitruous oxide use & & $8 \%$ & $7 \%$ & OR & .87 \\
\hline Psylocybin use & & $4 \%$ & $4 \%$ & OR & 1.10 \\
\hline Ketamine use & & $6 \%$ & $6 \%$ & OR & .97 \\
\hline LSD use & & $3 \%$ & $1 \%$ & OR & .52 \\
\hline Visits a big party twice a year or less & & $15 \%$ & $13 \%$ & $\mathrm{~V}$ & .06 \\
\hline - every two to six months & & $59 \%$ & $56 \%$ & & \\
\hline - every month or more & & $26 \%$ & $31 \%$ & & \\
\hline Visits a club/small party bimonthly & & $26 \%$ & $25 \%$ & $\mathrm{~V}$ & .02 \\
\hline - every two to four weeks & & $55 \%$ & $55 \%$ & & \\
\hline - every week or more & & $20 \%$ & $21 \%$ & & \\
\hline Age in years & $13-53$ & $25.44(6.86)$ & $24.52(6.47)$ & $\mathrm{d}$ & -.14 \\
\hline Expectation to feel very good & $1-5$ & $4.47 \quad(.68)$ & $4.39 \quad(.71)$ & $\mathrm{d}$ & -.11 \\
\hline Expectation to feel more connected & $1-5$ & $4.22 \quad(.87)$ & $4.18 \quad(.94)$ & $\mathrm{d}$ & -.04 \\
\hline Expectation to make contact easy & $1-5$ & $4.16 \quad(.92)$ & $4.05(1.03)$ & $\mathrm{d}$ & -.12 \\
\hline Expectation to understand self better & $1-5$ & $2.81(1.21)$ & $2.73(1.18)$ & $\mathrm{d}$ & -.07 \\
\hline Expectation to have better sex & $1-5$ & $3.07(1.26)$ & $3.21(1.28)$ & $\mathrm{d}$ & .11 \\
\hline Expectation to get a lot of energy & $1-5$ & $4.09 \quad(.91)$ & $4.23 \quad(.93)$ & $\mathrm{d}$ & .15 \\
\hline Expectation to live a more intense life & $1-5$ & $3.07(1.29)$ & $2.91(1.24)$ & $\mathrm{d}$ & -.12 \\
\hline Expectation to have a better life & $1-5$ & $2.62(1.34)$ & $2.54(1.27)$ & $\mathrm{d}$ & -.06 \\
\hline Expectation to damage health & $1-5$ & $3.93(1.09)$ & $4.04 \quad(.98)$ & $\mathrm{d}$ & .10 \\
\hline Expectation to feel bad for a few days & $1-5$ & $3.63(1.24)$ & $3.44(1.25)$ & $\mathrm{d}$ & -.15 \\
\hline Expectation to feel nauseous & $1-5$ & $1.94(1.10)$ & $1.94(1.15)$ & $\mathrm{d}$ & -.00 \\
\hline Expectation to get stiff jaws & $1-5$ & $3.46(1.25)$ & $3.48(1.24)$ & $\mathrm{d}$ & .01 \\
\hline Intention to cease ecstasy use & $1-5$ & $2.03 \quad(.82)$ & $2.26 \quad(.97)$ & $\mathrm{d}$ & $.26^{* *}$ \\
\hline Attitude & $1-5$ & $3.26(.58)$ & $3.44 \quad(.61)$ & $\mathrm{d}$ & $.31^{* * * *}$ \\
\hline Subjective norm & $-2-2$ & $0.51 \quad(.44)$ & $0.64 \quad(.56)$ & $\mathrm{d}$ & $.26^{* *}$ \\
\hline Perceived behavioural control & $1-5$ & $4.17(.91)$ & $3.99(1.02)$ & $\mathrm{d}$ & $-.19^{*}$ \\
\hline Descriptive norm regarding best friend & $1-4$ & $1.59(.85)$ & $1.57(.93)$ & $\mathrm{d}$ & -.01 \\
\hline Descriptive norm regarding friends & $1-5$ & $1.67(.69)$ & $1.70(.78)$ & $\mathrm{d}$ & .05 \\
\hline Moral norm & $1-5$ & $4.31(1.00)$ & $4.31 \quad(.93)$ & $\mathrm{d}$ & .00 \\
\hline Anticipated regret & $1-5$ & $2.36(1.14)$ & $2.15(1.04)$ & $\mathrm{d}$ & $-.19^{*}$ \\
\hline
\end{tabular}

${ }^{*} \mathrm{p}<.05,{ }^{* *} \mathrm{p}<.01,{ }^{* * *} \mathrm{p}<.001$. 
Levene's test for equality of variances indicated that the variance in intention at $t_{2}$ may not be equal for those who cease at $t_{3}$ and those who do not, and although this test was not significant for the first subsample, it may not be reliable given the low number of participants that ceased (5 out of 168 for the first subsample, and 8 out of 165 for the second subsample). Because manual inspection of the standard deviations did imply unequal variances (.69 vs. 1.08 for the first subsample and .87 vs. 1.48 for the second subsample), it may be more appropriate to consult the t-test for unequal variances, which did not achieve significance for either of the two subsamples $(t[4.10]=-2.04$ for the first subsample and $t[7.25]=-2.01$ for the second subsample).

Because the second measure of behaviour (whether participants had used ecstasy at $t_{2} / t_{3}$ or not) had more equal group sizes (at $t_{2}, 132$ out of 168 users had used ecstasy, and at t3, 112 of 165), its analysis is more reliable. A both measurements, the association with intention was weaker, but did achieve significance with the $\mathrm{t}$-test for unequal variances (at $\mathrm{t}_{2}$, Cohen's $\mathrm{d}=-.57, \mathrm{t}[51.24]$ $=2.84, \mathrm{p}<.01$; at $\mathrm{t}$, Cohen's $\mathrm{d}=-.68, \mathrm{t}[90.00]=3.90, \mathrm{p}<.001)$. These results support the strong predictive role of intention to cease ecstasy use for subsequent ecstasy use. The association between intention to use ecstasy, rather than to cease ecstasy use, and subsequent ecstasy cessation (i.e. the first behavioural measurement) is weaker both at $\mathrm{t}_{2}$ (Cohen's $\mathrm{d}=-.95$ ) and $\mathrm{t}_{3}$ (Cohen's $\mathrm{d}=-.82$ ). Intention to cease is thus a better predictor of cessation than intention to use ecstasy. Combined, these analyses make clear that closer inspection of the determinants of intention to cease ecstasy use determinants is warranted.

The correlations between all determinants, and their means and standard deviations, are shown in Table 7.2. In the first subsample, intention is strongly associated to the TPB determinant attitude, moderately to subjective norm, and weakly to descriptive norms regarding friends and moral norm. In the second subsample, intention is strongly associated to attitude, moderately to descriptive norm regarding friends, and weakly to descriptive norm regarding best friend, moral norm, subjective norm, anticipated regret and PBC. To verify these apparent differences between the correlations between these determinants (the determinant configurations) in the two subsamples, the differences between correlations were also calculated. The effect sizes and significance levels from this analysis are shown in Table 7.3. When looking at the TPB determinants, there were significant meaningful differences in the correlations between intention and $\mathrm{PBC}$, intention and both descriptive norm measures, 


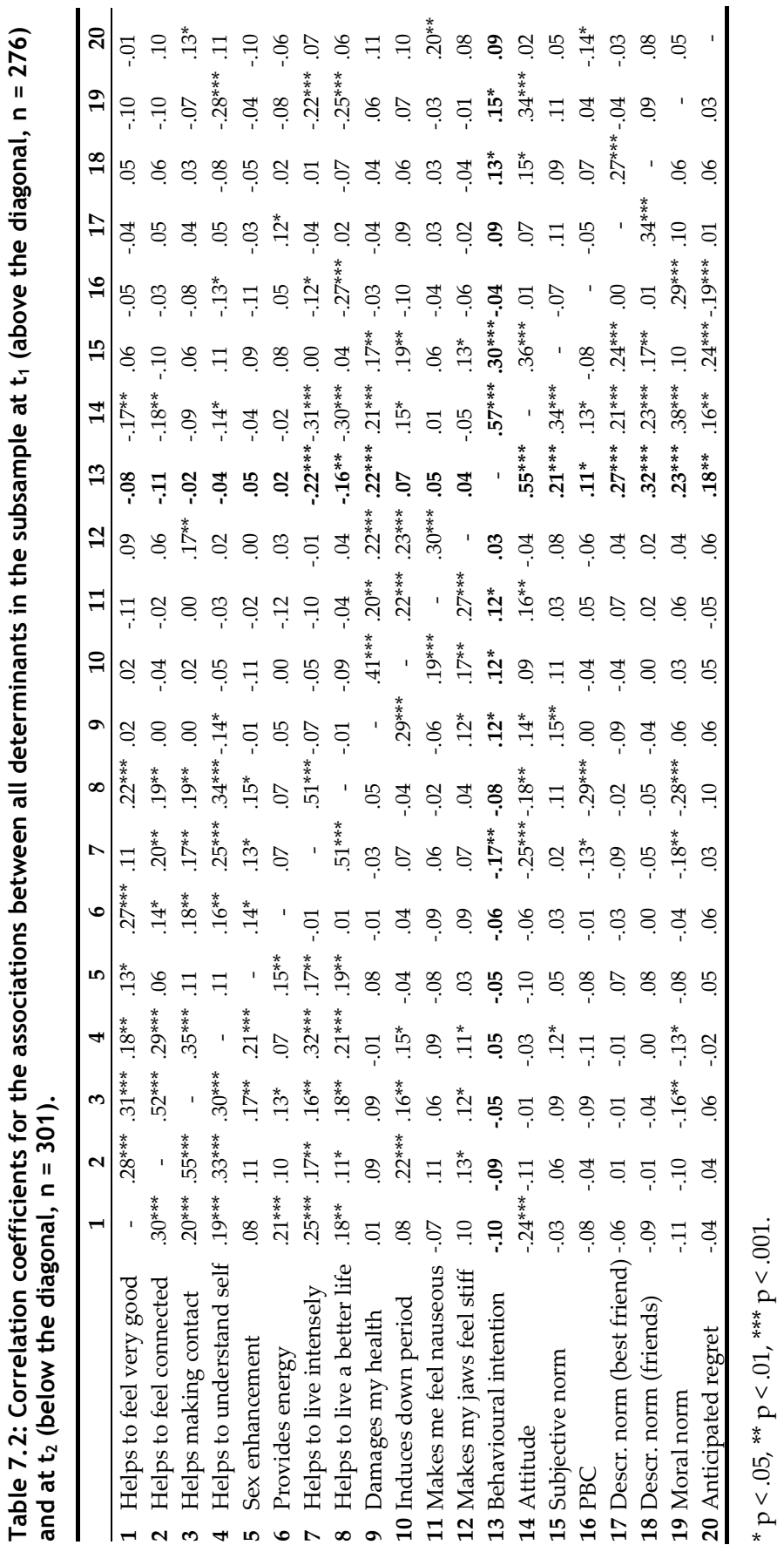




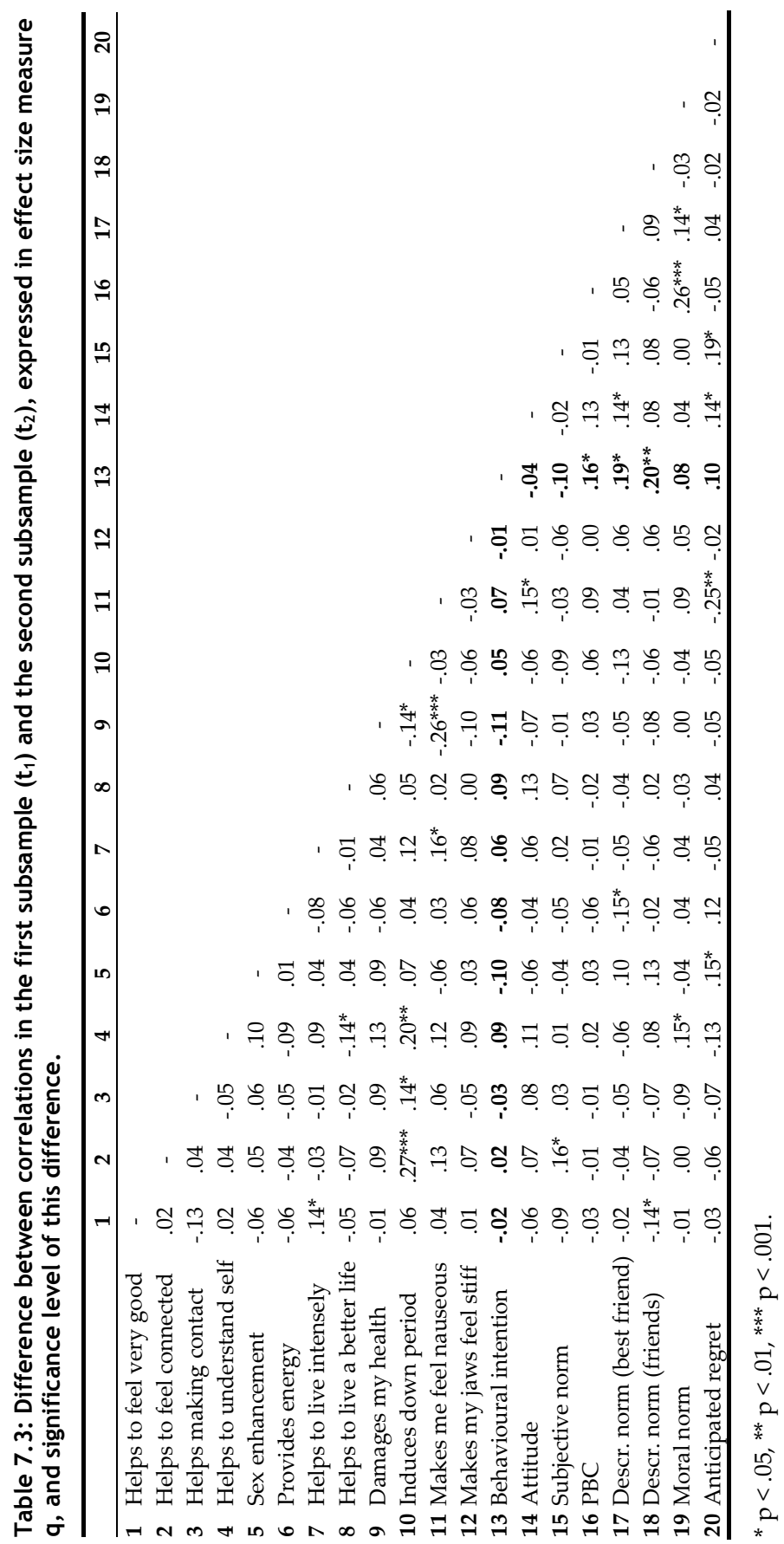


attitude and anticipated regret, subjective norm and descriptive norm regarding friends, subjective norm and anticipated regret, moral norm and PBC, and moral norm and descriptive norm regarding best friend. Although again, these differences are small, they do confirm the dissimilarity of the two samples, which will be considered in the discussion.

Regression weights in regression analyses of intention on the traditional (step 1) and additional (step 2) TPB determinants are shown in Table 7.4. In the first subsample, only attitude achieved significance, with the total model explaining $34 \%$ of the variation in intention (a parsimonious model with only attitude explains $32 \%$ ). In the second subsample, interestingly, also the descriptive normative measures (both regarding best friend and other friends) achieve significance, and here, the total model explains 37\% (a parsimonious model with only the significant predictors explains 35\%).

To assess the degree of overlap between the expectation approach and the TPB approach, we conducted two analyses. Because the expectations were measured at $t_{1}$, these analyses were conducted for the first subsample only. First, to establish the degree to which the expectations explain variation in TPB's attitude, attitude was regressed upon the expectations. The results are shown in Table 7.5. The expectations together explain only $20 \%$ of the variation in TPB's attitude measure. The significantly contributing expectations are the expectation that ecstasy helps to feel very good, to live life more intensely, to

Table 7.4: Regression analyses to predict intention from traditional (step 1) and additional (step 2) TPB determinants in the first $\left(t_{1}\right)$ and second $\left(t_{2}\right)$ subsample.

\begin{tabular}{lcccc}
\hline & \multicolumn{2}{c}{$\begin{array}{c}\text { First subsample } \\
(\mathbf{n}=\mathbf{2 7 5})\end{array}$} & \multicolumn{2}{c}{$\begin{array}{c}\text { Second subsample } \\
(\mathbf{n}=\mathbf{2 9 9})\end{array}$} \\
\hline & $\beta$ step 1 & $\beta$ step 2 & $\beta$ step 1 & $\beta$ step 2 \\
Attitude & $.53^{* * *}$ & $.55^{* * *}$ & $.54^{* * * *}$ & $.47^{* * *}$ \\
Subjective norm & .10 & .10 & .03 & -.03 \\
PBC & .03 & -.02 & .04 & .06 \\
Descriptive norm (best friend) & & .02 & & $.14^{* *}$ \\
Descriptive norm (other friends) & & .02 & & $.18^{* * *}$ \\
Moral norm & & -.06 & & .00 \\
Anticipated regret & & .08 & & .09 \\
$\mathrm{R}^{2}$ & .33 & .34 & .31 & .37 \\
$\mathrm{R}^{2}$ change & .33 & .01 & .31 & .06 \\
F of $\mathrm{R}^{2}$ change & $44.98^{* * *}$ & 1.04 & $43.44^{* * * *}$ & $7.83^{* * *}$ \\
DfF (change) & 3 & 4 & 3 & 4 \\
DfF (error) & 271 & 267 & 295 & 291 \\
\hline
\end{tabular}

${ }^{*} \mathrm{p}<.05,{ }^{* *} \mathrm{p}<.01,{ }^{* * *} \mathrm{p}<.001$. 
Table 7.5: Regression analyses where attitude was predicted from the ecstasy expectations, and regression analyses where the residuals were predicted from the ecstasy expectations (these residuals are the differences between measured intention and intention predicted by a parsimonious model consisting of the significant predictors in step 2 in Table 7.4).

\begin{tabular}{lcc}
\hline & $\beta$ s for attitude $(\mathbf{N}=\mathbf{2 7 6})$ & $\beta$ s for residuals $(\mathbf{N}=\mathbf{2 7 5})$ \\
\hline Help to feel very good & $-.13^{*}$ & -.01 \\
Helps feeling more connected & -.11 & -.03 \\
Helps to make contact easier & .07 & .05 \\
Helps to understand myself better & .02 & .09 \\
Sex enhancement & .03 & .06 \\
Provides energy & .02 & .01 \\
Helps to live life more intensely & $-.20^{* *}$ & -.06 \\
Helps to live a better life & $-.17^{*}$ & .00 \\
Damages my health & $.19^{* *}$ & $.15^{*}$ \\
Makes me feel bad for days after use & .08 & -.08 \\
Makes me feel nauseous & -.06 & .05 \\
Makes my jaws feel stiff & -.08 & .03 \\
$\mathrm{R}^{2}$ & .20 & .04 \\
F of R & $5.41^{* * *}$ & .91 \\
Dff (model) & 12 & 12 \\
DfF (error) & 263 & 262 \\
\hline
\end{tabular}

${ }^{*} \mathrm{p}<.05,{ }^{* *} \mathrm{p}<.01,{ }^{* * *} \mathrm{p}<.001$.

live a better life, and that ecstasy damages ones health. Second, we examined whether these expectations have additional predictive value over the TPB. We did this by saving, for every participant, their predicted intention to use ecstasy as predicted by the parsimonious model described above. The difference between each participants' measured intention and their predicted intention (the residual) represents the part of intention that cannot be explained by the TPB determinants. We then regressed this residual upon the expectations. This shows what percentage of intention, of the part that cannot be explained by the TPB determinants, can be explained by the expectations, providing a measure of their additional value. The advantage of this approach compared to conducting a hierarchical regression analysis is that in this way, only the variation in intention that is not already accounted for by the TPB determinants is considered, whereas in a hierarchical regression analysis, it is possible that expectations' regression coefficients achieve significance by explaining variation that was previously explained by for example attitude. As can be seen in Table 7.5, the model fails to achieve significance, explaining only $4 \%$ of the unexplained part of intention. Because $65 \%$ of the intention to cease using ecstasy remains unexplained (see Table 7.4), this means that the expectations 
together explain an additional 3\% of intention. This 3\% is mainly due to the expectation that ecstasy damages ones health, the only significant predictor in the model.

At $t_{3}$, we asked participants who indicated that they had not used ecstasy because they wanted to cease, why they had not used ecstasy. The results are shown in Table 7.6. The most frequently endorsed reason was transition to another life phase (endorsed by $42 \%$ of the participants), followed by health reasons (37\%), tolerance (29\%), experiencing negative effects $(24 \%)$, decreasing ecstasy quality $(13 \%)$, no longer attending dance events/parties $(11 \%)$, and influence of ecstasy on professional or private life (10\%). Of the 'different reasons' that participants supplied, some don't reflect a clear reason (e.g. "just don't feel like drugs any more"), some seem to fall in the predefined categories (e.g. "I don't like them and the quality has degraded"), and some indicate additional reasons that were not in the list: the unpleasant side effects of ecstasy and preferring different drugs over ecstasy.

Table 7.6: Reasons for ceasing ecstasy use provided by ex-users at $t_{3}(N=38)$.

\begin{tabular}{|c|c|c|c|}
\hline \multirow[b]{2}{*}{ Reason } & \multicolumn{2}{|c|}{ Responses } & \multirow{2}{*}{$\begin{array}{c}\text { Cases } \\
\%\end{array}$} \\
\hline & $\mathbf{N}$ & $\%$ & \\
\hline The quality of ecstasy decreased & 5 & $6 \%$ & $13 \%$ \\
\hline I enjoy ecstasy less, or notice less of its effects & 11 & $13 \%$ & $29 \%$ \\
\hline I no longer attend the locations where I used to use ecstasy (parties/clubs) & 4 & $5 \%$ & $11 \%$ \\
\hline I notice that I feel more down or depressed in daily life & 9 & $11 \%$ & $24 \%$ \\
\hline Because of my mental or physical health & 14 & $17 \%$ & $37 \%$ \\
\hline My ecstasy use started to influence my work/study/private life & 4 & $5 \%$ & $11 \%$ \\
\hline My friends stopped using ecstasy & 1 & $1 \%$ & $3 \%$ \\
\hline My friends make negative critical remarks about my use & 1 & $1 \%$ & $3 \%$ \\
\hline I got into a relationship or married & 8 & $10 \%$ & $21 \%$ \\
\hline I got a (different) job & 1 & $1 \%$ & $3 \%$ \\
\hline I got a child (or several) & 1 & $1 \%$ & $3 \%$ \\
\hline I have gone to another life phase & 16 & $20 \%$ & $42 \%$ \\
\hline Different reasons: & 7 & $9 \%$ & $18 \%$ \\
\hline \multicolumn{4}{|l|}{ Just don't feel like drugs any more } \\
\hline \multicolumn{4}{|l|}{ I don't feel a need } \\
\hline \multicolumn{4}{|l|}{ I think ecstasy is a boring drug } \\
\hline \multicolumn{4}{|l|}{ I don't like them and the quality has degraded } \\
\hline \multicolumn{4}{|l|}{ Unpleasant side effects } \\
\hline \multicolumn{4}{|l|}{ I prefer speed } \\
\hline \multicolumn{4}{|l|}{ Ecstasy started using me } \\
\hline Total & 82 & $100 \%$ & $216 \%$ \\
\hline
\end{tabular}




\section{Discussion}

First, the results will be briefly summarised. Users' intention to cease using ecstasy was highly predictive of subsequent self-reported cessation. When looking at the determinants underlying intention in the first subsample, bivariate analyses show that attitude is strongly related to intention, moderately to subjective norm, and weakly to descriptive norms regarding friends and moral norm. Within the second subsample, attitude is strongly related to intention, and weakly to all normative variables, PBC and anticipated regret. Analyses of the differences between the correlations with intention in the two subsamples show significant meaningful differences for PBC and both descriptive norm measures. Multivariately, in the first subsample, only attitude achieves significance when predicting intention to cease ecstasy use $\left(\mathrm{R}^{2}=.34\right)$, whereas in the more persistent subsample, also both descriptive norm variables achieve significance $\left(\mathrm{R}^{2}=.37\right)$. Subsequent analyses showed that although the expectations explained $20 \%$ of TPB's attitude, together, they could not explain variation in intention that was not already explained by the TPB.

The second subsample had a higher intention to cease, and higher attitude and subjective norm, than the first subsample; perceived behavioural control (PBC) and both descriptive norm measures were associated to intention more strongly; and in multivariate analyses, both descriptive norm measures achieved significance in the second, but not the first, subsample. Although the bivariate differences were small, these differences indicate that the second subsample may not be a random sample. Interestingly, although intention was also related to drop-out at $t_{2}$ in the first subsample, participants who were retained had a lower mean intention at $t_{2}$. Since it is unlikely that all participants' intention to cease decreased over time (the opposite would have been conceivable [83], but a massive decrease in intention to cease is implausible), this means that more users with a high intention dropped out (possibly because users who became ex-users lost interest in the questionnaire). But then, how is it possible that intention in the second subsample is higher?

A simple explanation in line with the evidence is the following. As was recently observed by Marsden and colleagues [83], filling out a questionnaire on their ecstasy use can cause participants to cease their ecstasy use, so we can assume that also in the present sample, the measurement at $t_{1}$ increased participants intention to cease using. This increased intention explains the higher intention in the second subsample $\left(\mathrm{t}_{2}\right)$ compared to the first subsample $\left(t_{1}\right)$. Now, if we further assume that more participants, who ceased using 
ecstasy at $\mathrm{t}_{2}$, dropped out than participants who did not cease using ecstasy, we also explain why the intention to cease is lower among the retained users from the first subsample. Because users' intention to cease increased between $t_{1}$ and $t_{2}$, and the users with the highest intention managed to cease, relatively many of these dropped out. Because these users also had the highest intention to cease at $t_{1}$, the average intention to cease was lower among those in the first subsample that were retained at $t_{2}$ (note that in this first subsample, the intention was measured at $\mathrm{t}_{1}$ ).

Such a scenario would have two consequences. First, reported associations between intention and behaviour are underestimates of these associations' strength in the population. Second, the second subsample represents ecstasy users after their intention has been increased (indeed, less persistent ecstasy users). This means that the determinant configuration in the second sample indicates the determinants that should be targeted by an intervention that is administered after a prior intervention that successfully increases intention. Of course, this explanation would have to be verified by future research, in particular by studies with longitudinal designs [such as the NeXT study, e.g. 138]. In any case, these differences do mean that except in specific cases, the determinant configuration that should inform intervention development is the one mapped in the first subsample.

The current study suffers three limitations. First, the behavioural measure relies on self-reports. Even though these have been shown to be reliable [112; 157], of course, it would have been desirable to eliminate all possibility of measurement error. Second, no belief-based measures were used. Although earlier studies have found direct measures to yield no different results from belief-based measures [58], it would have been interesting to see whether these results would replicate. Third, a number of relevant beliefs and determinants have not been measured. This is partly because results from a recent qualitative review were not yet available. Future research should include more beliefs drawn from qualitative research so as to gain a better understanding of nonusers' intention to try out ecstasy. Fourth, the current sample was recruited purely by letting participants voluntarily participate. It cannot be excluded that certain groups of participants, for example non-users that are strongly inclined to remain non-users and have no interest in ecstasy at all, have not participated. The NeXT study [see for example 110] is an excellent example of a study utilising a design that does not suffer such flaws. 
Despite these limitations, this study does provide interesting results. First, this is the first study to address the behaviour ceasing ecstasy use. And perhaps related to this, it became clear that only one-third of ecstasy users' intention to cease ecstasy use is understood. Although this is promising for the first study examining this behaviour (reviews found mean $R^{2} s$ of .39 [46] and .41 [33]) it is also clear that interventions aiming to promote ecstasy cessation have an urgent need for more research to inform them. As long as it is not clear which determinants are relevant and which beliefs underlie these determinants, developing evidence-based interventions remains problematic. Qualitative studies have suggested that perhaps ecstasy users cease of their own accord in response to changing life circumstances, or when they move to 'the next phase' $[114 ; 147]$, and this is supported by the low proportion of explained variation in intention and by the fact that the reason for cessation, that was most endorsed, was "I have gone to another life phase". This issue definitely requires more research, before health promoters can rely on such 'automatic cessation', but if confirmed, this would radically change the kind of interventions that are called for (i.e. more harm reduction interventions, and less interventions targeting cessation).

Second, the observation that filling out a questionnaire can prompt users to cease their ecstasy use [83] seems to be corroborated. Furthermore, it seems that once users' intention to cease has been increased, descriptive norm and anticipated regret become more important determinants. However, without further research no clear conclusions can be drawn regarding this issue. Third, the current data do support the theoretical assumption that TPB's attitude encompasses the expectations from Social Cognitive Theory. These results also make clear that for ceasing ecstasy use, this attitude measure encompasses many expectations that are as yet unknown, as only one fifth of the variation in attitude is understood. Since it is these specific cognitive measures that can guide intervention development, it seems advisable to direct research attention to mapping these expectations. Such studies should, however, combine these measurements with other traditional and additional TPB determinants. This makes it possible to examine the relative relevance of these determinants, and whether indeed all expectations underlie attitude (and not other, as yet unidentified, determinants).

And finally, this study provides evidence for the importance of TPB's condition of compatibility [see 30]: the association strength between intention and behaviour was strongest when both measures were equally specific (i.e. 
when they both concerned ceasing ecstasy use), and became lower when intention to cease was associated with ecstasy use (rather than cessation), or when intention to use was associated with ecstasy cessation. This makes clear that studies that aim to inform ecstasy cessation interventions should measure intention and determinants of ceasing ecstasy use rather than of using ecstasy. Indeed, when comparing the bivariate associations between determinants and the intention to cease ecstasy use (in the random subsample at $\mathrm{t}_{1}$ ) to the associations found in a meta-analysis of the determinants of using ecstasy [35], it seems that indeed the determinant configuration of ceasing ecstasy use differs from that of using ecstasy.

Attitude is strongly associated to intention both for using and for ceasing, but subjective norm, descriptive norm and PBC are strongly associated to intention to use, whereas subjective norm is moderately associated to intention to cease, PBC not at all, descriptive norm regarding friends weakly and regarding best friend not at all. Moral norm is moderately associated to intention to use ecstasy, but weakly associated to intention to cease ecstasy use, and anticipated regret is weakly associated to intention to use, but not to intention to cease. Because the results from the meta-analysis represent an amalgamation of results from studies that use different measurement methods for the TPB determinants in different populations, and the current study used slightly different measurements again, it cannot be excluded that these measurement differences caused the different association strengths until a study compares samples where the same measurement was used. However, as these apparent differences are in line with the qualitative evidence [114; 147], and are predicted by the TPB [the condition of compatibility; see 30], it seems reasonable to assume that they do reflect real differences. Thus, whereas the strongest predictors of intention to use ecstasy are attitude, subjective norm, descriptive norm, and perceived behavioural control (all strongly associated to intention), the strongest predictors of intention to cease ecstasy are attitude (strongly associated), subjective norm (moderately associated), descriptive norm regarding friends, and moral norm (both weakly associated). This means that interventions aiming to promote ecstasy cessation would do well to target these determinants, rather than descriptive norms regarding best friend and PBC, which are not associated to intention to cease ecstasy use. 


\section{Chapter 8 Behavioural specificity in ecstasy use research: why we should not examine the determinants of using ecstasy}

Ecstasy use is potentially damaging to health [17; 20; 21] yet prevalent [74; 112], and although accordingly, a need for intervention development has been asserted, it has also been observed that evidence to base these interventions on is scarce [35]. If evidence-based interventions are to be developed, more research into the determinants of ecstasy use is necessary. One issue that begs resolution is formed by the potential differences between determinant configurations of the most studied behaviour so far, 'using ecstasy', and the two related behaviours 'trying out ecstasy' and 'ceasing ecstasy use'. Since a recent qualitative review pointed out these potential differences [114], two studies have mapped the determinant configurations of 'trying out ecstasy' [158] and 'ceasing ecstasy use' [159], and indeed conclude that these differ from the determinant configuration of using ecstasy. However, it is possible that the different association strengths that were found are the consequence of different measurement methods. To exclude this possibility, the current paper reports comparisons between determinant configurations of using ecstasy, trying out ecstasy, and ceasing ecstasy use that were mapped using the same measurements.

There are two reasons to assume that the determinants of related but distinct behaviours differ. The first lies in the formulation of the Theory of Planned Behaviour (TPB), the theoretical basis for most ecstasy use research, where Ajzen [30] states the relevance of measuring determinants specifically for the targeted behaviour. Thus, determinants of ceasing ecstasy use and trying out ecstasy should be assessed in relation to these behaviours, and it should not be assumed that the determinants of using ecstasy also predict trying out ecstasy or ceasing ecstasy use. The second reason supports this: a recent qualitative review found different reasons for trying out ecstasy, using ecstasy, 
and ceasing ecstasy use [114]. Such qualitative evidence requires quantitative corroboration to minimise biases involved in introspection, and the quantitative studies described above provided this [158; 159]. However, these studies suffer two limitations. First, different association strengths may be caused by different measurement methods of the TPB variables. Second, the association strengths could not be compared statistically. The current paper resolves these issues by reporting new analyses on data that was previously reported in the two publications on trying out ecstasy and ceasing ecstasy use [158; 159] and one additional publication on the determinants of using ecstasy in a sample of nonusers, a sample of users, and the combined sample [160]. By comparing determinant configurations that were mapped using the same measurements, the current paper can help us understand potential differences between behaviours.

\section{Methods}

The data have been gathered using an online questionnaire [the internet has been argued to be a suitable medium for studying hidden populations such as non-misusing illicit drug users; 149]. It was possible to tailor the questionnaire, enabling data collection for several behaviours simultaneously. Thus, the presently reanalysed data, that was originally reported in three different papers [158-160], was gathered in one large-scale study, where participants were split up into subsamples, and in each subsample, determinants of a specific behaviour were measured. Data are presently reported for four samples: two samples for using, one for trying out, and one for ceasing. Additional details as to the procedure can be found in the original publications. All TPB determinants were measured the same way in all subsamples, with two exceptions. First, in the trying out subsample, intention to use was not measured; rather intention to try out ecstasy was measured (the other determinants were measured for using). Second, descriptive norm was measured differently for all participants. For using ecstasy, ecstasy use of best friend, other friends with whom one attends parties, and other friends was measured; for trying out, whether ones best friend had tried out ecstasy was measured; for ceasing, whether ones best friend had ceased recently, and how many other friends had ceased recently. Additional details as to the measurements can be found in the original publications. Permission to perform 
this investigation was granted by the Ethical Committee Psychology of Maastricht University (the ECP).

As Cohen argued, "the primary product of a research inquiry is one or more measures of effect size" [153, p. 1310]. Therefore, rather than their significance, associations' meaningfulness will guide the discussion of the results. Associations are considered meaningful when they are non-trivial. We distinguish five levels of association strength (effect size): trivial, weak (Cohen's $\mathrm{d}>$.2; Pearson's $\mathrm{r}>$.1; Cramer's V > .1; odds ratio > 1.5), moderate (Cohen's d > .5; Pearson's r > .3; Cramer's V > .3; odds ratio > 2.5), strong (Cohen's d > .8; Pearson's $r>.5$; Cramer's V > .5; odds ratio $>4$ ), and very strong (Cohen's $d>$ 1.3; Pearson's r > .7; Cramer's V > .7; odds ratio > 10) [70; 109; see also 154; 155]. Differences between correlations were tested by converting the correlations to Fisher's Z, after which the effect size $\mathrm{q}$ for the difference between two correlations was calculated, and a $p$ value for this difference was attained by calculating the surface of the standard normal function for Fisher's $\mathrm{Z}$ for the difference, which consists of q divided by its standard error [see 159 for the exact formulas]. The difference between two correlations is considered small when $\mathrm{q}>=.1$; medium when $\mathrm{q}>=.3$; and large when $\mathrm{q}>=.5[70]$.

\section{Results}

The current paper reanalyses the data of 1213 participants. As can be seen from their characteristics, shown in Table 8.1, the samples are almost completely equivalent. The only significant meaningful differences are small differences. Specifically, non-users in the trying out sample (compared to the using sample) are more likely to be female, and users in ceasing sample (compared to the using sample) are slightly older, lower educated, use less alcohol, and more GHB. However, when considering the TPB determinants, there are larger differences. Non-users have a higher attitude, subjective norm, and PBC regarding trying out than ceasing. The determinants of ceasing use have been reversed, except anticipated regret (so higher values for intention indicate lower intentions to cease, higher values for PBC indicate lower PBC to cease, higher values for descriptive norm indicate that less friends ceased, et cetera). Still, however, all determinants of intention have very different means. This makes very clear that regarding their determinants, ceasing ecstasy use is not the opposite of using ecstasy. 
Table 8.1: Participant characteristics (total $\mathrm{N}=1213$ ).

\begin{tabular}{|c|c|c|c|c|c|c|}
\hline \multirow[b]{2}{*}{ Determinant } & \multicolumn{3}{|c|}{ Non-users } & \multicolumn{3}{|c|}{ Ecstasy users } \\
\hline & $\begin{array}{l}\text { Using } \\
(\mathrm{n}=234)\end{array}$ & $\Delta$ & $\begin{array}{c}\text { Trying out } \\
(\mathrm{n}=443)\end{array}$ & $\begin{array}{l}\text { Using } \\
(\mathrm{n}=260)\end{array}$ & $\Delta$ & $\begin{array}{l}\text { Ceasing } \\
(\mathrm{n}=276)\end{array}$ \\
\hline Gender (being female) & $44 \%$ & $t^{* *}$ & $56 \%$ & $39 \%$ & - & $42 \%$ \\
\hline Higher educated & $47 \%$ & - & $52 \%$ & $61 \%$ & $t^{*}$ & $50 \%$ \\
\hline Alcohol use & $85 \%$ & - & $86 \%$ & $90 \%$ & $+^{*}$ & $84 \%$ \\
\hline Tobacco use & $39 \%$ & - & $41 \%$ & $68 \%$ & - & $59 \%$ \\
\hline Cannabis use & $26 \%$ & - & $29 \%$ & $62 \%$ & - & $54 \%$ \\
\hline Speed use & $3 \%$ & - & $2 \%$ & $35 \%$ & - & $36 \%$ \\
\hline Cocaine use & $2 \%$ & - & $3 \%$ & $38 \%$ & - & $36 \%$ \\
\hline GHB use & $1 \%$ & - & $0 \%$ & $12 \%$ & $t^{* * *}$ & $24 \%$ \\
\hline Poppers use & $1 \%$ & - & $1 \%$ & $8 \%$ & - & $7 \%$ \\
\hline Nitruous oxide use & $0 \%$ & - & $2 \%$ & $7 \%$ & - & $8 \%$ \\
\hline Psylocybin use & $2 \%$ & - & $1 \%$ & $6 \%$ & - & $4 \%$ \\
\hline Ketamine use & $0 \%$ & - & $0 \%$ & $4 \%$ & - & $6 \%$ \\
\hline LSD use & $0 \%$ & - & $0 \%$ & $2 \%$ & - & $3 \%$ \\
\hline Visits a big party twice a year & $46 \%$ & - & $47 \%$ & $17 \%$ & - & $15 \%$ \\
\hline - every two to six months & $42 \%$ & & $43 \%$ & $63 \%$ & & $59 \%$ \\
\hline - every month or more & $12 \%$ & & $10 \%$ & $20 \%$ & & $26 \%$ \\
\hline ... club/small party bimonthly & $23 \%$ & - & $24 \%$ & $24 \%$ & - & $26 \%$ \\
\hline - every two to four weeks & $51 \%$ & & $56 \%$ & $55 \%$ & & $55 \%$ \\
\hline - every week or more & $26 \%$ & & $21 \%$ & $21 \%$ & & $20 \%$ \\
\hline Age & $20.30(5.17)$ & - & $20.50(5.10)$ & $23.63(5.71)$ & $+* * 2$ & $25.44(6.86)$ \\
\hline Intention (range: $1-5$ ) & $1.55(.89)$ & - & $1.65(1.01)$ & $3.92(1.00)$ & - & $3.97(0.82)$ \\
\hline Attitude (range: $1-5$ ) & $2.19(.97)$ & $t^{* *}$ & $2.43(1.04)$ & $3.79(.52)$ & $+++^{* * *}$ & * $2.74(0.58)$ \\
\hline Subjective norm (range: $1-5$ ) & $-.87(.64)$ & $t^{* *}$ & $-.72(.60)$ & $-.03(.45)$ & $+++^{* * *}$ & * $-.51(0.44)$ \\
\hline PBC (range: $-2-2$ ) & $3.34(1.33)$ & $++^{* * *}$ & $4.15(.90)$ & $4.72(.51)$ & $+++^{* * *}$ & * $1.83(0.91)$ \\
\hline Descriptive norm (range: $1-5$ ) & $2.32(1.07)$ & - & $2.26(1.37)$ & $3.79(.79)$ & $+++^{* * *}$ & * $4.37(0.62)$ \\
\hline Moral norm (range: $1-5$ ) & $2.27(1.33)$ & - & $2.49(1.37)$ & $4.41(.86)$ & $+++^{* * * *}$ & * $1.69(1.00)$ \\
\hline Anticipated regret (range: $1-5$ ) & $3.17(1.39)$ & - & $2.95(1.39)$ & $1.46(.74)$ & $+++^{* * *}$ & * $2.36(1.14)$ \\
\hline
\end{tabular}

$\Delta=$ effect size and significance of difference: - trivial and/or nonsignificant, + small, ++ medium, +++ large or larger, ${ }^{*} \mathrm{p}<.05,{ }^{* *} \mathrm{p}<.01,{ }^{* * *} \mathrm{p}<.001$.

Because these intention measures have been shown to be very predictive of subsequent behaviour [158-160], we will presently concern ourselves with the determinant configurations of these intention measures (i.e. the association strengths of these determinants with intention). The associations of the TPB determinants with the behavioural intention measures are shown in Table 8.2, including the effect size measures of the difference between these associations. When comparing the determinant configurations of trying out ecstasy and using ecstasy within non-users, only subjective norm and PBC differ, with small effects sizes. When comparing the determinant configurations of using ecstasy and ceasing ecstasy use within users, attitude, PBC, descriptive and moral 
norm, and anticipated regret all differ with small effect sizes. When comparing the determinant configurations of using ecstasy within non-users and users, attitude, subjective norm and anticipated regret differ with medium effect sizes, and PBC, descriptive norm and moral norm with small effects sizes. Clearly, although all determinant configurations are different, the difference between the determinant configurations of trying out ecstasy and using ecstasy is smaller than the difference between the determinant configurations of ceasing ecstasy use and using ecstasy. Most striking is the difference between the determinant configuration of using ecstasy within non-users and the determinant configuration within users.

Interestingly, despite the fact that three different measures for descriptive norm were used in the trying out sample, the ceasing sample, and in the using sample, the correlations between descriptive norm and intention differed most between users and non-users for the behaviour using ecstasy, which was the only comparison where descriptive norm was measured the same within both samples. The difference between the trying out sample and the using sample was trivial and did not even achieve significance, and the difference between the ceasing sample and the using sample is significant but small. This is an indication that all three descriptive norm measures managed to tap the descriptive norm construct satisfactorily similarly. Also, even though the intention measure that was used to assess intention of non-users in the using ecstasy sample was actually their intention to try out ecstasy, which does not adhere to the principle of compatibility between determinants and behaviour as formulated by Ajzen [30], the determinant configurations trying out and using

Table 8.2: Comparisons of determinant configurations for behavioural intentions to use ecstasy, to try out ecstasy, and to cease ecstasy use (total $\mathrm{N}=1213)^{1}$.

\begin{tabular}{|c|c|c|c|c|c|c|c|}
\hline \multirow[b]{2}{*}{ Determinant } & \multicolumn{3}{|c|}{ Non-users } & \multirow[b]{2}{*}{$\begin{array}{l}\Delta \\
\mathrm{q}\end{array}$} & \multicolumn{3}{|c|}{ Ecstasy users } \\
\hline & $\begin{array}{c}\text { Trying out } \\
(\mathrm{n}=443)\end{array}$ & $\begin{array}{l}\Delta \\
\mathrm{q} \\
\end{array}$ & $\begin{array}{c}\text { Using } \\
(\mathrm{n}=234)\end{array}$ & & $\begin{array}{c}\text { Using } \\
(n=260)\end{array}$ & $\begin{array}{l}\Delta \\
\mathrm{q}\end{array}$ & $\begin{array}{l}\text { Ceasing } \\
(n=276)\end{array}$ \\
\hline Attitude & .67 & $.00^{\mathrm{ns}}$ & .67 & -.41 & .39 & $-.24^{* *}$ & .57 \\
\hline Subjective norm & .34 & $.16^{*}$ & .47 & -.34 & $.18^{* *}$ & $-.13^{\mathrm{ns}}$ & .30 \\
\hline PBC & $.15^{* *}$ & $.25^{* *}$ & .38 & $-.15^{*}$ & .25 & .29 & $-.04^{\text {ns }}$ \\
\hline Descriptive norm & .26 & $-.01^{\mathrm{ns}}$ & .24 & $-.26^{* *}$ & $-.01^{\mathrm{ns}}$ & $-.15^{*}$ & $.14^{*}$ \\
\hline Moral norm & .60 & $-.09 \mathrm{~ns}$ & .54 & $-.27^{* *}$ & .33 & $.19^{*}$ & $.15^{*}$ \\
\hline Anticipated regret & -.52 & $-.09 \mathrm{~ns}$ & -.58 & .39 & -.26 & $.18^{*}$ & $-.09 \mathrm{~ns}$ \\
\hline
\end{tabular}

${ }^{1}$ All statistics are significant at $\mathrm{p}<.001$, unless indicated otherwise: ${ }^{*} \mathrm{p}<.05,{ }^{* *} \mathrm{p}<.01$, ns not significant $(\mathrm{p}>.05)$. 
among non-users differed less than the other determinant configurations. This is an indication that although non-users' attitude, subjective norm, and PBC regarding trying out ecstasy are different from their attitude, subjective norm, and $\mathrm{PBC}$ regarding using ecstasy, their intentions to try out ecstasy are similar to their intention to use ecstasy.

\section{Discussion}

The results that are presently reported make very clear that the determinant configurations of trying out ecstasy, using ecstasy, and ceasing ecstasy use differ. In addition, the determinant configurations of using ecstasy differ between non-users and ecstasy users.

This study has two limitations. First, among non-users, instead of intention to use ecstasy, intention to try out ecstasy was measured. Although the results support the argument that for non-users, these intentions are comparable, this should be studied before any conclusions can be drawn. It is after all also clear that non-users' attitude, subjective norm and PBC regarding trying out ecstasy are different from non-users' attitude, subjective norm and PBC regarding using ecstasy. It can not be excluded that the determinant configurations of trying out ecstasy and using ecstasy differ more than is currently apparent, but that this is masked because the wrong intention measure was used. Second, the descriptive norm measure that was used was different for trying out ecstasy, for ceasing ecstasy, and for using ecstasy. Although the results again indicate that this measurement managed to tap the descriptive norm construct adequately for all three behaviours, it is again possible that descriptive norm's association to intention actually differs more strongly between the different behaviours, but that this is masked because different measurements were used.

These admonitions notwithstanding, interesting lessons emerge from these results. The analyses clearly show differences in the determinant configurations of trying out ecstasy, ceasing ecstasy use, and using ecstasy. Interventions aiming to prevent use should target mainly attitude, moral norm, anticipated regret (strongly associated to intention), place less importance on subjective norm (moderately associated), and even less on descriptive norm and PBC (weakly associated). Interventions aiming to promote cessation should target mainly attitude (strongly associated), place lesser importance on subjective norm (moderately associated), and even less on descriptive and 
moral norm (weakly associated). Of course, more research is necessary to corroborate these findings.

Finally, it is very clear that future studies into ecstasy use should be very specific about the behaviour they target. In addition, non-users and ecstasy users should not be considered to have the same determinant structure. It has been suggested that there is merit in distinguishing even more user groups [59], and it will be interesting to see what degree of distinction remains informative. It is likely that these conclusions regarding specificity of behaviour and usergroup can be generalised to other drugs, such as cocaine and GHB, so it would be advisable for future studies into these drugs to acknowledge the need to specificity of behaviour and user-group as well. 



\section{Chapter 9 Determinants of ecstasy testing: informing evidence-based intervention development}

Ecstasy use is prevalent [38; 39] and potentially damaging to health [20;36; 37]. To minimize this damage, harm reduction interventions may prove more beneficial than interventions promoting abstinence [35; 114; 147; 159]. An important harm reduction practice that reduces ecstasy-related harm is ascertaining pill content, as dangers of ecstasy use are exacerbated by the fact that pills sold as 'ecstasy' can contain several substances and doses thereof [133]. In the Netherlands in 2006, less than $90 \%$ of the tested pills was pure (i.e. contained exclusively 3,4-methyldioxymethamphetamine (MDMA), the active component of 'ecstasy'), in doses ranging from a few milligrams to over 200 milligrams, with a mean of 78 milligrams [127]. Using untested pills creates risks by potentially exposing users to unexpected or unwanted drugs or even poison, or to doses that can be considerably higher then what those users are used to.

Despite these risks and variations in content and dose, in 2006 only 3,656 pills were tested [127], whereas most Dutch studies find that two-thirds of a dance event's visitors use ecstasy $[8 ; 13 ; 74 ; 86 ; 112]$, and it is estimated that in the Netherlands, even the large dance events alone already host between seven and eight hundred thousand people yearly [11]. Thus, it appears desirable to increase ecstasy testing, and behaviour change interventions targeting the relevant modifiable determinants may achieve this [2]. However, evidencebased intervention development is precluded by the paucity of quantitative research on determinants of ecstasy testing. The current paper reports the results of two studies addressing this caveat.

Although ecstasy users try to determine pill content and purity with a host of different methods [161], only laboratories can provide certainty as to pill content and dose of MDMA [162]. In addition to this direct benefit, pill testing programs provide a number of indirect benefits, such as providing a channel 
for communication of other harm reduction messages, allowing immediate initiation of warning campaigns in the case of detection of poisonous pills, and enhancing surveillance of drug markets [161; 162]. However, even in those countries where testing agencies exist (e.g. the Netherlands [162] and France [163]), no studies have identified psychosocial correlates of pill testing. A qualitative study by Benschop, Rabes and Korf [162] among ecstasy users showed that $85 \%$ of participating ecstasy users had their pills tested because they wanted to know the pill contents, $60 \%$ because of warnings, $50 \%$ had concerns about health, and $34 \%$ wanted to know if their dealer could be trusted. The most frequently mentioned reasons to not have ecstasy tested were: trust in dealer (57\%), 'haven't come around to it yet' (48\%), no testing facility nearby $(36 \%)$, location testing facility unknown (36\%), worries about anonymity $(26 \%)$, intention to use ecstasy regardless of test results (26\%) and 'it's exciting not to know what effect you'll get' (25\%). These reasons have been supported by another Dutch qualitative study [147]. A number of international studies have addressed pill testing as one of several harm reduction strategies[80; 137]. A recent review [114] summarised the following reasons to get ecstasy tested: avoiding negative side-effects, minimizing the 'come-down' and neurotoxicity, and avoiding a 'bad pill'. However, self-reported reasons need not predict behaviour or intention: the same review reported reasons for using ecstasy that a recent meta-analysis [35] found to be unrelated to intention to use ecstasy. In addition, these studies did not assess association strength with intention or behaviour, and therefore cannot sufficiently guide intervention development. The studies reported in the current paper address this gap.

Planned behaviours such as testing (for the sake of brevity and readability, 'testing ecstasy' or simply 'testing' will be used when the behaviour 'getting ones ecstasy tested at a test-service' is meant; likewise, when 'behaviour' or 'intention' are used without specification, they concern testing) are predicted by determinants postulated in the Theory of Planned Behaviour (TPB; [30; 33; 41; $46 ; 164])$. The TPB posits intention as proximal cognitive determinant of behaviour. Intention, in turn, is predicted by attitude (i.e. evaluation of the likelihood and desirability of that behaviours consequences), subjective norm (i.e. perception of others' approval of the behaviour) and perceived behavioural control (PBC, i.e. perception of control based on perception of skills and external obstacles/facilitators, also known as self-efficacy [30]).

In addition to measuring these traditional TPB variables, three additional social cognitive variables that earlier research found related to ecstasy use were 
measured. Although using ecstasy is a different behaviour then getting ecstasy tested, nonetheless this research is the best available indication as to which determinants may be relevant. Subjective descriptive norm is an extension of the traditional subjective normative construct and addresses the perceived behaviour of social referents (see [142]; for its role in ecstasy use, see [56; 58]). Anticipated regret (or affect) refers to the amount of negative emotions one experiences when prospectively imagining not having performed the target behaviour (see [143; 144]; for its role in ecstasy use, see [59]). Habit has also been found related to ecstasy use (see [60]), and though habit is often not considered something health promotion interventions can change, a recent paper [77] on potential changeability of habit supports explorative inclusion in the current study. Finally, because personality may play an important role in explaining behaviour [165], has been found to be related to ecstasy use [74], and may likewise be relevant for getting ecstasy tested, the Big Five Index was also included [BFI; 166; 167].

Because this was the first study into the determinants of ecstasy testing, little was know about the applicability of the TPB and other theories that posited the measured variables at the time of study design, and related to this, the many measured variables necessitated leaving out other variables.

Therefore, we reserved the possibility to include additional exploratory items at the third measurement, which were generated after and based on the results of the first measurement. Regarding testing, a number of qualitative questions were asked and some additional attitudinal beliefs, willingness to use untested ecstasy, and risk perception were measured. Sensation seeking [168] and impulsiveness [169] were also included, to see whether the independence of these constructs with testing that was found by Benschop et al. [162] would be replicated. For the sake of clarity, these additional exploratory variables measured at the third measurement will be reported as study 2 , whereas the analyses of the TPB variables, measured at the first and second measurements, will be described as study 1 .

\section{Method}

\section{Procedure}

An online questionnaire study was conducted, as the internet has been argued to be a suitable medium when studying hidden populations such as nonmisusing illicit drug users [149]. Participants were recruited by links at several 
dance-related Dutch websites (most participants came from the online community at http://partyflock.nl). The online questionnaire was administered online by a self-chosen virtual interviewer in a Flash interface [150; also see 151]. To activate the proper context for respondents, the interview took place to the background of several party pictures while dance music was playing. Server-side parsing of the content (using PHP and MySQL; see [152]) enabled tailoring of the questionnaire to the respondent (i.e. presentation of every item depended upon previous answers).

This possibility to tailor the questionnaire enabled data collection for several behaviours that are related to ecstasy use. Only results pertaining to testing will be reported here, and therefore only methodological details relevant to these results. At the first measurement $\left(\mathrm{t}_{1}\right)$, participants provided informed consent in a way approved by our university's Psychological Ethics Committee. Then, demographics, drug use, and party behaviour were measured for all participants, after which a subsample of participants answered questions about the intention to get ecstasy tested and the underlying determinants (the other participants answered questions about the determinants of other behaviours).

After three months, participants could access the follow-up measurement $\left(t_{2}\right)$, where their testing behaviour and intention were measured, and for participants with a low intention, the reason why they did not intent to get their ecstasy tested. Five months later (logistical problems delayed this follow-up two months), participants could access the second follow-up measurement ( $\left.t_{3}\right)$, where again behaviour and intention were measured, in addition to impulsiveness and sensation seeking, and number of behavioural willingness and perceived risk measures. Participants were attended to the follow-ups by email, and six weekly reminders were sent out.

\section{Measurements study 1}

At the first measurement ( $\left.\mathrm{t}_{1}\right)$, demographic variables (gender, age, education and urbanity), drug use and party visiting frequency were measured with one item each. Personality was measured using the Big Five Index [166; 167]. These variables will hereafter be referred to as distal variables, as they are assumed to be more cognitively distant from intention and behaviour than the specific social cognitive variables, which will therefore be referred to as proximal variables. Behavioural intention to get ecstasy tested was measured with two items (i.e. 'imagine that in three weeks, you want to use ecstasy at a party, and you already have the pills. Would you get your ecstasy tested?', followed by 'do you think that you would indeed do that?', both with answer options 
absolutely not-absolutely; range 1-5). Attitude was measured with five semantic differentials (i.e. 'I think that testing is/would make me ...', unpleasant-pleasant, bad-good, unwise-wise, not nice-nice, unhappy-happy; range 1-5). Subjective norm was measured by multiplying an item tapping injunctive subjective norm (e.g. 'how would your parents feel if you were to test?', disapprovingapproving; range -2-2, also included an option 'I don't know' with the same value as option 'neutral', i.e. 0) with an item tapping motivation to comply (e.g. 'how important do you find your parents' opinion about whether you test?', very unimportant-very important; range 1-5) for best friend, other friends, and parents, and dividing the product by 5 to get a range of $-2-2$. Perceived behavioural control was measured with two items (i.e. 'does it seem easy to you to test?', 'do you think you would manage to test?', absolutely not-absolutely; range $1-5)$.

Subjective descriptive norm was measured by three items about the behaviour of one's best friend, friends with whom one attended parties, and other friends (e.g. 'do you think your best friend tests?', absolutely notabsolutely; range 1-5) with the request to give an estimate when this was not known. Prototype was measured by one item (i.e. 'I think that testing has a positive image at parties', absolutely not-absolutely; range 1-5). Anticipated regret was measured by three items (i.e. 'imagine that you're at a party, you didn't test, but you want to take a pill. Imagine how you would feel. Would you [regret, worry about, feel guilty about] not having tested?', not at all-very much; range 1-5) and habit was measured by two items (i.e. 'is testing [a habit of yours, something you do automatically]?', absolutely not-absolutely; range $1-5)$.

At the second $\left(t_{2}\right)$ and third $\left(t_{3}\right)$ measurements, intention was measured with the first intention item used at $\mathrm{t}_{1}$. The behaviours of using ecstasy and testing ecstasy were measured with one item each (i.e. 'since the last questionnaire, how often have you [used/tested] ecstasy?'; participants typed in a number). At the second measurement, after intention had been measured, low-intenders were asked to specify the reason for their low intention using a forced-choice format with the options in Table 9.3. Reliabilities of personality and cognitive variables are listed in Table 9.2. An earlier study found that regarding ecstasy use, subjective norm pertaining to parents is generally irrelevant [35]. It seems that this may be because $43 \%$ did not know their parents' position, as opposed to $3 \%$ for best friend and $9 \%$ for other friends. Parental norm was therefore not combined into the subjective norm scale. 


\section{Measurements study 2}

A number of additional variables was explored at the third measurement. The BSSS [168] was administered to assess sensation seeking ( 8 items, $\alpha=.73$ ) and the BIS-11 [169] to assess impulsiveness (30 items, $\alpha=.81$ ). Also, a number of beliefs (see Table 9.5) were measured, generated on the basis of a qualitative study [for details, see 147], and the percentage of the ecstasy estimated to be pure was measured (i.e. unadulterated). Furthermore, exploratory behavioural willingness variables were measured ('imagine that you would want to use ecstasy at a party, but you did not get it tested. Would you be willing to use the ecstasy nonetheless?' and six items consisting of the leading statement 'imagine that you wanted to get your ecstasy tested, but you didn't. Would you be willing to use ecstasy if ...' followed by 'a friend offers it to you', 'the friend tells you that the ecstasy has been tested', 'the friend already used the ecstasy him/herself', and the same three statements for 'a stranger' rather than 'a friend'), as well as willingness to get ecstasy tested at a party ('imagine that you wanted to get your ecstasy tested before a party, but circumstances prevented this. Would you get your ecstasy tested at the party?'). Participants were also asked whether they had ever gotten their ecstasy tested (not just in the past three months), and if not, why not, and whether they knew where they could get ecstasy tested. They had the opportunity of being sent extra information (their response was stored). Finally, perceived risk of using ecstasy, using tested ecstasy, and using untested ecstasy were measured ('if I use [ecstasy, tested ecstasy, untested ecstasy], this is...', completely harmless-very harmful; range 1-5).

\section{Analyses}

As Cohen argued, "the primary product of a research inquiry is one or more measures of effect size" [153, p. 1310]. Especially with large samples, trivial associations can become significant. Therefore, rather than their significance, associations' meaningfulness will guide the discussion of the results.

Associations are considered meaningful when they are non-trivial. We distinguish five levels of association strength (effect size): trivial, weak (Cohen's $\mathrm{d}>.2$; Pearson's $\mathrm{r}>.1$; Cramer's V $>.1$; odds ratio $>1.5$; omega squared $\left(\omega^{2}\right)=$ .01 ), moderate (Cohen's d > .5; Pearson's r > .3; Cramer's V > .3; odds ratio > 2.5; $\omega^{2}=.06$ ), strong (Cohen's d > .8; Pearson's $r>.5$; Cramer's V > .5; odds ratio > 4; $\omega^{2}=.14$ ), and very strong (Cohen's d > 1.3; Pearson's r > .7; Cramer's V > .7; odds ratio > 10) [70; 109; see also 154; 155]. For the significance tests of bivariate associations between one dichotomous and one continuous variable, the t-test 
for unequal variances will be used (in recognition of the issues pointed out by Ruxton [156]).

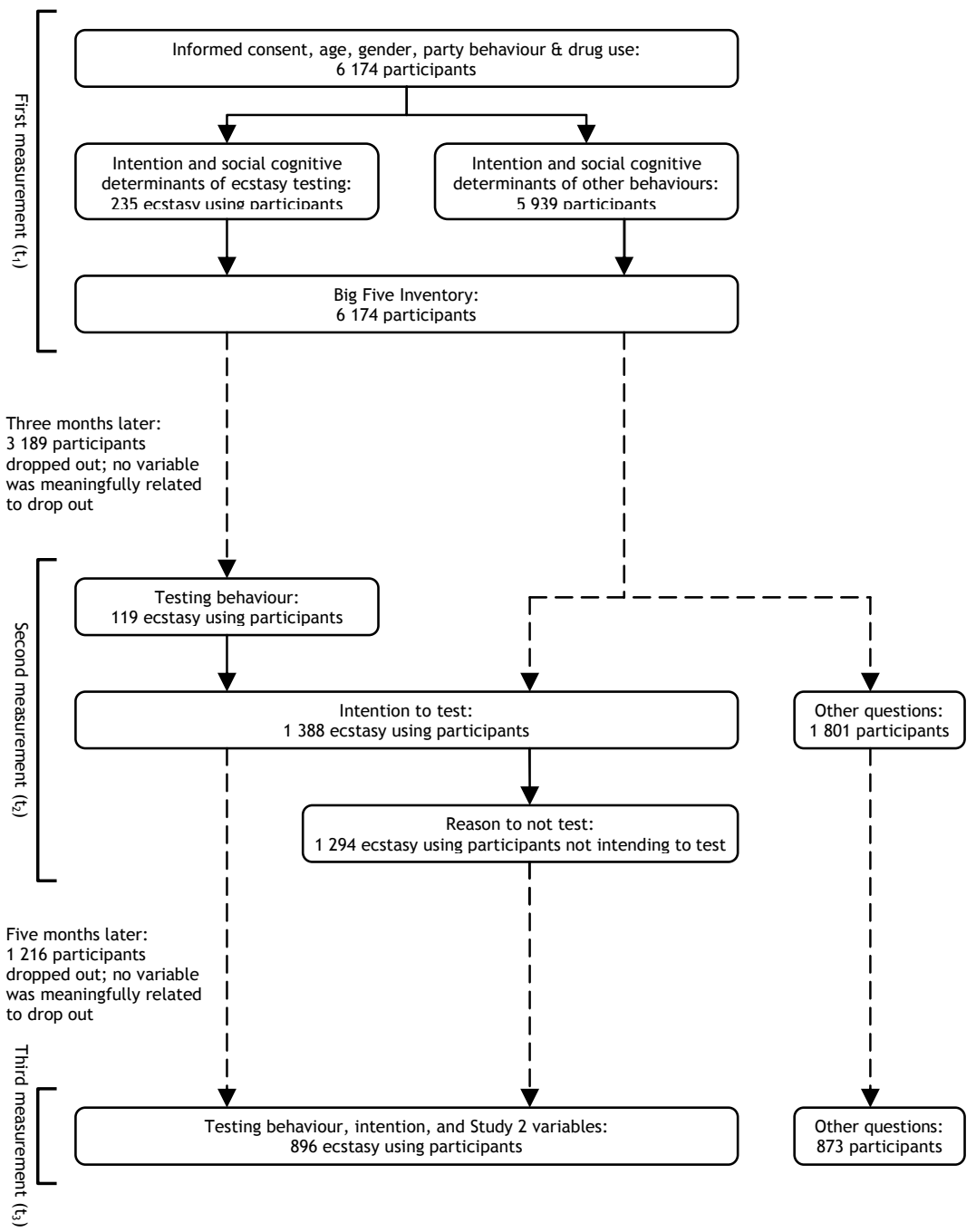

Figure 9.1: Procedure of the questionnaire. 


\section{Results}

\section{Results study 1}

At t1, 6174 non-users, ecstasy users and ex-users participated (see Figure 9.1). Of these, 235 ecstasy users participated in the ecstasy testing subsample. At $t_{2}$, the testing behaviour of 119 of these 235 ecstasy users was measured. In addition, the testing intention of 1388 ecstasy users was measured, and for the 1294 ecstasy users with a low intention the reason for that low intention was assessed. Drop-out analyses for demographic variables, used drugs, and party behaviour showed no variables to be significantly and meaningfully associated to whether participants dropped out at $t_{2}$ or t3 (largest Cohen's $d=-.165$ for age, largest $\mathrm{OR}=.708$ for education).

Of the 119 of the 235 participants in the ecstasy testing subsample for whom behaviour was measured at $\mathrm{t}_{2}, 102(86 \%)$ had used ecstasy in the past three months (and could therefore have tested that ecstasy prior to use). However, 91 participants had not gotten their ecstasy tested (of those who did, 8 participants got their ecstasy tested once, 2 participants twice, and 1 participant three times), a distribution which prohibits multivariate analyses. To be able to assess the association between intention at $t_{1}$ and subsequent behaviour, we compared those who had not tested with those who had. This revealed a very strong significant association between intention and subsequent behaviour $(\mathrm{d}=3.6, \mathrm{p}<.001$, see Table 9.1), which was confirmed by the very strong association between intention at $\mathrm{t}_{2}$ and behaviour at $\mathrm{t}_{3}(2.07 \mathrm{vs} .3 .86 ; \mathrm{d}=$ $1.95, \mathrm{p}<.001, \mathrm{n}=646$ vs. $111 ; 56$ vs. 9 of these participants had provided data about testing at $\mathrm{t}_{1}$ ). A logistic regression with only intention as predictor of behaviour showed that a one-fifth increase in intention made the likelihood of getting ecstasy tested four times as large $\left(\mathrm{OR}\left(\mathrm{t}_{1}-\mathrm{t}_{2}\right)=15.2, \mathrm{p}<.001 ; \mathrm{OR}\left(\mathrm{t}_{2}-\mathrm{t}_{3}\right)=\right.$ $3.9, \mathrm{p}<.001)$. Thus, study of intention's determinants seemed expedient.

The subsample of 235 participants that was examined at $t_{1}$ is described in Table 9.1. Age, club/small party visiting frequency, speed, psilocybin and ketamine use, age of first ecstasy use, ecstasy consumption both per year and at a party, and absolute frequency of use all had significant bivariate associations with intention to test. Age, cannabis use, ecstasy consumption at a party and last use occasion had significant bivariate associations with ecstasy testing. Of the personality variables reported in Table 9.2, only conscientiousness was bivariately associated to intention to test with a weak association. All traditional TPB variables (attitude, subjective norm and PBC) were significantly associated 
Table 9.1: Means (standard deviations provided in parentheses) of distal variables, and their association with intention and behaviour.

\begin{tabular}{|c|c|c|c|c|c|}
\hline \multirow[b]{2}{*}{ Variable name/categories } & \multirow{2}{*}{$\begin{array}{c}\begin{array}{c}\text { Univariate } \\
\text { summary at } t_{1} \\
(n=235)\end{array} \\
\% \text { or mean }\end{array}$} & \multicolumn{2}{|c|}{$\begin{array}{l}\text { Association with } \\
\text { intention at } t_{1} \\
(n=235)\end{array}$} & \multicolumn{2}{|c|}{$\begin{array}{c}\text { Association with } \\
\text { behaviour at } t_{2} \\
(n=102)\end{array}$} \\
\hline & & Unit & Value & Unit & Value \\
\hline Age in years & $25.13(6.41)$ & $\mathrm{r}$ & $.23^{* * *}$ & $\mathrm{~d}$ & $1.13^{*}$ \\
\hline Gender (being female) & $40 \%$ & $\mathrm{~d}$ & .09 & OR & 1.75 \\
\hline Higher educated & $53 \%$ & $\mathrm{~d}$ & .04 & OR & .90 \\
\hline Visits a big party twice a year or less & $20 \%$ & $\omega^{2}$ & .01 & $\mathrm{~V}$ & .18 \\
\hline - every two to six months & $59 \%$ & & & & \\
\hline - every month or more & $21 \%$ & & & & \\
\hline Visits a club/small party bimonthly & $34 \%$ & $\omega^{2}$ & $.04^{* *}$ & $\mathrm{~V}$ & .18 \\
\hline - every two to four weeks & $47 \%$ & & & & \\
\hline - every week or more & $19 \%$ & & & & \\
\hline Alcohol use & $83 \%$ & $d$ & -.20 & OR & .32 \\
\hline Tobacco use & $65 \%$ & $\mathrm{~d}$ & -.24 & OR & .33 \\
\hline Cannabis use & $51 \%$ & $\mathrm{~d}$ & -.14 & OR & $.18^{* 1}$ \\
\hline Speed use & $43 \%$ & $d$ & $-.45^{* * *}$ & OR & .25 \\
\hline Cocaine use & $43 \%$ & $\mathrm{~d}$ & -.22 & OR & .32 \\
\hline GHB use & $18 \%$ & $\mathrm{~d}$ & .01 & OR & 2.03 \\
\hline Poppers use & $9 \%$ & $\mathrm{~d}$ & -.03 & OR & 1.09 \\
\hline Nitruous oxide use & $7 \%$ & $\mathrm{~d}$ & .50 & OR & 1.20 \\
\hline Psylocybin use & $4 \%$ & $d$ & $-.49^{*}$ & OR & .89 \\
\hline Ketamine use & $6 \%$ & $\mathrm{~d}$ & $-.57^{* * *}$ & OR & .88 \\
\hline LSD use & $1 \%$ & $\mathrm{~d}$ & -.68 & OR & .89 \\
\hline Age of first ecstasy use in years & $19.70(5.58)$ & $\mathrm{r}$ & $.24^{* *}$ & $\mathrm{~d}$ & $1.29^{* *}$ \\
\hline Duration of ecstasy use in years & $5.43(4.14)$ & $\mathrm{r}$ & .05 & $\mathrm{~d}$ & -.02 \\
\hline Ecstasy consumption in lifetime ${ }^{2}$ & $258.56(474.19)$ & $\mathrm{r}$ & -.08 & $\mathrm{~d}$ & -.31 \\
\hline Ecstasy consumption per year ${ }^{2}$ & $48.75(71.88)$ & $\mathrm{r}$ & $-.18^{* *}$ & $\mathrm{~d}$ & -.24 \\
\hline Ecstasy consumption at one party ${ }^{2}$ & $2.57(1.50)$ & $\mathrm{r}$ & $-.28^{* *}$ & $\mathrm{~d}$ & $-.45^{*}$ \\
\hline Uses ecstasy three times a year or less & $18 \%$ & $\omega^{2}$ & $.04^{*}$ & $\mathrm{~V}$ & .22 \\
\hline - every two to three months & $25 \%$ & & & & \\
\hline - every one to two months & $24 \%$ & & & & \\
\hline - one to three times a month & $24 \%$ & & & & \\
\hline - once a week or more & $9 \%$ & & & & \\
\hline Uses ecstasy at a party (almost) never & $9 \%$ & $\omega^{2}$ & .01 & $\mathrm{~V}$ & .15 \\
\hline - sometimes & $14 \%$ & & & & \\
\hline - about half the time & $14 \%$ & & & & \\
\hline - often & $17 \%$ & & & & \\
\hline - (almost) always & $52 \%$ & & & & \\
\hline Last use occasion $<2$ weeks ago & $46 \%$ & $\omega^{2}$ & .02 & $\mathrm{~V}$ & $.33^{*}$ \\
\hline - 2-4 weeks ago & $17 \%$ & & & & \\
\hline - 1-2 months ago & $21 \%$ & & & & \\
\hline - 3-6 months ago & $11 \%$ & & & & \\
\hline$->6$ months ago & $5 \%$ & & & & \\
\hline
\end{tabular}

${ }^{1}$ This was the only valid significance test of chi-square (i.e. no cells with an expected count of less than 5), ${ }^{2}$ in pills. 
to intention to test, but only attitude strongly. PBC was associated moderately to intention, and subjective norm weakly. Only attitude and PBC were also associated to testing behaviour, both with strong associations. All additional social cognitive variables were significantly and strongly or very strongly associated to both intention and behaviour.

In addition to these social cognitive determinants, the reasons to not test ecstasy were assessed at $t$. The frequencies are shown in Table 9.3: over half of the participants indicated not to test because they trust their dealer or producer $(52 \%)$, whereas $17 \%$ did not know where to get their ecstasy tested, and $3 \%$ worried about anonymity. Though significance of an analysis of variance of intention indicated an association between reason and intention, it was a weak association $\left(\omega^{2}=.039, \mathrm{p}<.001, \mathrm{n}=1294\right)$.

In order to determine to what degree the measured determinants predict intention, a hierarchical regression analysis was conducted, modelling intention

Table 9.2: Measured personality and social cognitive variables, reliabilities, and associations to intention and behaviour.

Association to Association to

Scale information at $t_{1}$ intention at $t_{1}$ behaviour at $t_{2}$

\begin{tabular}{|c|c|c|c|c|c|}
\hline \multirow[b]{2}{*}{ Variable } & \multicolumn{3}{|c|}{$(n=235)$} & \multirow{2}{*}{$\frac{(n=235)}{r}$} & \multirow{2}{*}{$\frac{(\mathrm{n}=102)}{\mathrm{d}}$} \\
\hline & $\mathbf{k}$ & $\alpha$ & Mean & & \\
\hline \multicolumn{6}{|l|}{ Variables measured at $t_{1}$} \\
\hline \multicolumn{6}{|l|}{ Personality (Big Five Index) } \\
\hline Openness & 10 & .78 & $3.72(.64)$ & .12 & -.32 \\
\hline Conscientiousness & 9 & .80 & $3.26(.65)$ & $.23^{* * *}$ & .69 \\
\hline Extraversion & 8 & .82 & $3.86(.66)$ & .00 & .22 \\
\hline Agreeableness & 9 & .72 & $3.65(.57)$ & .05 & -.02 \\
\hline Neuroticism & 8 & .78 & $2.55(.67)$ & -.08 & -.18 \\
\hline \multicolumn{6}{|l|}{ Specific cognitive (traditional TPB) } \\
\hline Intention & 2 & .92 & $2.25(1.12)$ & - & $3.62^{* * *}$ \\
\hline Attitude & 5 & .75 & $3.85(.72)$ & $.52^{* * *}$ & $1.10^{* * *}$ \\
\hline Subjective norm & 2 & -1 & $.74(.60)$ & $.20^{* *}$ & -.08 \\
\hline Subjective norm (parents) & 1 & -1 & $.24(.77)$ & $.19^{* *}$ & .20 \\
\hline Perceived behavioural control & 2 & .85 & $3.77(1.19)$ & $.31^{* * *}$ & $1.06^{* * *}$ \\
\hline \multicolumn{6}{|l|}{ Specific cognitive (additional) } \\
\hline Subjective norm (descriptive) & 3 & -1 & $2.31(1.09)$ & $.57^{* * *}$ & $1.43^{* *}$ \\
\hline Anticipated regret & 3 & .90 & $1.55(.82)$ & $.64^{* * *}$ & $2.50^{* *}$ \\
\hline Habit & 2 & .95 & $1.70(1.06)$ & $.74^{* * *}$ & $5.13^{* * *}$ \\
\hline
\end{tabular}

${ }^{1}$ Because subjective norm measures are indices rather than scales, the different items are not assumed to measure the same variable. This violation of the assumption of parallelity prohibits calculation of Cronbach's alpha. ${ }^{*} \mathrm{p}<.05,{ }^{* *} \mathrm{p}<.01,{ }^{* * *} \mathrm{p}<.001$. 
Table 9.3: Reasons to not get ecstasy tested $\left(t_{2}, n=1294\right)$.

\begin{tabular}{lccc}
\hline Reason & \% & Mean intention & Standard deviation \\
\hline I don't know where I can get my ecstasy tested & 17 & 2.18 & .80 \\
I always buy from a producer & 4 & 2.24 & .91 \\
My dealer always buys from a producer & 4 & 2.00 & .76 \\
My dealer always gets it tested & 12 & 2.47 & .91 \\
I trust my dealer & 39 & 1.94 & .72 \\
I fear that the testing is not anonymous & 3 & 2.00 & .84 \\
Different reason & 22 & 2.10 & .83 \\
\hline
\end{tabular}

as a function of the variables in Table 9.1 and Table 9.2. In the first block, of the distal variables in Table 9.1 and the personality variables, those that were significantly associated with intention were entered, and in the second block, those that did not achieve significance were removed again. In the third block, the traditional TPB measures were entered, and in the fourth block, the additional social cognitive measures. Habit was entered in the fifth block to provide insight into the predictability of intention without this potentially hardto-modify determinant. The results of the last four blocks are shown in

Table 9.4: Prediction of intention to get ecstasy tested from distal variables (block 2), traditional TPB variables (block 3 ), additional social cognitive variables (block 4), habit (model 5) at $t_{1}, n=235$.

\begin{tabular}{lcccc}
\hline Variable & Block 2 & Block 3 & Block 4 & Block 5 \\
\hline Standardized betas of: & & & & \\
$\quad$ Age of first use & $.19^{* *}$ & $.140^{*}$ & .04 & -.02 \\
Ecstasy consumption at one party & $-.13^{*}$ & -.06 & -.03 & -.03 \\
Absolute frequency of ecstasy use & $-.22^{* * * *}$ & $-.17^{* *}$ & $-.10^{* *}$ & $-.11^{* *}$ \\
Conscientiousness & $.20^{* * *}$ & $.13^{*}$ & $.10^{*}$ & .04 \\
Attitude & & $.36^{* * * *}$ & $.15^{* *}$ & $.10^{*}$ \\
Subjective norm & .05 & .03 & .02 \\
Subjective norm (parents) & & .07 & .04 & .04 \\
Perceived behavioural control & & $.17^{* *}$ & $.12^{* *}$ & .07 \\
Descriptive subjective norm & & & $.23^{* * * *}$ & $.13^{*}$ \\
Anticipated regret & & & $.39^{* * * *}$ & $.20^{* * * *}$ \\
$\quad$ Habit & .17 & .37 & .57 & $.45^{* * * *}$ \\
$\mathrm{R}^{2}$ & -.02 & .21 & .20 & .66 \\
$\mathrm{R}^{2}$ change & .95 & $18.5^{* * * *}$ & $50.7^{* * * *}$ & $59.0^{* * * *}$ \\
F of change & 6 & 4 & 2 & 1 \\
Df (change) & 224 & 226 & 224 & 223 \\
Df (error) & .91 & .74 & .63 & .45 \\
Lowest tolerance & & & &
\end{tabular}

${ }^{*} \mathrm{p}<.05,{ }^{* *} \mathrm{p}<.01,{ }^{* * *} \mathrm{p}<.001,{ }^{* * * *} \mathrm{p}<.0001$. 
Table 9.4. In the final model, $66 \%$ of intention was explained. To check the predictive value of the TPB alone, another regression analysis was run with only the traditional TPB variables, where the TPB explained $30 \%$ of the variance in intention, with attitude and $\mathrm{PBC}$ as significant predictors $\left(\beta_{\text {attitude }}=.45, \beta_{\mathrm{PBC}}=\right.$ $.17)$.

\section{Results study 2}

Because study 1 was the first study into the determinants of getting ecstasy tested, we addressed the relevance of a number of additional variables at the third measurement in an exploratory manner in order to guide future research. A number of beliefs associated to testing ecstasy were measured, and participants' responses and the associations to intention are shown in Table 9.5. Only the beliefs that testing ecstasy helps/is safer and that ecstasy is tested anonymously were associated to intention, and only moderately and weakly, respectively (see Table 9.5).

At t3, 896 ecstasy users provided useful data. Of these, 35\% had ever tested their ecstasy. This group had a significantly higher intention to test than those who had never tested before ( 2.0 vs 3.2; $\mathrm{d}=1.3, \mathrm{p}<.001$ ). Of those who had not tested, $40 \%$ knew where they could get their ecstasy tested, but this knowledge was not associated to intention to test ecstasy. Of those who did not know, 57\% (134 participants) opted to receive an e-mail with a link to this location, but this was again unrelated to intention. On average, the 896 participants estimated that $36 \%$ of the ecstasy out there was pure, which was significantly but weakly associated to intention $(\mathrm{r}=.18, \mathrm{p}<.001)$.

Table 9.5: Beliefs about getting ecstasy tested $\left(t_{3}, n=896\right)$.

\begin{tabular}{lcccccc}
\hline & \multicolumn{3}{c}{$\begin{array}{c}\text { Percentage of } \\
\text { chosen answers }\end{array}$} & $\begin{array}{c}\text { Association } \\
\text { with intention }\end{array}$ \\
\cline { 2 - 6 } Belief & $\mathbf{1}$ & $\mathbf{2}$ & $\mathbf{3}$ & $\mathbf{4}$ & $\mathbf{5}$ & $\mathbf{r}$ \\
\hline Testing helps/is safer & $2 \%$ & $3 \%$ & $15 \%$ & $44 \%$ & $37 \%$ & $.32^{* * * *}$ \\
Most ecstasy out there is pure $^{1}$ & $18 \%$ & $41 \%$ & $32 \%$ & $8 \%$ & $1 \%$ & .06 \\
If ecstasy is not pure, it contains poison $^{1}$ & $11 \%$ & $33 \%$ & $44 \%$ & $11 \%$ & $2 \%$ & -.04 \\
If ecstasy is not pure, it is less good for your health $^{2}$ & $6 \%$ & $16 \%$ & $44 \%$ & $27 \%$ & $8 \%$ & .03 \\
Ecstasy is tested anonymously $^{2}$ & $3 \%$ & $5 \%$ & $21 \%$ & $36 \%$ & $36 \%$ & $.16^{* * *}$ \\
Ecstasy is tested for free $^{2}$ & $9 \%$ & $9 \%$ & $27 \%$ & $27 \%$ & $29 \%$ & .02 \\
\hline
\end{tabular}

1 The numbers 1-5 represent respectively completely disagree, disagree, neither agree nor disagree, agree and completely agree, ${ }^{2}$ The numbers $1-5$ represent respectively absolutely false, probably false, don't know, true and absolutely true, ${ }^{* * *} \mathrm{p}<.001$. 
In a situation where participants ended up at a party with untested ecstasy, $17 \%$ would not test at the party and $66 \%$ would (17\% was unsure). Participants' willingness to use untested ecstasy in seven different situations is shown in Table 9.6. Only $8 \%$ was unwilling, while $81 \%$ was willing, to use untested ecstasy. Willingness increased even further when the ecstasy was offered by a friend, and $91 \%$ was willing to use ecstasy offered by a friend who had already used that same ecstasy. Participants were less eager when ecstasy was offered by a stranger, but still, $22 \%$ was willing to use ecstasy if the stranger claimed to have used it already. Even among participants with a high intention (four or higher on the five-point scale; indicating that they would 'probably' get their ecstasy tested), 46\% was willing to use untested ecstasy, and $82 \%$ was willing to use ecstasy when a friend claimed he/she had already used it (see Table 9.6).

Sensation seeking was not $(\mathrm{r}=-.046, \mathrm{p}=.17, \mathrm{n}=896)$, and impulsiveness weakly $(\mathrm{r}=-.125, \mathrm{p}<.001, \mathrm{n}=896)$ associated to intention. Mean perceived risk of using ecstasy was 3.0 (corresponding to 'quite harmful' on the original 5point scale). The perceived risk of using tested ecstasy was also 3.0, but the perceived risk of using untested ecstasy was 3.3 (smallest paired $t[895]=9.2, p<$ $.001)$, indicating that any given ecstasy pill was considered equally harmless or harmful as tested ecstasy, unless it was explicitly stated that the pill was not tested.

Table 9.6: Percentages of testing-related willingness in different situations $\left(t_{3}\right)$ for all participants and those with a high intention (4 or higher).

\begin{tabular}{|c|c|c|c|c|c|c|}
\hline \multirow[b]{2}{*}{ Willingness to use untested ecstasy at a party if... } & \multicolumn{3}{|c|}{$\begin{array}{l}\text { All participants } \\
\qquad(\mathrm{n}=896)\end{array}$} & \multicolumn{3}{|c|}{$\begin{array}{l}\text { High intention subset } \\
\qquad(\mathrm{n}=159)\end{array}$} \\
\hline & $\mathrm{No}^{1}$ & Maybe & Yes $^{2}$ & $\mathrm{No}^{1}$ & Maybe & Yes $^{2}$ \\
\hline you brought it yourself & $8 \%$ & $11 \%$ & $81 \%$ & $26 \%$ & $28 \%$ & $46 \%$ \\
\hline a friend offers it to you & $7 \%$ & $10 \%$ & $83 \%$ & $18 \%$ & $18 \%$ & $64 \%$ \\
\hline a friend offers it and claims that it has been tested & $4 \%$ & $8 \%$ & $88 \%$ & $4 \%$ & $11 \%$ & $85 \%$ \\
\hline a friend offers it and has used it him/herself & $3 \%$ & $6 \%$ & $91 \%$ & $5 \%$ & $13 \%$ & $82 \%$ \\
\hline a stranger offers it to you & $69 \%$ & $20 \%$ & $11 \%$ & $84 \%$ & $11 \%$ & $5 \%$ \\
\hline $\begin{array}{l}\text { a stranger offers it and claims that it has been } \\
\text { tested }\end{array}$ & $68 \%$ & $20 \%$ & $12 \%$ & $82 \%$ & $11 \%$ & $7 \%$ \\
\hline a stranger offers it and has used it him/herself & $56 \%$ & $22 \%$ & $22 \%$ & $72 \%$ & $14 \%$ & $14 \%$ \\
\hline
\end{tabular}

${ }^{1}$ Aggregate of categories 'absolutely not' and 'probably not', ${ }^{2}$ Aggregate of categories 'probably' and 'absolutely'. 


\section{Discussion}

Study 1 examined the Theory of Planned Behaviour (TPB) in relation to getting ecstasy tested at a test-service, and explored the role of some additional variables in a longitudinal online survey. Whether participants got their ecstasy tested was strongly predicted by prior intention to get ecstasy tested, with a one-fifth increase in intention corresponding to a four times higher likelihood of testing. Intention, in turn, was bivariately associated to a number of distal and proximal variables. Multivariate analyses showed the strongest predictors to be the traditional TPB variables attitude and perceived behavioural control (PBC), and additionally descriptive norm, anticipated regret, and habit. Exploration at the second measurement revealed that most low-intending participants did not test because they trusted their dealer, supporting the findings by Benschop et al. [162].

Further investigation in study 2 at the third measurement showed that the traits sensation seeking and impulsiveness were found to have trivial or weak associations with intention to test, also supporting earlier research [162]. Further, the beliefs that testing helps/is safer and that ecstasy is tested anonymously were found related to intention. For those who had never tested, knowledge about where to test was not associated to intention, nor was willingness to receive information by e-mail, indicating that informing people of the location and protocol of testing facilities should not be expected to suffice to increase testing. Participants estimated about one third of the ecstasy to be pure, and accordingly, almost two thirds of the participants disagreed with the statement that most ecstasy is pure. Additionally, less than half disagreed with the statement that impure ecstasy contained poison. Thus, testing would clearly seem the sensible thing to do for most participants, but these variables were only trivially or weakly related to intention, and although almost two-thirds of the participants were willing to test ecstasy at a party if possible, over fourfifths were also willing to use untested ecstasy, even more when this was offered by a friend. One-fifth was even willing to use ecstasy offered by a stranger, though these percentages seemed lower among high-intenders. Risk perception measures indicated that when it was not specified whether ecstasy was tested, it was considered equally harmful as tested ecstasy, whereas untested ecstasy was considered more harmful.

So, in addition to providing information about testing facilities, which cognitions should an intervention target? Those who tested ecstasy indicated this to be habitual, and interventions aiming to create a habit of testing should 
prompt creation of implementation intentions and/or utilise environmental cues (see [77], [170] and chapter 4 of Bartholomew et al. [2] for details). However, creation of implementation intentions presupposes a positive intention, so it seems wise to target those variables predicting intention in a model without habit (anticipated regret, descriptive norm, attitude and PBC). Inducing anticipated regret seems advisable (see chapter 4 of [2]). Changing descriptive norm is somewhat challenging given the low percentage of ecstasy users that gets its ecstasy tested, but perhaps this can be addressed by emphasising that almost everybody is willing to test their ecstasy (see Table 9.6). Turning to attitude, analysis of potential underlying beliefs measured at t3 suggest that emphasizing that testing facilities work anonymously (if true in the country of intervention) and that they provide a precise content description of tested pills may serve to increase positive expectancies and thereby attitude. PBC should also be addressed, for example by clearly explaining the procedure, possibly even using guided practice [2], for instance, when an interactive medium (e.g. the internet) is available for the intervention.

The high willingness to use untested pills, in combination with the low estimates of the proportion of pills that was unadulterated, and the number of people who indicated that they 'trust their dealer', indicate that personal susceptibility regarding obtaining adulterated pills seems very low. Methods for increasing personal susceptibility include prompting re-evaluation or presenting scenarios (see [2]), but attempts at increasing personal susceptibility should be combined with increasing PBC to prevent backfiring [see 71; 72; 134]. Finally, interventions should carefully avoid addressing the percentage of adulterated pills, as most people actually overestimate this (as noted in the introduction, over $80 \%$ of the pills is pure). 



\section{Chapter 10 Discussion}

This thesis reports the results of studies into the determinants of ecstasy use and harm reduction strategies. In this discussion, the determinant configurations identified in this thesis will be summarized. In addition, limitations of the studies and the implications of the results for future research will be discussed. First, however, the results reported in each chapter will be summarised and the logic behind each consecutive study will be addressed.

\section{Overview}

Chapter 1 illustrated how ecstasy has become one of the most prevalent party drugs, which in combination with its potential harmfulness and the inefficacy of legislative measures that is evidenced by its prevalence, justifies development of health promotion interventions aiming to regulate its use. Then, the results were provided of a needs assessment that clarified the specific behaviours to be addressed in such interventions. The following behaviours were identified: trying out ecstasy; ceasing ecstasy use; refusing offered ecstasy; not using more than once every four to six weeks; not using more than $1.5 \mathrm{mg}$ MDMA per $1 \mathrm{~kg}$ of bodyweight; getting ecstasy pills tested at a testing facility before use; sleeping at least eight hours in the three nights before use; drinking two litres of water on each of the three days before use; drinking half a litre of water hourly during use; chilling out for at least 20 minutes every two hours during use; and not combining ecstasy with alcohol, cocaine, speed or GHB. Identification of the determinant configurations of each of these behaviours is prerequisite to the development of an evidence-based intervention addressing any of these behaviours. 


\section{Synthesising the literature}

To synthesise the state of the art regarding the determinant configurations of the these behaviours identified in the needs assessment, a meta-analysis was conducted [35], and its results are reported in chapter 2. Although this metaanalysis' database query was deliberately designed to include publications about all behaviours related to ecstasy use, only publications addressing the behaviour 'using ecstasy' were found. Through quantitative synthesis of these studies, the determinant configuration of 'using ecstasy' emerged. The most relevant determinants were attitude (specifically positive outcomes regarding mood control and social facilitation, and negative outcomes regarding escalating use and physical and mental side effects); subjective and descriptive norms regarding one's friends, partner and peers; perceived control regarding obtaining ecstasy and control in relation to being with friends who use, going out dancing, being offered ecstasy and ecstasy being available; habit; moral norm; and anticipated regret. This determinant configuration provides an evidence base for interventions addressing the behaviour "using ecstasy". However, it cannot guide interventions that target any of the behaviours that were identified in the needs assessment. Although it could be argued that the behaviour 'using ecstasy' is a generic behavioural category that encompasses specific behaviours (e.g. trying out ecstasy, ceasing ecstasy use, and using less frequently), determinant configurations of related but different behaviours may differ $[30 ; 32 ; 84]$. This meta-analysis therefore suggests that the literature lacks a reliable evidence base for interventions addressing any of the behaviours suggested by the needs assessment.

Because of its quantitative nature, this meta-analysis employed very severe inclusion criteria. These inclusion criteria may have caused exclusion of studies that contain valuable non-quantitative information about potential determinants of a behaviour. To address this possibility, a qualitative review was conducted that summarised all studies into the reasons of ecstasy use and related behaviours that were excluded by the meta-analysis. The results were reported in chapter 3 . This review indicated that there are different reasons for starting ecstasy use, ceasing ecstasy use, using ecstasy, and other related behaviours. This suggests that the determinant configurations of starting or ceasing ecstasy use do differ from that of using ecstasy. Furthermore, for those reasons that were reported both in the qualitative review and in the metaanalysis, results sometimes diverged: although most did, not all reasons that were reported frequently in the review corresponded to beliefs that were 
meaningfully associated to intention of behaviour in the meta-analysis (i.e. Cohen's d <.2 [109]).

Regarding the current aim of developing an intervention to minimise ecstasy-related harm, two lessons emerge from the meta-analysis and the review. First, only the determinant configuration of the behaviour 'using ecstasy' has been studied quantitatively. Second, this determinant configuration need not be predictive of the determinant configurations of other behaviours. Because the literature provides no evidence base regarding the determinant configurations of the behaviours specified by the needs assessment, new research is required to map these determinant configurations and thereby enable evidence-based intervention development.

\section{The situation in the Netherlands}

Of the 32 studies into determinants or reasons of ecstasy use published so far, only two had been conducted in the Netherlands. Both Dutch studies only addressed outcome expectancies. Almost all other studies had been conducted in the United States (US), the United Kingdom (UK), and Australia, and these results may not generalise to the Netherlands for two reasons. First, the Netherlands have traditionally had a more liberal drug policy than other countries, especially compared to the US [120-123]. This less repressive policy (e.g. people who get arrested for ecstasy possession are not prosecuted unless the amount of ecstasy implies dealing) allowed harm reduction initiatives to flourish [123]. In this environment, drug use patterns may well differ from those in other countries, particularly with regards to the application of harm reduction strategies (HRSs). Second, the palette of dance drugs in the Netherlands is different from that in other countries. Methamphetamine use, for example, while prevalent in Australia [125] and having been described as an 'epidemic' in the US [126], is virtually nonexistent in the Netherlands [127; 128]. LSD use shows a similar but less pronounced pattern [38; 112]. As recreational drugs have been shown to be each others substitutes [129], these differences in drug prevalences may well impact ecstasy use patterns. Because of this questionable generalisability, it is not known whether new research in the Netherlands can use the results from the previous studies synthesised in chapters 2 and 3 as a starting point. Thus, although mapping determinant configurations requires quantitative research (qualitative data precludes assessment of the relative association strengths of determinants with intention or behaviour), it nonetheless seemed expedient to first conduct a qualitative 
study to assess whether ecstasy use patterns in the Netherlands are similar to those in the US, UK and Australia.

There is another reason why a qualitative study seemed expedient. In chapter 3 , one of the most frequently reported reasons for cessation is a loss of interest, change in life circumstances, or interference with 'normal life'. This implied that at least a number of ecstasy users cease ecstasy use automatically. In addition, the most relevant determinants of 'using ecstasy' identified in chapter 2 appear to comprise mostly beliefs that seem hard to influence. If the determinant configuration of 'using ecstasy' does turn out to be similar to that of 'ceasing ecstasy', this might imply that it is also hard to induce cessation. Finally, the only published intervention so far aimed to reduce ecstasy use, but found the intervention to be no more successful than the control condition [83]. Together, these three observations suggest that for most users, cessation is a consequence of loss of interest or changing life circumstances. If this would be confirmed for the Netherlands, an intervention aiming to minimise ecstasyrelated harm should definitely focus on promotion of harm reduction strategies (HRSs) rather than on promoting cessation.

A qualitative interview study was conducted among 32 Dutch dance scene participants, and the results are reported in chapter 4 . This study showed that ecstasy use patterns in the Netherlands indeed appeared similar to those in the US, UK and Australia. In addition, it revealed that cessation of ecstasy use appeared to occur mostly automatically when users moved to what they themselves described as 'the next phase'. The first finding meant that the determinants constituting the determinant configuration of 'using ecstasy' may provide a useful starting point for quantitative studies mapping the determinant configurations of the behaviours suggested by the needs assessment. The second finding implied that it seems unwise to develop interventions that aim to induce ecstasy use cessation. Large-scale quantitative verification is needed to further inform a decision as substantial as whether or not to target cessation. All in all, the three studies reported in chapters 2, 3 and 4 summarised all research into the determinants of and reasons for ecstasy use and related behaviours so far. They established that none of the behaviours suggested by the needs assessment has been studied; indicated that determinant configurations of related but different behaviours may differ. They also indicated that the results, although mainly obtained in the US, UK and Australia, appear to generalise to the Netherlands. Finally, they indicated that cessation likely occurs automatically for most users, without the need (or 
possibility) for an intervention. These results served as the basis for a largescale quantitative study to map the determinant configurations of the behaviours suggested by the needs assessment.

\section{Party Panel}

To map the determinant configurations of each of the 14 behaviours suggested in the needs assessment (see Table 1.1), an online survey was conducted. To enable comparison of the determinant configurations of these behaviours with that of 'using ecstasy', this behaviour was also included. The online survey was powered by a flexible content-management system, the information architecture of which is illustrated in Appendix 10.i. This particular combination of technologies enabled the combination of two important aspects of the survey. On the one hand, the survey could be tailored in great detail. On the other hand, in contrast to most HTML-based tailored survey, the entire survey was presented in a Flash interface. This enabled survey administration by a self-chosen animated interviewer (participants could choose from two male and two female interviewers) in a context that consisted of pictures of dance events, while dance music played. This contextual resemblance of situations to which most questions in the survey pertained is relevant to optimise validity of the answers. In addition, the use of a self-chosen virtual agent was thought to increase commitment. Finally, by making the questionnaire more pleasant, we hoped to minimize attrition. In communication with the participants, the survey was called 'Party Panel'.

The tailoring functionality made it possible to measure some variables for all participants and some variables only for participants who satisfied a specified criterion (e.g. present different questions to ecstasy users, non-users and ex-users). This functionality was required because it would take hours to measure all potentially relevant determinants for all 15 behaviours. Tailoring enabled streaming participants into 1 of 15 cells, each of which corresponded to a behaviour. Only non-users were asked questions about 'trying out ecstasy', and no non-users were asked questions about 'ceasing ecstasy use', 'moderating use frequency', 'moderating use intensity' and combining ecstasy with alcohol, speed, coke and GHB. Ex-users were only asked questions about 'using ecstasy', 'ceasing ecstasy use' and 'refusing offered ecstasy'. With around 7000 participants, this resulted in 25 subsamples of on average 280 participants each. This first measurement $\left(\mathrm{t}_{1}\right)$ was followed by follow-ups after three $\left(\mathrm{t}_{2}\right)$ and eight $\left(\mathrm{t}_{3}\right)$ months. In the first follow-up questionnaire $\left(\mathrm{t}_{2}\right)$, participants were again streamed into different cells, to measure determinants of a different behaviour. 
However, because of anticipated drop-out, proportionally more participants were streamed into the cells of 'trying out ecstasy', 'ceasing ecstasy use', and 'using ecstasy'. For non-users and ex-users, therefore, only one subsample attained acceptable size: 'trying out ecstasy' and 'ceasing ecstasy use', respectively. For users, only the subsamples of 'ceasing ecstasy use', 'moderating use frequency', and combining with coke, speed and alcohol attained acceptable sizes. Thus, at the first follow-up, seven additional subsamples were generated. In the current thesis, the results from five of the total of 32 subsamples were reported.

In chapter 5 , the determinant configurations of using ecstasy in a sample of non-users, a sample of ecstasy users, and the combined sample are reported. In chapter 6, the determinant configuration of trying out ecstasy in a sample of non-users is reported. In chapter 7, the determinant configurations of ceasing ecstasy use in a random sample of users and a sample of less persistent users are reported. In chapter 8 , the results are reported of a study that compared these determinant configurations. These results indicated that the determinant configurations of all three behaviours were different. Although the determinant configurations of trying out ecstasy and using ecstasy were quite similar among non-users, the determinant configurations of using ecstasy and ceasing ecstasy use were different among ecstasy users. In addition, the determinant configurations of using ecstasy were different for non-users than for users.

This suggests that whereas results from studies into the determinants of using ecstasy may provide some evidence as to determinants are relevant (but only when samples comprised exclusively non-users), results from studies into the determinants of using ecstasy cannot be considered as evidence base for interventions targeting cessation (not even when samples comprised exclusively users). When a determinant distinguished between non-users and ecstasy users, it did not always predict intention to use in any of the two groups. This suggests that studies comparing non-users and users cannot inform intervention development regarding trying out ecstasy or ceasing ecstasy use.

Regarding ceasing ecstasy use, the determinants explained at most $34 \%$ of the variation in intentions. Combined with the results of the qualitative study, this indicates that relevant determinants have not been measured. This is consistent with the possibility that users cease ecstasy use due to factors such as a loss of interest or a change in life circumstances. Further evidence for this is provided in chapter 7 , where ex-users were asked by they had ceased using 
ecstasy: the most endorsed reason was "I have gone to another life phase" (endorsed by 16 ex-users, $42 \%$ of the cases). The results of the syntheses of the literature, the interview study, and these quantitative results all suggest that most ecstasy users cease their ecstasy use after a number of months or years without the need for an intervention. This implies that evidence-based interventions aiming to minimise ecstasy-related damage may be more efficient if they aim to promote harm reduction strategies (HRSs) rather than cessation. Therefore, there is a need to map the determinant configurations of harm reduction strategies to enable evidence-based intervention development.

Although the literature offers no comparison of HRSs in terms of their beneficial health effects, of those listed in the needs assessment reported in chapter 1, getting ecstasy tested at a testing facility is regarded as the most important one by experts from the field (see Appendix 10.i). Testing facilities constitute the only means of ascertaining the exact content of an ecstasy pill. Doing so can prevent two potential risks. First, pills sold as ecstasy can contain other drugs or even poison. This is very dangerous, because when a pill contains, for example, $100 \mathrm{mg}$ of methamphetamine, this is likely to result in severe neurotoxicity or even death [16]. Of course, the damage that unidentified poisoned pills could cause speaks for itself. Second, even if a pill contains solely MDMA, dosage may vary between a few to over 200 milligrams. This is dangerous because users who normally have pills of low dosage (e.g. $30 \mathrm{mg}$ ) may habitually take three or four pills simultaneously to ingest the desired dosage of MDMA. If they buy new pills from a more potent batch (e.g. $120 \mathrm{mg}$ ) without being aware of the increased potency, they are likely to ingest three or four pills as usual, thereby exposing themselves to an exceptionally high dosage of MDMA.

Because it seems that interventions should aim at promoting harm reduction strategies, and because getting ecstasy tested at a testing facility seems a very important harm reduction strategy, it seems very important to map the determinant configuration of getting ecstasy tested. In chapter 9, data allowing the mapping of this determinant configuration is reported, and additionally, results of a small-scale exploratory study. The determinant configuration itself is reported in the next section. Regarding the exploratory measures, it appeared that most participants estimated the proportion of adulterated pills to be higher than this was in reality. In addition, a substantial proportion of participants expected adulterated pills to contain poison. Yet, many participants were willing to consume untested pills, particularly when 
friends claimed to have used pills from the same batch already. Perceived susceptibility of obtaining adulterated pills thus seemed very low.

\section{Determinants of ecstasy use and harm reduction strategies}

The studies reported in this thesis mapped the determinant configurations of trying out ecstasy, ceasing ecstasy use, and getting ecstasy tested at a testing facility. For all three behaviours, prior intention to perform that behaviour strongly predicted whether the behaviour was indeed performed. This confirmed the value of mapping these determinant configurations, which are shown in Table 10.1. Regarding trying out ecstasy, attitude, moral norm and anticipated regret have strong associations with intention to try out ecstasy, and subjective norm and the expectation that ecstasy makes one feel very good have moderate associations with intention. Regarding ceasing ecstasy use, only attitude is associated strongly to intention to cease, and subjective norm and the expectation that ecstasy damages one's health have moderate associations with intention. Regarding getting ecstasy tested, habit iss associated to intention very strongly. Attitude, descriptive norm, and anticipated regret have strong associations, and perceived behavioural control has a moderate association.

Although these association strengths can guide intervention development, they should not be considered a sufficient evidence base. This information should be complemented with information about the determinants' changeability. The resulting selection of determinants can then guide intervention development. In Intervention Mapping, this resulting selection of determinants should be crossed with the so-called performance objectives that underlie the target behaviours. A performance objective is defined as a subbehaviour at the lowest meaningful level of specification (e.g. for testing ecstasy, a performance objective could be 'calling the testing facility to make an appointment to deliver a pill'). The resulting matrix is the matrix of change objectives: from the combination of each performance objective with each determinant emerge concrete intervention targets called change objectives. An example of such a change objective for the performance objective 'calling the testing facility to make an appointment to deliver a pill' and the determinant 'perceived behavioural control' would be to 'express confidence in one's ability to call to make an appointment to get ecstasy tested'.

These concrete, explicit change objectives can then be targeted by an intervention. Of course, this knowledge of what to change does not help one in 
Table 10.1: Determinant configurations of trying out ecstasy, ceasing ecstasy use, and getting ecstasy tested.

\begin{tabular}{|c|c|c|c|}
\hline \multirow[b]{2}{*}{ Determinant } & \multicolumn{3}{|c|}{ Relevance* } \\
\hline & Trying out ecstasy & Ceasing ecstasy use & $\begin{array}{c}\text { Getting ecstasy } \\
\text { tested }\end{array}$ \\
\hline \multicolumn{4}{|l|}{ Traditional TPB determinants } \\
\hline Attitude & +++ & +++ & +++ \\
\hline Subjective norm & ++ & ++ & + \\
\hline Perceived behavioural control & + & o & ++ \\
\hline \multicolumn{4}{|l|}{ Additional TPB determinants } \\
\hline Descriptive norm (aggregate) & & & +++ \\
\hline Descriptive norm (best friend) & + & o & \\
\hline Descriptive norm (friends) & & + & \\
\hline Moral norm & +++ & + & \\
\hline Anticipated regret & --- & o & +++ \\
\hline Habit & & & ++++ \\
\hline \multicolumn{4}{|l|}{ Positive expectations } \\
\hline feel very good & ++ & o & \\
\hline feel more connected & + & - & \\
\hline make contact more easily & + & o & \\
\hline understand oneself better & + & o & \\
\hline have better sex & + & o & \\
\hline get a lot of energy & + & o & \\
\hline live a more intense life & + & - & \\
\hline have a better life & + & - & \\
\hline \multicolumn{4}{|l|}{ Negative expectations } \\
\hline damage health & - & ++ & \\
\hline feel bad for a few days & - & o & \\
\hline feel nauseous & - & o & \\
\hline get stiff jaws & o & $\mathrm{o}$ & \\
\hline
\end{tabular}

* The symbols + and - denote positive and negative associations with intention, respectively. One symbol denotes a weak association, two symbols a moderate association, three symbols a strong association, and four symbols a very strong association. Zeroes (o) indicate meaningless (trivial) associations; see [154].

deciding how to achieve that change. There are, however, theories that do. These are summarised in chapters 3 and 7 of Bartholomew et al. [2]. This book also offers guidance in continuing the intervention mapping process from here on. In brief, this would include discussing the matrices of change objectives with representatives of the target populations and the implementers, matching the change objectives to theoretical methods, devising practical strategies which are translations of these generic methods into practice, discussing these practical strategies with representatives of the target population and implementers, subsequently integrating these strategies into one coherent 
program, and finally pilot testing and evaluating the program. The specific theoretical methods and practical strategies that will eventually be chosen are a function of the discussion with the target group and implementers, but also of other factors such as the specific program context and available resources.

\section{Limitations of the reported studies}

The studies reported in this thesis suffer several limitations. The meta-analysis was limited in its conclusions by the scarcity of quantitative research that addressed ecstasy use. Because only 10 publications were included, only a small number of studies with opposing effects could negate the conclusions. The qualitative review covered 22 publications, but the qualitative nature of this review precluded drawing conclusions regarding the relevance of the identified reasons. In addition, because these 22 publications covered a variety of behaviours, the literature base for each distinct behaviour was still limited. All in all, there was very little information available on ecstasy use to guide the empirical studies. This caused one of the limitations of the qualitative study reported in chapter 4 . The scarcity of prior research necessitated gathering data on many different behaviours, limiting the data that could be gathered on any one behaviour.

The quantitative Party Panel study, results of which are reported in chapters 5, 6, 7, 8 and 9, suffers a similar limitation. Because of the paucity of prior research addressing the included behaviours, no information was available as to which variables were the most important to measure. Only the two theoretical perspectives identified in the meta-analysis were addressed (the Theory of Planned Behaviour and the expectation approach). Many potentially relevant theories could not be included, and consequently their role may remain unduly disregarded. This is the case both for social cognitive theories and for other theories and models that may help in explaining behaviour, such as theories with a focus on implicit processing. This narrow theoretical approach may have caused omission of important determinants. Especially concerning ceasing to use ecstasy, the low proportions of explained variation in intention certainly seem to point in this direction. Among potentially omitted determinants are external determinants: all studies addressed personal determinants, whereas environmental factors may play a role in determining behaviour as well. Especially for ceasing ecstasy use, there are indications that cessation is mainly prompted by environmental factors. 
A second limitation of the Party Panel studies is two-fold: in retrospect, the combination of chosen follow-up time of three months and subsample size of 250-300 participants per subsample often led to situations where few people had performed the studied behaviour at follow-up. Larger subsamples or a longer time to follow-up would likely have resulted in more non-users that tried out ecstasy, more users that ceased ecstasy use, and more users that had their ecstasy tested. This would have allowed more thorough analyses of these groups.

A third limitation is related to the nature of the Theory of Planned Behaviour (TPB). Generally, the same TPB variables were measured for all behaviours. The items constituting these measurements used the exact same phrasing, to allow between-behaviour comparison of determinant configurations. However, when the TPB is applied with such consistency, problems occur in that not all TPB variables have been designed to be symmetrically applicable. For example, regarding ecstasy use cessation, one measures the intention to cease use, the attitude regarding cessation, the subjective norm regarding cessation, and the perceived behavioural control regarding cessation. Applying this model to trying out ecstasy, one measures the intention to try out ecstasy, the attitude regarding trying out ecstasy, the subjective norm regarding trying out ecstasy, and perceived behavioural regarding trying out ecstasy. However, perceived behavioural control regarding refraining from trying out ecstasy may have more predictive value. Therefore, to optimise explained variation in intention, it would have been better to not apply the same measurement model to the measurement of the TPB variables for the different behaviours. However, although this would probably have resulted in higher proportions of explained variation, it would also have made comparison of different determinant configurations less straightforward: for one behaviour, PBC over performing the target behaviour would have been measured; for another behaviour, PBC over not performing the target behaviour would have been measured.

A limitation that transcends the individual studies is the fact that results were only studied for young people in western society. Other cultures were deliberately excluded from the meta-analysis and the review, and all empirical data was collected from young people in western society. Although this deliberate exclusion of other cultural contexts was itself an acknowledgement of potential cultural differences, these differences were not examined, and 
therefore it remains unclear whether the present results can generalise to other cultures.

The greatest limitation of the current thesis is a consequence of the combination of three things. First, there are many different ecstasy use-related behaviours; second, research into these behaviours lacks; and third, intervention on any given behaviour requires data on many determinants, measured at a very specific level. Ideally, all potentially relevant determinants are measured for all performance objectives. However, the studies reported in this thesis did not measure determinants of performance objectives, but of more broadly defined behaviours. In addition, not all potentially relevant determinants were measured, but only those that proved relevant in earlier research into using ecstasy. Even with these limitations, it would not have been possible to measure these data for all behaviours that were studied if it had not been possible to use the sophisticated tailoring that was possible because online questionnaires were used. And even in this situation, variables had to be measured so economically that this may have impaired reliability or validity. An alternative would have been to restrict all studies to one behaviour or even one performance objective. The chosen approach allows future research into many ecstasy use-related behaviours simultaneously, but the price to pay is likely lower explained variation of each of the addressed behaviours.

\section{Implications for future research}

Despite these limitations, the data reported in this thesis bear a number of implications for future research. With regards to ecstasy use specifically, four conclusions can be drawn. First, the results reported in this thesis clearly indicate that social cognitive theories can play a valuable role in explaining ecstasy use and related behaviours. Second, future research into ecstasy use should strive to address additional determinants. This means integrating more theoretical perspectives and including determinants based on reasons reported in qualitative research. Third, concrete behaviours such as 'ceasing ecstasy use' and 'trying out ecstasy' or 'starting ecstasy use' should be targeted by studies aiming to inform intervention development, rather than the more abstract behaviour of 'using ecstasy'. Fourth, as ecstasy use appears to be a phase that ends automatically for most people, it appears more urgent to identify the determinants of harm reduction strategies than to identify the determinants of ceasing ecstasy use. Thus, research into ecstasy use should address harm 
reduction strategies, measuring constructs from the Theory of Planned Behaviour, expectancies, and determinants based on the qualitative research thus far, all related to concrete and specific behaviours (rather than, for example, the generic 'applying harm reduction strategies').

Four additional conclusions transcend ecstasy-use related research. First, meta-analyses cannot be considered sufficient tools in synthesising the literature: they need to be complemented with qualitative reviews. By virtue of their strict quantitative approach, meta-analyses provide only a very narrow view into the literature, excluding many studies that may provide valuable pointers for future research. By considering these excluded studies, qualitative reviews remain very valuable tools in synthesising the state of the literature. Second, conclusions from such qualitative reviews need to be quantitatively verified. As was also the case in the current review, results from qualitative research may not be corroborated by quantitative data. Thus, a balanced synthesis of the state of the art requires both meta-analytical and qualitative reviews.

A second and related conclusion is that in general, neither quantitative nor qualitative methods can suffice in mapping a behaviour's determinant configuration. Qualitative studies are required to explore which beliefs may be relevant to determine a behaviour. Quantitative studies can then address the relative relevance of each of these beliefs and overarching variables. Thus, neglecting qualitative research may result in determinant configurations that omit relevant determinants, whereas without quantitative research, it remains unknow which determinants are the most relevant in predicting behaviour. The current thesis reports both literature overviews and empirical studies, and of each type, both qualitative and quantitative studies. Every study has yielded results that would have remained obscured without application of that particular combination of methodologies. Thus, for future research into behavioural determinants, it is certainly advised to utilise these same tools.

Third, determinant configurations should be considered behaviourally specific. Thus, when aiming to inform intervention development, studies should address behaviours that are the intervention targets of such an intervention. Determinant configurations of trying out a drug and of ceasing to use a drug have to be measured and analysed separately. Similarly, determinant configurations of exercising physical activity once or twice and of maintaining such exercise over time may very well differ, and each of these determinant configurations could be different from the determinant 
configuration of the more abstract behaviour 'exercising a physical activity'. It is important to measure a behaviour and the determinants of that behaviour as specifically as possible.

Fourth, the current studies show the possibilities of online research. It is possible to develop questionnaires that activate the proper context for participants, only present relevant items, and employ powerful tailoring strategies to gather data on a host of different behaviours or issues in one questionnaire. These possibilities are especially valuable for health promotion research, as intervention development often requires information on many different determinants of many different performance objectives. The strengths of such designs can be harnessed to a greater degree if combined with statistical methods such as mixed regression, where different participants can supply data on different predictors in a regression model. This theoretically enables collecting data on random subsets of determinants and performance objectives in one large sample.

\section{Concluding remarks}

The second and third chapters of this thesis evidence the complementary nature of meta-analyses and qualitative reviews, thereby emphasizing the value of each method. In addition, the third chapter indicated that reasons for related but distinct behaviours may differ, and that ecstasy use seems to end automatically for most users. This was confirmed by the qualitative study reported in the fourth chapter, where the application of these findings to the Dutch situation was confirmed as well. The data reported in the fifth, sixth, seventh and eighth chapters are the first to address the distinction of trying out ecstasy, ceasing ecstasy use and using ecstasy, a distinction that indeed proves fruitful. Finally, in the ninth chapter, the results of the first study into the determinants of an ecstasy use-related harm reduction strategy are reported. These studies yielded several conclusions, three of which have particularly general implications. First, research into behavioural determinants should complement qualitative and quantitative methodologies. This applies not only to empirical research, but also to literature syntheses. Second, determinant configurations should be considered behaviourally specific. Determinants of a behaviour need not be the same for related behaviours. Similarly, the determinants that predict behaviour among people who regularly perform that behaviour (e.g. ecstasy users) can be different determinants than those that 
predict the same behaviour among people who do not regularly perform that behaviour (e.g. non-users). Also, determinants that differentiate between such groups need not predict intention in either of those groups. Finally, ecstasy use interventions should aim at promoting harm reduction, rather than abstinence. Because most ecstasy users appear to cease of their own accord, more health benefits can be achieved by promoting consistent application of harm reduction strategies than by promoting abstinence. 
Appendix 10.i: the information architecture of the content management system that underlied Party Panel.

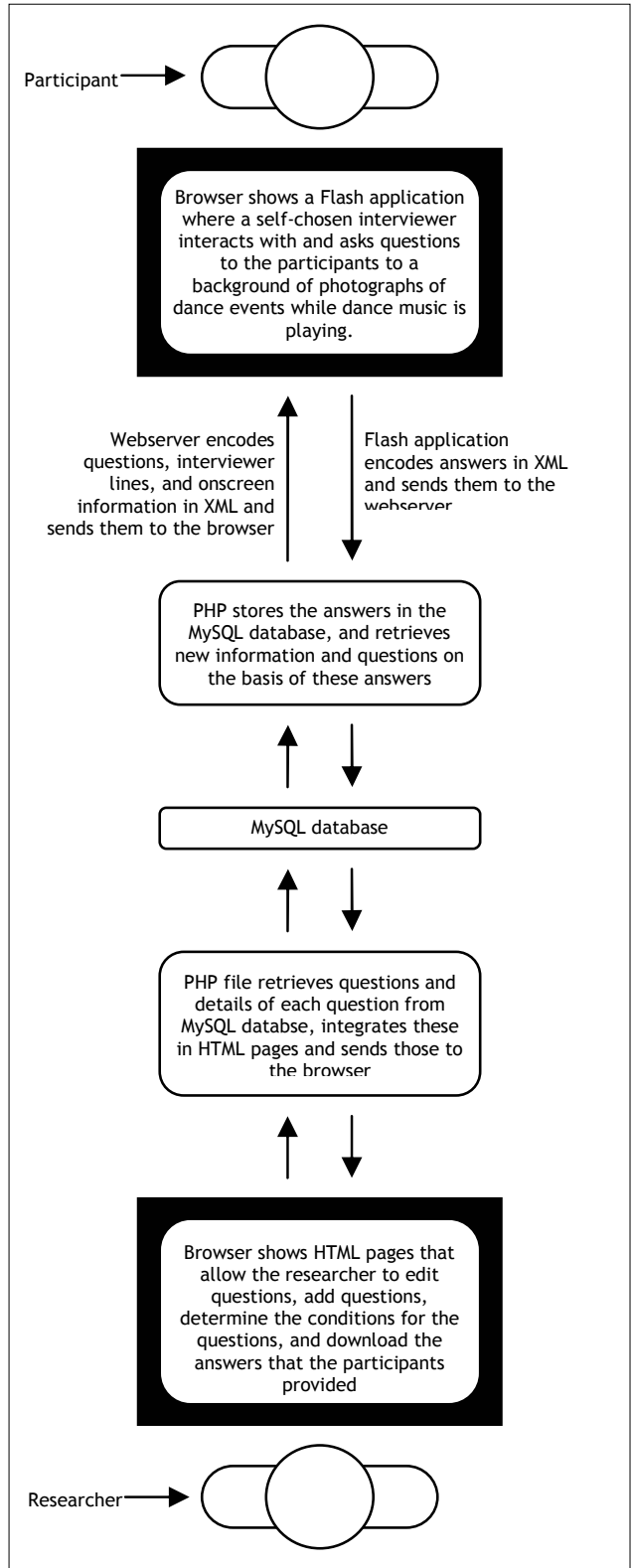




\section{Numbered reference list}

1. Samenspannen tegen XTC [Banding together against ecstasy] (2001). Den Haag: Ministerie van Justitie.

2. Bartholomew, L. K., Parcel, G. S., Kok, G., \& Gottlieb, N. H. (2006). Intervention mapping: designing theory and evidence-based health promotion programs. San Francisco, CA: Jossey-Bass.

3. Freudenmann, R. W., Öxler, F., \& Bernschneider Reif, S. (2006). The origin of MDMA (ecstasy) revisited: The true story reconstructed from the original documents. Addiction, 101, 1241-1245.

4. Hardman, H. F., Haavik, C. O., \& Seevers, M. H. (1973). Relationship of the structure of mescaline and seven analogs to toxicity and behavior in five species of laboratory animals. Toxicology and Applied Pharmacology, 25, 299-309.

5. Riedlinger, J. E. (1985). The scheduling of MDMA: a pharmacist's perspective. Journal of Psychoactive Drugs, 17, 167-171.

6. Baylen, C. A., \& Rosenberg, H. (2006). A review of the acute subjective effects of MDMA/ecstasy. Addiction, 101, 933-947.

7. Levy, K. B., O'Grady, K. E., Wish, E. D., \& Arria, A. M. (2005). An in-depth qualitative examination of the ecstasy experience: Results of a focus group with ecstasy-using college students. Substance Use and Misuse, 40, 1427-1441.

8. $\quad$ ter Bogt, T., Engels, R., Hibbel, B., Van Wel, F., \& Verhagen, S. (2002). "Dancestasy": Dance and MDMA use in Dutch youth culture. Contemporary Drug Problems, 29, 157181.

9. Nichols, D. E. (1986). Differences between the mechanism of action of MDMA, MBDB, and the classic hallucinogens: Identification of a new therapeutic class: Entactogens. Journal of Psychoactive Drugs, 18, 305-313.

10. Terphoven, A. v., \& Beemsterboer, T. (2004). Door! Dance in Nederland [Keep going! Dance in the Netherlands]. Amsterdam: Contact.

11. KPMG (2002). Dance in Nederland - De betekenis en impact van dance op de Nederlandse economie en maatschappij: een verkenning [Dance in the Netherlands - The meaning and impact of dance on the Dutch economy and society: an exploration]. Amstelveen: KPMG Special Services B.V.

12. Trimbos Instituut (2007). Nationale Drug Monitor [National drug monitor]. Utrecht: Trimbos Instituut.

13. ter Bogt, T., \& Engels, R. C. M. E. (2005). Partying Hard: Party style, motives for and effects of MDMA use at rave parties. Substance Use and Misuse, 40, 1479-1502. 
14. Kelly, B. C., Parsons, J. T., \& Wells, B. E. (2006). Prevalence and predictors of club drug use among club-going young adults in New York city. Journal of Urban Health, 83, 884-895.

15. Ricaurte, G. A., Yuan, J., Hatzidimitriou, G., Cord, B. J., \& McCann, U. D. (2002). Severe dopaminergic neurotoxicity in primates after a common recreational dose regimen of MDMA ("ecstasy"). Science, 297, 2260-2263.

16. Ricaurte, G. A., Yuan, J., Hatzidimitriou, G., Cord, B. J., \& McCann, U. D. (2003). Severe dopaminergic neurotoxicity in primates after a common recreational dose regimen of MDMA ("ecstasy"): Retraction. Science, 301, 1479.

17. Kalechstein, A. D., De La Garza, R., II, Mahoney, J. J., III, Fantegrossi, W. E., \& Newton, T. F. (2007). MDMA use and neurocognition: A meta-analytic review. Psychopharmacology, 189, 531-537.

18. Karlsen, S. N., Spigset, O., \& Slordal, L. (2008). The dark side of ecstasy: neuropsychiatric symptoms after exposure to 3,4methylenedioxymethamphetamine. Basic and Clinical Pharmacology and Toxicology, 102, 15-24.

19. Laws, K. R., \& Kokkalis, J. (2007). Ecstasy (MDMA) and memory function: a metaanalytic update. Human psychopharmacology, 22, 381-388.

20. Gouzoulis Mayfrank, E., \& Daumann, J. (2006). Neurotoxicity of methylenedioxyamphetamines (MDMA; ecstasy) in humans: how strong is the evidence for persistent brain damage? Addiction, 101, 348-361.

21. Zakzanis, K. K., Campbell, Z., \& Jovanovski, D. (2007). The neuropsychology of ecstasy (MDMA) use: a quantitative review. Human psychopharmacology, 22, 427-435.

22. Lyvers, M. (2006). Recreational ecstasy use and the neurotoxic potential of MDMA: current status of the controversy and methodological issues. Drug and Alcohol Review, 25, 269-276.

23. de Win, M. M. L., Jager, G., Vervaeke, H. K. E., Schilt, T., Reneman, L., Booij, J., Verhulst, F. C., den Heeten, G. J., Ramsey, N. F., Korf, D. J., \& van den Brink, W. (2005). The Netherlands XTC Toxicity (NeXT) study: Objectives and methods of a study investigating causality, course, and clinical relevance. International Journal of Methods in Psychiatric Research, 14, 167-185.

24. Jager, G., de Win, M. M., van der Tweel, I., Schilt, T., Kahn, R. S., van den Brink, W., van Ree, J. M., \& Ramsey, N. F. (2008). Assessment of cognitive brain function in ecstasy users and contributions of other drugs of abuse: results from an FMRI study. Neuropsychopharmacology official publication of the American College of Neuropsychopharmacology, 33, 247-258.

25. Jager, G., de Win, M. M., Vervaeke, H. K., Schilt, T., Kahn, R. S., van den Brink, W., van Ree, J. M., \& Ramsey, N. F. (2007). Incidental use of ecstasy: No evidence for harmful effects on cognitive brain function in a prospective fMRI study. Psychopharmacology, 193, 403-414.

26. Verheyden, S. L., Henry, J. A., \& Curran, H. V. (2003). Acute, sub-acute and longterm subjective consequences of 'ecstasy' (MDMA) consumption in 430 regular users. Human Psychopharmacology: Clinical and Experimental, 18, 507-517.

27. ter Bogt, T., Schmid, H., Gabhainn, S. N., Fotiou, A., \& Vollebergh, W. (2006). Economic and cultural correlates of cannabis use among mid-adolescents in 31 countries. Addiction, 101, 241-251. 
28. Shewan, D., Dalgarno, P., \& Reith, G. (2000). Perceived risk and risk reduction among ecstasy users: the role of drug, set, and setting. International Journal of Drug Policy, 10, 431-453.

29. Parrott, A. C., Rodgers, J., Buchanan, T., Ling, J., Heffernan, T., \& Scholey, A. B. (2006). Dancing hot on Ecstasy: physical activity and thermal comfort ratings are associated with the memory and other psychobiological problems reported by recreational MDMA users. Human Psychopharmacology: Clinical and Experimental, 21, 285-298.

30. Ajzen, I. (1991). The theory of planned behavior. Organizational Behavior and Human Decision Processes, 50, 179-211.

31. Fishbein, M., \& Ajzen, I. (1975). Belief, attitude, intention and behavior: An introduction to theory and research. Reading, MA: Addison-Wesley.

32. Fishbein, M., Triandis, H. C., Kanfer, F. H., Becker, M. H., Middlestadt, S. E., \& Eichler, A. (2001). Factors influencing behavior and behavior change. In A. Baum, T. R. Revenson \& J. E. Singer (Eds.), Handbook of Health Psychology (pp. 3-17). Hillsdale, NJ: Lawrence Erlbaum Associates.

33. Godin, G., \& Kok, G. (1996). The theory of planned behavior: A review of its applications to health-related behaviors. American Journal of Health Promotion, 11, 8798.

34. Bandura, A. (1986). Social foundations of thought and action: A social cognitive theory. Upper Saddle River, NJ, US: Prentice-Hall, Inc.

35. Peters, G.-J. Y., Kok, G. J., \& Abraham, C. (2008). Social cognitive determinants of ecstasy use to target in evidence-based interventions: a meta-analytic review. Addiction, 103, 109-118.

36. Thomasius, R., Zapletalova, P., Petersen, K., Buchert, R., Andresen, B., Wartberg, L., Nebeling, B., \& Schmoldt, A. (2006). Mood, cognition and serotonin transporter availability in current and former ecstasy (MDMA) users: The longitudinal perspective. Journal of Psychopharmacology, 20, 211-225.

37. Zakzanis, K. K., \& Campbell, Z. (2006). Memory impairment in now abstinent MDMA users and continued users: a longitudinal follow-up. Neurology, 66, 740-741.

38. McCambridge, J., Mitcheson, L., Winstock, A., \& Hunt, N. (2005). Five-year trends in patterns of drug use among people who use stimulants in dance contexts in the United Kingdom. Addiction, 100, 1140-1149.

39. Parsons, J. T., Kelly, B. C., \& Wells, B. E. (2006). Differences in club drug use between heterosexual and lesbian/bisexual females. Addictive Behaviors, 31, 23442349.

40. Albarracin, D., Gillette, J. C., Earl, A. N., Glasman, L. R., Durantini, M. R., \& Ho, M. H. (2005). A test of major assumptions about behavior change: a comprehensive look at the effects of passive and active HIV-prevention interventions since the beginning of the epidemic. Psychological Bulletin, 131, 856-897.

41. Webb, T. L., \& Sheeran, P. (2006). Does changing behavioral intentions engender behavior change? A meta-analysis of the experimental evidence. Psychological Bulletin, 132, 249-268.

42. Climko, R. P., Roehrich, H., Sweeney, D. R., \& Al Razi, J. (1986). Ecstacy: a review of MDMA and MDA. International Journal of Psychiatry in Medicine, 16, 359-372. 
43. Greer, G., \& Strassman, R. J. (1985). Information on "Ecstasy". American Journal of Psychiatry, 142, 1391.

44. Marcos, A. C., \& Johnson, R. E. (1988). Cultural patterns and causal processes in adolescent drug use: The case of Greeks versus Americans. International Journal of the Addictions, 23, 545-572.

45. Deng, F., Vaughn, M. S., \& Lee, L. J. (2001). Drug offenders in Taiwan and the United States: A cross-cultural analysis. Substance Use and Misuse, 36, 1677-1697.

46. Armitage, C. J., \& Conner, M. (2001). Efficacy of the theory of planned behaviour: A meta-analytic review. British Journal of Social Psychology, 40, 471-499.

47. Wu, Y., Stanton, B. F., Galbraith, J., Kaljee, L., Cottrell, L., Li, X., Harris, C. V., D'Alessandri, D., \& Burns, J. M. (2003). Sustaining and broadening intervention impact: a longitudinal randomized trial of 3 adolescent risk reduction approaches. Pediatrics, 111, e32-e38.

48. Carlson, R. G., Falck, R. S., McCaughan, J. A., \& Siegal, H. A. (2004). MDMA/Ecstasy use among young people in Ohio: perceived risk and barriers to intervention. Journal of Psychoactive Drugs, 36, 181-189.

49. Sherlock, K., \& Conner, M. (1999). Patterns of ecstasy use amongst club goers on the UK 'dance scene'. International Journal of Drug Policy, 10, 117-129.

50. Corapcioglu, A., \& Ogel, K. (2004). Factors associated with ecstasy use in Turkish students. Addiction, 99, 67-76.

51. Sim, T., Jordan Green, L., Lee, J., Wolfman, J., \& Jahangiri, A. (2005). Psychosocial correlates of recreational ecstasy use among college students. Journal of American College Health, 54, 25.

52. Wu, Z. H., Holzer, C. E., 3rd, Breitkopf, C. R., Grady, J. J., \& Berenson, A. B. (2006). Patterns and perceptions of ecstasy use among young, low-income women. Addictive Behaviors, 31, 676-685.

53. Yu, R. L., \& Ko, H. C. (2006). Cognitive determinants of MDMA use among college students in Southern Taiwan. Addictive Behaviors, 31, 2199-2211.

54. Boys, A., \& Marsden, J. (2003). Perceived functions predict intensity of use and problems in young polysubstance users. Addiction, 98, 951-963.

55. Boys, A., Marsden, J., Griffiths, P., Fountain, J., Stillwell, G., \& Strang, J. (1999). Substance use among young people: The relationship between perceived functions and intentions. Addiction, 94, 1043-1050.

56. Conner, M., Sherlock, K., \& Orbell, S. (1998). Psychosocial determinants of ecstasy use in young people in the UK. British Journal of Health Psychology, 3, 295-317.

57. Engels, R. C. M. E., \& Ter Bogt, T. (2004). Outcome Expectancies and Ecstasy Use in Visitors of Rave Parties in the Netherlands. European Addiction Research, 10, 156-162.

58. McMillan, B., \& Conner, M. (2003). Applying an extended version of the theory of planned behavior to illicit drug use among students. Journal of Applied Social Psychology, 33, 1662-1683.

59. McMillan, B., Sherlock, K., \& Conner, M. (2003). Expanding the traditional user versus non-user dichotomy amongst ecstasy users. Journal of Community and Applied Social Psychology, 13, 15-28.

60. Orbell, S., Blair, C., Sherlock, K., \& Conner, M. (2001). The theory of planned behavior and ecstasy use: roles for habit and perceived control over taking versus obtaining substances. Journal of Applied Social Psychology, 31, 31-47. 
61. Umeh, K., \& Patel, R. (2004). Theory of planned behaviour and ecstasy use: an analysis of moderator-interactions. British Journal of Health Psychology, 9, 25-38.

62. Yacoubian, G. S., Boyle, C., Harding, C. A., \& Loftus, E. A. (2003). It's a rave new world: Estimating the prevalence and perceived harm of ecstasy and other drug use among club rave attendees. Journal of Drug Education, 33, 187-196.

63. Petraitis, J., Flay, B. R., \& Miller, T. Q. (1995). Reviewing theories of adolescent substance use: organizing pieces in the puzzle. Psychological Bulletin, 117, 67-86.

64. Conner, M., \& Sparks, P. (1996). The theory of planned behaviour and health behaviours. In M. Conner \& P. Norman (Eds.), Predicting health behaviour: Research and practice with social cognition models (pp. 121-162). Buckingham, England: Open University Press.

65. De Vries, H., Backbier, E., Kok, G., \& Dijkstra, M. (1995). The impact of social influences in the context of attitude, self-efficacy, intention, and previous behavior as predictors of smoking onset. Journal of Applied Social Psychology, 25, 237-257.

66. Abraham, C., Sheeran, P., \& Johnston, M. (1998). From health beliefs to selfregulation: Theoretical advances in the psychology of action control. Psychology and Health, 13, 569-591.

67. Abraham, C., \& Sheeran, P. (2003). Implications of goal theories for the theories of reasoned action and planned behaviour. Current Psychology, 22, 264-280.

68. Manstead, A. S. R., \& Parker, D. (1995). Evaluating and extending the Theory of Planned Behaviour. In W. Stroebe \& M. Hewstone (Eds.), European Review of Social Psychology (Vol. 6, pp. 69-95). Chichester, England: Wiley.

69. Feather, N. T. (Ed.). (1982). Expectations and actions: Expectancy-value models in psychology. Hillsdale, NJ: Erlbaum.

70. Cohen, J. (1988). Statistical power analysis for the behavioral sciences (2nd ed.). Hillsdale, NJ: Lawrence Erlbaum Associates.

71. Ruiter, R. A. C., Abraham, C., \& Kok, G. (2001). Scary warnings and rational precautions: A review of the psychology of fear appeals. Psychology and Health, 16, 613-630.

72. Witte, K. (1995). Fishing for success: Using the persuasive health message framework to generate effective campaign messages. In E. Maibach \& R. L. Parrott (Eds.), Designing health messages: Approaches from communication theory and public health practice (pp. 145-166). Thousand Oaks, CA, US: Sage Publications, Inc.

73. Boys, A., Marsden, J., Fountain, J., Griffiths, P., Stillwell, G., \& Strang, J. (1999). What influences young people's use of drugs? A qualitative study of decisionmaking. Drugs: Education, Prevention and Policy, 6, 373-387.

74. ter Bogt, T. F. M., Engels, R. C. M. E., \& Dubas, J. S. (2006). Party people: Personality and MDMA use of house party visitors. Addictive Behaviors, 31, 1240-1244.

75. Cialdini, R. B. (2003). Crafting normative messages to protect the environment. Current Directions in Psychological Science, 12, 105-109.

76. Fishbein, M., \& Cappella, J. N. (2006). The role of theory in developing effective health communications. Journal of Communication, 56, S1-S17.

77. Verplanken, B., \& Wood, W. (2006). Interventions to break and create consumer habits. Journal of Public Policy and Marketing, 25, 90-103. 
78. Schoenmakers, T., Wiers, R. W., Jones, B. T., Bruce, G., \& Jansen, A. T. M. (2007). Attentional re-training decreases attentional bias in heavy drinkers without generalization. Addiction, 102, 399-405.

79. Orbell, S., \& Hagger, M. (2006). Temporal framing and the decision to take part in type 2 diabetes screening: Effects of individual differences in consideration of future consequences on persuasion. Health Psychology, 25, 537-548.

80. Allott, K., \& Redman, J. (2006). Patterns of use and harm reduction practices of ecstasy users in Australia. Drug and Alcohol Dependence, 82, 168-176.

81. Robson, P., \& Bruce, M. (1997). A comparison of 'visible' and 'invisible' users of amphetamine, cocaine and heroin: two distinct populations? Addiction, 92, 17291736.

82. Boys, A., Marsden, J., \& Strang, J. (2001). Understanding reasons for drug use amongst young people: A functional perspective. Health Education Research, 16, 457469.

83. Marsden, J., Stillwell, G., Barlow, H., Boys, A., Taylor, C., Hunt, N., \& Farrell, M. (2006). An evaluation of a brief motivational intervention among young ecstasy and cocaine users: No effect on substance and alcohol use outcomes. Addiction, 101, 1014-1026.

84. Eves, F., Hoppe, R., \& McLaren, L. (2003). Prediction of specific types of physical activity using the theory of planned behavior. Journal of Applied Biobehavioral Research, 8, 77-95.

85. ResearchSoft, T. (2005). Endnote 9.01.

86. Engels, R. C., \& ter Bogt, T. (2004). Outcome expectancies and ecstasy use in visitors of rave parties in The Netherlands. European addiction research, 10, 156-162.

87. Allott, K., \& Redman, J. (2006). Patterns of use and harm reduction practices of ecstasy users in Australia. Drug and Alcohol Dependence, 82, 168-176.

88. Bellis, M. A., Hughes, K., Calafat, A., Juan, M., Ramon, A., Rodriguez, J. A., Mendes, F., Schnitzer, S., \& Phillips-Howard, P. (2008). Sexual uses of alcohol and drugs and the associated health risks: a cross sectional study of young people in nine European cities. BMC public health ISE: 1471 2458, 8, 155.

89. Carlson, R. G., Falck, R. S., McCaughan, J. A., \& Siegal, H. A. (2004). MDMA/Ecstasy Use Among Young People in Ohio: Perceived Risk and Barriers to Intervention. Journal of Psychoactive Drugs, 36, 181-189.

90. Copeland, J., Dillon, P., \& Gascoigne, M. (2006). Ecstasy and the concomitant use of pharmaceuticals. Addictive behaviors, 31, 367-370.

91. Dundes, L. (2003). DanceSafe and ecstasy: protection or promotion? Journal of health and social policy, 17, 19-37.

92. Fendrich, M., Wislar, J. S., Johnson, T. P., \& Hubbell, A. (2003). A contextual profile of club drug use among adults in Chicago. Addiction, 98, 1693-1703.

93. Fountain, J., Bartlett, H., Griffiths, P., Gossop, M., Boys, A., \& Strang, J. (1999). Why say no? Reasons given by young people for not using drugs. Addiction Research, 7, 339-353.

94. Gamma, A., Jerome, L., Liechti, M. E., \& Sumnall, H. R. (2005). Is ecstasy perceived to be safe? A critical survey. Drug and alcohol dependence, 77, 185-193.

95. Gourley, M. (2004). A subcultural study of recreational ecstasy use. Journal of Sociology, 40, 59-73. 
96. Hansen, D., Maycock, B., \& Lower, T. (2001). 'Weddings, parties, and anything. International Journal of Drug Policy, 12, 181-199.

97. Levy, K. B., O'Grady, K. E., Wish, E. D., \& Arria, A. M. (2005). An in-depth qualitative examination of the ecstasy experience: results of a focus group with ecstasy-using college students. Substance use and misuse, 40, 1427-1441.

98. Riley, S. C. E., \& Hayward, E. (2004). Patterns, trends, and meanings of drug use by dance-drug users in Edinburgh, Scotland. Drugs: Education, Prevention and Policy, 11, 243-262.

99. Rodgers, J., Buchanan, T., Pearson, C., Parrott, A. C., Ling, J., Heffernan, T., \& Scholey, A. B. (2006). Differential experiences of the psychobiological sequelae of ecstasy use: Quantitative and qualitative data from an internet study. Journal of Psychopharmacology, 20, 437-446.

100. Soellner, R. (2005). Club drug use in Germany. Substance use and misuse, 40, 12791293.

101. Solowij, N., Hall, W., \& Lee, N. (1992). Recreational MDMA use in Sydney: a profile of 'Ecstacy' users and their experiences with the drug. British journal of addiction, 87, 1161-1172.

102. Sterk, C. E., Theall, K. P., \& Elifson, K. W. (2007). Getting into ecstasy: comparing moderate and heavy young adult users. Journal of psychoactive drugs, 39, 103-113.

103. Sumnall, H. R., Cole, J. C., \& Jerome, L. (2006). The varieties of ecstatic experience: an exploration of the subjective experiences of ecstasy. Journal of psychopharmacology Oxford, England, 20, 670-682.

104. Topp, L., Hando, J., Dillon, P., Roche, A., \& Solowij, N. (1999). Ecstasy use in Australia: patterns of use and associated harm. Drug and alcohol dependence, 55, 105115.

105. Verheyden, S. L., Henry, J. A., \& Curran, H. V. (2003). Acute, sub-acute and longterm subjective consequences of 'ecstasy' (MDMA) consumption in 430 regular users. Human psychopharmacology, 18, 507-517.

106. Verheyden, S. L., Maidment, R., \& Curran, H. V. (2003). Quitting ecstasy: an investigation of why people stop taking the drug and their subsequent mental health. Journal of psychopharmacology Oxford, England, 17, 371-378.

107. Winstock, A. R., Griffiths, P., \& Stewart, D. (2001). Drugs and the dance music scene: A survey of current drug use patterns among a sample of dance music enthusiasts in the UK. Drug and Alcohol Dependence, 64, 9-17.

108. http://ecstasyresearch.eu/qualitativereview.

109. Cohen, J. (1992). A power primer. Psychological Bulletin, 112, 155-159.

110. Vervaeke, H. K. E., Benschop, A., \& Korf, D. J. (2008). Fear, rationality and opportunity: Reasons and motives for not trying ecstasy. Drugs: Education, Prevention and Policy, 15, 350 - 364.

111. Rosenberg, H., Baylen, C., Murray, S., Phillips, K., Tisak, M. S., Versland, A., \& Pristas, E. (2008). Attributions for abstinence from illicit drugs by university students. Drugs: Education, Prevention and Policy, 15, 365 - 377.

112. van de Wijngaart, G. F., Braam, R., de Bruin, D., Fris, M., Maalste, N. J. M., \& Verbraeck, H. T. (1999). Ecstasy use at large-scale dance events in the Netherlands. Journal of Drug Issues, 29, 679-702. 
113. Sterk, C. E., Theall, K. P., \& Elifson, K. W. (2006). Young adult ecstasy use patterns: Quantities and combinations. Journal of Drug Issues, 36, 201-228.

114. Peters, G.-J. Y., \& Kok, G. (Submitted). A structured review of reasons for ecstasy use and related behaviours: pointers for future research. BMC Public Health.

115. Hansen, D., Maycock, B., \& Lower, T. (2001). 'Weddings, parties, and anything...', a qualitative analysis of ecstasy use in Perth, Western Australia. International Journal of Drug Policy, 12, 181-199.

116. Topp, L., Hando, J., Dillon, P., Roche, A., \& Solowij, N. (1999). Ecstasy use in Australia: Patterns of use and associated harm. Drug and Alcohol Dependence, 55, 105-115.

117. Solowij, N., Hall, W., \& Lee, N. (1992). Recreational MDMA use in Sydney: A profile of "ecstasy" users and their experiences with the drug. British Journal of Addiction, 87, 1161-1172.

118. Verheyden, S. L., Maidment, R., \& Curran, H. V. (2003). Quitting ecstasy: An investigation of why people stop taking the drug and their subsequent mental health. Journal of Psychopharmacology, 17, 371-378.

119. Gamma, A., Jerome, L., Liechti, M. E., \& Sumnall, H. R. (2005). Is ecstasy perceived to be safe? A critical survey. Drug and Alcohol Dependence, 77, 185-193.

120. Spruit, I. P. (1999). Ecstasy use and policy responses in the Netherlands. Journal of Drug Issues, 29, 653-678.

121. Uitermark, J. (2004). The origins and future of the Dutch approach towards drugs. Journal of Drug Issues, 34, 511-532.

122. Duncan, D. F., \& Nicholson, T. (1997). Dutch drug policy: A model for America? Journal of Health and Social Policy, 8, 1-15.

123. Uitermark, J., \& Cohen, P. (2005). A clash of policy approaches: The rise (and fall?) of Dutch harm reduction policies towards ecstasy consumption. International Journal of Drug Policy, 16, 65-72.

124. Griffiths, P., Mravcik, V., Lopez, D., \& Klempova, D. (2008). Quite a lot of smoke but very limited fire--the use of methamphetamine in Europe. Drug and alcohol review ISE: 1465 3362, 27, 236-242.

125. Topp, L., Degenhardt, L., Kaye, S., \& Darke, S. (2002). The emergence of potent forms of methamphetamine in Sydney, Australia: A case study of the IDRS as a strategic early warning system. Drug and Alcohol Review, 21, 341-348.

126. Rawson, R. A., Anglin, M. D., \& Ling, W. (2002). Will the methamphetamine problem go away? Journal of Addictive Diseases, 21, 5-19.

127. Trimbos Instituut. (2007). DIMS jaarbericht 2006 [DIMS year report 2006]. Utrecht: Trimbos Instituut.

128. Nabben, T., Benschop, A., \& Korf, D. J. (2007). Antenne 2006: trends in alcohol, tabak en drugs bij jonge Amsterdammers [Antenna 2006: Alcohol, tobacco and drug trends among Amsterdam adolescents and young adults]. Amsterdam: Rozenberg Publishers.

129. Sumnall, H. R., Tyler, E., Wagstaff, G. F., \& Cole, J. C. (2004). A behavioural economic analysis of alcohol, amphetamine, cocaine and ecstasy purchases by polysubstance misusers. Drug and Alcohol Dependence, 76, 93-99.

130. Topp, L., Barker, B., \& Degenhardt, L. (2004). The external validity of results derived from ecstasy users recruited using purposive sampling strategies. Drug and Alcohol Dependence, 73, 33-40. 
131. Wang, J., Carlson, R. G., Falck, R. S., Siegal, H. A., Rahman, A., \& Li, L. (2005). Respondent-driven sampling to recruit MDMA users: a methodological assessment. Drug and Alcohol Dependence, 78, 147-157.

132. NVivo. (2001). Melbourne, Australia: QSR International Pty Ltd.

133. Parrott, A. C. (2004). Is ecstasy MDMA? A review of the proportion of ecstasy tablets containing MDMA, their dosage levels, and the changing perceptions of purity. Psychopharmacology 173, 234-241.

134. Albarracin, D., Durantini, M. R., \& Earl, A. (2006). Empirical and theoretical conclusions of an analysis of outcomes of HIV-prevention interventions. Current Directions in Psychological Science, 15, 73-78.

135. Bedi, G., \& Redman, J. (2006). Letters to the Editor: Recreational Ecstasy Use: Acute Effects Potentiated by Ambient Conditions? Neuropsychobiology, 53, 113.

136. Bedi, G., \& Redman, J. (2006). Recreational ecstasy use: acute effects potentiated by ambient conditions? Neuropsychobiology, 53, 113.

137. Panagopoulos, I., \& Ricciardelli, L. A. (2005). Harm reduction and decision making among recreational ecstasy users. International Journal of Drug Policy, 16, 54-64.

138. Vervaeke, H. K., van Deursen, L., \& Korf, D. J. (2008). The role of peers in the initiation and continuation of ecstasy use. Substance Use and Misuse, 43, 633-646.

139. Vervaeke, H. K. E., Korf, D. J., Benschop, A., \& van den Brink, W. (2007). How to find future ecstasy-users: Targeted and snowball sampling in an ethically sensitive context. Addictive Behaviors, 32, 1705-1713.

140. von Sydow, K., Lieb, R., Pfister, H., Hofler, M., \& Wittchen, H. U. (2002). Use, abuse and dependence of ecstasy and related drugs in adolescents and young adults--a transient phenomenon? Results from a longitudinal community study. Drug and Alcohol Dependence, 66, 147-159.

141. Kelly, B. C. (2007). Club drug use and risk management among "Bridge and Tunnel" youth. Journal of Drug Issues, 37, 425-444.

142. Rivis, A., \& Sheeran, P. (2003). Descriptive norms as an additional predictor in the theory of planned behaviour: A meta-analysis. Current Psychology, 22, 218-233.

143. van Empelen, P., Kok, G., Jansen, M. W. J., \& Hoebe, C. J. P. A. (2001). The additional value of anticipated regret and psychopathology in explaining intended condom use among drug users. AIDS Care, 13, 309-318.

144. Abraham, C., \& Sheeran, P. (2003). Acting on Intentions: the role of anticipated regret. British Journal of Social Psychology, 42, 495-511.

145. McMillan, B., \& Conner, M. (2003). Using the theory of planned behaviour to understand alcohol and tobacco use in students. Psychology, Health and Medicine, 8, 317-328.

146. French, D. P., \& Hankins, M. (2003). The expectancy-value muddle in the theory of planned behaviour--and some proposed solutions. British Journal of Health Psychology, 8, 37-55.

147. Peters, G.-J. Y., Kok, G. J., \& Schaalma, H. P. (In press). Careers in ecstasy use: do ecstasy users cease of their own accord? Implications for intervention development. BMC Public Health.

148. Boys, A., Lenton, S., \& Norcross, K. (1997). Polydrug use at raves by a Western Australian sample. Drug and Alcohol Review, 16, 227-234. 
149. Duncan, D. F., White, J. B., \& Nicholson, T. (2003). Using Internet-based surveys to reach hidden populations: Case of nonabusive illicit drug users. American Journal of Health Behavior, 27, 208-218.

150. Macromedia. (2005). Macromedia Flash. San Fransisco, CA.

151. Reimers, S., \& Stewart, N. (2007). Adobe flash as a medium for online experimentation: A test of reaction time measurement capabilities. Behavior Research Methods, 39, 365-370.

152. Goritz, A. S., \& Birnbaum, M. H. (2005). Generic HTML Form Processor: A versatile PHP script to save Web-collected data into a MySQL database. Behavior Research Methods, 37, 703-710.

153. Cohen, J. (1990). Things I Have Learned (So Far). American Psychologist, 45, 13041312.

154. Kirk, R. E. (2007). Effect magnitude: a different focus. Journal of Statistical Planning and Inference, 137, 1634-1646.

155. Rosenthal, J. A. (1996). Qualitative descriptors of strength of association and effect size. Journal of Social Service Research, 21.

156. Ruxton, G. D. (2006). The unequal variance t-test is an underused alternative to Student's t-test and the Mann-Whitney U test. Behavioral Ecology, 17, 688-690.

157. Welp, E. A. E., Bosman, I., Langeman, M. W., Totte, M., Maes, R. A. A., \& van Ameijden, E. J. C. (2003). Amount of self-reported illicit drug use compared to quantitative hair test results in community-recruited young drug users in Amsterdam. Addiction, 98, 987-994.

158. Peters, G.-J. Y., Kok, G. J., \& Abraham, C. S. (in preparation). Social cognitive determinants of trying out ecstasy: why interventions based on research into using ecstasy may have a hard time preventing ecstasy use.

159. Peters, G.-J. Y., Kok, G. J., \& Abraham, C. S. (in preparation). Social cognitive determinants of ceasing ecstasy use: ceasing is not the opposite of using.

160. Peters, G.-J. Y., Kok, G. J., \& Abraham, C. S. (in preparation). Social cognitive determinants of ecstasy use: Does studying mixed samples of non-users and users leads to over-estimation of association strengths?

161. Johnston, J., Barratt, M. J., Fry, C. L., Kinner, S., Stoove, M., Degenhardt, L., George, J., Jenkinson, R., Dunne, M., \& Bruno, R. (2006). A survey of regular ecstasy users' knowledge and practices around determining pill content and purity: Implications for policy and practice. International Journal of Drug Policy, 17, 464-472.

162. Benschop, A., Rabes, M., \& Korf, D. J. (2002). Pill testing, ecstasy and prevention. Amsterdam: Rozenberg Publishers.

163. Giraudon, I., \& Bello, P.-Y. (2007). Monitoring ecstasy content in France: Results from the national surveillance system 1999-2004. Substance Use and Misuse, 42, 15671578.

164. Conner, M., \& Armitage, C. J. (1998). Extending the theory of planned behavior: A review and avenues for further research. Journal of Applied Social Psychology, 28, 1429-1464.

165. Conner, M., \& Abraham, C. (2001). Conscientiousness and the theory of planned behavior: Toward a more complete model of the antecedents of intentious behavior. Personality and Social Psychology Bulletin, 27, 1547-1561. 
166. Benet-Martinez, V., \& John, O. P. (1998). Los cinco grandes across cultures and ethnic groups: Multitrait multimethod analyses of the Big Five in Spanish and English. Journal of Personality and Social Psychology, 75, 729-750.

167. Gosling, S. D., Rentfrow, P. J., \& Swann, W. B., Jr. (2003). A very brief measure of the Big-Five personality domains. Journal of Research in Personality, 37, 504-528.

168. Hoyle, R. H., Stephenson, M. T., Palmgreen, P., Pugzles Lorch, E., \& Donohew, R. L. (2002). Reliability and validity of a brief measure of sensation seeking. Personality and Individual Differences, 32, 401-414.

169. Patton, J. H., Stanford, M. S., \& Barratt, E. S. (1995). Factor structure of the Barratt Impulsiveness Scale. Journal of Clinical Psychology, 51, 768-774.

170. Wood, W., \& Neal, D. T. (2007). A new look at habits and the habit-goal interface. Psychological Review, 114, 843-863. 



\section{Alphabetic reference list}

Abraham, C., \& Sheeran, P. (2003a). Acting on Intentions: The Role of Anticipated Regret. British Journal of Social Psychology, 42, 495-511.

Abraham, C., \& Sheeran, P. (2003b). Implications of Goal Theories for the Theories of Reasoned Action and Planned Behaviour. Current Psychology, 22, 264-280.

Abraham, C., Sheeran, P., \& Johnston, M. (1998). From Health Beliefs to Self-Regulation: Theoretical Advances in the Psychology of Action Control. Psychology and Health, 13, 569-591.

Ajzen, I. (1991). The Theory of Planned Behavior. Organizational Behavior and Human Decision Processes., 50, 179-211.

Albarracin, D., Durantini, M. R., \& Earl, A. (2006). Empirical and Theoretical Conclusions of an Analysis of Outcomes of Hiv-Prevention Interventions. Current Directions in Psychological Science, 15, 73-78.

Albarracin, D., Gillette, J. C., Earl, A. N., Glasman, L. R., Durantini, M. R., \& Ho, M. H. (2005). A Test of Major Assumptions About Behavior Change: A Comprehensive Look at the Effects of Passive and Active Hiv-Prevention Interventions since the Beginning of the Epidemic. Psychological Bulletin, 131, 856-897.

Allott, K., \& Redman, J. (2006a). Patterns of Use and Harm Reduction Practices of Ecstasy Users in Australia. Drug and Alcohol Dependence, 82, 168-176.

Allott, K., \& Redman, J. (2006b). Patterns of Use and Harm Reduction Practices of Ecstasy Users in Australia. Drug and Alcohol Dependence, 82, 168-176.

Armitage, C. J., \& Conner, M. (2001). Efficacy of the Theory of Planned Behaviour: A Meta-Analytic Review. British Journal of Social Psychology, 40, 471-499.

Bandura, A. (1986). Social Foundations of Thought and Action: A Social Cognitive Theory. Upper Saddle River, NJ, US: Prentice-Hall, Inc.

Bartholomew, L. K., Parcel, G. S., Kok, G., \& Gottlieb, N. H. (2006). Intervention Mapping: Designing Theory and Evidence-Based Health Promotion Programs. San Francisco, CA: Jossey-Bass.

Baylen, C. A., \& Rosenberg, H. (2006). A Review of the Acute Subjective Effects of MDMA/Ecstasy. Addiction, 101, 933-947.

Bedi, G., \& Redman, J. (2006a). Letters to the Editor: Recreational Ecstasy Use: Acute Effects Potentiated by Ambient Conditions? Neuropsychobiology, 53, 113.

Bedi, G., \& Redman, J. (2006b). Recreational Ecstasy Use: Acute Effects Potentiated by Ambient Conditions? Neuropsychobiology, 53, 113.

Bellis, M. A., Hughes, K., Calafat, A., Juan, M., Ramon, A., Rodriguez, J. A., et al. (2008). Sexual Uses of Alcohol and Drugs and the Associated Health Risks: A Cross 
Sectional Study of Young People in Nine European Cities. BMC public health ISE: $14712458,8,155$.

Benet-Martinez, V., \& John, O. P. (1998). Los Cinco Grandes across Cultures and Ethnic Groups: Multitrait Multimethod Analyses of the Big Five in Spanish and English. Journal of Personality and Social Psychology, 75, 729-750.

Benschop, A., Rabes, M., \& Korf, D. J. (2002). Pill Testing, Ecstasy and Prevention. Amsterdam: Rozenberg Publishers.

Boys, A., Lenton, S., \& Norcross, K. (1997). Polydrug Use at Raves by a Western Australian Sample. Drug and Alcohol Review., 16, 227-234.

Boys, A., \& Marsden, J. (2003). Perceived Functions Predict Intensity of Use and Problems in Young Polysubstance Users. Addiction, 98, 951-963.

Boys, A., Marsden, J., Fountain, J., Griffiths, P., Stillwell, G., \& Strang, J. (1999). What Influences Young People's Use of Drugs? A Qualitative Study of Decision-Making. Drugs: Education, Prevention and Policy, 6, 373-387.

Boys, A., Marsden, J., Griffiths, P., Fountain, J., Stillwell, G., \& Strang, J. (1999). Substance Use among Young People: The Relationship between Perceived Functions and Intentions. Addiction., 94, 1043-1050.

Boys, A., Marsden, J., \& Strang, J. (2001). Understanding Reasons for Drug Use Amongst Young People: A Functional Perspective. Health Education Research, 16, 457-469.

Carlson, R. G., Falck, R. S., McCaughan, J. A., \& Siegal, H. A. (2004a). MDMA/Ecstasy Use among Young People in Ohio: Perceived Risk and Barriers to Intervention. Journal of Psychoactive Drugs, 36, 181-189.

Carlson, R. G., Falck, R. S., McCaughan, J. A., \& Siegal, H. A. (2004b). MDMA/Ecstasy Use among Young People in Ohio: Perceived Risk and Barriers to Intervention. Journal of Psychoactive Drugs, 36, 181-189.

Cialdini, R. B. (2003). Crafting Normative Messages to Protect the Environment. Current Directions in Psychological Science, 12, 105-109.

Climko, R. P., Roehrich, H., Sweeney, D. R., \& Al Razi, J. (1986). Ecstacy: A Review of MDMA and Mda. International Journal of Psychiatry in Medicine, 16, 359-372.

Cohen, J. (1988). Statistical Power Analysis for the Behavioral Sciences (2nd ed.). Hillsdale, NJ: Lawrence Erlbaum Associates.

Cohen, J. (1990). Things I Have Learned (So Far). American Psychologist, 45, 1304-1312.

Cohen, J. (1992). A Power Primer. Psychological Bulletin, 112, 155-159.

Conner, M., \& Abraham, C. (2001). Conscientiousness and the Theory of Planned Behavior: Toward a More Complete Model of the Antecedents of Intentious Behavior. Personality and Social Psychology Bulletin, 27, 1547-1561.

Conner, M., \& Armitage, C. J. (1998). Extending the Theory of Planned Behavior: A Review and Avenues for Further Research. Journal of Applied Social Psychology, 28, 1429-1464.

Conner, M., Sherlock, K., \& Orbell, S. (1998). Psychosocial Determinants of Ecstasy Use in Young People in the Uk. British Journal of Health Psychology, 3, 295-317.

Conner, M., \& Sparks, P. (1996). The Theory of Planned Behaviour and Health Behaviours. In M. Conner \& P. Norman (Eds.), Predicting Health Behaviour: Research and Practice with Social Cognition Models (pp. 121-162). Buckingham, England: Open University Press. 
Copeland, J., Dillon, P., \& Gascoigne, M. (2006). Ecstasy and the Concomitant Use of Pharmaceuticals. Addictive behaviors, 31, 367-370.

Corapcioglu, A., \& Ogel, K. (2004). Factors Associated with Ecstasy Use in Turkish Students. Addiction, 99, 67-76.

De Vries, H., Backbier, E., Kok, G., \& Dijkstra, M. (1995). The Impact of Social Influences in the Context of Attitude, Self-Efficacy, Intention, and Previous Behavior as Predictors of Smoking Onset. Journal of Applied Social Psychology, 25, 237-257.

de Win, M. M. L., Jager, G., Vervaeke, H. K. E., Schilt, T., Reneman, L., Booij, J., et al. (2005). The Netherlands Xtc Toxicity (Next) Study: Objectives and Methods of a Study Investigating Causality, Course, and Clinical Relevance. International Journal of Methods in Psychiatric Research, 14, 167-185.

Deng, F., Vaughn, M. S., \& Lee, L. J. (2001). Drug Offenders in Taiwan and the United States: A Cross-Cultural Analysis. Substance Use and Misuse, 36, 1677-1697.

Duncan, D. F., \& Nicholson, T. (1997). Dutch Drug Policy: A Model for America? Journal of Health and Social Policy, 8, 1-15.

Duncan, D. F., White, J. B., \& Nicholson, T. (2003). Using Internet-Based Surveys to Reach Hidden Populations: Case of Nonabusive Illicit Drug Users. American Journal of Health Behavior., 27, 208-218.

Dundes, L. (2003). Dancesafe and Ecstasy: Protection or Promotion? Journal of health and social policy, 17, 19-37.

Engels, R. C., \& ter Bogt, T. (2004a). Outcome Expectancies and Ecstasy Use in Visitors of Rave Parties in the Netherlands. European addiction research, 10, 156-162.

Engels, R. C. M. E., \& Ter Bogt, T. (2004b). Outcome Expectancies and Ecstasy Use in Visitors of Rave Parties in the Netherlands. European Addiction Research, 10, 156-162.

Eves, F., Hoppe, R., \& McLaren, L. (2003). Prediction of Specific Types of Physical Activity Using the Theory of Planned Behavior. Journal of Applied Biobehavioral Research, 8, 7795.

Feather, N. T. (Ed.). (1982). Expectations and Actions: Expectancy-Value Models in Psychology. Hillsdale, NJ: Erlbaum.

Fendrich, M., Wislar, J. S., Johnson, T. P., \& Hubbell, A. (2003). A Contextual Profile of Club Drug Use among Adults in Chicago. Addiction, 98, 1693-1703.

Fishbein, M., \& Ajzen, I. (1975). Belief, Attitude, Intention and Behavior: An Introduction to Theory and Research. Reading, MA: Addison-Wesley.

Fishbein, M., \& Cappella, J. N. (2006). The Role of Theory in Developing Effective Health Communications. Journal of Communication, 56, S1-S17.

Fishbein, M., Triandis, H. C., Kanfer, F. H., Becker, M. H., Middlestadt, S. E., \& Eichler, A. (2001). Factors Influencing Behavior and Behavior Change. In A. Baum, T. R. Revenson \& J. E. Singer (Eds.), Handbook of Health Psychology (pp. 3-17). Hillsdale, NJ: Lawrence Erlbaum Associates.

Fountain, J., Bartlett, H., Griffiths, P., Gossop, M., Boys, A., \& Strang, J. (1999). Why Say No? Reasons Given by Young People for Not Using Drugs. Addiction Research, 7, 339-353.

French, D. P., \& Hankins, M. (2003). The Expectancy-Value Muddle in the Theory of Planned Behaviour--and Some Proposed Solutions. British Journal of Health Psychology, 8, 37-55. 
Freudenmann, R. W., Öxler, F., \& Bernschneider Reif, S. (2006). The Origin of MDMA (Ecstasy) Revisited: The True Story Reconstructed from the Original Documents. Addiction, 101, 1241-1245.

Gamma, A., Jerome, L., Liechti, M. E., \& Sumnall, H. R. (2005a). Is Ecstasy Perceived to Be Safe? A Critical Survey. Drug and Alcohol Dependence, 77, 185-193.

Gamma, A., Jerome, L., Liechti, M. E., \& Sumnall, H. R. (2005b). Is Ecstasy Perceived to Be Safe? A Critical Survey. Drug and alcohol dependence, 77, 185-193.

Giraudon, I., \& Bello, P.-Y. (2007). Monitoring Ecstasy Content in France: Results from the National Surveillance System 1999-2004. Substance Use and Misuse, 42, 1567-1578.

Godin, G., \& Kok, G. (1996). The Theory of Planned Behavior: A Review of Its Applications to Health-Related Behaviors. American Journal of Health Promotion., 11, 87-98.

Goritz, A. S., \& Birnbaum, M. H. (2005). Generic Html Form Processor: A Versatile Php Script to Save Web-Collected Data into a Mysql Database. Behavior Research Methods, 37, 703-710.

Gosling, S. D., Rentfrow, P. J., \& Swann, W. B., Jr. (2003). A Very Brief Measure of the BigFive Personality Domains. Journal of Research in Personality, 37, 504-528.

Gourley, M. (2004). A Subcultural Study of Recreational Ecstasy Use. Journal of Sociology, 40, 59-73.

Gouzoulis Mayfrank, E., \& Daumann, J. (2006). Neurotoxicity of Methylenedioxyamphetamines (MDMA; Ecstasy) in Humans: How Strong Is the Evidence for Persistent Brain Damage? Addiction, 101, 348-361.

Greer, G., \& Strassman, R. J. (1985). Information On "Ecstasy". American Journal of Psychiatry, 142, 1391.

Griffiths, P., Mravcik, V., Lopez, D., \& Klempova, D. (2008). Quite a Lot of Smoke but Very Limited Fire--the Use of Methamphetamine in Europe. Drug and alcohol review ISE: $14653362,27,236-242$.

Hansen, D., Maycock, B., \& Lower, T. (2001a). 'Weddings, Parties, and Anything. International Journal of Drug Policy, 12, 181-199.

Hansen, D., Maycock, B., \& Lower, T. (2001b). 'Weddings, Parties, and Anything...', a Qualitative Analysis of Ecstasy Use in Perth, Western Australia. International Journal of Drug Policy., 12, 181-199.

Hardman, H. F., Haavik, C. O., \& Seevers, M. H. (1973). Relationship of the Structure of Mescaline and Seven Analogs to Toxicity and Behavior in Five Species of Laboratory Animals. Toxicology and Applied Pharmacology, 25, 299-309.

Hoyle, R. H., Stephenson, M. T., Palmgreen, P., Pugzles Lorch, E., \& Donohew, R. L. (2002). Reliability and Validity of a Brief Measure of Sensation Seeking. Personality and Individual Differences., 32, 401-414.

Http://Ecstasyresearch.Eu/Qualitativereview.

Jager, G., de Win, M. M., van der Tweel, I., Schilt, T., Kahn, R. S., van den Brink, W., et al. (2008). Assessment of Cognitive Brain Function in Ecstasy Users and Contributions of Other Drugs of Abuse: Results from an Fmri Study. Neuropsychopharmacology official publication of the American College of Neuropsychopharmacology, 33, 247-258.

Jager, G., de Win, M. M., Vervaeke, H. K., Schilt, T., Kahn, R. S., van den Brink, W., et al. (2007). Incidental Use of Ecstasy: No Evidence for Harmful Effects on Cognitive Brain Function in a Prospective Fmri Study. Psychopharmacology, 193, 403-414. 
Johnston, J., Barratt, M. J., Fry, C. L., Kinner, S., Stoove, M., Degenhardt, L., et al. (2006). A Survey of Regular Ecstasy Users' Knowledge and Practices around Determining Pill Content and Purity: Implications for Policy and Practice. International Journal of Drug Policy, 17, 464-472.

Kalechstein, A. D., De La Garza, R., II, Mahoney, J. J., III, Fantegrossi, W. E., \& Newton, T. F. (2007). MDMA Use and Neurocognition: A Meta-Analytic Review. Psychopharmacology, 189, 531-537.

Karlsen, S. N., Spigset, O., \& Slordal, L. (2008). The Dark Side of Ecstasy: Neuropsychiatric Symptoms after Exposure to 3,4Methylenedioxymethamphetamine. Basic and Clinical Pharmacology and Toxicology, $102,15-24$.

Kelly, B. C. (2007). Club Drug Use and Risk Management Among "Bridge and Tunnel" Youth. Journal of Drug Issues, 37, 425-444.

Kelly, B. C., Parsons, J. T., \& Wells, B. E. (2006). Prevalence and Predictors of Club Drug Use among Club-Going Young Adults in New York City. Journal of Urban Health, 83, 884-895.

Kirk, R. E. (2007). Effect Magnitude: A Different Focus. Journal of Statistical Planning and Inference, 137, 1634-1646.

KPMG (2002). Dance in Nederland - De Betekenis En Impact Van Dance Op De Nederlandse Economie En Maatschappij: Een Verkenning [Dance in the Netherlands - the Meaning and Impact of Dance on the Dutch Economy and Society: An Exploration]. Amstelveen: KPMG Special Services B.V.

Laws, K. R., \& Kokkalis, J. (2007). Ecstasy (MDMA) and Memory Function: A MetaAnalytic Update. Human psychopharmacology, 22, 381-388.

Levy, K. B., O'Grady, K. E., Wish, E. D., \& Arria, A. M. (2005a). An in-Depth Qualitative Examination of the Ecstasy Experience: Results of a Focus Group with EcstasyUsing College Students. Substance Use and Misuse, 40, 1427-1441.

Levy, K. B., O'Grady, K. E., Wish, E. D., \& Arria, A. M. (2005b). An in-Depth Qualitative Examination of the Ecstasy Experience: Results of a Focus Group with EcstasyUsing College Students. Substance use and misuse, 40, 1427-1441.

Lyvers, M. (2006). Recreational Ecstasy Use and the Neurotoxic Potential of MDMA: Current Status of the Controversy and Methodological Issues. Drug and Alcohol Review, 25, 269-276.

Macromedia (2005). Macromedia Flash. San Fransisco, CA.

Manstead, A. S. R., \& Parker, D. (1995). Evaluating and Extending the Theory of Planned Behaviour. In W. Stroebe \& M. Hewstone (Eds.), European Review of Social Psychology (Vol. 6, pp. 69-95). Chichester, England: Wiley.

Marcos, A. C., \& Johnson, R. E. (1988). Cultural Patterns and Causal Processes in Adolescent Drug Use: The Case of Greeks Versus Americans. International Journal of the Addictions, 23, 545-572.

Marsden, J., Stillwell, G., Barlow, H., Boys, A., Taylor, C., Hunt, N., et al. (2006). An Evaluation of a Brief Motivational Intervention among Young Ecstasy and Cocaine Users: No Effect on Substance and Alcohol Use Outcomes. Addiction, 101, 1014-1026.

McCambridge, J., Mitcheson, L., Winstock, A., \& Hunt, N. (2005). Five-Year Trends in Patterns of Drug Use among People Who Use Stimulants in Dance Contexts in the United Kingdom. Addiction, 100, 1140-1149. 
McMillan, B., \& Conner, M. (2003a). Applying an Extended Version of the Theory of Planned Behavior to Illicit Drug Use among Students. Journal of Applied Social Psychology, 33, 1662-1683.

McMillan, B., \& Conner, M. (2003b). Using the Theory of Planned Behaviour to Understand Alcohol and Tobacco Use in Students. Psychology, Health and Medicine, 8, 317-328.

McMillan, B., Sherlock, K., \& Conner, M. (2003). Expanding the Traditional User Versus Non-User Dichotomy Amongst Ecstasy Users. Journal of Community and Applied Social Psychology, 13, 15-28.

Nabben, T., Benschop, A., \& Korf, D. J. (2007). Antenne 2006: Trends in Alcohol, Tabak En Drugs Bij Jonge Amsterdammers [Antenna 2006: Alcohol, Tobacco and Drug Trends among Amsterdam Adolescents and Young Adults]. Amsterdam: Rozenberg Publishers.

Nichols, D. E. (1986). Differences between the Mechanism of Action of MDMA, MBDB, and the Classic Hallucinogens: Identification of a New Therapeutic Class: Entactogens. Journal of Psychoactive Drugs., 18, 305-313.

Nvivo. (2001). Melbourne, Australia: QSR International Pty Ltd.

Orbell, S., Blair, C., Sherlock, K., \& Conner, M. (2001). The Theory of Planned Behavior and Ecstasy Use: Roles for Habit and Perceived Control over Taking Versus Obtaining Substances. Journal of Applied Social Psychology, 31, 31-47.

Orbell, S., \& Hagger, M. (2006). Temporal Framing and the Decision to Take Part in Type 2 Diabetes Screening: Effects of Individual Differences in Consideration of Future Consequences on Persuasion. Health Psychology, 25, 537-548.

Panagopoulos, I., \& Ricciardelli, L. A. (2005). Harm Reduction and Decision Making among Recreational Ecstasy Users. International Journal of Drug Policy, 16, 54-64.

Parrott, A. C. (2004). Is Ecstasy MDMA? A Review of the Proportion of Ecstasy Tablets Containing MDMA, Their Dosage Levels, and the Changing Perceptions of Purity. Psychopharmacology . 173, 234-241.

Parrott, A. C., Rodgers, J., Buchanan, T., Ling, J., Heffernan, T., \& Scholey, A. B. (2006). Dancing Hot on Ecstasy: Physical Activity and Thermal Comfort Ratings Are Associated with the Memory and Other Psychobiological Problems Reported by Recreational MDMA Users. Human Psychopharmacology: Clinical and Experimental, 21, 285-298.

Parsons, J. T., Kelly, B. C., \& Wells, B. E. (2006). Differences in Club Drug Use between Heterosexual and Lesbian/Bisexual Females. Addictive Behaviors, 31, 2344-2349.

Patton, J. H., Stanford, M. S., \& Barratt, E. S. (1995). Factor Structure of the Barratt Impulsiveness Scale. Journal of Clinical Psychology, 51, 768-774.

Peters, G.-J. Y., \& Kok, G. (Submitted). A Structured Review of Reasons for Ecstasy Use and Related Behaviours: Pointers for Future Research. BMC Public Health.

Peters, G.-J. Y., Kok, G. J., \& Abraham, C. (2008). Social Cognitive Determinants of Ecstasy Use to Target in Evidence-Based Interventions: A Meta-Analytic Review. Addiction, 103, 109-118.

Peters, G.-J. Y., Kok, G. J., \& Abraham, C. S. (in preparation-a). Social Cognitive Determinants of Ceasing Ecstasy Use: Ceasing Is Not the Opposite of Using. 
Peters, G.-J. Y., Kok, G. J., \& Abraham, C. S. (in preparation-b). Social Cognitive Determinants of Ecstasy Use: Does Studying Mixed Samples of Non-Users and Users Leads to over-Estimation of Association Strengths?

Peters, G.-J. Y., Kok, G. J., \& Abraham, C. S. (in preparation-c). Social Cognitive Determinants of Trying out Ecstasy: Why Interventions Based on Research into Using Ecstasy May Have a Hard Time Preventing Ecstasy Use.

Peters, G.-J. Y., Kok, G. J., \& Schaalma, H. P. (In press). Careers in Ecstasy Use: Do Ecstasy Users Cease of Their Own Accord? Implications for Intervention Development. BMC Public Health.

Petraitis, J., Flay, B. R., \& Miller, T. Q. (1995). Reviewing Theories of Adolescent Substance Use: Organizing Pieces in the Puzzle. Psychological Bulletin, 117, 67-86.

Rawson, R. A., Anglin, M. D., \& Ling, W. (2002). Will the Methamphetamine Problem Go Away? Journal of Addictive Diseases, 21, 5-19.

Reimers, S., \& Stewart, N. (2007). Adobe Flash as a Medium for Online Experimentation: A Test of Reaction Time Measurement Capabilities. Behavior Research Methods, 39, 365-370.

ResearchSoft, T. (2005). Endnote 9.01.

Ricaurte, G. A., Yuan, J., Hatzidimitriou, G., Cord, B. J., \& McCann, U. D. (2002). Severe Dopaminergic Neurotoxicity in Primates after a Common Recreational Dose Regimen of MDMA ("Ecstasy"). Science, 297, 2260-2263.

Ricaurte, G. A., Yuan, J., Hatzidimitriou, G., Cord, B. J., \& McCann, U. D. (2003). Severe Dopaminergic Neurotoxicity in Primates after a Common Recreational Dose Regimen of MDMA ("Ecstasy"): Retraction. Science, 301, 1479.

Riedlinger, J. E. (1985). The Scheduling of MDMA: A Pharmacist's Perspective. Journal of Psychoactive Drugs, 17, 167-171.

Riley, S. C. E., \& Hayward, E. (2004). Patterns, Trends, and Meanings of Drug Use by Dance-Drug Users in Edinburgh, Scotland. Drugs: Education, Prevention and Policy, $11,243-262$.

Rivis, A., \& Sheeran, P. (2003). Descriptive Norms as an Additional Predictor in the Theory of Planned Behaviour: A Meta-Analysis. Current Psychology, 22, 218-233.

Robson, P., \& Bruce, M. (1997). A Comparison of 'Visible' and 'Invisible' Users of Amphetamine, Cocaine and Heroin: Two Distinct Populations? Addiction, 92, 17291736.

Rodgers, J., Buchanan, T., Pearson, C., Parrott, A. C., Ling, J., Heffernan, T., et al. (2006). Differential Experiences of the Psychobiological Sequelae of Ecstasy Use: Quantitative and Qualitative Data from an Internet Study. Journal of Psychopharmacology, 20, 437-446.

Rosenberg, H., Baylen, C., Murray, S., Phillips, K., Tisak, M. S., Versland, A., et al. (2008). Attributions for Abstinence from Illicit Drugs by University Students. Drugs: Education, Prevention and Policy, 15, 365 - 377.

Rosenthal, J. A. (1996). Qualitative Descriptors of Strength of Association and Effect Size. Journal of Social Service Research, 21.

Ruiter, R. A. C., Abraham, C., \& Kok, G. (2001). Scary Warnings and Rational Precautions: A Review of the Psychology of Fear Appeals. Psychology and Health, 16, 613-630.

Ruxton, G. D. (2006). The Unequal Variance T-Test Is an Underused Alternative to Student's T-Test and the Mann-Whitney U Test. Behavioral Ecology, 17, 688-690. 
Samenspannen Tegen Xtc [Banding Together against Ecstasy]. (2001). Den Haag:

Ministerie van Justitie.

Schoenmakers, T., Wiers, R. W., Jones, B. T., Bruce, G., \& Jansen, A. T. M. (2007).

Attentional Re-Training Decreases Attentional Bias in Heavy Drinkers without Generalization. Addiction, 102, 399-405.

Sherlock, K., \& Conner, M. (1999). Patterns of Ecstasy Use Amongst Club Goers on the Uk 'Dance Scene'. International Journal of Drug Policy, 10, 117-129.

Shewan, D., Dalgarno, P., \& Reith, G. (2000). Perceived Risk and Risk Reduction among Ecstasy Users: The Role of Drug, Set, and Setting. International Journal of Drug Policy, 10, 431-453.

Sim, T., Jordan Green, L., Lee, J., Wolfman, J., \& Jahangiri, A. (2005). Psychosocial Correlates of Recreational Ecstasy Use among College Students. Journal of American College Health, 54, 25.

Soellner, R. (2005). Club Drug Use in Germany. Substance use and misuse, 40, 1279-1293.

Solowij, N., Hall, W., \& Lee, N. (1992a). Recreational MDMA Use in Sydney: A Profile of 'Ecstacy' Users and Their Experiences with the Drug. British journal of addiction, 87, 1161-1172.

Solowij, N., Hall, W., \& Lee, N. (1992b). Recreational MDMA Use in Sydney: A Profile Of "Ecstasy" Users and Their Experiences with the Drug. British Journal of Addiction, 87, 1161-1172.

Spruit, I. P. (1999). Ecstasy Use and Policy Responses in the Netherlands. Journal of Drug Issues., 29, 653-678.

Sterk, C. E., Theall, K. P., \& Elifson, K. W. (2006). Young Adult Ecstasy Use Patterns: Quantities and Combinations. Journal of Drug Issues, 36, 201-228.

Sterk, C. E., Theall, K. P., \& Elifson, K. W. (2007). Getting into Ecstasy: Comparing Moderate and Heavy Young Adult Users. Journal of psychoactive drugs, 39, 103-113.

Sumnall, H. R., Cole, J. C., \& Jerome, L. (2006). The Varieties of Ecstatic Experience: An Exploration of the Subjective Experiences of Ecstasy. Journal of psychopharmacology Oxford, England, 20, 670-682.

Sumnall, H. R., Tyler, E., Wagstaff, G. F., \& Cole, J. C. (2004). A Behavioural Economic Analysis of Alcohol, Amphetamine, Cocaine and Ecstasy Purchases by Polysubstance Misusers. Drug and Alcohol Dependence, 76, 93-99.

ter Bogt, T., Engels, R., Hibbel, B., Van Wel, F., \& Verhagen, S. (2002). "Dancestasy": Dance and MDMA Use in Dutch Youth Culture. Contemporary Drug Problems, 29, 157-181.

ter Bogt, T., \& Engels, R. C. M. E. (2005). Partying Hard: Party Style, Motives for and Effects of MDMA Use at Rave Parties. Substance Use and Misuse, 40, 1479-1502.

ter Bogt, T., Schmid, H., Gabhainn, S. N., Fotiou, A., \& Vollebergh, W. (2006). Economic and Cultural Correlates of Cannabis Use among Mid-Adolescents in 31 Countries. Addiction, 101, 241-251.

ter Bogt, T. F. M., Engels, R. C. M. E., \& Dubas, J. S. (2006). Party People: Personality and MDMA Use of House Party Visitors. Addictive Behaviors, 31, 1240-1244.

Terphoven, A. v., \& Beemsterboer, T. (2004). Door! Dance in Nederland [Keep Going! Dance in the Netherlands]. Amsterdam: Contact.

Thomasius, R., Zapletalova, P., Petersen, K., Buchert, R., Andresen, B., Wartberg, L., et al. (2006). Mood, Cognition and Serotonin Transporter Availability in Current and 
Former Ecstasy (MDMA) Users: The Longitudinal Perspective. Journal of Psychopharmacology, 20, 211-225.

Topp, L., Barker, B., \& Degenhardt, L. (2004). The External Validity of Results Derived from Ecstasy Users Recruited Using Purposive Sampling Strategies. Drug and Alcohol Dependence, 73, 33-40.

Topp, L., Degenhardt, L., Kaye, S., \& Darke, S. (2002). The Emergence of Potent Forms of Methamphetamine in Sydney, Australia: A Case Study of the Idrs as a Strategic Early Warning System. Drug and Alcohol Review, 21, 341-348.

Topp, L., Hando, J., Dillon, P., Roche, A., \& Solowij, N. (1999a). Ecstasy Use in Australia: Patterns of Use and Associated Harm. Drug and Alcohol Dependence., 55, 105-115.

Topp, L., Hando, J., Dillon, P., Roche, A., \& Solowij, N. (1999b). Ecstasy Use in Australia: Patterns of Use and Associated Harm. Drug and alcohol dependence, 55, 105-115.

Trimbos Instituut. (2007a). Dims Jaarbericht 2006 [Dims Year Report 2006]. Utrecht: Trimbos Instituut.

Trimbos Instituut (2007b). Nationale Drug Monitor [National Drug Monitor]. Utrecht: Trimbos Instituut.

Uitermark, J. (2004). The Origins and Future of the Dutch Approach Towards Drugs. Journal of Drug Issues, 34, 511-532.

Uitermark, J., \& Cohen, P. (2005). A Clash of Policy Approaches: The Rise (and Fall?) of Dutch Harm Reduction Policies Towards Ecstasy Consumption. International Journal of Drug Policy, 16, 65-72.

Umeh, K., \& Patel, R. (2004). Theory of Planned Behaviour and Ecstasy Use: An Analysis of Moderator-Interactions. British Journal of Health Psychology, 9, 25-38.

van de Wijngaart, G. F., Braam, R., de Bruin, D., Fris, M., Maalste, N. J. M., \& Verbraeck, H. T. (1999). Ecstasy Use at Large-Scale Dance Events in the Netherlands. Journal of Drug Issues., 29, 679-702.

van Empelen, P., Kok, G., Jansen, M. W. J., \& Hoebe, C. J. P. A. (2001). The Additional Value of Anticipated Regret and Psychopathology in Explaining Intended Condom Use among Drug Users. AIDS Care., 13, 309-318.

Verheyden, S. L., Henry, J. A., \& Curran, H. V. (2003a). Acute, Sub-Acute and Long-Term Subjective Consequences of 'Ecstasy' (MDMA) Consumption in 430 Regular Users. Human psychopharmacology, 18, 507-517.

Verheyden, S. L., Henry, J. A., \& Curran, H. V. (2003b). Acute, Sub-Acute and Long-Term Subjective Consequences of 'Ecstasy' (MDMA) Consumption in 430 Regular Users. Human Psychopharmacology: Clinical and Experimental, 18, 507-517.

Verheyden, S. L., Maidment, R., \& Curran, H. V. (2003a). Quitting Ecstasy: An Investigation of Why People Stop Taking the Drug and Their Subsequent Mental Health. Journal of Psychopharmacology, 17, 371-378.

Verheyden, S. L., Maidment, R., \& Curran, H. V. (2003b). Quitting Ecstasy: An Investigation of Why People Stop Taking the Drug and Their Subsequent Mental Health. Journal of psychopharmacology Oxford, England, 17, 371-378.

Verplanken, B., \& Wood, W. (2006). Interventions to Break and Create Consumer Habits. Journal of Public Policy and Marketing, 25, 90-103.

Vervaeke, H. K., van Deursen, L., \& Korf, D. J. (2008). The Role of Peers in the Initiation and Continuation of Ecstasy Use. Substance Use and Misuse, 43, 633-646. 
Vervaeke, H. K. E., Benschop, A., \& Korf, D. J. (2008). Fear, Rationality and Opportunity: Reasons and Motives for Not Trying Ecstasy. Drugs: Education, Prevention and Policy, $15,350-364$.

Vervaeke, H. K. E., Korf, D. J., Benschop, A., \& van den Brink, W. (2007). How to Find Future Ecstasy-Users: Targeted and Snowball Sampling in an Ethically Sensitive Context. Addictive Behaviors, 32, 1705-1713.

von Sydow, K., Lieb, R., Pfister, H., Hofler, M., \& Wittchen, H. U. (2002). Use, Abuse and Dependence of Ecstasy and Related Drugs in Adolescents and Young Adults--a Transient Phenomenon? Results from a Longitudinal Community Study. Drug and Alcohol Dependence, 66, 147-159.

Wang, J., Carlson, R. G., Falck, R. S., Siegal, H. A., Rahman, A., \& Li, L. (2005). Respondent-Driven Sampling to Recruit MDMA Users: A Methodological Assessment. Drug and Alcohol Dependence, 78, 147-157.

Webb, T. L., \& Sheeran, P. (2006). Does Changing Behavioral Intentions Engender Behavior Change? A Meta-Analysis of the Experimental Evidence. Psychological Bulletin, 132, 249-268.

Welp, E. A. E., Bosman, I., Langeman, M. W., Totte, M., Maes, R. A. A., \& van Ameijden, E. J. C. (2003). Amount of Self-Reported Illicit Drug Use Compared to Quantitative Hair Test Results in Community-Recruited Young Drug Users in Amsterdam. Addiction., 98, 987-994.

Winstock, A. R., Griffiths, P., \& Stewart, D. (2001). Drugs and the Dance Music Scene: A Survey of Current Drug Use Patterns among a Sample of Dance Music Enthusiasts in the Uk. Drug and Alcohol Dependence, 64, 9-17.

Witte, K. (1995). Fishing for Success: Using the Persuasive Health Message Framework to Generate Effective Campaign Messages. In E. Maibach \& R. L. Parrott (Eds.), Designing Health Messages: Approaches from Communication Theory and Public Health Practice. (pp. 145-166). Thousand Oaks, CA, US: Sage Publications, Inc.

Wood, W., \& Neal, D. T. (2007). A New Look at Habits and the Habit-Goal Interface. Psychological Review, 114, 843-863.

Wu, Y., Stanton, B. F., Galbraith, J., Kaljee, L., Cottrell, L., Li, X., et al. (2003). Sustaining and Broadening Intervention Impact: A Longitudinal Randomized Trial of 3 Adolescent Risk Reduction Approaches. Pediatrics, 111, e32-e38.

Wu, Z. H., Holzer, C. E., 3rd, Breitkopf, C. R., Grady, J. J., \& Berenson, A. B. (2006). Patterns and Perceptions of Ecstasy Use among Young, Low-Income Women. Addictive Behaviors, 31, 676-685.

Yacoubian, G. S., Boyle, C., Harding, C. A., \& Loftus, E. A. (2003). It's a Rave New World: Estimating the Prevalence and Perceived Harm of Ecstasy and Other Drug Use among Club Rave Attendees. Journal of Drug Education, 33, 187-196.

Yu, R. L., \& Ko, H. C. (2006). Cognitive Determinants of MDMA Use among College Students in Southern Taiwan. Addictive Behaviors, 31, 2199-2211.

Zakzanis, K. K., \& Campbell, Z. (2006). Memory Impairment in Now Abstinent MDMA Users and Continued Users: A Longitudinal Follow-Up. Neurology, 66, 740-741.

Zakzanis, K. K., Campbell, Z., \& Jovanovski, D. (2007). The Neuropsychology of Ecstasy (MDMA) Use: A Quantitative Review. Human psychopharmacology, 22, 427-435. 


\section{English summary}

Ecstasy has become one of the most prevalent party drugs. In combination with its potential harmfulness and the inefficacy of legislative measures that is evidenced by its prevalence, this justifies development of health promotion interventions aiming to regulate its use. The current thesis reports the results of studies aiming to inform such intervention development. The first chapter briefly outlines the history, social-cultural context, and effects of the drug ecstasy. Then, the results are provided of a needs assessment that identified the specific behaviours to be addressed in interventions aiming to regulate ecstasy use. The following behaviours were identified: trying out ecstasy; ceasing ecstasy use; refusing offered ecstasy; not using more than once every four to six weeks; not using more than $1.5 \mathrm{mg}$ MDMA per $1 \mathrm{~kg}$ of bodyweight; getting ecstasy pills tested at a testing facility before use; sleeping at least eight hours in the three nights before use; drinking two litres of water on each of the three days before use; drinking half a litre of water hourly during use; chilling out for at least 20 minutes every two hours during use; and not combining ecstasy with alcohol, cocaine, speed or GHB.

To synthesise the state of the art regarding the determinant configurations (the relative relevance of a behaviour's determinants) of these behaviours identified in the needs assessment, a meta-analysis was conducted, and its results are reported in chapter 2 . Although this meta-analysis' database query was deliberately designed to include publications about all behaviours related to ecstasy use, only publications addressing the behaviour 'using ecstasy' were found. Through quantitative synthesis of these studies, the determinant configuration of 'using ecstasy' emerged. The most relevant determinants were attitude (specifically positive outcomes regarding mood control and social facilitation, and negative outcomes regarding escalating use and physical and mental side effects); subjective and descriptive norms regarding one's friends, partner and peers; perceived control regarding obtaining ecstasy and control in relation to being with friends who use, going out dancing, being offered ecstasy 
and ecstasy being available; habit; moral norm; and anticipated regret. This determinant configuration provides an evidence base for interventions addressing the behaviour "using ecstasy". However, it is not known whether it can also guide interventions that target any of the behaviours that were identified in the needs assessment. Although it could be argued that the behaviour 'using ecstasy' is a generic behavioural category that encompasses specific behaviours (e.g. trying out ecstasy, ceasing ecstasy use, and using less frequently), determinant configurations of related but different behaviours may differ (Ajzen, 1991; Eves et al., 2003; Fishbein et al., 2001). The meta-analysis therefore suggests that the literature lacks a reliable evidence base for interventions addressing any of the behaviours suggested by the needs assessment.

Because of its quantitative nature, the meta-analysis employed very severe inclusion criteria. These inclusion criteria may have caused exclusion of studies that contain valuable non-quantitative information about potential determinants of a behaviour. To address this possibility, a qualitative review was conducted that summarised all studies into the reasons of ecstasy use and related behaviours that were excluded by the meta-analysis. The results are reported in chapter 3 . This review indicated that there are different reasons for starting ecstasy use, ceasing ecstasy use, using ecstasy, and other related behaviours. This suggests that the determinant configurations of starting or ceasing ecstasy use do differ from that of using ecstasy. Furthermore, for those reasons that were reported both in the qualitative review and in the metaanalysis, results sometimes diverged. Although most did, not all reasons that were reported frequently in the review corresponded to beliefs that were meaningfully associated to intention of behaviour in the meta-analysis (i.e. Cohen's d <.2; Cohen, 1992). Finally, it appeared that many ecstasy users cease use automatically due to a change in life circumstances or loss of interest.

The meta-analysis and the review yielded three conclusions of particular relevance. First, only the determinant configuration of the behaviour 'using ecstasy' has been studied quantitatively. Second, this determinant configuration need not be predictive of the determinant configurations of other behaviours. Third, ecstasy use-related interventions may do better to target harm reduction strategies than to try to induce cessation. Because the literature provides no evidence base regarding the determinant configurations of the behaviours specified by the needs assessment, it was concluded that new research was required to map these determinant configurations and thereby enable evidence- 
based intervention development. Of the 33 studies into determinants or reasons of ecstasy use that were included in the literature overview in chapters 2 and 3 , only 2 had been conducted in the Netherlands. These results may not generalise to the Netherlands, so new research in the Netherlands may not be able to use the results from the studies synthesised in chapters 2 and 3 as a starting point. In addition, in determining which behaviours should be targeted by an intervention, it seems useful to verify whether users indeed cease use automatically.

To study the Dutch situation, as well as to address whether Dutch users cease use automatically, a qualitative study was conducted among among 32 Dutch dance scene participants. The results are reported in chapter 4 . This study showed that ecstasy use patterns in the Netherlands indeed appear similar to those in the US, UK and Australia. In addition, it confirmed that cessation of ecstasy use appeared to occur mostly automatically when users moved to what they themselves described as 'the next phase'. The first finding meant that the determinants resulting from the meta-analysis about 'using ecstasy' may provide a starting point for new quantitative research in the Netherlands. Although it is likely that determinants of other behaviours will turn out to differ, whether this is the case can only be decided through such research. The second finding implied that it seems unwise to develop interventions that aim to induce ecstasy use cessation. Large-scale quantitative verification was needed to further inform a decision as substantial as whether or not to target cessation.

To map the determinant configurations of each of the 14 behaviours suggested in the needs assessment, an online survey was conducted. To enable comparison of the determinant configurations of these behaviours with that of 'using ecstasy', this behaviour was also included. In chapters 5, 6, and 7, the determinant configurations of using ecstasy, trying out ecstasy and ceasing ecstasy were reported. In chapter 8 , a comparative study is reported. The results indicated that although among non-users, the determinant configurations of trying out ecstasy and using ecstasy were quite similar (i.e. the determinants that were relevant for using ecstasy were also relevant for trying out ecstasy), among ecstasy users, the determinant configurations of using ecstasy and ceasing ecstasy use were different (i.e. the determinants that were relevant for using ecstasy were not always relevant for ceasing ecstasy use). In addition, the determinant configuration of using ecstasy was different for non-users than for users (i.e. determinants of using ecstasy that were relevant for users were not 
always relevant for non-users). Further, when a determinant distinguished between non-users and ecstasy users, it did not always predict intention to use in either of the two groups (i.e. determinants on which users scored substantially higher than non-users were not always associated to intention to use in either of the two groups).

These findings have a number of implications for the usefulness of studies into the determinants of ecstasy use for intervention development. First, results from studies into the determinants of using ecstasy among non-users do indeed constitute evidence to base interventions on, but only when samples comprised exclusively non-users. Second, results from studies into the determinants of using ecstasy among users cannot be considered as evidence base for interventions targeting cessation. Third, studies comparing non-users and users cannot inform intervention development regarding trying out ecstasy or ceasing ecstasy use. Furthermore, regarding ceasing ecstasy use, the determinants explained at most $37 \%$ of the variation in intentions. Combined with the results of the qualitative study, this indicates that relevant determinants have not been measured. This is consistent with the possibility that users cease ecstasy use due to factors such as a loss of interest or a change in life circumstances. For all three behaviours, intention strongly predicted subsequent behaviour. Regarding the determinant configuration of trying out ecstasy, attitude, moral norm and anticipated regret had large associations with intention to try out ecstasy. Subjective norm and the expectation that ecstasy makes one feel very good had moderate associations with intention. Regarding the determinant configuration of ceasing ecstasy use, only attitude was associated strongly to intention to cease. Subjective norm, subjective norm relating to parents, descriptive norm relating to best friend and friends, moral norm, and the expectation that ecstasy damages one's health had moderate associations with intention.

The results of the syntheses of the literature, the interview study, and these quantitative results all suggest that most ecstasy users cease their ecstasy use after a number of months or years without the need for an intervention. This implies that evidence-based interventions aiming to minimise ecstasyrelated damage may be more efficient if they aim to promote harm reduction strategies (HRSs) rather than cessation. Getting ecstasy tested at a testing facility seems a very important harm reduction strategy. In chapter 9, data allowing the mapping of this determinant configuration is reported, and additionally, results of a small-scale exploratory study. Regarding the 
determinant configuration of testing ecstasy, habit was associated to intention to test very strongly. Attitude, descriptive norm, and anticipated regret had strong associations, and perceived behavioural control had a moderate association. Regarding the exploratory measures, it appeared that most participants estimated the proportion of adulterated pills to be lower than this was in reality. In addition, a substantial proportion of participants expected adulterated pills to contain poison. Yet, many participants were willing to consume untested pills, particularly when friends claimed to have used pills from the same batch already. Perceived susceptibility of obtaining adulterated pills thus seemed very low.

In all, the social cognitive approach used in this thesis provided relevant determinants of the addressed behaviours. However, it was also clear that environmental variables should be taken into account, and there likely remain personal variables that can be useful additions to the tested models. Also, the reported quantitative studies showed how useful the internet can be in examining determinant configurations of multiple behaviours with a largely hidden population such as recreational illicit drug users. Furthermore, on the basis of these studies, three conclusions can be drawn that have particularly general implications. First, research into behavioural determinants should complement qualitative and quantitative methodologies. This applies not only to empirical research, but also to literature syntheses. Second, determinant configurations should be considered behaviourally specific. Determinants of a behaviour need not be the same for related behaviours (i.e. determinants of using ecstasy can differ from determinants of ceasing ecstasy use). In addition, among people who regularly perform a behaviour (e.g. ecstasy users), this behaviour can be predicted by different determinants than among people who do not regularly perform that behaviour (e.g. non-users). Also, determinants that differ between such groups need not predict intention in either of those groups. Third, ecstasy use interventions should aim at promoting harm reduction, rather than abstinence. Because most ecstasy users appear to cease of their own accord, more health benefits can be achieved by promoting correct and consistent application of harm reduction strategies. 



\section{Nederlandse samenvatting}

Ecstasy is een van de meest gebruikte party drugs geworden. Gecombineerd met de potentiële schadelijkheid en de ineffectiviteit van juridische maatregelen (getuige de hoge gebruikscijfers) rechtvaardigt dit de ontwikkeling van gezondheidsbevorderende interventies die ecstasygebruik reguleren. Het huidige proefschrift beschrijft de resultaten van studies die erop gericht waren om ontwikkeling van dergelijke interventies te informeren. Het eerste hoofdstuk vat kort de geschiedenis, sociaal-culturele context, en effecten van de drug ecstasy samen. Vervolgens worden de resultaten beschreven van een probleemanalyse die in kaart bracht op welke specifieke gedragingen een interventie zich zou moeten richten. Dit resulteerde in de volgende gedragingen: ecstasy uitproberen; stoppen ecstasy te gebruiken; aangeboden ecstasy weigeren; niet vaker dan eens in de vier tot zes weken gebruiken; niet meer dan 1.5 mg MDMA per kilo lichaamsgewicht gebruiken; ecstasypillen laten testen voor gebruik; elk van de drie nachten voor gebruik tenminste acht uur slapen; elk van de drie dagen voor gebruik tenminste twee liter water drinken; tijdens gebruik elk uur tenminste een halve liter water drinken; tijdens gebruik elke twee uur tenminste 20 minuten afkoelen in de chill-out; en ecstasy niet combineren met alcohol, cocaïne, speed of GHB.

Om de stand van zaken betreffende de determinantenconfiguraties (de relatieve relevantie van de determinanten van een gedraging) van deze gedragingen uit de probleemanalyse te integreren werd een meta-analyse uitgevoerd. De resultaten worden gerapporteerd in hoofdstuk 2. Hoewel de database query van deze meta-analyse opzettelijk was opgezet om publicaties over alle ecstasygebruik-gerelateerde gedragingen te omvatten, werden er alleen publicaties gevonden over het gedrag 'ecstasy gebruiken'. Door middel van kwantitatieve synthese van deze studies ontstond een beeld van de determinantenconfiguratie van 'ecstasy gebruiken'. De belangrijkste determinanten waren attitude (in het bijzonder positieve 
uitkomstverwachtingen betreffende het goed voelen door gebruik en facilitatie van sociale interactie en negatieve uitkomstverwachtingen betreffende toenemend gebruik en fysieke en mentale bijwerkingen); subjectieve en descriptieve normen betreffende iemands vrienden, partner en leeftijdsgenoten; waargenomen controle betreffende het verkrijgen van ecstasy en de beschikbaarheid van ecstasy; gewoonte; morele norm; en geanticipeerde spijt. Deze determinantenconfiguratie kan als basis dienen voor de ontwikkeling van interventies die zich richten op 'ecstasy gebruiken'. Echter, het is niet bekend of dit ook als basis kan dienen voor de ontwikkeling van interventies die zich richten op de gedragingen uit de probleemanalyse. Hoewel men zou kunnen stellen dat het gedrag 'ecstasy gebruiken' een generieke categorie van gedrag is die specifiekere gedragingen omvat (zoals ecstasy uitproberen, stoppen met ecstasygebruik, of minder vaak gebruiken), kunnen determinantenconfiguraties van gerelateerde maar verschillende gedragingen verschillen (Ajzen, 1991; Eves et al., 2003; Fishbein et al., 2001). Het lijkt er dus op dat de literatuur geen betrouwbare basis kan bieden voor de ontwikkeling van interventies die zich richten op de gedragingen die uit de probleemanalyse kwamen.

Echter, vanwege zijn kwantitatieve aard gebruikte de meta-analyse erg strikte inclusiecriteria. Door deze strikte inclusiecriteria kunnen studies, die waardevolle kwalitatieve informatie bevatten over mogelijke determinanten van gedrag, desaniettemin zijn geëxcludeerd. Teneinde deze mogelijkheid te onderzoeken is een kwalitatieve review uitgevoerd. Deze review omvatte alle studies naar redenen van ecstasygebruiken gerelateerde gedragingen, die waren uitgesloten door de meta-analyse. De resultaten worden gerapporteerd in hoofdstuk 3. Deze review gaf aan dat er verschillende redenen zijn voor beginnen met ecstasy, stoppen met ecstasy, ecstasy gebruiken, en andere gerelateerde gedragingen. Dit impliceert dat de determinantenconfiguraties van beginnen met ecstasy en stoppen met ecstasy inderdaad verschillen van die van 'ecstasy gebruiken'. Bovendien gold dat, voor de redenen die in zowel de review als de meta-analyse voorkwamen, de resultaten soms uiteenliepen. In de kwalitatieve literatuur werden sommige redenen frequent gerapporteerd terwijl in de meta-analyse bleek dat deze redenen niet betekenisvol samenhangen met intentie of gedrag (c.q. Cohen's d <.2; Cohen, 1992). Tot slot leek het er op dat veel ecstasygebruikers stopten door een verandering in levensomstandigheden of omdat ze interesse verloren.

Drie conclusies uit de meta-analyse en de review zijn in het bijzonder van belang. Ten eerste is alleen de determinantenconfiguratie van 'ecstasy 
gebruiken' kwantitatief onderzocht. Ten tweede hoeft deze determinantenconfiguratie niet voorspellend te zijn voor de determinantenconfiguraties van andere gedragingen. Ten derde lijkt het er op dat interventies betreffende ecstasygebruiker beter aan doen zich te richten op 'harm reduction' dan te proberen mensen te laten stoppen met ecstasygebruik. Omdat de literatuur geen evidentie biedt over de determinantenconfiguraties van de gedragingen die uit de probleemanalyse kwamen, werd geconcludeerd dat nieuw onderzoek nodig was om deze determinantenconfiguraties in kaart te brengen, zodat 'evidence-based' interventieontwikkeling mogelijk zou worden. Van de 33 studies naar de determinanten van ecstasygebruik in het literatuuroverzicht in hoofdstuk 2 en 3 zijn er maar 2 uitgevoerd in Nederland. Omdat deze resultaten wellicht niet naar Nederland gegeneraliseerd kunnen worden, kan nieuw onderzoek in Nederland deze resultaten misschien niet als uitgangspunt gebruiken. Verder is het raadzaam om te verifiëren of ecstasygebruikers inderdaad vaak uit zichzelf stoppen, voordat wordt besloten op welke gedragingen de interventieontwikkeling zich moet richten.

Om de situatie in Nederland te onderzoeken, en te onderzoeken of mensen uit zichzelf stoppen met ecstasygebruik, werd een kwalitatieve studie uitgevoerd onder 32 Nederlanders uit de Dance scene. De resultaten worden besproken in hoofdstuk 4 . De resultaten suggereren dat het ecstasygebruik in Nederland vergelijkbaar is met dat in de VS, het Verenigd Koninkrijk, en Australië. Bovendien werd bevestigd dat de meeste gebruikers uit zichzelf leken te stoppen met ecstasygebruik wanneer gebruikers naar "de volgende fase" gingen, zoals ze dat zelf omschreven. De eerste bevinding betekent dat de belangrijke determinanten uit de meta-analyse over 'ecstasy gebruiken' kunnen worden gemeten als uitgangspunt voor nieuw kwantitatief onderzoek in Nederland. Hoewel het aannemelijk is dat determinanten voor andere gedragingen zullen blijken te verschillen, kan pas worden bezien of dat inderdaad zo is na een dergelijke studie. De tweede bevinding impliceert dat het onverstandig lijkt om interventies te ontwikkelen die zich richten op het aanzetten tot stoppen met ecstasygebruik. Voordat een beslissing kan worden genomen die zo ingrijpend is als de beslissing om interventies niet te richten op stoppen met ecstasygebruik, is echter grootschalige kwantitatieve bevestiging nodig.

Om de determinantenconfiguratie van elk van de 14 gedragingen uit de probleemanalyse in kaart te brengen, is een online vragenlijststudie opgezet. Om de determinantenconfiguraties van deze gedragingen te kunnen 
vergelijken met die van 'ecstasy gebruiken' is deze gedraging ook opgenomen. In hoofdstukken 5, 6 en 7 word de determinantenconfiguraties gerapporteerd van ecstasy gebruiken, ecstasy uitproberen, en stoppen met ecstasygebruik. In hoofdstuk 8 wordt een vergelijkende studie gerapporteerd. De resultaten suggereren dat, onder niet-gebruikers, de determinantenconfiguraties van ecstasy uitproberen en ecstasy gebruiken vergelijkbaar zijn (c.q. de determinanten die belangrijk waren voor ecstasy gebruiken waren ook belangrijk voor ecstasy uitproberen). Echter, onder gebruikers verschillen de determinantenconfiguraties van ecstasy gebruiken en stoppen met ecstasy (c.q. de determinanten die belangrijk waren voor ecstasy gebruiken waren niet altijd belangrijk voor stoppen met ecstasy). Bovendien verschillen de determinantenconfiguraties voor ecstasy gebruiken tussen niet-gebruikers en gebruikers (c.q. determinanten van ecstasy gebruiken die belangrijk waren voor gebruikers waren niet altijd belangrijk voor niet-gebruikers). Verder bleek dat als een determinant onderscheid maakte tussen niet-gebruikers en gebruikers, deze determinant niet altijd de intentie om te gebruiken in één van die twee groepen voorspelde (c.q. een determinant waar gebruikers substantieel hoger op scoorden dan niet-gebruikers, hing niet altijd samen met intentie om te gebruiken in één van die twee groepen).

Deze bevindingen hebben een aantal implicaties voor de bruikbaarheid van studies naar determinanten van ecstasygebruik voor interventieontwikkeling. Ten eerste kunnen de resultaten van studies naar de determinanten van ecstasy gebruiken onder niet-gebruikers inderdaad gebruikt worden om interventies te ontwikkelen, maar alleen als de steekproeven uitsluitend niet-gebruikers betreffen. Ten tweede kunnen interventies die gebruikers er toe willen bewegen te stoppen met ecstasygebruik geen gebruik maken van resultaten van studies naar de determinanten van ecstasy gebruiken onder gebruikers. Ten derde kunnen studies die determinanten tussen nietgebruikers en gebruikers vergelijken niet gebruikt worden om interventies op te baseren. Verder verklaarden de determinanten van stoppen met ecstasy maximaal 37\% van de intentie om te stoppen. Gecombineerd met de resultaten van de kwalitatieve studie suggereert dit dat belangrijke determinanten niet zijn gemeten. Dit komt overeen met de mogelijkheid dat gebruikers stoppen met gebruik door factoren zoals veranderingen in levensomstandigheden of verlies van interesse. Met betrekking tot de determinantenconfiguratie van ecstasy uitproberen waren attitude, morele norm en geanticipeerde spijt sterk geassocieerd met intentie om ecstasy uit te proberen. Subjectieve norm en de 
verwachting dat je je tijdens ecstasygebruik erg goed voelt waren matig geassocieerd. Met betrekking tot de determinantenconfiguratie van stoppen met ecstasy was alleen attitude sterk geassocieerd met intentie. Subjectieve norm, subjectieve norm betreffende ouders, descriptieve norm betreffende beste vriend en vrienden, morele norm, en de verwachting dat ecstasygebruik slecht is voor de gezondheid waren allemaal matig geassocieerd met intentie.

De resultaten van beide literatuurstudies, de interviewstudie, en deze kwantitatieve data suggereren dat de meeste ecstasygebruikers na een aantal maanden of jaren uit zichzelf stoppen met ecstasygebruik zonder dat daar een interventie voor nodig is. Dit impliceert dat evidence-based interventies met het doel ecstasy-gerelateerde schade te minimaliseren wellicht efficiënter zijn als ze zich richten op het bevorderen van de toepassing van harm reduction strategieën dan als ze proberen mensen te laten stoppen. Ecstasy laten testen bij een testservice of inleverpunt lijkt een heel belangrijke harm reduction strategie te zijn. In hoofdstuk 9 worden data gerapporteerd die het mogelijk maakt deze determinantenconfiguratie in kaart te brengen. Verder worden de resultaten van een kleinschalig exploratief onderzoek gerapporteerd. Met betrekking tot de determinantenconfiguratie van ecstasy laten testen was gewoonte zeer sterk geassocieerd met intentie. Attitude, descriptieve norm en geanticipeerde spijt waren sterk geassocieerd, en waargenomen controle over het gedrag waren matig geassocieerd. Met betrekking tot de exploratieve maten leek het erop dat de meeste deelnemers de proportie 'pure' pillen (met uitsluitend MDMA als werkzame stof) lager inschatten dan deze in werkelijkheid is. Bovendien verwachte een substantiële proportie van de deelnemers dat 'onpure' pillen iets giftigs bevatten. Toch waren veel deelnemers bereid om ongeteste pillen te gebruiken, helemaal wanneer vrienden beweerden al pillen uit dezelfde batch gebruikt te hebben. De waargenomen susceptibiliteit leek dus erg laag.

$\mathrm{Al}$ met al heeft de sociaal cognitieve aanpak die in dit proefschrift is gebruikt relevante determinanten opgeleverd voor de onderzochte gedragingen. Het was echter ook duidelijk dat omgevingsvariabelen in ogenschouw genomen dienen te worden, en er zijn hoogstwaarschijnlijk nog persoonlijke variabelen die zinvolle toevoegingen kunnen vormen voor de geteste modellen. Verder lieten de gerapporteerde studies zien hoe bruikbaar het internet kan zijn bij het bestuderen van determinantenconfiguraties van verschillende gedragingen onder een grotendeels verborgen populatie zoals recreatieve gebruikers van illegale drugs. Tot slot kunnen op basis van deze studies drie conclusies worden getrokken met bredere implicaties. Ten eerste 
moet onderzoek naar gedragsdeterminanten kwalitatieve en kwantitatieve methoden met elkaar complementeren. Dit betreft niet alleen empirisch onderzoek, maar ook literatuurstudies. Ten tweede dienen determinantenconfiguraties te worden beschouwd als specifiek voor een gedrag. Determinanten van een gedrag hoeven niet hetzelfde te zijn voor gerelateerde gedragingen (c.q. determinanten van 'ecstasy gebruiken' kunnen verschillen van determinanten van stoppen met ecstasy). Bovendien kan, onder mensen die een gedrag regelmatig uitvoeren (bv. ecstasygebruikers), dat gedrag voorspeld worden door andere determinanten dan onder mensen die dat gedrag niet regelmatig uitvoeren (bv. niet-gebruikers). Verder hoeven determinanten die verschillen tussen twee van zulke groepen de intentie in elk van die groepen niet te voorspellen. Ten derde dienen ecstasygebruik gerelateerde interventies zich te richten op het bevorderen van harm reduction, en niet op het proberen mensen te laten stoppen. Omdat de meeste ecstasygebruikers uit eigen initiatief stoppen kan meer gezondheidswinst worden behaald door correcte en consistente toepassing van harm reduction strategieën te bevorderen. 


\section{Curriculum Vitae}

Gjalt-Jorn Peters was born on the $26^{\text {th }}$ of October 1981 in Sneek, Fryslân, in the Netherlands. He obtained his voorbereidend wetenschappelijk onderwijs (VWO; pre-university secondary education) diploma in 1999 at "OSG Sevenwolden" in Heerenveen. Because of his long-time interest in computers, he initially decided to study Computer Science at the University of Twente in Enschede, during the first year he discovered that this study was very similar to the study of Applied Mathematics. As this did not appeal to him and did not correspond to his competences, he decided to abort this study. In September 2000, he started to study Psychology at Maastricht University in Maastricht. He graduated and received his doctorandus degree (master's degree) cum laude in cognitive psychology, specifically cognitive ergonomics, in 2004. He started working on his Ph.D. as an assistent in opleiding (AIO; Ph.D. candidate) in September 2003. In 2005, he was visiting fellow in Brighton for two months. Since January 2008, he is employed at Maastricht University as a researcher, working on a project on the effectiveness of fear appeals, and reasons and determinants of the use of fear appeals in development of health promotion interventions. He has a special interest in recreational drug use, methodology, statistics, reviews and metaanalyses, fear appeals, and the use of computer- and internet technology in research and intervention development. 



\section{Acknowledgements}

It is impossible for me to write an acknowledgements section that does justice to everybody that deserves to be acknowledged. Therefore, I will have to be content with leaving almost everything unsaid, and saying too little about too few people.

First, of course, I want to thank Gerjo for his mentorship over the past six years. I never thought I could learn so much from someone, and still have so much left to learn. I also want to thank Charles, for his welcome when I visited Brighton, and Herman, for his willingness to be co-promoter, despite the late hour at which we asked this of him, and all three, for their supervision.

I want to thank Dirk and Jochen for being my paranymphs and especially, for enriching my life with their friendship, and providing fun, support and wisdom. For this, I also want to thank Hans, Hugo, Marijn, and Tim, and Harm, who I also want to thank for his wise advice.

I want to thank Erik, Kees, Mariolina and Saskia for having let me play a part in the resurrection of Provum (and the splitting off of the Phd Academy), and never telling anybody that they actually did all the work. It was great!

I want to thank Janny and Wim for raising me a critical and independent thinker. I also want to thank them, and Tjitte-Jelte and Hidde-Finne, for the family they are, and the way they fill my life. I want to thank Bonnie and Ale for the enrichment to this family that they have become. Finally, I want to thank Kees and Addie for teaching me to wash my hands before dinner.

And finally, I want to thank Mariolina, for being the most delightful person I know, for sharing this with me, for caring for me and letting me care for her, and for letting me learn from her and with her. I also want to thank her for everything else.

I want to thank everybody else who has played a role in my life the past years (which has pretty much been defined by this project) for their understanding that although I am grateful to them, I do not make that explicit here. 
